\title{
EXPLORING TRANSITIONS:
}

\section{WORKING IN 'THE SPACE BETWEEN THE NO}

\section{LONGER AND THE NOT YET'}

\author{
by
}

Janice Ruth Clayton

A Thesis Submitted to the Victoria University of Wellington in fulfillment of the

requirements for the degree of

Doctorate of Philosophy

in

Nursing

Victoria University of Wellington

2008 


\begin{abstract}
This thesis uncovers a personal journey of reflective practice in Aotearoa / New Zealand. The focus for reflection is on my emerging role as a nurse facilitating transitions using a dialectical approach in the context of a private nursing practice. Transitions encompass: life changes, loss, and adjustment to changes in function. Dialectical nurse facilitation of transition (DNFT) is a way of exploring self in the transitional space between 'the no longer and the not yet'. In this facilitated process people potentially discover paradoxes, tensions, and creative energy, as they search for a way forward.
\end{abstract}

The research design details a dialectical heuristic quest through journaling and reflecting on practice supervision and peer review, over a two year period. Exemplars written after reflecting on case notes reveal the lived experiences of participants Sophie, Grace, Rose, Faith, Lilo, and Charles (pseudonyms). These case reviews show the complexity of patterns for people undergoing transitions and nurse facilitation.

A relational pattern for DNFT encompasses compassionate engagement, catalytic mirroring, and interconnectedness. A transitional pathway from impasse to transformation shows itself as the people I work with search for clarity about the nature and meaning of self. The transitional pathway is mirrored in practice supervision and peer review in my search for professional clarity and groundedness. This reveals a mutual transformational process going beyond the boundaries of feelings and reason, into the regions of the human energy field and spiritual essence of self.

This integral approach finds resonance with nursing, Buddhist, and psycho-social philosophies and theories that posit human beings as the embodiment of spiritual energy. An exploration of literature encompasses nursing theories, facilitation, dialogue, loss, grief, spirituality and transition. These show how the patterns that I find, both resonate, and are divergent from extant knowledge. 
This thesis sheds light on the often hidden aspects of reflection and nursing practice and may support professional and personal growth. It also provides a basis for evaluative research on the effectiveness of DNFT in health care settings in the future. Discussions regarding the expansion of these reflective and praxis genres are included which may be of interest to nursing education and practice contexts.

Key Words: Heuristic Nursing Research . Dialectical . Facilitation . Transition 


\section{Acknowledgements}

I would like to acknowledge and thank a number of people who have supported me with this thesis. I would not be able to complete this work without the willingness of the participants; Sophie, Grace, Faith, Rose, Charles, and Lilo, who allowed me to exemplify their journeys of transition. I value their courage to actively work on their transitions and for allowing me to share in the discoveries they made.

There are my supervisors, Dr Rose McEldowney, whose guidance and skillful facilitation of the academic process I greatly appreciate; and Dr Alison Dixon, whose wisdom, pragmatism, and passion for nursing inspire me. The Victoria University of Wellington Nursing Midwifery and Health residential schools, the generous support of faculty members, and fellow students supported this supervision. I have valued the transformational practice supervision from Piers Heaney who has been with me on this journey of transition. A mutual interdependent peer review process with Catherine McKergow challenged and supported me in my nursing practice.

Family and friends have also supported me in this journey; especially my partner Albert for his unconditional love, and my daughters Anna with her valuable editing advice, and Catherine for her lively interest in my work. There are also fellow travelers on the spiritual journey and the SGINZ Buddhist family.

Without the offer and financial support of the full-time General Scholarship for $\mathrm{PhD}$ from the Victoria University of Wellington, this thesis would have been difficult for me to achieve. 


\section{Disclaimer}

Although I am influenced by practice supervision / peer review, and the tenets of Nichiren Daishonin Buddhism, the views that I posit in this thesis are solely my own and do not necessarily reflect the views of these people. 


\section{Dedication}

I would like to dedicate this thesis to the memory of my mother and father who are no longer on this earth but continue to reveal their influence and spirit in my life. 


\section{Table of Contents}

\section{Page}

$\begin{array}{lc}\text { Abstract } & \text { ii } \\ \text { Acknowledgements } & \text { iv } \\ \text { Table of Contents } & \text { vii } \\ \text { Disclaimer } & \mathrm{v} \\ \text { Dedication } & \text { vi } \\ \text { List of Figures } & \mathrm{xviii} \\ \text { List of Tables } & \mathrm{xx} \\ \text { PREFACE } & 1\end{array}$

$\begin{array}{ll}\text { PART ONE } & 2\end{array}$

CHAPTER ONE Introduction: An Overview of the Thesis 3

$\begin{array}{ll}\text { Nursing pioneers } & 5\end{array}$

$\begin{array}{ll}\text { Addressing the resistance forces in nursing } & 6\end{array}$

Searching for unity: Convergence of nursing schools of thought 8

Theory-research -practice: A triad of survival for nurses?

Embedding the learning of facilitation and energy facilitation in nursing $\quad 9$

$\begin{array}{ll}\text { Learning through reflection } & 11\end{array}$

$\begin{array}{lr}\text { Summary } & 12\end{array}$ 
The socio-political context of this thesis

Loss, transition and nursing

Transition

Facilitation

Dialectical approach

Integral nursing practice

Addressing the what, why, how, of this research

Reflection and reflexivity

Integrating philosophy and method

Design and ethical implications

Significance of the study

Summary and overview of the thesis

CHAPTER THREE Coming to Know about Loss, Grief and Transition

Loss, grief, chronic stress and illness 
CHAPTER FOUR Becoming a Dialectical Nurse Facilitator of Transition: Synthesizing Nursing, Humanism and Buddhism

Section Two: Facilitation: A relational, dialogical and humanistic

act

Influential relational theories in mental health nursing

Spirituality and nursing care in mental health

Section Three: The influence of Buddhism on my nursing practice 
$\begin{array}{ll}\text { Illness related to karma } & 91\end{array}$

Buddhist ideas about context: The three realms of existence 94

The realm of the individual: Mind-body-spirit 94

$\begin{array}{ll}\text { Ten life-states } & 97\end{array}$

$\begin{array}{lr}\text { Ten factors of life } & 100\end{array}$

$\begin{array}{lr}\text { Life-force } & 105\end{array}$

$\begin{array}{ll}\text { Summary } & 110\end{array}$

CHAPTER FIVE $\quad$ Research Design 112

Section One: Western philosophies of dialectics 112

$\begin{array}{ll}\text { Hegelian dialectics } & 113\end{array}$

$\begin{array}{ll}\text { Material dialectics } & 114\end{array}$

$\begin{array}{ll}\text { Relational dialectics } & 115\end{array}$

$\begin{array}{ll}\text { Rowan's influence on this dialectical inquiry } & 117\end{array}$

$\begin{array}{ll}\text { Primary level thinking } & 118\end{array}$

$\begin{array}{ll}\text { Existentialism } & 119\end{array}$

$\begin{array}{ll}\text { Phenomenology } & 119\end{array}$

$\begin{array}{lr}\text { Social level thinking } & 120\end{array}$

$\begin{array}{lr}\text { Realized level thinking } & 121\end{array}$

Section Two: Eastern philosophies of dialectics 122 
The pattern of interdependence between the individual, social context and the physical environment

An integration of levels and moments of dialectical inquiry with nursing ways of knowing

Six moments in a dialectical research cycle

Questions to address rigour

Self-reflection

Ethics, data collection and synthesis

Selection of participants

Case review 
PART TWO

CHAPTER SIX Epiphanies in Personal Knowing

The dark night of the soul

Finding spirit in the midst of tragedy

Saying goodbye to my mother

CHAPTER SEVEN Being-Doing-Experiencing Praxis: A

Heuristic Reflection of Dialectical Nurse

Facilitation of Transition

Section One: Foundation patterns for nursing praxis

Being grounded and connected

Turangawaewae

Moving from alone to all-one: A mutual process

Working with the negative tendencies of others

The importance of self-care 166

The paradox of being goal orientated and allowing things to evolve

Looking at life through a spiritual lens 
Energy facilitation

Change: A process of energy re-patterning 
Living with paradoxes

Reflection on supervision and peer review about the process orientation

of DNFT

Summary

CHAPTER EIGHT Seeing Patterns: An Integral Approach

to the Dialectical Nurse Facilitation of

Transition

Being-doing-experiencing praxis

Relational connections in DNFT

The mutuality of transition

Mutuality in 'caring with' and caring for self

Transition work and self-responsibility

Nursing knowing and facilitation

Becoming grounded in practice knowledge

Being grounded in ethics

Being grounded in oneself 
Transforming resistance tension to creative energy: A compassionate act

DNFT as a dialogical process

Giving feedback

Compassionate interconnection and intuition: Becoming a Catalytic mirror 236

Summary

CHAPTER NINE Finding Resonance and Dissonance: Tapping into the Collective Consciousness about Transition, Facilitation and Nursing

Florence Nightingale's legacy

Florence Nightingale's healing space (poem) 
The dialectic of change

The importance of self-care in nurse facilitation

Transpersonal care

Nurse facilitation of energy

Nursing and energy facilitation: Developments and tensions

Energy facilitation and research: Tensions in method

Nursing and spirituality

Summary

CHAPTER TEN Expanding Nursing Horizons in Health Care 266

Revisiting the dialectical cycles of questioning 267

Concluding comments 
Appendix A: Ethical approval

Appendix B: Ethical approval of amendments

Appendix D: Consent to provide supervision / peer review in the practice context of a $\mathrm{PhD}$ thesis

Appendix E: Information sheet for participants

Appendix F: Consent to participate in research 


\section{List of Figures}

Figure 1: Releasing emotions

Figure 2: What's on the table for the future?

Figure 3: The 'to-ing and fro-ing' in a dialectical process

Figure 4: Embryonic forms

Figure 5: The rooster box

Figure 6: Resistance forces

Figure 7: A search for the integration of self

Figure 8: Perceptions and conceptions of self and others in moments

of social tension

Figure 9: Finding a softer lens for viewing self

Figure 10: Discovering energy fields

Figure 11: Awakening

Figure 12: The many colours of transitions

Figure 13: An overview of the work of DNFT

Figure 14: Nurses and people in transition are unique complex beings in mind-body-spirit, each with infinite potential

Figure 15: Anam cara energy connection

Figure 16: All people are involved in ongoing cycles of transition 
Figure 18: Qualities for transition: A mutual process

Figure 19: Foundation patterns for praxis: A mutual process

Figure 20: Bridging the negative-positive continuum: Finding a middle way

Figure 21: Colours of change

Figure 22: Finding core essence through the resistance tension

Figure 23: Discovering the dialectics of tension: Transforming resistance to creativity

Figure 24: Synthesis of the mutuality of Dialectical Nurse

Facilitation of Transition

Figure 25: A journey towards transformation 


\section{List of Tables}

Table 1: Questions addressed in this thesis 29

Table 2: Changing ideas about loss, grief and transition $\quad 50$

Table 3: Clayton's synthesis of unitary and caring nursing philosophies and theories

Table 4: Facilitation influences for DNFT

Table 5: Basic Buddhist principles for practice

Table 6: Nichiren's classification of Buddhist views on illness and approaches to recovery

Table 7: The person in context

Table 8: Energy centres (chakra systems) 108

Table 9: A synthesis of Western dialectical philosophies

Table 10: Clayton's way of integrating feelings, thoughts, process and content, based on Rowan's dialectical levels of thought and Carper's ways of knowing

Table 11: Clayton's dialectical self questioning process in research and practice, based on Rowan's dialectical moments of a research cycle and Carper's ways of knowing

Part 1: Being

Part 2: Thinking 
Part 3: Doing

Part 4: Experiencing

Part 5: Integrating

Part 6: Communicating

Table 12: Clayton's adaptation of Rowan's dialectical six questions,

to guide dialectical reflection and dialectical inquiry process

Table 13: Clayton's adaptation of Moustakas' phases of heuristic

research

Table 14: Self-reflective processes to elicit patterns of nursing knowing

Table 15: Comparisons of practice supervision and peer review

Table 16: Foundation patterns for DNFT

Table 17: Patterns for transitional moments, nursing intentions and facilitation 


\section{PREFACE}

Writing a heuristic thesis is a delightful challenge. Contained within this work are the private reflections, thoughts and experiences of not only myself but the people that participated in this work, namely, Sophie, Grace, Faith, Charles, Rose, and Lilo. I ask that the reader is mindfully respectful of these reflections and also the effect that an exploration of transition may have on you the reader. For this reason I mark the transitions of this work with the symbol of gates ${ }^{1}$. As we transit through the cycles of movement and transitions in this thesis the misty ghost of the mythical figure of Janus ${ }^{2}$ appears with the keys of change, to open to new beginnings, and to reflect the guidance of sun and moon.

The initial aspect of this thesis which includes literature reviews on the topics informing my work and the way in which I frame the research, is included in Part One, symbolized by a formal gate.

In Part Two, an archway reveals an entranceway into a contemplative space, inviting those who enter to sit in mindful reflection of the experiences of transitions that unfold, and a synthesis of patterns of my work to be revealed.

Part Three, viewed through a lattice gate looks outward into the nursing practice world, offering discussions, critiques and syntheses of extant nursing theories and philosophies pertaining to DNFT.

\footnotetext{
${ }^{1}$ The gates presented in this thesis were photographed at my home.

${ }^{2}$ Janus is the mythical Roman God of gates, doors, beginnings, and endings. He holds the keys to the changes in seasons, both in nature and in civilizations, integrating warmth-cold, peace-war, and past-future dialectics of human experience. His name is integrated into the first month of the year, January. His face appears on many Roman coins throughout time. He is often shown in these depictions to hold a key, symbolizing the opening to the gates of change (Janus. Encyclopeadia Mythica. Retrieved July 03, 2007, from http://www.pantheon.org/articles/j/janus.html).
} 


\section{PART ONE}

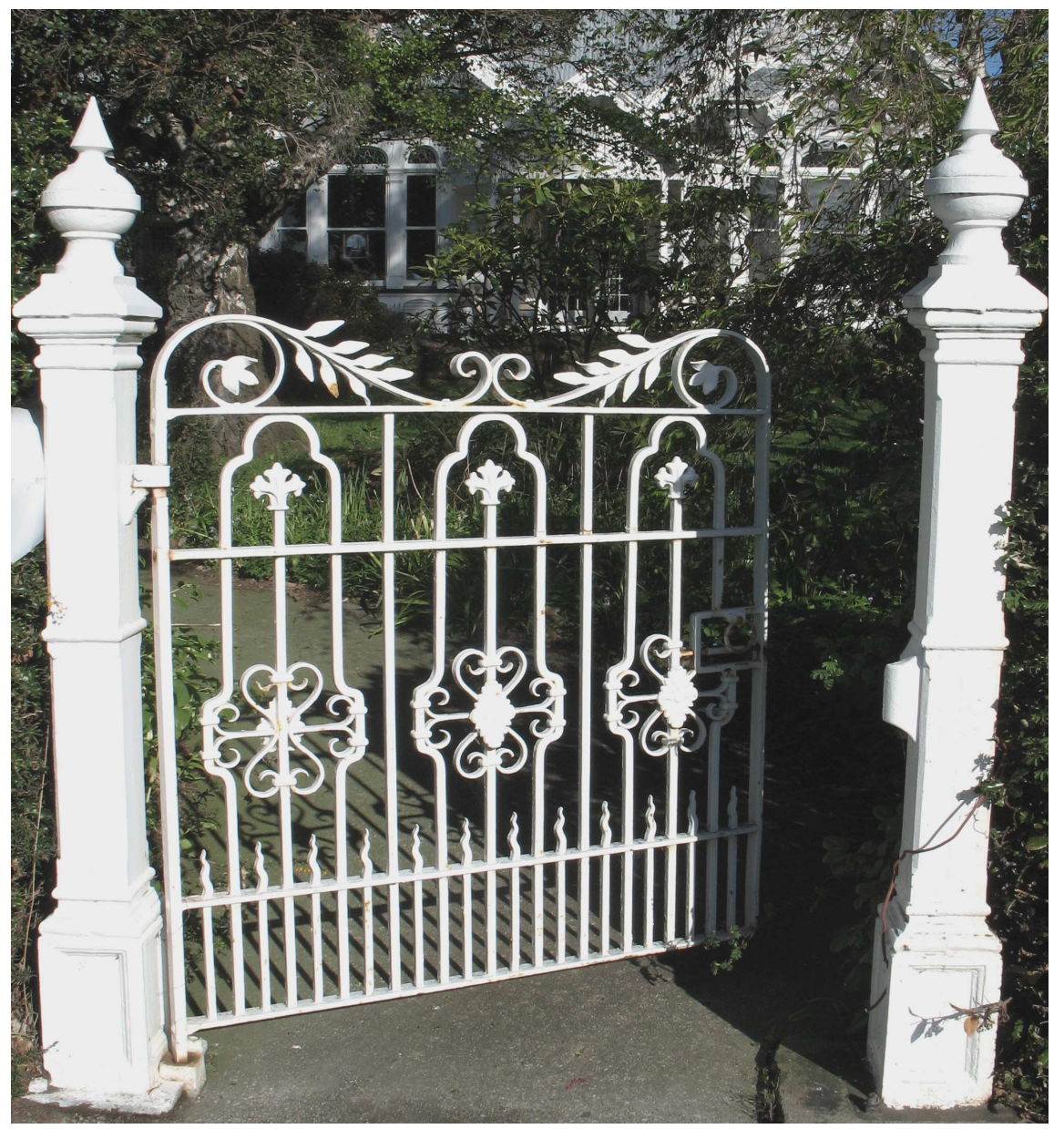

You who want

Knowledge

See the Oneness

Within

There you

Will find

The clear mirror

Already waiting ( Hadewijch, ii, Antwerp, $13^{\text {th }}$ Century) ${ }^{3}$

${ }^{3}$ Translation by Jane Hirshfield (1997). 


\section{CHAPTER ONE Introduction: An Overview of the Thesis}

This beginning chapter invites the reader to engage in a philosophical exploration of nursing that leads to a new paradigm that is facilitative, dialectical, transformative and energizing. An exploration of the work of nursing philosophers, theorists and writers was a starting place for this odyssey. I reveal in this overview how I traversed through the practice world of nursing. This locates the thesis within a national and international context. Embedded within the thesis is my lineage in nursing which crosses cultural and socio-political barriers encompassing the dialectic of 'change as crisis and change as opportunity.'

It is customary in Aotearoa New Zealand ${ }^{4}$ especially in the Maori cultural context, to begin a formal welcome by way of issuing a challenge (Haka) ${ }^{5}$. Although I am not Maori I believe the metaphor of the Haka incorporates the dialectic of welcome and challenge all-at-once and offers an invigorating way to begin my exploration of a transition that spans three decades of nursing.

This thesis posits an expansion of nursing ontology and epistemology which makes transparent the hitherto invisible nature of nursing work as facilitators of transition. I position dialectical nurse facilitation of transition as a specialist advanced practice that could be embedded in the role of the Nurse Practitioner (NP), especially in the areas of mental health, and palliative care. The utility of the role of dialectical nurse facilitator of transition (DNFT) also potentially fits within the education and supervision of nurses, especially in relation to preparing nurses to develop an expanded view of nursing; into a deeper understanding of self, spirituality, and energy fields.

The timing of this thesis resonates with other developments and transitions which are taking place in the health service in Aotearoa at this time. I refer to the expanded role of nurses in communities as NPs (see Ministry of Health (MOH, 1998; 2002) and trends in the mental health sector to advance recovery approaches which hold the centrality of the person in care; making a departure from treatment programmes which are patriarchal, narrow, and confining (Mental Health Commission (MHC), 1998;

\footnotetext{
${ }^{4}$ Aotearoa means Land of the Long White Cloud. It is the given name of New Zealand by the Maori people who are the indigenous people of the land (Tangata Whenua). I use both names interchangeably in this thesis.

${ }^{5} \mathrm{~A}$ Haka is a traditional Maori dance usually performed as a welcome, a signal of an important occasion, or a prelude to a challenge or war.
} 
2001; 2007). In Aotearoa New Zealand, Maori Treaty partners have been leading the way in proposing expanded versions of health which not only address the multidimensionality of persons, families and communities, but also posit the importance of spirituality and the interdependent relationship that exists between people and the land (Pere, 1984; Durie, 1998; 1999). Western dualistic cosmologies have held a colonising dominance in health which is reflected in disparities in statistics of Maori and non-Maori health and wellbeing (Ministry of Social Development, 2003). Although this situation is being addressed in Aotearoa (See Te Puni Kokiri (Realising Maori Potential), 2007), I suggest more can be done to address colonising influences by using integral approaches to health services and research (Cram, et al., 2003).

Cracks are starting to show in the ground of the nursing profession itself as nurses, beset by demands which foreground the importance of technologies, and political correctness; lose sight of the person in care who has faded into the background, occluded by the rolling mists of disease entities, risk factors, and problems (Barker \& Buchanan-Barker, 2005). These cracks become landfalls creating impasses in nursing worlds. Nurses have forgotten their real identities as people who walk beside people in life-death, illness-wellbeing dialectics, facilitating an expansion of life-states and creating conducive environments for a return to health, or a peaceful departure into death (Newman 1994; Parse 1999; Watson \& Smith 2001; Reed, 2000). The stress of these identity crises is felt by nurses in the reality of 'burnout'. Those who survive burnout, long to return to their real roles in these dialectics; to come home to the essence of nursing care, and the synergy of healing practice. Nurses seek new roles and better conditions to enact them (Rolls, 2007; Annals, 2007; Black, 2007). As these roles take shape and the mists clear a little, internal resistances show up, creating walls in the interior worlds of nurses as they battle with the sense of their own limitations, and a growing feeling that there is not enough time, not enough space, not enough knowledge, not enough support, to do the things that they would like to do in the healing space (Black, 2007). These walls are strengthened by another layer of external resistances coming in from socio-political environmental contexts, presenting a paradoxical diminishing of esteem whilst at the same time asking for more and more, time, energy, skills, and education, with fewer resources (Black, 2007). The tension is mounting for nurses. Could this be the moment to ask the existential questions? Who 
am I as a nurse? What are my guiding philosophies? What is my nursing purpose? And what does it all mean?

\section{Nursing pioneers}

The meaning of nursing as a healing canon was never questioned by nurse ancestors such as Florence Nightingale who, in her Notes on Nursing, itemised in minute detail, the real lived life of nurses and their patients. So much so, that one can almost smell the stench of the unventilated rooms located in the musty dark corners of cities where the suffering of ill-health was endured, in her day. In considering the essentials for healing and reparation; Florence left no stone unturned in her determination to hold up the interdependence of self and environment and the work of Divine influences in the healing process. She was noticed by poets and patients alike, as a manifestation of the archetypes of angel and healer (Longfellow, 1857; Myss, 2001). She was also noticed with chagrin by the military and medical forces as she made her presence felt in the trenches of the Crimean war (Ikeda, 2002b). Her presence brought a softer edge to the trauma of injury, experienced in those troubled times. She had the courage to go there, in a time where the possibilities for women were limited and resources had to be created from very little but faith and an intuition that the time was right to bring her visions into being. Likewise Martha Rogers heralded a new departure for nursing and an entry into the space-age world of relativity, unity, and energy fields. Those who followed, such as Margaret Newman, specified how this expansion of consciousness could happen, and Rosemarie Rizzo Parse unfolded aspects of human becoming in a new age. The facilitative nature of nursing was detailed by Hildegard Peplau who, undaunted by the disapproving voices of her medical peers, published an enduring work on interpersonal relations in nursing, laying a foundation for others, such as Phil Barker to take these tenets forward in mental health, into the metaphorical ocean of nursing care. Jean Watson lifted out and showcased the caring nature of nursing, finding the spiritual essence of nursing in compassion which is 'caritas' nursing. Energy facilitator pioneers Dolores Krieger and Janet Mentgen held out olive branches to health-care services, as they created a space for nurses to learn and to heal the subtleties of the human energy field.

These nursing pioneers, and many others, have laid the foundation for a groundswell of nursing praxes to emerge in the $21^{\text {st }}$ Century; where at least some of the stony 
ground on a well trodden path has been levelled. It is a good time to reflect with mindful intention to become really clear about nursing identities, and to decide, where to from here? This is a difficult task when the profession is divided in its ontological and epistemological positioning in the health-care world (Parse, 1999; Im \& Meleis, 1999; Watson \& Smith, 2001; Barrett, 2002; Barker \& Buchanan -Barker, 2005).

\section{Addressing resistance forces in nursing}

Parse (1999) believes that the nursing profession faces both opportunities and struggles in the advancement and transformation of practice in this current age. Whilst nursing remains an appendage of the medical model, it runs the risk of being submerged in the eclecticism of the applied sciences of medicine, sociology, and psychology. This situation is a paradox since there has been a clear intention by nurses over five decades to specify theories and frameworks of nursing (Peplau, 1952; Rogers, 1971; Newman, 1986; Parse, 1981; Watson, 1979; and Barker; 2002). Parse (1999) posits nursing as a 'basic science' (broad) which is distinct from 'applied science' (narrow). Basic science within a simultaneity paradigm and 'human becoming' school of thought, offers a very different form of care than nursing services coming from mechanistic or dimensionality models, adopted by applied science schools. Parse (1999) attempts to summarise the principles of 'human becoming' care as follows:

[n] urses are with persons as they enhance their own quality of life.

Nurses do not focus only on persons who are ill, as is often the case with the practice of traditional nursing (p.1384).

In Parse's nursing world, nurses engage with people and their families in flexible ways, determined by the needs of the people in care in a range of contexts. For example, homes, hospitals, day-care facilities, telephone conversations and E-mails. Documentation is a co-construction using the person's own words, meanings, and views, in the assessment process; rather than generic assessment forms primarily focusing on disease and the formulation of labels and diagnoses. In these nurse-person encounters nurses are authentically present, inviting and respecting the choices people make about their health patterns and quality of life, rather than imposing nursing care- 
plans with predetermined parameters. These views resonate with approaches posited by Gadow (1980); MHC (1998); Barker and Buchanan Barker (2005); Newman (2005) and basic tenets of the Treaty of Waitangi ${ }^{6}$ (Ramsden, 2002). In my interpretation of Parse's views I see that the relationship between nurses and people is distinguished from traditional nursing practices that attribute labels, such as NANDA-I diagnoses (North American Nursing Diagnoses Association, 2007). Parse (1999) makes a departure from the standardization of health-care and education basing the delivery of nursing care on the unique needs of the person, uncovered in an authentic relationship. Parse's views imply that nurses are not neutral and detached beings; rather, they are unique with beliefs and values whilst at the same time respecting the views beliefs and values of others. In the evolving changing situations that people seek support of nurses, there is a mutual growing awareness of meanings about health and about life and death. Nurses support people to grow in their knowledge and understanding so that they are able to make informed choices about actions they will take to enhance their wellbeing. I believe that for nurses to do this they need to know who they are, and enact their basic values and beliefs in this healing dynamic, rather than subscribing to eclectic ministrations of health-care determined by the dominating cultures of health-care systems. From an ethical point of view Parse (1999) posits:

The inherent ethic ... [r]equires the person's value priorities be respected. The human becoming nurse, then, would not label, diagnose, plan for, make judgements about, or exert pressure to change a person's way of living, as is often true with other guides to nursing practice (p.1386).

To enact this ethic of nursing care a shift in thinking is required, presenting both a challenge and an opportunity for nurses in evolving models of health-care in communities. I believe this could not be done unless nurses become engaged in ongoing nurse-led evaluative research into the effectiveness and acceptance of this way of practicing. Nurses would need to continue to delineate nursing from other health-care traditions. This requires a synthesis of theoretical disparities between

\footnotetext{
${ }^{6}$ The Treaty of Waitangi is the founding document between the Maori people and the British Government signed in 1840 that addresses, governance, partnership, pariticpation and protection of land and assets.
} 
schools of thought that run the gamut of humanitarian ethics, moral imperatives of care, relational, and unitary patterns of nursing practice (Watson \& Smith, 2001).

\section{Searching for unity: Convergence of nursing schools of thought}

An integration of caring science and the science of unitary human beings is sought by Watson and Smith (2001) between these hitherto parallel schools of thought, to make a creative space for growth in the advancement of nursing ontology and epistemology in this age. At the same time it is important for nurses to celebrate the integrity of specific theories. Doing so, would enable nurses to combine in socio-political endeavours to integrate unique and diverse roles of nurses in health-care delivery (Watson \& Smith, 2001). In a sense that is what I do in this thesis, as I seek resonance with extant nursing ontology's and epistemologies, with my evolving knowing about dialectical nurse facilitation of transition (DNFT). Like Watson and Smith (2001) I also seek integration between science and spirit, caring and unitary perspectives, as I delve deeper into the nature of nursing work, as I understand it.

Picard and Jones (2005) in discussions with nursing theorists Margaret Newman, Jean Watson and Sr Callista Roy, also raise the issue of the need for convergence of unitary and caring philosophies and theories of nursing. Newman spoke of shifting the notion of nursing as science, to praxis; to capture the experiential nature of nursing work emerging from theory, research, and practice. Focusing on nursing as praxis, would then emphasize pattern recognition, mutuality, and transformation. Both Watson and Newman agree that caring is the moral imperative for nursing, and that knowledge and caring are part of the standard for nursing that is ethical. In Newman's (1994) version of health as expanding consciousness (HEC) she makes it clear that this does not involve the eradication of suffering. Instead, nurses work with the realities of suffering to facilitate an expansion of consciousness which embraces rather than denies the significance of experiences of vulnerability, suffering, and illness.

\section{Theory-research-practice: A triad of survival for nurses?}

Authors Im and Meleis (1999); Parse (1999); Barrett (2002); Newman, Watson, Roy; in Picard and Jones (2005) all agree that links between theory, research, and practice are what will potentially take the profession of nursing forward in the $21^{\text {st }}$ century. Im and Meleis (1999) support the use of practice journals and the inclusion of 'clinician 
wisdom' in theory development. They also propose a closer relationship between research, theory, and practice, using integrative approaches and forging international links. The development of situation-specific theories is suggested by Im and Meleis (1999) to reflect the diversity of theories, views, and contexts, existing across the profession of nursing. Im and Meleis (1999) explain in the following:

[t]he development of situation-specific theories which give a description, explanation, and understanding of specific nursing phenomena limited to specific populations is proposed... (p.22).

To explain further, situation-specific theories differ from the abstractions of grand or middle range theories, allowing for variety in methodologies. This has the effect of opening the scope of nursing out, rather than narrowing it down. In a sense I suggest that this thesis, although, not proposing a situation-specific theory, does present a research process that represents the often hidden significance of practice supervision, peer review, and case review. In doing this I show patterns pertaining to nurse-person relations in the facilitation of specific types of transitions in the context of private practice in Aotearoa; with the view to widening the horizons and scope of nursing practice. In my research process, I believe that the generic aspects of the work of DNFT that could be developed and refined further by the nursing profession across health contexts; are the facilitative aspects of nursing.

\section{Embedding the learning of facilitation and energy facilitation in nursing}

As stated previously, facilitative aspects of nursing have often been assumed to come under the umbrella of counselling skills or communication skills. I write from personal experience as a previous student and lecturer of nursing, that learning such skills has previously been drawn extensively from other disciplinary contexts such as psychotherapy, counselling, and psychology. The effect of this approach has, I believe, de-contextualized facilitative skills from authentic nursing situations; and in my experience, is strongly resisted by students. Although grand theorists such as Peplau, and middle-range theorists such as Barker, have done much to keep the facilitative and relational aspects of nursing in context, especially in mental health; sadly there is a tendency for the nursing profession and nursing education systems to minimize the 
importance of these aspects. This minimizing and de-contextualizing of the facilitative role of nursing could, I believe, lead to the demise of nursing itself if the importance of it is not revived and restored to its appropriate place; firmly embedded in the centre of the theory, philosophy, and practice of nursing.

Currently facilitative, micro-counselling, or communication skills, are often organized into nursing curricula as skill sets, and separate subjects. This configuration of learning is, I believe, flawed in a number of ways and is most likely the reason for such strong resistance by students and by nurses in practice. This view is corroborated by Feilding and Llewelyn (1987) who identified the need to address the problem of a 'one size fits all' approach to communication skills in the education of nurses. Hartrick (1997) proposed a greater emphasis on the relational aspects of nursing instead of skills based learning. This view runs counter to the later writing of Bowles, Mackintosh and Torn (2001) who posited solution-focused brief therapy (SFBT) communication training as a way of achieving rapid results at the clinical face, rather than a non-directive approach with an emphasis on the therapeutic relationship. Whilst the efficacy of SFBT may be helpful in certain situations and a desired way of engendering motivation to change for some people; I do not think it is helpful to frame SFBT as a "toolbox to be dipped into" as Bowles et al., (2001 p.351) implies. Chant, Jenkinson, Randle, and Russell (2002) suggest a closer integration of theory and practice in learning communication skills at undergraduate and postgraduate levels. They also call for an appreciation of the socio-political barriers, especially management, policies, and biomedical dominance that reinforce a task oriented role of nurses; and attempt to prescribe and define nursing work. The current emphasis on health outcomes seems to hark back to the era of task and content orientated practice which is condoned by Coombs and Meehan (2003) and questioned by Lakeman (2004) as an antithesis to the recovery approach. Lakeman suggests that it is the quality of the relationship rather than the type of intervention that is important, otherwise the focus shifts from the person to the outcome which can "[s]trip the person's experience of all meaning and reduce it to predetermined categories" (Lakeman, 2004, p.212).

I suggest that the only way that facilitative skills can be authentically learned and applied is in the embedded-ness of philosophies and theories within the practice setting. On this theme Barrett (2002) expresses a concern that there is growing 
evidence showing in nursing articles that very little linkage is made between practice and nursing theories, philosophies, or frameworks. This trend is inevitable if the central tenets of nursing are not embedded within every aspect of the learning process.

Watson and Smith (2002) remind nurses that there is a perceived mandate from the public, to provide a relational, ethical, and humanitarian service to society. These ideas are worth bearing in mind, in the acquisition of practice skills and their implementation. It is my contention, based on my research process in this thesis, that a growing trend towards reflective practice is the way forward to achieving this integration.

\section{Learning through reflection}

A move away from the construction of nursing models and prescriptions for nursingcare; and a move towards reflective practice and the increased awareness of self in practice contexts, underpins the writings of Johns (2004ab and 2005). Johns (2004a) reveals a span of reflective practice uncovering layers of meanings in nursing. These layers reveal a range from a cognitive doing process, to a way of being, which is mindful reflective practice. In Johns' (2004a) assessment of different ways of viewing reflective practice, his range shows the potential for reflection to take place from objective reductionist views, or to move towards reflection to be seen as a mindful practice. This mindful practice of intuitive knowing, arises from evolving being and experiencing. In proposing mindful practice as a way of being a reflective practitioner, Johns (2004a) seeks an integration between these opposing trajectories in a similar way to Rowan's (1997) primary, social, realized, levels of thinking. In this way, rational objective thought is tempered with emotional and intuitive knowing; in context. This encompasses being, doing, thinking, experiencing, and integrating. I suggest integrative reflective practices for nurses resonates with the MHC (2001; 2007); and a heuristic methodology for exploring the personal, empirical, ethical, aesthetic and contextual aspects of nursing knowing (Carper, 1978; White, 1995). In this way, I believe that a deepening understanding of philosophies and theories can take place.

In Aotearoa mental health services, registered nurses comprise a significantly higher ratio of health-care professionals serving public health-care facilities than any other 
professional group (MHC, 2007). The amount of research, consultation, and planning by the MHC from 1998-2007; has firmly established a pathway for the Recovery Approach to steer NZ mental health services in the direction of integrative ways of working, cultural sensitivity, and humanitarian ethics. An envisioning process by persons whose lives have been affected by mental illness; write of a service that they expect to see by 2014, that is inclusive of spiritual, and alternative, ways of providing care, along with support in major life events (MHC, 2004). In spite of these NZ trends, the paradigm shifts required in the world of nursing practice are slow to occur as nurses continue to align themselves with medical models and join the labelling game with North American Nursing Diagnosis Association - International (NANDA-I, 2007) diagnostic sets.

In this thesis I propose a return for mental health nurses to a nursing focus that highlights the relational, dialogical, facilitative, aspects of nursing to a level of refinement and expertise. This, I believe, would improve access to appropriate integrative care at the time of need. On this point I refer to Bond (2002) who found the availability of immediate counselling by health-care professionals in primary healthcare settings in the UK, to be beneficial to persons using the services, as well as being cost effective. In addition to these benefits planned counselling sessions were found to reduce GP visits, mental health consultations, and the need for medication (Bond, 2002). Similar benefits were found in support of youth at risk of suicide in NZ, where skilled assessment, support, and good therapeutic relationships were seen to be important in suicide prevention (Hider, 1998).

\section{Summary}

In this overview of the thesis I position the research and scholars whose paradigmatic work informed this thesis in the foreground to show how they have helped me to develop a vision about knowledge and practice and the kind of questions that were appropriate to begin such exploration. There is much to be learned from extant international theories and philosophies and I have represented a taste of what informs the whole. I believe that it is timely in the $21^{\text {st }}$ Century, as strategies of general health and mental health come into alignment; for nurses in Aotearoa to formulate nursing frameworks that are embedded in this socio-cultural context; coming from the ground of praxis (Ministerial Advisory Committee on Complementary and Alternative Health 
Care in New Zealand (MACCAH); 2004; MOH, 1998;2002; MHC 1998; 2001; 2004; 2007). The mandate is already within NZ for nurses to be an integral part of this process. A way forward that I see for nurses to retain and consolidate the essence of nursing in practice, is to be fully engaged in this process; moving forward with creative energy rather than being caught up at the impasse of resistance tension; and engaging in dualism with medicine and science. I suggest that progress comes about through integration and continued evolution in innovative compassionate nursing approaches, which hold people as central to their implementation. This integration necessitates a positive paradigm shift for nurses.

Shifting paradigms, I believe, requires an inward movement towards reflection and deep self-knowing which can be achieved by embracing self-reflective practice, based on practice supervision, peer review, and case review (Johns 2004a,b; Johns \& Freshwater 2005). This inward movement can form the reflection on, and research into, being, doing, experiencing, thinking about, and integrating nursing practice. An outward movement of explicating empirical, ethical, personal, aesthetic, culturally embedded nursing frameworks; and communicating them in health worlds, enables the development of praxis potentials (see Carper, 1978; Jacobs-Kramer \& Chinn, 1988; White, 1995; Johns, 2004a,b; Rowan 1997; Clayton, 2004).

This thesis is intended to make a contribution to these suggested paradigm shifts through the explication of the what, why, how of DNFT using a reflective framework as a research process and as praxis development. I will show the evolution of a dialectical research method into a way of working with people who are in transition. I describe how I found primary, social and realized levels of thinking and feeling in moments of being, doing, experiencing, thinking, integrating, and communicating; in a heuristic praxiological process. These levels and moments are also experienced in the facilitation process itself and mirrored in transitional moments. All of these aspects are central to the philosophical inquiry that unfolds in this thesis.

In Chapter Two I give the reader a way into the evolution of thinking providing an overview of the developing research project that addresses the what, why and how of this thesis and the meanings with respect to the language and conceptual frameworks that form the basis for development in the thesis. 


\section{Chapter Two Background to the Study}

This thesis emerged after a personal process of transition from my role as an educator of a health and wellbeing course, to beginning a private nursing practice facilitating transitions. The origins of an enduring interest in the process of transition can be traced back to experiences of nursing practice and education over thirty years, primarily in mental health. The facilitative role of the nurse in support of people in transition is emphasized in this thesis, as an aspect of expert nursing practice in mental health, which can be applied in autonomous nursing roles in community health care.

The fact that I entered the field of nursing from the inaugural Aotearoa New Zealand comprehensive nursing programme in 1973 was, on reflection, significant to my current interest, as being involved in a major transition in nursing education plunged me into an epoch of a paradigm shift in nursing. This paradigm shift from task orientated to principle based nursing created an open space for the development of theoretical and philosophical frameworks for nursing practice in NZ. In many respects my early education in nursing took me only to the perfunctory aspects of nursing theory and practice. However, my work in the mental health field called for a deeper philosophical basis for my practice. Searching for a philosophy for practice was in some way motivated by my experiences as an educator in nursing; first as a lecturer in the last psychiatric nursing programme in Christchurch, NZ, and later as a lecturer within an Occupational Therapy School in Dunedin, NZ. It was this move into a completely different field and way of thinking about health-care that led to a quest for a synthesis of my knowing about caring for people and the healing process. It was in this context that I developed a health and wellbeing course for people in recovery, mainly from mental illness. This became the subject of my Masters thesis, detailed in Clayton and Tse (2003) and Clayton (2004).

During this time I became aware of the significance of loss, grief, and transition in the onset of mental illness, especially depression. I found that this awareness resonated with growing evidence of a relationship between loss, grief, and transition and chronic stress which can eventually lead to serious illness in susceptible individuals (Selye, 1956; Holmes \& Rahe 1967; and Donnelly, Eburne \& Kittleson, 2001). This growing 
awareness resonated with much of the research and evolvement of loss, grief, and transition theory that I review in this thesis.

I began to develop a private nursing service in 2004 with an integral focus to support people in transition. As I was framing up my practice as a nurse facilitating transitions, I could see that there was potential for ambiguity about what I was providing, for example, some could view the service as being primarily counselling. I did not intend to emulate counselling services; rather to offer a service which drew on the breadth of my knowledge as a nurse, and the integral nature of my practice. For the purposes of explicating an integral approach arising from nursing ontology I chose to progress these developing ideas in the scholarly inquiry of a doctoral thesis. I also felt it was timely to write about this work because to some extent roles for nurses were being expanded in the socio-cultural contexts of health-care delivery in Aotearoa NZ. I discuss some of these changes in the next section.

\section{The socio-political context of this thesis}

The development of private nursing services with an integral focus is supported in principle by the $\mathrm{MOH}$ directives in NZ that encourage nurse led services ( $\mathrm{MOH}, 1998$; 2002). Considerable work has been done by the MOH to expand the scope of nursing in Aotearoa. This work began with a ministerial taskforce on nursing in 1998. The MOH (1998, p.26) stated,

Nursing needs to be central to all future developments in health care in order to support improved service integration and better health care planning. In addition nursing may offer increased access for groups with a poor uptake of services.

The MOH (1998) proposed the development of new nursing roles that are autonomous, recognizing nursing expertise in implementing health promotion and health care within the community. This taskforce highlighted the development of the Nurse Practitioner role in NZ, which is considered the most advanced level of clinical nursing practice $(\mathrm{MOH}, 2002)$. Alongside these developments in nursing, other 
government documents such as the MHC's The Blueprint for Mental Health Services in New Zealand (1998) signalled the need for integrated approaches to mental health care. A clear indication was being given to health professionals operating solely from clinical models; to enlarge the scope of their practice and come into line with consumer identified needs. Broadly speaking, integral or holistic practice is defined by the MHC (1998) as incorporating four dimensions of health: physical, mental, social and spiritual. This draws on the Maori 'Te Whare Tapa Wha' model, which is often described as the four cornerstones of wellbeing (Durie, 1998).

The service I provide as an independent nurse facilitator is integral in the sense that it promotes health and wellbeing by an exploration of mind-body-spirit principles, so that people can work toward optimal health in their situation. This focus for practice is supported by NZ trends to move towards integrative models of care (MACCAH) 2004).

The MOH (2002) acknowledges the existence of four generic models of nursing. These are: Integrated nursing teams; nurse consultancy; independent practice; nurse practitioner specialty services/clinics. The third identified model relates to nurses as independent practitioners, who are self employed and offer services directly to the public. The service identified in this study would fall into this category. In this thesis I fully describe my work within the framework of advanced nursing roles, mainly in mental health contexts.

These socio-political developments signalled a transition for nurses and expanding potentials for practice development. Support for loss, grief, and transition in susceptible people for illness prevention, however, was more accessible for those with an identified diagnosis of disease. Much of my background reading reviewed in the following section on this subject, confirmed this assumption.

\section{The relationship between transition and illness}

The effects of loss, grief, and transition have been the subject of human interest for many centuries. Religions such as Christianity and Buddhism addressed the suffering 
of loss and change in many of their writings. For example, in the Christian Bible (Revised Standard Version, RSV) the personal experience of loss was recorded in the book of Job and the trials of the nation of Israel were recorded in the book of Lamentations. From a Buddhist perspective, Hochswender, Martin and Morino (2001) give an historical account of Buddha Shakyamuni's ${ }^{7}$ journey towards enlightenment after becoming aware that all human beings have to face the four sufferings of birth, sickness, aging, and death.

The subject of loss and mourning abound in literature; (see epic works of William Shakespeare in Gillespie, 2001). These are works that I was exposed to in my formative years. Paradoxically there seems to be a tendency for Western societies to minimize and in some instances deny the experience of grief (Worden, 1983, and Ilot, 1996). This tendency to minimize and deny grief runs deep. In NZ it is difficult for a person to access affordable subsidized support, specifically for loss and grief, even though there is a plethora of literature and research indicating links between stressful life events such as loss and grief, and the onset of illness. This is especially so for those who do not integrate loss in ways that enable them to continue living in relative health and wellbeing (Bowlby, 1973; Worden, 1983; Parkes, 1980; Dohrenwend \& Dohrenwend, 1974; Holmes \& Masuda, 1974; Rahe, 1974; Paykel, 1974; Theorell, 1974; Neimeyer, 2001a).

Factions exist within empirical medical sciences that search for quantifiable evidence; and psychosocial sciences, which tend to seek experiential qualitative evidence. When it comes to distributing funds, this dichotomy is of high importance. In NZ, funding for health is still heavily weighted towards treatment of diagnosable diseases, rather than on prevention and working with vulnerable groups, although this is gradually changing. Kübler-Ross (1970) cites denial as a mental mechanism operating in defence of the impact of loss and grief. I suggest this mechanism of denial is not just an individual response but also a societal and political one: 'If we ignore the problem,

\footnotetext{
7 Shakyamuni was an Indian Prince also known as Siddharta Gautama (around 563-483 BC). His journey into spiritual awareness came about when he witnessed four sights; a sight of an elderly person struggling to walk, a sick man, a dead man, and a monk in a state of deep relaxation. Hitherto he ${ }^{7}$ had been protected from any form of suffering or decay; these sights led him to question what he saw and derive satisfactory meaning for them. He renounced his princely role and took on the life of an ascetic. This life of self-denial and fasting over a six year period did not illuminate the suffering to his satisfaction, and he retreated beneath a Bodhi tree to meditate. He was said to be in a meditative state for 49 days before he became enlightened and was thereafter referred to as Gautama Buddha, or, Shakyamuni Buddha (Wickramasinghe,1988).
} 
perhaps it will go away'. This minimizing attitude towards the impact of loss and grief and the lack of accessible expert help for major transitions, not associated with illness, can lead to serious personal and public safety issues. The following example in NZ September 2005 reported by TVNZ, One News (2005) and followed up later by David Eames (2006), exemplifies this point.

As I was watching the media hype on election night September 2005, an uncharted plane was reported to be circling around the city of Auckland. The pilot signalled his intention to crash into the city's Sky Tower. Rather than being politically motivated as was first thought, it transpired in later news items that the pilot, reported he was deeply distressed by a recent relationship break-up. The pilot indicated that he was feeling suicidal in response to this major loss, in spite of recent mental health care that did not, in his mind, reduce the extent of his distress.

Although this example is somewhat extraordinary, it is by no means unusual for life events to precipitate violent or suicidal responses for individuals with minimum support networks (Hider, 1998; World Health Organization (WHO), 2007). The question that remains is: Does supportive intervention ameliorate the potential effects of major life events in susceptible individuals, and prevent illness, suicidal and / or violent acts? If so, what kind of intervention is beneficial? And, who should deliver it?

\section{Loss, transition and nursing}

Within nursing literature, integrative dimensions of nursing and nurses as change agents have been explored by a number of nurse theorists and researchers (Peplau, 1952; Rogers, 1971; Travelbee, 1971; Parse, 1981; Newman, 1986; McEldowney, 2002; Barker \& Buchanan-Barker 2005). Nurse researchers Meleis and Trangenstein (1994) stated "transition is a central focus of nursing" (p.225). They indicated that nursing theories such as unitary human development, expanding consciousness, human becoming, and caring, are congruent with facilitating transitions and proposed that more coherent frameworks need to be formulated in nursing to understand and work with transition. The role of nursing in the facilitation of transition is seen by Meleis and Trangenstein to be unique, because in their view, only the nursing profession has the knowledge base to cover all dimensions of transitions. With this 
knowledge I hypothesize that nurses have the potential to work with people to prevent major illnesses and to improve the quality of life for individuals at risk.

To address transitional work with people as a nurse, I evolved a way of working with people that I refer to as Dialectical Nurse Facilitation of Transition (DNFT). This work involves an exploration of the tensions a person is living with and aspects of life that are important to them. For example, a person may start to think that their core beliefs and values no longer fit with the situation they are now facing. Trying to understand it all can leave them feeling bewildered as they grapple with it alone. Everything changes, including how a person feels physically, emotionally, socially, and spiritually. Some people struggle with this change process, especially when those close to them find it difficult to cope with their grief. This may leave a person feeling unable to fully express their feelings of loss and lead to increased stress as the tension builds up. Simply put, the DNFT process involves an exploration of the tensions being experienced by the person physically, emotionally, socially, and spiritually; and being guided to discover strengths in the person's ability to manage their health in changing situations and crises. As stated previously, this role could easily be interpreted as counselling or psychotherapy.

Some would argue that this is not the domain of nurses, and suggest that the clergy or counsellors are more equipped for this work. That view may have merit, however I wonder about the utility of it in the rapidly changing practice world of nurses who get up close to life and death, existential distress, and anguish. For example, in my lived experience of being a nurse in mental health contexts I have encountered people in existential distress countless times. As I have been considering these matters, I realize the facilitative skills of the nurse to inspire hope in desperate situations will vary significantly depending on the health-care setting and length of contact with people in their care. The ability of the nurse to authentically meet people where they are at and facilitate hope remains the same no matter how brief the contact, and can have a profound impact. I suggest the impact of these encounters can be pivotal to the direction the healing dynamic can take. As I make sense of extended experiences in the practice world, especially in mental health, I reflect on patterns emerging in my role as a DNFT. Because DNFT is arguably new territory for nurses, specific details 
about this practice is likely to be of interest to both the world of practice and theory development within nursing.

My decision to use the word transition as a way of looking at change, especially in relation to loss and grief, is to focus on the process orientation of movement through change, rather that the content, for example, loss. My understanding of transition follows.

\section{Transition}

According to Encarta Dictionary UK (Online 2005) transition denotes a process of change in state, form, or activity. A thesaurus check reveals meanings of the process of evolution or conversion. Evolution in this context means to advance or progress. Conversion could involve renovation, alteration or adaptation. Transition usually entails a change in wellbeing and self-concept and can reveal patterns of response to change over the lifespan. William Bridges (1980) describes the process of transition as beginning with an ending, followed by a period of uncertainty and inner turmoil, leading to a new beginning. This period of uncertainty, identified by Bridges as a neutral zone, implies a space. This space is often described by those I see, as a time of emptiness and uncertainty. For some people it is a time when they need skilled support; especially those who have a hard time coping with the bewilderment and distress that transitions can often bring up. In these situations, it is helpful to have a person who understands the territory of transitions to walk alongside them, coaching, encouraging, supporting, and challenging.

In my role as a nurse and educator I began to wonder about how I work with people to bring about change. In my Masters thesis I explored and was influenced by the emancipatory facilitative work and philosophies of Paulo Freire (1974; 1985; 1998). Facilitation as a way of supporting transitions was also influenced by the work of nurse academic Afaf Meleis which I read in the mid 1990s. Nursing involvement in facilitation of transition was found by Meleis and Tangenstein (1994) in roles of education, practice, administration, and research in at least five types of transitions. These transitions include developmental transitions such as midlife, social relations, 
life events, health/illness (especially chronic illnesses) and changes in the workplace. Indicators for successful transitions according to Meleis and Trangenstein include emotional wellbeing, mastery, and good relationships. Later Meleis, Sawyer, Im, Messias, and Schumacher (2000) expanded the role of nurses as facilitators of transition into a middle range theory. I explore similarities and differences of my philosophies and practices to this theory in Chapter Eight of this thesis.

Although working with transitions in nursing practice is clearly an area of concern for nurses as identified by the writings of Meleis et al.; when I say that transition, grief, and loss is my specialty in the mental health area, people often make the following comment, "So you are a counsellor then". This is not just a public perception; it is also shared by other professional groups such as medicine and psychology. Counselling is not seen as part of a nursing role even though it is identified as a competency in the definition of a NP scope of practice (MOH, 2002). At a political level in NZ, funding is usually attached to specific roles of health professionals and, at this time, if a person visits a nurse without counselling or psychotherapy qualifications, they are unlikely to be eligible for subsidies. Within the nursing profession it would appear that minimal attention or validation is being given to the actual skill acquisition experientially, and theoretically, that mental health nurses develop as counsellors, in the general sense. Mental health nurses are still going to training agencies outside their practice discipline, such as psychotherapy, to have their skills validated. Crowe and Luty (2005) acknowledge a potential role for nurses as interpersonal psychotherapists in the care of people with depression, loss and grief. They recommend that nurses receive specific training for this work by qualified psychotherapists to enable them to practice in this area. Although specialized knowledge development is important do nurses actually have to turn to other knowledge bases to find it? Hildegard Peplau in her seminal text Interpersonal Relations in Nursing (1952) identified at least six nursing roles in mental health, one of which is a counselling role. Her theory provided a coherent framework of interpersonal and counselling aspects of nursing practice and remains an important reference point for mental health nursing in the $21^{\text {st }}$ century.

In this thesis I take the position that facilitation of transition encompasses basic counselling, education, and health promotion, while at the same time incorporating nursing knowledge about change processes, especially changing states of being within 
the integration of physical, emotional, social, and spiritual health and wellbeing. I suggest that the difference between nursing and counselling, or psychotherapy, is the focus. Further, I posit that the focus of nursing is on health and wellbeing, and that the psychotherapeutic process is a vehicle in a mutual participatory process between the nurse and the person. I felt I needed to develop more clarity about the distinction between counselling and facilitation in nursing. My initial exploration of the meaning of facilitation began with the word itself.

\section{Facilitation}

Urdang and Long's (1979) definition of facilitate means to 'to make easier; assist the progress of'. The Encarta Dictionary UK (Online 2005) defines a facilitator as, "somebody who aids or assists in a process, especially by encouraging people to find their own solutions to problems or tasks". Synonyms of facilitation in the thesaurus are: "launch pad, catalyst, and spur". A launch pad, in this context, means a starting point for progress. A catalyst is a "stimulus to change". A spur, in the human relations context, is to induce a change in the person either through reward or punishment. On the positive side, synonyms of spur are to urge, encourage, and prompt. On the negative side, to goad, drive, incite, provoke, or inflame. Mostly these meanings imply an active process, but in the case of drive, the meaning can also denote constraint or holding back. Primarily, the meaning of facilitation implies encouragement of the person to take action, to try harder. However, I note meanings ascribed to facilitation can also reveal a dialectical tension between an active positive process, an active negative process, and a restrictive process.

Facilitation, or being a facilitator, is imbued with deeper meanings when combined with transition. In my practice as a nurse, I embrace the Celtic notion of anam cara written about by John O’Donohue (1997). Drawing on his writings, I take anam to mean soul, and cara friend. Anam cara, in the Celtic sense, is used as a name for a person who is a spiritual guide or teacher (O'Donohue, 1997). An anam cara is a person with whom someone reveals his or her inner processes; it is a person who awakens the soul journey, which will ultimately lead to a return to the inner self. This journey is usually the beginning of a discovery of new energy, a sense of creativity, an 
awakening to a sense of purpose, new meaning, and making peace with our constant companion, death. Death is not just about the body and the loss of it. Death is encountered in times of transition and is often the subject of human fear, and therefore why human beings avoid the inner reality of it. To face transition is to face death. According to O'Donohue (1997): "Friendship with our death would enable us to celebrate the eternity of the soul which death cannot touch" (p.18). Notable Western philosophers such as Johannes Eckhart and Jean-Paul Sartre, write of the underlying fear of both life and death as being emptiness, nothingness and aloneness. The writings of Mystics and religions, both East and West expound on the transcendence of human notions of the duality between life and death, towards a sense of oneness with all life. These themes underlay the philosophies that are explored in this thesis.

In his writings O'Donohue (1997) refers to another dimension of anam cara, the Buddhist tradition of kalyanamitra or noble friend. A kalyanamitra will not accept facades, rather their role is to challenge with compassion, in both critical and creative ways, to encourage the other to reveal their real self. The notions of loving-kindness, written about by nurse theorists Margaret Newman (1986) and Jean Watson (1979; 2005a) are fused in anam cara and kalyanamitra and form the basis for my understanding of facilitation.

I am also influenced by the dialectical research methodology inspired by the work of John Rowan (1997). I applied Rowan's dialectical methodology in my Masters thesis to help me uncover the meaning of facilitation as an educator. I found that the dialectical research process had become integrated into my way of working as a nurse facilitating transitions. This integration showed the evolution of nursing practice to praxis defined by Roberts and Taylor (2002) as: "Change through deliberate and systematic critical reflection on practice" (p.536).

My view of the meaning of dialectical as both research and praxis started out as a dialogical, relational process. As I became more deeply involved in dialectical process however, I found a resonance with more ancient philosophies such as Buddhism which 
I had been practising over the span of my Masters research. I trace this journey of coming to understand a dialectical research process in the next section.

\section{Dialectical approach}

It was the integrative nature of the dialectical research process I was attracted to, which emphasizes synthesis of opposites and living with paradox. I also realized that the principles of dialectical philosophy incorporated the Buddhist understanding of 'The Middle Way', in that it accepts life as cyclic. To explain further, in terms of relationships, Daisaku Ikeda ${ }^{9}$ (2002a) suggests that taking a non-dual perspective enables one to go beyond idealism and uniformity in order to reconcile contradictions and transcend opposing views. In a sense, for some, this may seem a lengthy process. It involves waiting for people to discover in the reality of life, all things, ideas, and ways of being, have merit, whilst at the same time they are changing and evolving. From a Buddhist perspective, this means that people in the cyclic process of change, can actively allow and enable the highest potential to surface. A fighting and forcing energy cannot do this. For example, if I attempt to force a daffodil to flower in autumn, I not only disturb its natural cyclic process of activity and latency but I may disturb its naturally occurring process and prevent it from blooming in spring.

I also found some parallels in my approach to dialectics with psychologist Marsha Linehan's (1993) therapeutics with borderline personality disorder. Linehan applies dialectical philosophy extensively to her work as a therapist, and describes three principles, which she identifies as: Integration, polarity, and change. It is the tension between the polarities that the person experiences, for example, the thinking, feeling, and positive and negative experiences in the social milieu that has the potential to shape the person's understanding of the world. This is similar to the process of reasoning, described by philosopher Hegel, known as thesis, antithesis and synthesis,

\footnotetext{
${ }^{8}$ The Middle Way is defined by The English Buddhist Dictionary Committee (TEBDC, 2002) as: "The way or path that transcends polar extremes" (p.405).

${ }^{9}$ Daisaku Ikeda is a lay Buddhist who is Japanese. He is president of the Soka Gakkia (value creation) International Organization and is spiritual leader to the millions of Nichiren Daishonin Buddhist practitioners around the world. A prolific author on the subject of Nichiren Daishonin Buddhism, Daisaku Ikeda writes about the essential meaning of the Nichiren Daishonin school, which proposes that each human being, without exception, can attain enlightenment through accessing their inherent Buddha nature.
} 
and interpreted and adapted by Rowan (1997), as primary, social, and realized levels of thinking.

I also draw on the integral humanistic nursing theories of Martha Rogers (1971); Rosemarie Parse (1981); Margaret Newman (1986); Dolores Krieger (1981; 1997); Jean Watson (1979; 2005a); and Phil Barker (2002). Energy field theories such as those espoused by Rogers, Parse, Newman, and Krieger among others, at first seemed highly abstract and difficult to understand. As time passed and as I became more aware of the spiritual essence of the life-force itself through my practice of Buddhism, I realized that these theories have had a ground breaking influence, precipitating a paradigm shift in nursing to encompass metaphysical and dialectical approaches to health and wellbeing. In my practice I have found surfacing the spiritual essence of the life-force is an essential part of the process of transitioning (see also: Reed, 1992; Smith, 1994; Long, 1997; Narayanasamy, 1999; Delgado, 2005; Wilding, MuirCochrane, \& May, 2006). Likewise relational, (see Peplau, 1952; Parse, 1992; and Newman 1994); and caring aspects of nursing espoused by Barker (2002) and Watson (2005a) inform nursing knowledge about the philosophy of the relationship between the nurse and person. In their respective writings they posit a professional relationship that goes beyond the boundaries of a cognitive approach, into the essence of a humane and spiritual connection. The influence of their work is evident in my search for ways of explicating nurse facilitation. Although other nursing theories and philosophies are also explored, the nurse theorists cited above focus on integrative nursing philosophy and practice and resonate with the way in which I have shaped my nursing practice and this research project. I give an overview of my understanding of an integral nursing approach in the next section.

\section{Integral nursing practice}

The word integral means "composed of parts that together make a whole", or "without missing parts that together make a whole" (Encarta Dictionary UK, Online, 2007). In a nursing context I use the word integral to imply interconnection between the mindbody-spirit. The way that I understand integral comes from the Buddhist notion of the 
oneness of self and environment from The Writings of Nichiren Daishonin ${ }^{10}$ (TWND), (1999).

I became attracted to the Nichiren School of Buddhism in the late 1990s after thirty or so years of practicing Christianity. I gradually came to realize that the source of spirit seemed to be internal rather than external. At that time, my thinking was shifting from a dualistic cosmology to a unitary cosmology. I had previously been both attracted to, and repelled by, Eastern religions such as Buddhism. I was attracted by their emphasis on personal self-awareness and spiritual growth, and I was repelled by the tendency for Buddhist schools to withdraw from the mainstream of society, and also for their seemingly oppressive stance towards women. I found that Nichiren also experienced these tensions and expounded a contrary interpretation of Buddha Shakyamuni's teaching of these views. Nichiren was considered a rebellious and controversial sage in his time because he refuted the worship of Stupas ${ }^{11}$, which externalized the Buddha nature. In his teachings, based on the Lotus Sutra, he maintained that all persons, inclusive of women, had the potential to attain enlightenment. He posited that the practice of Buddhism is lived out in the ordinariness of day-to-day life, rather than being removed from society. Nichiren justified this deviation from other schools of Buddhist thought, based on the earlier sutras of Shakyamuni, which were said to be expedient to the culture of the time. The Lotus Sutra, according to Nichiren, referring to the earlier synthesis of Shakyamuni's Sutras by the Chinese scholar and sage T'ient'ai (AD 538-97); was thought to be Shakyamuni's synthesis of his collective teachings. Nichiren, therefore, established his teachings entirely on the Lotus Sutra (TWND, 1999).

Based on my understanding of Buddhism, I have a view that integral is more than the interconnectedness of the mind-body-spirit; rather, it is the relationship that humans have with the universe as a whole which includes all matter, living, and non living, seen, or unseen. This relationship resembles a crystalline form, multidimensional in

\footnotetext{
${ }^{10}$ Nichiren Daishonin (1222-1282) was a Japanese founder of a Buddhist school of thought that posits that the essence of the teachings of the founder of Buddhism, Shakyamuni Buddha, was in the Lotus Sutra. This essence was identified as the Lotus Sutra title, Myoho-Renge -Kyo, and was embodied in a mandala, known as a Gohonzon. This mandala is the focus of daily practice and meditation for observing the mind. The basis of Nichiren teaching is that each person has Buddha nature which can be accessed by faith, study, and the practice of chanting Nam-myoho-renge-kyo (TEBDC, 2002).

${ }^{11}$ A Stupa is a statue of Buddha.
} 
nature and reflecting the dialectic of light and shade. It is mysterious, fascinating, and ever changing. In nursing contexts, and in particular mental health contexts, integrality is a principle that I draw on in my nursing practice when working with people who are confronted with a sense of disconnection, disharmony or crisis in the face of loss, grief, and transition.

Another word commonly used by nurses to mean integral, is holism. My experience of the use of the word holism is that it is often misunderstood within the health profession and frequently connected solely with spirituality. For this reason I often use the word integral as a synonym to holism, to depict the meaning in a more accessible way. I do so in this thesis for the same reason.

I explain in the following section, my application of a dialectical approach to form questions that address the integration of the epistemology and ontology of DNFT.

\section{Addressing the what, why, and how, of this research}

Initially I framed my research proposal as an evaluative study for the purpose of revealing the value of facilitation to participants. Eventually after some reflection I found that I needed to first embark on a journey exploring the territory of DNFT for the purpose of theory and praxis development. This led to my decision to undertake a dialectical philosophical inquiry which could also be considered a praxiological inquiry (Conner, 2002). My understanding of praxiological process drawing on Conner's work is; a way of integrating philosophical aspects of a research methodology into practice knowledge. In the context of this thesis dialectical philosophy and heuristic methodology facilitates a way of praxiological inquiry that is reflective and exploratory, enabling an open search for patterns in my practice world of DNFT. 
In choosing the final title ${ }^{12}$ of this thesis, Exploring transitions: Working' in the space between the no longer and the not yet', I wanted to invite the reader to anticipate a work that opens up a subject for exploration and that also encounters mystery. I do a thesaurus check as I ponder the meaning of a 'space between' and find that it could mean a room, a gap, an area, or outer space. In the context in which the word is used in this thesis, I believe it could represent a metaphorical room, a breathing space, a place for discovery and freedom. A gap is a pause, or a chasm, it could also represent a way of escape, a distance to travel, or a window where new vistas can be glimpsed. As an area, it may be a place one goes - perhaps to sit, to contemplate, to talk, to write and to heal. Outer space implies infinity, depth, universal connection, and energy. All of these potentials and patterns became evident in this thesis. "No longer and not yet" is a phrase I quote from Rowe (1980 p.13). Rowe refers to this in-between space as an 'anxious space' characterized by the emotion of fear and often motivating the person to seek relief from this feeling.

'No longer' represents the past, something that can never be repeated; and 'not yet' can seem like a time of incubation, emptiness, or darkness. In the world of the imagination it is a future of possibilities and potentials, inspiring one to move forward. The space between the no longer and the not yet, in transitions was exemplified in my experiences, and those I worked with showing the potential for feelings of ambiguity and uncertainty. The in between moment of the 'not yet' implies the present moment. This moment for many voyagers could be a metaphorical fork in the road inviting choice.

I posed the following question to begin this exploration of transitions and the work of nurse facilitation in the space between "the no longer and the not yet": What patterns emerge in the practice of Dialectical Nurse Facilitation of Transition?

This question was designed to address both the epistemology of dialectical nurse facilitation, and the ontology, of being a facilitator of transition. An epistemological

\footnotetext{
${ }^{12}$ The original Title of the study was: Expanding nursing horizons in health care: The application of a dialectical approach to facilitate transition and improve health and wellbeing. This title appears in appendices (see p. 283291).
} 
examination of DNFT draws extensively on theoretical knowledge which focuses on relational, humanistic, integrated models of care, embracing not only the human-tohuman encounter but also human interconnectedness with all aspects of the universe. It also draws on extant knowledge of loss, grief, and transition.

The question addresses three broad components: A personal exploration of the patterns of DNFT; an exploration and explication of how reflecting on research can integrate theory and practice and become praxis; and an exploration of ways that DNFT could expand the horizons of nursing praxis in health care contexts nationally and internationally. I include these components to the main question in Table 1 below, as a reference point for the reader.

Table 1: Questions addressed in this thesis

\begin{tabular}{|l}
\hline What patterns emerge in the practice of Dialectical Nurse Facilitation of \\
Transition? \\
\hline 1. Why is a personal exploration of the patterns of DNFT essential to an \\
epistemological and ontological integration? \\
2. How does reflecting on research integrate theory and practice and become praxis? \\
3. What significance does DNFT praxis hold for nurses nationally and internationally \\
\hline
\end{tabular}

In framing the research methodology I draw on a synthesis of Eastern and Western ideas about dialectical philosophy. This includes Hegelian, material, relational and psychological dialectics, especially drawing on the work of John Rowan's (1997) A dialectical paradigm for research and Barbara Carper's (1978) Fundamental patterns of knowing in nursing. It also includes Buddhist 'Middle Way' philosophy. The method and design of this thesis includes an in-depth process of self-reflection inspired by Christopher Johns' (2004b) Becoming a reflective practitioner and Clark Moustakas' (1990) Heuristic research: Design, methodology, and applications. These methods of self-reflections help me to address the central question of this thesis. 
In answering the ontological aspect of my research questions, I traced my nursing ancestry and brought theories of influence forward into a unique nursing philosophical and theoretical framework for practice in the specialty of DNFT. Primary, social, and realized levels of experience are elucidated in the phenomenology of 'being' or 'lived experience'. To explain further, Rowan (1997) conceptualizes primary level thinking as thinking that is processed through experience, emotion, and perception. This is similar to Carper's (1978) notion of 'personal knowing' and 'aesthetic knowing', which I refer to when framing a dialectical research method and design. In this thesis, primary level thinking is included in the reflective and reflexive aspects of my practice (explained further in the next section) expressed through journaling, story telling and poetry.

My awareness of the importance of doing this came about as I integrated insights arising from self-reflection and my habitual pattern of journaling key personal and practice experiences. Journaling has been a self-motivated, life-long process. From the vantage point of expanded practice in nursing, primarily in mental health and education, I see that it has sustained me through challenging times in my private and practice worlds.

\section{Reflection and reflexivity}

Reflection is a meditative process in order to make sense of thoughts and memories (Taylor, 2000). Johns sees reflection as a process engaging the head, heart, and hands to be mindful of thoughts, feelings and responses to situations in practice. Reflexivity is defined by Johns (2004b) as “[1]ooking back and reviewing self”s development over time..." (p.4). It is the combination of reflection and reflexivity that enables one to engage in a dialogical process with self; exploring paradoxes and integrating the ideal of practice with the reality. It is in this process that nursing practice becomes praxis.

In terms of Rowan's (1997) proposed moments of experience, personal knowing draws on experiences of 'encounter'. In this case, my own encounter and engagement with transition. This includes exploring my own transition from education and mental health nursing, to becoming a DNFT. 
These explorations lead to a paradoxical process of both narrowing and specifying an aspect of advanced practice, whilst at the same time, potentially expanding horizons for nurses in health-care settings who may consider integrating aspects of these explorations in their practice. In doing this it is not my intention to posit a theoretical model for nursing praxis. Rather, I make transparent my developing self-awareness through reflexivity and reflecting on practice. I introduce the methodology that guides my research process in the next section.

\section{Integrating philosophy and method}

To describe the emerging role of DNFT and the adaptation of the dialectical research process into a theoretical framework for praxis, it is necessary to explicate and interpret the epistemological position of dialectical philosophy. To address Rowan's primary, social and realized levels of thought, Rowan proposed six moments of experience: being, thinking, project, encounter, making-sense and communication. Within these moments, Rowan suggested six cycles of questioning to address the research process: positivist-efficiency, addressing validity and rigour; alienationauthenticity, addressing the role of the researcher; political-patriarchal, addressing the socio-political context; dialectical, addressing the paradoxes and transformations; legitimacy, addressing the appropriateness of the design; and relevance, addressing whether it will be valuable to practice.

Social levels of experience attend to socio-political-cultural contexts of 'being'. In this thesis I situate myself in Aotearoa NZ bicultural society in the $21^{\text {st }}$ century, practising as an independent mental health nurse in a community. As previously stated, this is a time in the history of nursing in Aotearoa when new roles for nurses, such as NPs, are being developed at a political level. Rowan (1997) suggested that social level exploration involves exploring the tensions which exist that enable, disable, or obstruct the enactment of roles. In my situation, I look at the social level in the formation and enactment of my role as a DNFT. In terms of Rowan's moments of experience framework, this comprises both 'encounter' and 'project' and 'making sense'. This exploration spans the thesis and is written in an integrated way. 
Realization involves the synthesis of both epistemology and ontology and is essentially a cognitive process, or as Rowan puts it, the 'thinking through' and 'making sense' moments of experience. In this thesis, realization is my integration of personal knowing and research findings into a theoretical and philosophical framework for the practice of DNFT.

I discuss how I integrate Rowans's work into my methodology, method, and design, in Chapter Five.

\section{Design and ethical implications}

Coming to know how to answer the research questions posed in this introduction unearthed a tension for me that related to a deeply rooted fear I had about the question of acceptability of using personal knowing as the basis for the explication and synthesis of nursing practice when so much emphasis and credibility is linked with quantifiable research in health. I decided not to do an evaluative study but still felt uncomfortable about letting go of people's experiences of transition facilitation; thus, I framed a new proposal that involved practice supervision, peer review, and instrumental case review. The use of case studies to explicate practice has been used historically in nursing and psychology to seek, refine, or test theory and to provide indepth description, interpretation and evaluation (Benner, 1984; Higgins, 1993). Higgins (1993) describes the case study as the 'bedrock of social or clinical work' (p.14). Although this thesis does not specifically use a case study approach, the exemplars of case reviews augment reflections from supervision and peer review. I used the following process of instrumental case review so that the sensitive issues surrounding each of the transitions I worked with would not be revealed.

I retrospectively reviewed case notes of Sophie, Grace, Faith, Rose, Charles and Lilo (pseudonyms), who were involved in facilitation work with me, to construct exemplars. These exemplars were instrumental to the description of facilitation, rather than the focus of the research data, and elucidated patterns of facilitation (Stake, 1994). In this way the life stories of these people were not revealed. This protected 
the privacy of those who agreed to participate and prevented inducing an unnecessary layer of vulnerability to those who participated.

Practice supervision and peer review serves to improve the safety of the both the practitioner and the participants and is commonly accepted practice in all levels of caring activity in Aotearoa NZ. This is distinct from academic supervision, which addresses the research process. In addition, permission and approval from the Victoria University of Wellington Human Ethics Committee was obtained, to review case notes from my practice in the following three categories: Loss; changes in the person's life world; and adjustment to diagnosis of disease for themselves or significant others (refer Appendices A \& B).

I write reflective journals after practice supervision with an expert in the field of transition, grief, and loss; and after peer review, with a colleague involved in similar practice. In the context of this thesis, these influences enabled me to embark on a search for meanings and patterns shaping my philosophical, theoretical nursing knowing and the praxis of dialectical nurse facilitation of transition; complementing the dialectical research process.

The value of in-depth self-reflection, according to Moustakas (1990), is to discover the meaning of experience through uncovering subjective implicit knowing. Moustakas (1990) describes six phases of heuristic research, including: initial engagement; immersion; incubation; illumination; explication and creative synthesis which I integrate and adapt in my research design.

The description and interpretation of dialectical research process is philosophical inquiry. The adaptation of this dialectical process to a framework for practice comprises the ontological position of the research. The ontological aspect of this research question requires the revelation of the development of self knowledge, reflection, and creative expression. The elucidation of ontology comes about in an 
interwoven form of insights, made in practice supervision, peer review sessions, and personal reflective journaling.

The involvement of expert and peer supervisors in this process requires ethical attention such as anonymity, confidentiality, and disclaimer clauses (refer appendices C \& D). Attention was paid to these issues in the information and consent forms. Terms were negotiated with the supervisor and peer reviewer and refined to accommodate recommendations. These aspects of the research process were presented to the Victoria University of Wellington for ethical approval (refer Appendix A).

When the research was completed, an executive summary and chapters, including exemplars, was offered to each participant. The practice supervisor, and peer reviewer were offered a full copy of the thesis at completion.

\section{Significance of the study}

This thesis makes transparent processes for nurses developing in-depth self-awareness through reflective practice. The need for this in nursing is outlined in the recovery competencies for health professionals in mental health (MHC, 2001). The importance of reflective practice is resonant with international nursing writers and philosophers (see Taylor, 2000; Johns, 2004a; 2004b; Johns \& Freshwater, 2005; Watson, 2005b) and is growing in emphasis in NZ (see Conner, 2004; Nursing Council of New Zealand, 2005; (NCNZ). Effective practice supervision and peer review is pivotal to the development of heightened self-awareness in nursing practice contexts (see Bond, \& Holland, 1998; Morton-Cooper \& Palmer, 2000; Fulton \& Oliver 2001; Consedine, 2004; and Johns, 2004b). As yet there is little in the nursing literature in NZ that explicitly explains and discusses the integration of practice supervision, peer review and case review. This thesis will make a major contribution to the what, why, how, (refer p.18) of reflective practice in both the Aotearoa NZ and international contexts, especially in mental health.

This thesis adds to the international nursing discourse on the subject of facilitating transitions (See Meleis \& Trangenstein, 1994; Im \& Meleis, 1999; and Meleis et al., 2000); and the nurse as a change agent (see Travelbee, 1971; and McEldowney, 2002).The similarities and differences between nurse facilitation and counselling are 
explored, revealing both support for nurse facilitation and barriers that exist to enacting this role. This thesis specifies the relational and dialogical aspects of nursing, answering the extant nursing discourses of (Burnard; 1999; Barker 2002; Conner, 2004; Doane, \& Varcoe, 2005; and Litchfield, 2005).

The scientific value of this project is that it provides an in-depth qualitative description, explanation, and interpretation of the process of nursing practice, specifically dialectical nurse facilitation of loss, grief, and transition; in the specialty of mental health. The benefit of this research is that it provides an in-depth explication of the practice of DNFT providing a foundation for evaluative studies of this practice on health and wellbeing and illness prevention. This research also provides insight into the ways in which people experience, and can be supported by nurses in the crises and stress of major life events. The findings could lead to further research into the benefits of specialized nursing support in times of transition and the prevention of depression, suicide, physical illness, and spiritual distress for identified vulnerable groups. This will make a national and international contribution because it has implications for the care of people who are triggered by major life events to suicide and/or the development of illness (see Holmes \& Rahe 1967; World Health Organization (WHO), 2007).

Research findings add to knowledge about advanced nursing practice in Aotearoa NZ community health-care settings. The findings of these inquiries lead to a proposal that registered nurses in NZ can initiate and develop specialized roles within community health-care contexts from a nursing philosophical base, which is distinct from other professions.

In addition this thesis reveals aspects of integral nursing which is congruent with trends revealed in MACCAH (2004). These trends show a growing demand for complementary and alternative approaches to health by the public of Aotearoa NZ and the desire for integrated care that addresses all aspects of the person, family, and environment. The application of a dialectical approach as a way of providing integral nursing care makes a contribution to extant international nursing discourses on complementary, alternative, and dialectical approaches (see Rogers, 1971; Parse, 
1981; Krieger, 1981; Newman, 1986; Barrett; 2003; Watson, 2002; and Picard \& Jones, 2005).

The communication of findings is likely to be of interest to the nursing profession both nationally and internationally, the $\mathrm{MOH}$, and other practice disciplines with an interest in transition. Findings about the process of facilitation of transition and its relationship to health and wellbeing may be of interest to the general public.

\section{Summary and overview of the thesis}

In the introductory chapter I place this thesis in the Aotearoa NZ context of change and increasing autonomy and responsibility for nurses in practice. A DNFT role for nurses in the mental health and primary health-care contexts is proposed in this thesis. This facilitative role encompasses an integral approach to nursing, which uncovers the dialectic of facilitation and counselling and spans all chapters of this thesis. In revealing the practice context through reflective journaling of peer review, practice supervision, and case reviews, the role of nurse as facilitator is authenticated, enabling the reader to vicariously experience the ontology of DNFT.

This thesis is organized into three parts to signal different vantage points and lenses from which this thesis is viewed and written. Part One includes the introduction and the theoretical pre-understandings that shape my work as a DNFT. It also includes the philosophies and methodologies that guide my research process. Part Two reveals the world of DNFT praxis. Part Three comprises the discussion of patterns emerging in Part Two and their relevance to national and international practice contexts.

There are ten chapters in this thesis. In line with a qualitative research process, the explication of the epistemology and ontology of nursing practice requires a combination of classical academic and creative writing. So that the reader can track the different styles; reflections, stories, and poems of the researcher are written in italics. Italics, bolding, and capitalization are also used for emphasis and naming of patterns. Insets are used for exemplars arising from case reviews. Creative artworks are presented as figures. 
The literature review of this thesis is extensive in order to encompass the dimensions of DNFT. I foreground influences and theories which inform my work in Chapters One, Two, and Three. This precedes my methodology, method and design chapter as follows.

Chapter Three, details prevailing theoretical influences about loss, grief, and transition which spans my growing interest in the topic from the 1970s-2000s.

Chapter Four is divided into three sections. In Section One I review the theories and philosophies of humanistic, integrative, transformative, and research processes of nurses such as: Rogers, Newman, Parse, Watson, Krieger, Peplau and Barker, that influence my nursing practice. In Section Two I review facilitation, counselling, and dialogue, from nursing, psychology, psychotherapy, and philosophical schools of thought. These influences have shaped my facilitative practice. Section Three, reveals the influence of Buddhism on my philosophical development of humanism, dialectics, and integral nursing practice. I do not have an agenda to suggest that others follow this pathway. In this context, as author of this thesis, my intention is to shed an introductory light on aspects of Buddhism that relate to the subject of transition and the dialectical process.

Chapter Five, sets out the methodology, method and design of this thesis and is divided into three sections. Section One, reveals the philosophical underpinnings from Western philosophies showing how these influences are integrated into my research method and design. Section Two, reveals an Eastern perspective of dialectics, specifically Buddhist Middle Way philosophy and Taoism, and their respective influences on my work. Section Three, specifies the method and design of reflective practice through practice supervision, peer review, and case review. Data collection processes and ethical issues are addressed in this section, and practice supervision and peer review is defined.

Personal stories, reflections, exemplars, and patterns, from practice supervision, peer review, and case review, form the core of the thesis in Chapters Six Seven and Eight. In Chapter Six I foreground personal stories that lead to my attraction and engagement with DNFT. 
Chapter Seven is divided into two sections. In Section one I explicate foundation patterns underpinning DNFT, basing them on exemplars from practice supervision, peer review, and case reviews. Patterns of transition from reflective journaling and case review are revealed in Section Two.

An integration and synthesis of heuristic knowing and extant knowledge are woven into patterns making transparent a personal framework for praxis in Chapter Eight.

I explore and discuss both resonance and dissonance with theoretical texts pertaining to these emergent patterns in Chapter Nine.

The implications for the education and practice of nurses for both nurse facilitation (NF) and DNFT are explored in relationship to health-care contexts in Aotearoa NZ, and international contexts in Chapter Ten. This includes implications and limitations of the thesis and possibilities for the nursing profession in the future.

I conclude this thesis with a reflection of the research process and findings. 


\section{CHAPTER THREE Coming to Know about Loss, Grief, and Transition}

In this chapter I trace the origins of major research and intervention theories on loss, grief, and transition that have influenced my practice as a nurse. This provides the reader an insight into the theoretical platforms from which I develop this thesis for DNFT.

I start by discussing the associations made between loss, grief, and chronic illness by researchers (see Dohrenwend and Dohrenwend's 1974 anthology). Evidence was growing that skilful professional intervention for susceptible individuals can support the grieving process and prevent illness (Paykel 1974; Parkes 1980). The potential benefits of professional support; precipitated the development of interventions and theories on loss, grief and transition, which has undergone an evolution since the mid $20^{\text {th }}$ Century.

I trace this evolution from stage models for loss and grief (see Freud 1957; Bowlby 1973; Kübler-Ross 1970; Parkes 1972; and Worden 1983); to the development of contemporary constructivist approaches; for example, narrative therapy (see Neimeyer's 2001a anthology). Because narrative therapy has some resonance with DNFT this review enables a beginning point for discussion about the nature of counselling and facilitation that I expand on in Chapter Three.

Finally I discuss transitional work as a process of personal growth and changed views of self-identity. I offer a personal exemplar (in italics) alongside influential writings (see Bridges 1980; Satir, Banmen, Gerber \& Gomori 1991) that guided my journey through change.

\section{Loss, grief, chronic stress and illness}

Dohrenwend and Dohrenwend's (1974) anthology of researchers' work examined the relationship between stressful life events and physical illness. Among the contributors to this topic were Holmes and Rahe (1967) authors of a scale for measuring major life events as indicators for developing illness in susceptible individuals (Rahe, 1974). 
Although the original scale has been refined over time, it was an attempt to provide measurable evidence for the relationship between stressful life events and the development of illness. With regard to physical and chemical responses to stressful life events, Theorell (1974) found a link between the elevation of catecholamine excretion in stressed individuals and coronary artery disease. Psychosocial aspects of stress in relation to life events were addressed by Cobb (1974) who proposed that personal coping strategies, defences, genetic disposition, attitudes towards illness, medical care, accessibility of social support, and attitudes of significant others, had a relationship to the development of stress related problems that arose for individuals. Cobb (1974) suggested these factors needed to be specifically measured in research.

Antonovsky (1974) drew on his own experience of stressful life events in war torn Israel and noted the importance of subjective perception of the meaning of life events stating that "[r]olling with the punches and coming to liveable terms with suffering is an important component of resistance resources" (p. 251). Antonovsky recommended the examination of tensions created by life events, stressing the importance of social connection and support as being crucial to persons developing resilience to the effects of stress. I share Antonovsky's view that the discovery of tensions is important within physical, emotional, socio-cultural and spiritual dimensions of self. I apply this in Part Two in the explication of DNFT.

Researchers such as Mechanic (1974); Paykel (1974); Dohrenwend and Dohrenwend (1974) grappled with methodological issues and research findings about the cause and effect of major life events and the prevention of illness with supportive intervention. Although attempts by these researchers are made to validate the relationship between stressful life events and supportive intervention, evidence is fraught with biases and roadblocks. Mechanic (1974) indicates there is a problem in determining whether illness following a traumatic event or loss is caused by hereditary or environment. Nevertheless Mechanic (1974) indicates "[s]erious attention will have to be given to the development of viable practice models derived from a growing understanding of how life situations interact with the occurrence of illness" (p.89). According to Paykel (1974), there are mixed findings about the efficacy of supportive intervention for susceptible individuals, such as sufferers of depression and suicidal individuals. The most pervasive findings in studies by Dohrenwend and Dohrenwend (1974); Holmes 
and Masuda (1974); Rahe, (1974); Paykel, (1974) are the significance of the examination of contextual issues, personality variances and vulnerability within therapeutic assessment and intervention.

Major researchers of loss and grief such as Bowlby (1973); Kübler-Ross (1970); Parkes (1972); and Worden (1983), among others, gave attention to the development of 'viable practice models' for therapeutic assessment and intervention. These authors heralded the recognition of processes that people demonstrate in their "working through' of loss and grief, shifting commonly held public notions of loss and grief leading to a 'broken heart', which only time may alleviate. They developed professional practice by proposing standard models of grieving and helping. Stages and phases of loss and grief can seem to represent a mechanical linear way of looking at the processes. Nurse writer Costello (1995) in her review of a number of loss and grief theories such as Kübler-Ross (1970); Parkes (1972); and Worden (1983) suggested it was important that nurses did not adopt a linear approach to loss and grief as may be implied by the framing of these theories as phases and stages. Ilot (1996) offered an occupational therapy perspective discussing the importance of selfawareness and experiential learning, specifically about loss and grief. These were seen by Ilot as being essential for occupational therapists to gain an understanding of the loss and grief processes of the people that they are working with, which could also apply to nursing.

In the next section I review historical influences on understandings about loss, grief and transition, following the evolvements of thinking on the subject. These influences showed a dominance of medicine and psychiatry that typified the influences I encountered in my nursing education in the 1970s.

\section{Stage models of loss and grief}

Sigmund Freud (1957) was one of the early theorists on the subject of grief and loss, which he addressed in his 1917 work, Mourning and Melancholia. In the early 1900s, he proposed that grief is the withdrawal by the individual of energy that binds them to the object of loss. This is done, according to Freud, by bringing to consciousness relevant memories enabling the mourner to be free of, or detached from, bound up 
energy and to redirect energy to those living. Freud argues that mourning occurs, because the person comes to realize through loss that death can no longer be denied. The individual identifies with the lost loved one, introjecting their characteristics to preserve the connection. Strands of Freud's work can be traced in subsequent theorists described here, although the substance of his ideas has been challenged for his emphasis on pathology and his lack of substantial research on the subject (Neimeyer, 2001a; Hagman, 2001).

John Bowlby (1973; 1980), a psychiatrist and researcher for the WHO, studied the subject of attachment and loss extensively from the 1950s. He wrote four volumes on the subject, which looked at various facets of the origins of grief response and illness in his studies of maternal and child relationships. He posited that it is the social nature of humans to become emotionally attached, especially to the primary caregiver. Separation induces crying and searching which is a way of attempting a reunion. $\mathrm{He}$ mapped out patterns of responses to loss and illness development locating the origins of pathological conditions associated with loss, in early developmental phases of life. For example, if a person has a disrupted attachment in early life, difficulties with loss and attachment could be predicted later in life. His approach was psychoanalytical, seeking the origins of illness in the client's past experience, and like Freud, proposed that the central focus of grieving was on detachment and working towards a resolution.

Bowlby's contemporary, Colin Parkes $(1972 ; 1996)$ also a psychiatrist, framed loss and grief in an experiential way, identifying phases of feeling states to account for grief. He posited that people build up an assumptive world based on their experiences of life. It is at times of major loss that these assumptive worlds are challenged which can lead to fear and insecurity and a loss of meaning. In the grieving process Parkes identifies phases of; Experiencing the pain of grief; experiencing fear, guilt, anger, and resentment; experiencing apathy, aimlessness, and sadness; and moving towards the emergence of hope, and new directions. Parkes continues to write (see Parkes, 1983; 1996; 2006) and inspire works on loss and grief (Archer, 1999). Archer credits Parkes with moving beyond grief as a pathological phenomenon. In Parkes (2006) he reveals the dialectic of love and loss which brings with it the opportunity to return to 'inner space' to make meaning of the chaos and order of loss and grief. 
Psychiatrist, Elisabeth Kübler-Ross (1970) developed a theory based on her work and research with dying children and addressed the emotional states of those preparing to die. These emotional states are: denial, anger, bargaining, depression, and finally, acceptance. Her work was perhaps the most widely accessible to both professional groups and the public, bringing grieving processes out of the closet. I recall her work being referred to extensively in nursing education and practice in the 1970-80s in NZ. It was particularly applicable for those working in palliative care. Her journey into the spiritual realm was controversial, but revealed the inevitable connection between transition work and spirituality which she focused on in the later years of her work (Kübler-Ross, 1991; 1997).

William Worden $(1983 ; 2002)$ drew on the work of both Parkes and Bowlby, proposing a process of grieving which included four tasks that have to be achieved by the grieving person. These tasks were: To accept the reality of the loss; to experience the pain of grief; to adjust to an environment in which the deceased is missing; and to withdraw emotional energy from the deceased and reinvest it in other relationships. In proposing these tasks, he also wrote extensively on grief counselling and grief therapy. Worden (1983) described grief counselling as a facilitation of 'normal' grieving through these tasks to help the person face the reality of the loss. He suggested that facilitation should include, encouraging the expression of emotions, and supporting the person to readjust after the loss, and to reinvest in new life pathways. Worden, along with Parkes, suggested that a number of health professionals could be involved in this work, including doctors, nurses, psychologists, and social workers.

Worden (1983) recommended three approaches to facilitative counselling. First, everyone is offered support on the supposition that loss is distressing therefore it is compassionate to offer support. Second, help is given if needed and asked for; and third, help is given to vulnerable individuals who are most likely to have difficulty. This group includes those who have minimal support networks, sufferers of mental illnesses, or those who have experienced traumatic stress. Worden (1983) recommended that facilitative counsellors ideally provide opportunities for grieving persons to tell their story and express feelings. In addition, they offer ongoing support if required; identifying pathology, such as depressive illness, and referring these people to those qualified to help. Although, there has been much debate about the 
effectiveness of facilitative grief counselling to reduce the risk of mental disorders and psychosomatic disorders; Paykel (1974) and Parkes (1980) proffered some evidence that grief facilitation reduced the risk of depression and suicide for those with minimal support networks.

For most, supportive counselling is considered sufficient; however, according to Worden (1983), in the case of those who do not complete mourning it is considered appropriate to support people to resolve conflicts of separation, in the context of psychotherapy. Grief therapists support people to work through the resistance that occurs when they avoid mourning, and as a consequence, experience major disruptions in their daily functioning leading to chronic stress.

Although the above authors have done much to advance the understanding of processes of loss and grief to a wide audience of practitioners and populations in general, people tended to take the phases and stages literally, perceiving them as linear processes. According to Costello (1995), grief is being seen as an overlapping process unique to each person, including initial shock, disbelief and denial, an acute mourning phase, and a period of restitution. The stages are not fixed, and the person may pass backward and forward between them. They may even become locked in one or other stage, either partially or completely. There is no clear timeframe, and some people recover in a matter of weeks while others take a year or more to achieve some normality in their lives. Constructivist approaches to loss and grief have grown out of the stage and phase models, and offer alternate ways of understanding the facilitation of loss, grief, and transition. I discuss some of these approaches in the following section.

\section{Evolving approaches to loss, grief and transition}

Constructivist ways of looking at facilitating grief and transition process have been posited by contemporary authors on the subject (see Neimeyer, 2001b; Romanoff; Arvey; Harvey; Carlson, Huff, \& Green, 2001). Constructivism is a way that people make meaning through the narrative expression of their assumptive worlds (Parkes, 1996; 2006). In times of loss these assumptive worlds can be called to question, challenging the person's sense of meaning. A search for deeper meaning and a purpose for living for those who are grieving is the subject of NZ writer Piers 
(formally Pam) Heaney (2002) in Coming to grief: A survival guide to grief and loss. Heaney suggests that grief can precipitate an exploration and growth in the four dimensions of health, especially the spiritual dimension.

It is my view that cognitive or emotionally based counselling services, commonly available to people in loss, grief, and transition, do not tend to address these issues because the physical and spiritual dimensions sit outside their scope of practice. Nursing knowledge, however, does encompass integral dimensions of practice, thus, preparing nurses to work with transitions. The need for a dialectical way of thinking about loss, grief and transition is revealed in the writing of Busch (2001) who highlights the tendency of grieving people to vacillate between 'remembering and forgetting' 'letting go and keeping hold'. Busch reminds us that:

A lived life is in constant motion between joy and sorrow, hope and hopelessness, control and powerlessness, gratitude and bitterness, humour and gravity. These swings of the pendulum are manifestations of movement and life (p.3).

This thinking has resonance with both Newman (1986) and Parse (1992) and my way of working with people in transition; especially at times of ambiguous loss and in the contradictions that death can bring up (see, Golish, 2003; Toller, 2005); or disenfranchised loss, when the person may not be able to grieve because of social acceptance or the hidden nature of their grief (Doka, 2002). These ambiguities and contradictions, as suggested by these authors, often trigger a search for meaning, leading to a changed sense of self. I expand on these themes which led to the progression of theory beyond phases and stages to a constructivist approach under the next heading.

\section{Loss, grief, transition and the search for meaning}

Neimeyer (2001a) put together an anthology of major authors and researchers of grief and loss in a book entitled Meaning reconstruction and the experience of loss. In this anthology, old models such as those reviewed previously were compared, and new 
directions for grief support were offered. In summary, past models had emphasis on 'letting go', 'moving forward', and 'coming towards' a resolution. Models tended to be individually focused and had universal themes of grieving. In contrast, contemporary models highlight the uniqueness of grieving and the recognition that, rather than letting go and moving on, people often seek to develop and maintain bonds with loved ones after death. The focus of the grieving process is more on the changing identity of the mourners, their significant others, and families, in a cultural context.

Hagman (2001) refuted notions held by authors such as Freud, Bowlby, Parkes, and Kübler Ross, that resistance to grieving needs to be challenged. Rather, he suggests facilitation of grief involves; resonating with the person's style of grief, providing a safe empathic environment for the person to express sadness and begin a process of 'self-reorganization'. These ideas are similar to the ideas of Heaney (2002), who suggests that people may express their grief in predominately physical, emotional, intellectual or spiritual ways depending on the emphasis they express these domains in the normal course of life. Heaney suggests that there is a potential for emphasis to shift, as the event of loss propels the individual to find new ways of seeing the world. Along with Hagman and Heaney, I suggest facilitation that supports fresh meanings to emerge, and new patterns to evolve, has a better chance of achieving enhanced personal growth.

Resonating as a facilitator with those who are grieving, requires an empathic appreciation of the deep experience of mourning, eloquently described by Attig (2001) as follows:

We suffer heartbreak as we miss viscerally the physical presence of those we love. We meet their absence everywhere...in our yearning, we long for their return. We are at a loss to go on without them. We want desperately to love them still but we do not know how. Our suffering involves soul pain...Fearing that we can never find our way to feeling at home again, we find it difficult to care about anything at all (p.37). 
It is my opinion that those walking beside grieving persons need to understand that this is a journey of the heart and spirit, as persons struggle to find themselves in a changed world, where old meanings and patterns lay in disarray. A search for a new understanding of life and death begins, as people try to find where they fit into the scheme of things. This sometimes leads to a deeper spiritual awareness of a greater life force or a sense that life continues, in some shape or form, beyond death. People may have a sense of abandonment and aloneness as the search continues for threads of connection with the loved one, transcending physical form. In this process, new meanings can be found by grieving people to account for the mysteries and wonders of life and death.

Stroebe and Schut (2001) propose that facilitation of grieving involves supporting people to review positive and negative feelings and thoughts about the loss. This, they suggest, can be done through the use of photographs to construct a biography and a celebration of times spent together. According to Stroebe and Schut this "[a]llows the person to browse through their life with the loved one... [a]nd restore coherence to the narratives of their lives" (p.69). Klass (2001) affirms these views in this summation of current theories "The consensus that seems to be emerging among scholars and clinicians is that the purpose or goal of grief is the construction of a durable biography making the death count for something" (p.78).

Attig (2001) supports the theme of people seeking to 'make the death count for something' in the following,

They continue to give us their legacies. Sadly we cannot contribute directly to their lives any longer, but we still further their interests. And we can sense that they witness or support us as we give to others (p.4647).

It is this renewed sense of purpose in relation to the loss that can shift the sense of hopelessness, often expressed by those in the early stages of mourning, and give people a deeper sense of connection with loved ones than previously. Thus, tensions are lived with and integrated in a new relationship with loved ones who have passed 
on and woven into the fabric of a changing self-identity. Although I have so far described this as an individual process, families and significant others help the bereaved influence the shaping of new meanings through story telling. Depending on the sense of connection with family members and agreement about biographical depictions, this process may either strengthen family bonds or sever them (Winchester Nadeau, 2001).

What of those who don't find a way of integrating loss in ways described above? Traumas and losses with negative connotations such as violent acts, abuse, disasters, environmental tragedy, and suicide, may propel people and their families into a disoriented state. This may contribute to a heightened sense of vulnerability and a sense that the world is no longer a safe place. This is likely to have an impact on emotional and physical health if people do not have support within a close social network, or professional help (Davis, 2001). It may not necessarily be negative, as according to Davis (2001) "[s]ome consider their experience with trauma and loss to be a turning point in their lives, a watershed after which their sense of identity or purpose was transformed" (p.138). This is usually as a result of a time of reflection and construction of new meanings, in which the negative event can be transformed into positive acts of helping or valuing others in a new way.

On this theme of loss as a positive process, Calhoun and Tedeschi (2001) identified three areas of growth that can occur: Changed sense of self; changed relationships; and existential and spiritual growth. Examples of these areas of growth included a paradoxical potential for the person's self-identity to be more vulnerable, as well as becoming more resilient; and to become more empathic, transparent and emotionally expressive. Spiritually, people can review old beliefs and either affirm them or change them. In the process of these shifts in self-identity and meaning, there is suffering and emotional distress.

Therefore, it is important for those facilitating loss and grief to avoid statements of good things coming from loss, rather, allowing the person space and time to construct their own meanings. To do this, facilitators need to be cognizant of the person's unique way of being, expressing, and viewing the world. The skills of being a fully present listener, watching for cues and noticing growth as it shows itself, are essential 
in this process (Calhoun \& Tedeschi, 2001 and Neimeyer, 2001b). These ideas resonate with Antonovsky's (1974) ideas on the development of resilience and his emphasis on the importance of support in this process.

Being a witness to the grief of others requires as high level of skill and commitment as implied by the authors so far referred to in this review. Attending to oneself as well as others is essential in grief and transition work. I discuss this further under the next heading.

\section{Awareness of self and others in the facilitation of grief and transition}

The growth of persons working through change and loss has the potential for vicarious experiences of change to occur in the facilitator, which can be either positive or negative, depending on the extent to which the facilitator monitors and attends to their own change and loss processes. It is for this reason that I choose to use a reflective research process in this thesis to explicate my own growing insights about loss and change, using journals kept from practice supervision and peer review. This highlights the potential benefits of heuristic self-reflective research which has an autobiographical element, and draws on constructivist narratives that mirror the facilitation process itself. Neimeyer (2001b); Richards (2001); Arvay (2001); Harvey, Carlson, Huff and Green (2001); and Romanoff (2001); share the view that constructing narratives are important 'agents of change'. Romanoff (2001) writes about this aspect of her role as a facilitator and therapist in the following excerpt:

Narrative approaches view the therapeutic process as a facilitated journey wherein the telling and mutual understanding of the client's story will enable a new co-constructed story to emerge. Although the outcome or goal of therapy is not known at the outset, the desire and expectation of change is an explicit part of the therapeutic contract (p.249).

Romanoff (2001) further elaborates on the facilitative role as being a witness to the person's story and a ‘companion on the journey' of change. Neimeyer, (2001b) echoes these views in his statement: 
[p]eople seek consultation with helping professionals when they struggle with the meaning of the loss and its significance for their changed lives. Bereaved people often seek safe contexts in which they can tell (and retell) their stories of loss, hoping that therapists can bear to hear what others cannot, validating their pain as real without resorting to simple reassurance (p.263-264).

Emphasis on listening to the person's perception of their lives helps the person to shape their new identity and accommodate changed realities. It is not about coming to closure; rather, it is synthesizing memories of past events into changed understanding of our selves in the world.

I synthesize theories of loss, grief, and transition so far reviewed by summarizing them in Table 2 to depict philosophical shifts over time. This provides a starting point for further explication of DNFT in Part Two and further discussion in Part Three.

Table 2: Changing ideas about loss, grief and transition

\begin{tabular}{|c|c|}
\hline $\begin{array}{l}\text { Focus of early theories (see Freud, } \\
\text { Bowlby, Parkes, Kubler-Ross, \& } \\
\text { Worden). }\end{array}$ & $\begin{array}{l}\text { Focus of contemporary theories (see } \\
\text { Neimeyer, Hagman, Romanoff, Attig, } \\
\text { Winchester Nadeau, Davies, Stroebe \& } \\
\text { Schut, Calhoun \& Tedeschi). }\end{array}$ \\
\hline $\begin{array}{l}\text { Universal theories about grief and loss led } \\
\text { to development of stage and phase models } \\
\text { of loss and grief which emphasized: } \\
\text { - } \quad \text { Catharsis } \\
\text { - Letting go } \\
\text { - Resolving loss }\end{array}$ & $\begin{array}{l}\text { Theories acknowledge unique processes of } \\
\text { transitioning which involve: } \\
\text { - Making meaning } \\
\text { - Changing self-identity } \\
\text { - Integrating loss into everyday life } \\
\text { - Opportunities for growth and } \\
\text { - } \text { spiritual development } \\
\text { - } \text { Coneloping resilience } \\
\text {. Constructivist approaches }\end{array}$ \\
\hline Focus of therapy & Focus of facilitator \\
\hline $\begin{array}{l}\text { - Encouraging emotional release } \\
\text { - Working through phases } \\
\text { - Challenging resistance } \\
\text { - Detachment } \\
\text { - Reengagement }\end{array}$ & $\begin{array}{l}\text { - Being a witness } \\
\text { - Hearing the story - co-creating a } \\
\text { biography } \\
\text { - Exploration of meaning } \\
\text { - Co-creating new stories }\end{array}$ \\
\hline
\end{tabular}


In the next section, referring to the ideas of Bridges (1980) and Satir, Banmen, Gerber and Gomori (1991); I look at inner processes that integrate life experiences and how that can shape the formation of a new identity. I share aspects of a personal experience with transition, as an exemplar for my integration of these philosophical influences.

\section{Personal experiences of transitions and the process of integration}

This review has, so far, primarily addressed mourning the loss of loved ones. However, it is Bridges' (1980) personal inquiry into change processes, in his book Transitions: Making Sense of Life's Changes, that sheds more light for me on 'the no longer and the not yet'. Bridges, as stated previously, proposed a pathway through transition including at least three stages that are not linear or stepwise. These stages are: Endings; the neutral zone; and new beginnings. According to Bridges (1980) 'endings' incorporate a four-phase process of "disengagement, disidentification, disenchantment and disorientation”. Bridges uses the analogy of a Shaman leaving a village to embark on a journey of discovery, or Christ going into the wilderness for forty days and forty nights, as 'disengagement'. 'Disidentification' occurs when previously held roles change, and the person begins to question who they are.

I resonated with these processes in a personal transition that took place in 2003. This transition had elements of choice and pressure from an external situation, when I took voluntary redundancy from my role as an educator in health sciences. A part of me knew instinctively that change was needed, thus my decision to take voluntary redundancy. Another part of me, however, was deeply involved in a process of reform in teaching those with disabilities, detailed in Clayton and Tse (2003) and Clayton (2004). My decision was accelerated by the lack of support for this work in the context of economic restructuring in the educational institution where I was employed. This decision presented a dialectical tension for me which led me to make a choice that has altered my occupational pathway. In this process, I had to rapidly disengage from the institution that was a deeply uncomfortable experience of 'disidentification'.

This mirrored Bridges' experience of 'disengagement' from teaching that led to his conclusion that vocational transitions, where old roles have become such a significant part of the person's identity, can have a much greater effect than a person may imagine. Bridges described his own experience as follows: 
In the world of social identities, I was an interloper. I lived in the cracks and moved in the shadows...I had cast off the shell of my old identity like a lobster, and I was staying close to the rocks because I was still soft and vulnerable (p. 97-98).

As the old identity is shed, the question emerges: who am I? In the period of searching for a sense of a new identity, it seems like one is groping in the darkness. As in darkness and groping, it is easy to misinterpret any objects one may stumble over, as being bigger, scarier, and perhaps more threatening than they really are. As in my experience, and that of Bridges, one yearns for the old and the familiar, fantasizing and idealizing the role that has been let go. The experience can lead to the precipitous need to scurry back to the known - or as Bridges (1980) puts it, "[g]o though the play again with new actors" (p.101). Otherwise, a person could move into a period of 'disenchantment' with the past, and seek new meanings, roles, and purposes in life. In this time, there can be a period of lost-ness or 'disorientation'. In the words of Bridges, "The old sense of life as 'going somewhere' breaks down, and we feel like shipwrecked sailors on some existential atoll” (p.102).

In my case, this was a time when I socially detached myself from contact with the previous work context. I thought I would now, at last, have time to complete tasks that had been on the back burner, like gardening and decorating - but time seemed to disappear on meaningless, disconnected activities. It was as though I had been away to Mars.

Bridges described 'disorientation' as a deeply uncomfortable experience affecting the sense of time and space, leaving a void of emptiness. It is the fear of emptiness that in Bridges' words, "[a]wakens old fears and old fantasies about death and abandonment" (p.104). It is this fear that can lead to resistance, or a return to previous roles.

In my situation, an example of this process was in my applications for jobs that had elements of my previous work roles. In part, I did this because I felt an obligation to be engaged in meaningful work and to be making a contribution. It was only when I discovered that the tension created by doing this was greater than the prospect of 
emptiness and the potential that I would ultimately reach some deeper sense of who I am by staying with the process; that I was able to let go of these applications and proceed with the journey of change.

The second phase of the journey of transition, according to Bridges (1980), is 'the neutral zone', which he describes as a place without a name - an empty space of watching and waiting.

As stated previously, I may as well have travelled to Mars and back. I do not remember the vistas that I saw as I stared into space. I may have met the spirit guides that many who travel the 'neutral zone' encounter. I only know that when I passed through the 'neutral zone', visions of a new beginning started to emerge and ideas began to flow like a river. The journey towards a new identity, a part of which is described in this thesis, opened out to me.

Bridges (1980) shares an experience of opening to new beginnings given by a man who attended his transition workshop "I feel as though I've broken through a wall and can see the world for the first time" (p.116).

I remember a similar experience in an earlier transition when I wrote in my diary recorded as follows:

\section{I see misty shadows}

In front of me is a solid wall

Ifeel the wall separates me from where I want to go...

I see shadows of people who are important to me

Hope is painted in black letters which later emerge as gold

I see love on the wall and the bold womanly shape of myself

(Clayton, 2004, p.102-103).

Often preceding this sense of clarity and moves to 'new beginnings', it seems as though chaos reigns. Both Bridges (1980) and Satir et al., (1991) describe this as a necessary part of transition. Bridges describes chaos as "[a] primal state of pure energy to which the person returns for every true new beginning" (p.119). 
It was at this part of the process that I remember having a series of dreams on the themes of birth and death.

Bridges refers to this experience as a process of 'disintegration' and 'reintegration' and describes it as "[r]eturning for a time to the formlessness of the primal energy where renewal can take place" (p.120).

In my view, it is only at this time of emptiness that old brittle life patterns can be shed, like the cocoon of the caterpillar becoming a butterfly. In this space the past takes on a new meaning, as present realities have the potential to shape the future self - or - the person could just drift, as many do at this time, settling on the crustaceans of past lives. Bridges suggests that it may be beneficial to do a reflective autobiography at this time and consider what one really wants for the future, or to write an obituary, as it is sometimes helpful to have a vision of the effect before a cause is made. Of making a new beginning, he writes, "We forget how unimpressive beginnings really are, and we imagine instead some clear and conscious steps that we ought to be taking" (p.135).

I experience new beginnings like a figure gradually appearing through the mist. The shape is unclear at first, perhaps confusing, and providing I don't run away out of fear, the figure emerges into the foreground of my life unmistakably. It usually doesn't look like I thought it would, so if I don't reject it because it didn't meet my expectations, we merge and become one - a new identity, new patterns, new visions - eclipsing the old, entering the new chapter. I do not intend to imply that this is a simple process, and I offer a paradox, because it is both simple and difficult. The figure does not come unless it is called to me, and I don't call it unless I know I really want it, and I don't know that I really want it until I dream it, envision it, see a signpost of it, and listen very carefully to my inner voice - as the author of this new story.

How then, does one get past unrealistic expectations to welcome a new story? Lewis Carol, writer of the famous children stories of Alice in Wonderland $(1865 ; 1993)$ and Alice Through the Looking Glass $(1872 ; 1993)$, presented analogies of journeying into the inner self in his kidult whimsical stories. The Alice stories are described by Haughton (1998) as dialectical modernist parodies depicting the deconstruction of 
self-identity and worldly assumptions of a young girl in a Victorian social context. Haughton explains this as:

[a] quest to interpret and master the complex and strange phenomena of the largely adult world she encounters... What Alice knows, and how she interprets it, holds centre stage, giving her a paradoxical intellectual authority (p.1vi).

This theme of a person's version of the world holding 'centre stage' in the context of the nursing world is a theme explored by Patricia Munhall (1993) in Unknowing: Toward Another Pattern of Knowing in Nursing, and in my view is the key for both the traveller and the facilitator to get through the door to new beginnings. In Chapter Four I review Munhall's ideas about unknowing, along with nursing, facilitation, and Buddhist philosophies and theories that influence my integral and dialectical approach. 


\section{Becoming a Dialectical Nurse Facilitator of Transition: Synthesizing Nursing, Humanism and Buddhism}

This chapter includes three sections that make up a foundational literature review of contributing influences to the shaping of my becoming and being a DNFT. Patterns of integrality and interconnectedness are central to my work. In Section One, I review pivotal nursing authors and theories who contribute to my deepening understanding of unitary and humanistic patterns for nurse facilitation.

In Section Two, I spotlight facilitation as a dialogical, relational, and humanistic process delineating facilitation from the profession of counselling. Nurse facilitation is framed through a process of synthesis of the basic tenets of facilitation and counselling, drawing on theories in nursing, psychology, and psychotherapy.

Dialogue, humanism and integrality are central to the practice of modern Buddhism which draws on a universal principle of cyclic change. In Section Three, I specify how this principle guides my understanding of human beings and change and how this is both similar and different from prevailing theories discussed in Sections One and Two.

\section{Section One: Nursing theories and philosophies of influence}

My entry into the nursing field as a registered nurse in the mid 1970s was at a time when paradigms espousing mechanistic views of people and reductionism as a way of understanding mind and body, were being challenged in nursing. US nurse theorist Martha Rogers, stepped out of bio-psycho-social theories of nursing in a radical way, to propose both a philosophical and scientific basis for nursing practice. She made a departure from dichotomous thinking about health and illness, and proposed that nurses move from placing a value on these states of being and recognize the evolutionary dynamic of human beings and their environment (Rogers 1971; 1980). 
Rogers in her theory The Science of Unitary Human Beings (SUHB) $(1971 ; 1980)$ drew on her background in science and physics to propose a theory for nursing that incorporated four building blocks of nursing science. The nomenclature she used to describe them evolved over time, her latest versions included: energy fields, openness, pandimensionality, and patterning. Energy refers to the interconnectedness between human beings and their environment; and fields refer to the continuous motion or 'synchrony' that unites these energies without boundaries. Openness refers to human beings and the environment as open systems in a constant state of change or 'helicy' evolving together. Pandimensionality refers to the energy field of human beings and the environment which is infinite; transcending space and linear time. Past-presentfuture is infused according to Rogers, thus rendering so-called paranormal experiences such as precognition, clairvoyance, energy healing, and telepathy as ordinary everyday experiences. Patterning is what distinguishes the human energy fields from the environmental fields. 'Resonancy' happens in the changes that occur in the human and environmental electrical magnetic fields.

Rogers' work departed from notions of holism as 'sums of parts' to 'integrality', which emphasizes the irreducible nature of human beings and the environment (Malinski \& Manhart Barrett 1994). Her perspective on nursing indicates that nurses support people to achieve wellbeing by reaching their potential (Malinski et al., 1994). She was future orientated in her projections of nursing roles, suggesting that the nursing profession stands on its own as a practice discipline maintaining a focus of service to people and promotion of health, rather than to pathological, and psychological aberrations. Rogers (1983) suggested that the dialectical skills of "synthesis and pattern seeing are survival skills for the $21^{\text {st }}$ Century" (p.283).

Jean Watson (2005a), although giving credit to Roger's work, holds a differing view of health by proposing that health is achieved through harmony in a mind-body-spirit connection. This concept of balance is refuted by Rogers (1980), who stated, "Life is transcendence; it does not seek some balance" (p.222). Watson (2005a) highlights the concept of spirituality, in contrast to Rogers who emphasizes the evolution of energy. Watson (1979) developed a humanist theory centred on the concept of ten carative 
factors which could provide a focus for nursing practice. In forming this theory she was attempting to make explicit often nebulous aspects of nursing values and knowledge, and to capture the subjective inner healing processes and the life world of people experiencing caring and healing. Her theory has evolved from carative factors, a term that she now finds limiting, to clinical caritas processes. Caritas according to Watson (2005a) comes from the Greek word meaning 'to cherish, or appreciate'. Watson (2005a) explains as follows

"[t]his relationship between love and caring connotes evolving within a cosmology that is both metaphysical and transcendent with the coevolving human in the universe" (p.4).

The maturation of Watson's (2005a) theory towards ethical, moral, philosophical, development is evident as she makes the spiritual and self-growth aspects of nursing more explicit. In her writing she makes her intention to project the caring aspects of nursing into the future, evident. She distinguishes nursing roles from that of other professions. Watson symbolizes her intention of unity between mind-body-spirit connections by creating one word. She takes Rogers' concept of unitary human beings into the nursing process of 'transpersonal care'; a term she uses to describe the expansion of nursing care into the relationship that transcends ego states into spirituality and the interconnectedness of all life. In this way, Watson (2005a) suggests that people 'tap into' healing possibilities. Watson (2005a) writes about the intentionality of the nurse to focus on healing and wholeness, rather than illness. Krieger (1997) also uses the term 'transpersonal care', attributing the concept of transpersonal dimensions to Abraham Maslow's ideas about expanding states of consciousness. In Krieger's extensive work with energy healing, she describes transpersonal care as an act of being fully present to the other through 'centering' and focusing on healing work with intentionality and compassion. Krieger (1997) describes compassion as, “[e]ssentially a passion for another's wellbeing” (p.88).

Krieger (1981) developed a practice based on non-invasive nursing interventions, a work that showed some resonance with Rogerian ideas and theories. Krieger termed 
nurses working in holistic ways 'renaissance nurses', "[g]uiding the client towards discovering opportunity in suffering to find meaning and discover their inherent potential to heal themselves" (p.132). She proposes an integrated understanding of holism whereby the psyche is the bridge between the physical self interconnected with the external universe and the interior consciousness. This is described by Krieger as the interconnectedness of energy, upon which she established the development and practice of guided imagery and therapeutic touch (TT). I pay attention to Rogers', Krieger's, and Watson's notions of energy connection in healing throughout the thesis.

Rogers' unitary theories also had a significant influence on Newman's $(1986 ; 1990)$ developing view of expanding consciousness and led to her understanding of health and illness "as a unitary process moving through variations of order and disorder" (p.38). According to Newman, this order and disorder is neither good nor bad; rather, it is a manifestation of the evolutionary pattern in the person's consciousness. Newman (1986) took up Rogers' notions of 'synthesis and pattern seeing' in her theoretical framework for practice, Health as Expanding Consciousness, (HEC). Newman (1986) defines the nursing role in pattern recognition as "[d]irected towards recognizing the pattern of interaction and accepting it as a process of evolving consciousness" (p.88).

Both Rogers and Newman hold the view that preventing or curing disease is not necessarily a helpful process if the opportunities for raised consciousness and pattern recognition in a state of illness are missed. Rogers (1971) advocated promotion of health rather than prevention, claiming, "Resolution of health problems is directly related to the dynamic innovative potentialities of life" (p.222). According to Newman patterns are always changing; therefore we need to be open to changes without judging. Evolving or expanding consciousness has the potential to occur when insights or pattern recognition come about following synthesis of difficulties experienced in everyday living. Establishing a rhythm in the relationship with the person is essential to generate insights. Timing and non-intervention are important in this process. Newman (1986) challenged notions of nursing practice as assessment of disease and intervention in order to 'fix' the problem. She viewed this as an anathema to the process of expanding consciousness. Rather, Newman (1986) proposed that nurses; 
"[e]nter into the partnership with the client with a mutual goal of participating in an authentic relationship trusting that in the process of its evolving, both will grow and become healthier in the sense of higher levels of consciousness" (p.68)

Facilitation according to Newman (1986) involves being in touch with ones own patterns, and acting like a reference point to enable others to become conscious of their patterns. Parse (1992) who is another unitary theorist holds the view of facilitation that is similar to Newman and constructivist approaches as shown in the following excerpt:

The nurse in true presence with person or family is not a guide or a beacon but rather an inspiring attentive presence that calls the other to shed light on the meaning moments of his or her life... The person is co author of his or her own health, free agent and meaning giver...(p.40).

Parse (1981) based her Man-Living-Health nursing model and later her Human Becoming Theory (1992) on Rogerian theory, modifying it to include existential, dialectical, and phenomenological thought influenced by the philosophies of Heidegger, Sartre, and Merleau-Ponty. This process of 'becoming' reveals a relationship between nurses and persons as paradoxical, in the sense that unique patterns of relating between nurses and persons co-exist in unity, especially when nurses can be truly present. Her focus is on meanings underlying the behaviour of human beings interacting with their environment. Three themes are presented in her theory: Meaning, rhythmicity, and transcendence. Meaning refers to a process of nurse and client co-creating meanings through expression of values and images. Rhythmicity refers to dialectic rhythmic patterns in the relationship, which she terms 'revealingconcealing' 'enabling-limiting' while 'connecting-separating'. These patterns reveal a universal tendency of human beings in relationships to show and hide, choose and reject, come close and move away. Transcendence involves moving beyond the present moment into the future, in the midst of ambiguity and constant change. The nursing process of human becoming in the words of Parse (1992) involves the 
facilitation of 'illuminating meaning' or 'shedding light', 'synchronizing rhythms' in the flow of coming and going, and 'mobilizing transcendence'; finding hope and a way forward in the context of the nurse-person relationship. Research using this approach tends to focus on universal meanings of hope in day-to-day living, grief, and suffering. These processes are relevant to my understanding of the relationship between nurse and person especially in the facilitation of loss, grief, and transition.

Parse distinguished her integral theory (which she refers to as a simultaneity paradigm) from dimensional, 'totalitarian' goal orientated nursing which places emphasis on 'the nursing process' and 'nursing diagnoses'.

Rogers, Newman and Parse in proposing unitary frameworks; and Watson and Krieger's, transpersonal compassionate nursing, all emphasize dialectical skills for nurses in their theories and philosophies. This I believe distinguishes their respective theories from dualistic ideas and goals for removal of suffering, and resolution of illness, which tends to be an underlying theme in health promotion and health-care practices in the Western world. All of these integral theories described require a commitment to nursing and to the growth of a high degree of self-knowledge, deep inner awareness, and interpersonal skills. I ask do current NZ educative experiential nursing programmes and competencies for practice prepare nurses for this level of sophistication? This is one of the tensions I experience as I position myself to apply some of these principles of integrative nursing practice to the facilitation of transition.

Discourses on the unitary and caring principles of openness and authenticity in nursing are taken up by nurse academics Carper (1978); Gadow (1980); and Munhall (1993) among others, who provide a salient starting point for an examination of nursing and philosophical theories about facilitation in Section Two.

A synthesis of a range of nursing theorists' worldviews, nursing intentions, and nursing qualities, reviewed above, are included in Table 3, forming a basis for further exploration on the facets of this synthesis, in relation to my practice as a facilitator. 
Table 3: Clayton's synthesis of unitary and caring nursing philosophies and theories

\begin{tabular}{|c|c|c|}
\hline Shared worldviews & Nursing intention & Nursing qualities \\
\hline $\begin{array}{l}\text { - } \begin{array}{l}\text { Paradoxes are } \\
\text { highlighted and } \\
\text { integrated }\end{array} \\
\text { - There is an emphasis } \\
\text { on meaning of } \\
\text { experiences and } \\
\text { process orientation } \\
\text { - There is an } \\
\text { interconnection } \\
\text { between self and the } \\
\text { human and non- } \\
\text { human environment } \\
\text { through the energy } \\
\text { field } \\
\text { - Self and environment } \\
\text { are open systems } \\
\text { Nursing is guided by } \\
\text { principles of holism } \\
\text { and } \\
\text { multidimensionality } \\
\text { Past present and } \\
\text { future are non-linear }\end{array}$ & $\begin{array}{l}\text { - } \begin{array}{l}\text { Become aware of } \\
\text { patterns, rhythms, and } \\
\text { values }\end{array} \\
\text { - Support change processes } \\
\text { - Support raised awareness, } \\
\text { self responsibility, and } \\
\text { heightened sense of } \\
\text { wellbeing through self- } \\
\text { reflection } \\
\text { - See potential in others } \\
\text { and support people to } \\
\text { realize their potential }\end{array}$ & $\begin{array}{ll}\text { - } & \text { Compassion } \\
\text { - } & \begin{array}{l}\text { Authentic } \\
\text { relation }\end{array} \\
\text { - } & \text { Openness } \\
\text { - } & \begin{array}{l}\text { Self- } \\
\text { awareness }\end{array}\end{array}$ \\
\hline
\end{tabular}

\section{Section Two: Facilitation: A relational, dialogical and humanistic act}

\section{Nursing, openness and authenticity}

Authenticity or 'being real' is derivative of a state of deep self-awareness, a practice advocated by Carper (1978); Munhall (1993); Krieger (1997); Newman (1990); Watson (2005a), and Johns (2004 a \& b), among others. I argue that becoming selfaware is an essential part of preparing for a facilitative role and can be achieved through reflective practice in the domain of personal knowing (Carper, 1978). Carper suggests nurses can achieve reciprocity using the authentic self therapeutically in encounters with people that also resonates with Parse (1992). Carper (1978) describes this process as follows: 
An authentic personal relation requires the acceptance of others in their freedom to create themselves and the recognition that each person is not a fixed entity, but constantly engaged in the process of becoming (p.19).

Similar ideas emerge in Parker (1990), who developed a 'relational ethic of care', described as the relationship between nurses and persons becoming travelling companions on a journey into the depths of intense experiences of change, where 'nurses are involved in co-constructing meanings of seemingly meaningless experiences' (p.38). This view is shared by previously mentioned constructivists Neimeyer (2001b); and Romanoff (2001) in relationship to the facilitation of grief and transition.

Barker and Whitehall (1997) identify a focus on mutuality, reflexiveness, and partnership in shaping core premises in mental health nursing, echoing the views of Parker (1990) and Parse (1992).

Sally Gadow (1980), in Existenial Advocay: Philosophical Foundations of Nursing, explores the paradoxical relationship between nurses, clients, and medicine, suggesting that nurses carry the responsibility of integrating the paradox through holistic approaches to care. In Gadow's view, nurses need to be aware of the potential for paternalism if they are not mindful of the ways that their knowledge can overshadow and dis-empower people. Gadow (1980) proposes that nurses can achieve (what she terms) 'existential advocacy' by subscribing to the principles of personal autonomy and self-determination in their practice. To do this, Gadow suggests nurses need to resolve the dichotomy between their professional role and their personal self.

The intimacy of the relationship between nurses and clients based on these views has been the subject of some concern, especially in practice arenas. Gadow (1980) provides a lucid explanation on the essential differences in the roles and perspectives of nurses and clients, and summarizes these differences under the headings of: Focus, intensity, and perspective. The focus, referred to by Gadow, is with the person and their experience. Although nurses may share an expression of empathy or concern with clients, there is no mutual support in these relationships because the focus is on 
the intensity of the person's experience. Perspectives of nurses and persons they work with differ.

The practice and theory of protecting the self from over involvement with people in health-care is attended to in all health professions. I share Gadow's view that segmenting the private self can lead to fragmentation at best and burnout at worst. I believe this happens because there is a high expenditure of energy in protecting and withholding the authentic self. Being authentic in the nursing relationship is addressed by a number of other nursing authors including Watson (1979); Krieger (1997); Newman (1990); Parse (1992); and Munhall (1993), and is pivotal to the practice of nurse facilitation of transition.

Munhall (1993) answers Carper's (1978) theory on nursing knowing and authenticity by proposing a pathway towards raising the awareness of both self and others' authenticity in nurse-person interactions through developing openness. In essence, Munhall suggests this is done by adopting an attitude of 'unknowing' - a process of gaining a perspective that backgrounds one's own experience, in order to adopt a capacity for openness to the other. This is a similar process to phenomenological research and is particularly pertinent in gaining insight into the subjective world of others. Munhall (1993) describes the paradoxical nature of the art of unknowing as:

[a]nother pattern of knowing. Knowing that one does not know something, one does not understand someone who stands before them and that the process does not fit into some pre-existing paradigm or theory is critical to the evolution and development of knowledge (p.125).

Munhall suggests that in many cases, while in the process of forming an impression and making a diagnosis, nurses can assume an attitude of authority moving from a facilitative approach to a didactic one, which can be perceived by people as knowing what is best for them. In this process, it is likely that people close off to inner knowing and a process of exploration necessary for personal growth, self-responsibility, and the recognition of authentic self identity - in other words 'being real'. Conversely, 
Munhall (1993) describes developing openness and empathic understanding of others as a 'de-centering' process 'allowing the person to be seen and heard' (p.126). This resonates with the nurse as therapist within the description of Cameron, Kapur, and Campbell (2005), who suggests that nurse therapists are "[p]roactively giving voice and bearing witness to the subjective lived experience of illness... while simultaneously recognizing as central the persons need to be understood" ( p.69). In this world of inter-subjectivity, as noted by Munhall, there is potential for 'agreement', which can lead to closure if it does not allow for 'disagreement' in the process of exploring all aspects of the person's experience. Munhall raises the danger of collusion when nurses' reach an agreement with clients based on a perceived shared view of projected difficulty within a situational context.

A common example of this in the nursing world may be the shared perception of the dominance of medicine in an organized health system. Nurses acknowledging that shared views with persons may foreclose on a full exploration of health-care options available to the person in their situation. Similarly, if there is disagreement using this example, there is potential for nurses to impose their views on persons and prevent an exploration in which persons reach decisions that they can own. This can lead to people feeling inferior and nurses adopting the position of the one who 'knows best'. However when it comes to human beings, unknowing and naivety in the situation is more likely to lead to full disclosure, exploration, and discovery. This interdependent process is described by Newman (1986) as a mutually beneficial process and by Parse (1992) as 'human becoming'.

Munhall (1993) applies the principles of unknowing to the intersecting worlds of nurses and people. As previously stated, unknowing requires a process of backgrounding or de-centering one's own understanding in favour of inquiring after the meaning for people (Munhall, 1993). I posit that nurses take the position of available witness; being with, hearing, sensing, and validating the experience of people; holding the notion of the whole being in a situated context, while at the same time recognizing the local issue being expressed as the domain of concern. Mutuality, referred to by Barker and Whitehall (1997), although not explicitly stated, could relate to the Rogerian notion of nurses and people involved in a holographic beam of interconnectedness experiencing the universal dynamic of change. In other words, 
while nurses and persons are having different experiences in the moment they are mutually encountering the life process, and thus can relate to one another.

Munhall summarizes unknowing in nursing as becoming open to the other and supporting the other to be fully who they are. I would add that this openness could be achieved in a mirroring relationship between nurses and people, each revealing their authentic self within roles that are the basis of meeting.

Key patterns for nursing knowledge underpinning DNFT that emerge from the writings of Rogers (1971) Carper (1978); Gadow (1980); Parse (1981;1992); Newman (1986, 1990); and Munhall (1993) are: openness, authenticity, and the mutuality of the life process experience. Relational aspects of nursing, psychotherapy, counselling, and facilitation, are discussed with respect to the paradoxical nature of authentic selves in relation to others; in particular, nurses and persons. A synthesis of Gadow's (1980) notion of nursing focus, intensity and perspective, and Munhall (1993) suggests a prelude to openness is unknowing. I turn now to theories that inform my nursing knowing about the relational aspects underpinning nurse facilitation in mental health.

\section{Influential relational theories in mental health nursing}

It could be something to do with the era in which I was educated as a nurse. The early 1970s was indeed a time of growth with regard to relational and humanistic caring for nurses. A number of nurses have addressed the relational interpersonal world of nursing, especially in mental health (see Peplau, 1952; Travelbee, 1971; Burnard, 1999; Stickley, 2002; Barker, 2002). Nurse writers such as Cameron et al., (2005) raise questions about untapped identity in relationship to nurses as therapists and suggest there is a dichotomy between biological and psychotherapeutic approaches. They suggest this dichotomy could be resolved by adopting viable nursing approaches, such as Barker's (2002) Tidal Model. Crowe and Luty (2005) share the view that nurses are ideally placed to provide structured psychotherapeutic intervention. As stated previously, it was Peplau (1952) who specified a counselling role for nurses. Over her long career as a nurse theorist working in mental health, Peplau developed and refined a viable interpersonal relations theory on which to base this role. Originally her 1952 text was delayed four years because it was considered too 
revolutionary for a nurse to publish without an endorsement from a medical person. I wonder whether her text is still too revolutionary for nurses in the $21^{\text {st }}$ Century as we grapple to understand and accept a counselling and facilitation role in practice contexts (Barker \& Buchanan-Barker, 2005). Barker and Buchanan-Barker (2005) muse on this in the following excerpt:

Peplau was the first psychiatric nurse to be taken seriously by psychiatric medicine, and will probably be the last, as the discipline looks set to chart a course focused on blending itself completely into psychiatric medicine, hence losing the distinctive focus that Peplau prized. She showed that ordinary connections that nurses make with their 'patients' could be turned into extraordinary educational journeys with the person learning more about how they had come to this point in their lives, and how, with help, they might move on again (p.191).

Peplau's (1952) theory was designed to explicate ways that nurses can facilitate change and enhance personal meaning in the lives of individuals and their families. She specified six nursing roles in the interpersonal relationship. These roles are: Stranger role, resource role, teaching role, counselling role, surrogate role, and active leadership. In identifying these roles, Peplau posited active roles for nurses that go beyond a neutral and listening stance, which is sometimes assumed in professional counselling. Peplau's description of developmental phases of the professional nurseclient relationship reveals a dynamic complex process, underpinning the role of nurses as catalysts for change and growth (see also Travelbee, 1971). These phases are described as follows: 'The orientation phase' is an introductory stage of gaining trust and initial assessment. 'The working phase' reveals the component of 'identification' to gain clarity about identified aims for care and treatment for persons in care; and "exploitation" to plan, learn about, and integrate aspects which promote health and well-being. A closure phase, known as the "termination phase" or resolution, attends to evaluation and review of the relationship and the progress of the identified issues, specifying the direction they will take in other contexts and relationships (Arnold \& Boggs, 2007). 
Barker (2002) draws extensively on the principles of Peplau's theory. Barker's Tidal Model is a metaphor for the unpredictable fluidic nature of human experience, encompassing the metaphors of 'storms at sea' for crises people encounter, 'piracy' for the sense of robbery of self, and 'drowning' and 'shipwreck' as ways of describing the overwhelming nature of the experience of a mental breakdown. It suggests nurses are involved in a 'rescue operation' and can facilitate clients to 'chart' helpful courses for their lives. This requires active participation of clients. Nursing involvement, according to Barker (2002) includes a holistic nursing assessment, which supports an autobiographical account of the client's experience of life to facilitate the promotion and validation of existing personal strengths, spiritual meanings, and social circumstances. This model was developed in Newcastle, in the United Kingdom, and has been introduced to clinical settings in Australia, New Zealand, parts of Europe, Scotland, Ireland, and Wales.

Barker (2002) encourages nurses to approach people with humility; to fully hear their story about the experience of being unwell rather than adopting a position of an allknowing professional, seeking to educate the person to cope with the situation or solve the problem. In this way, experiences of fluctuations in health and wellbeing are validated while the person seeks meaningful ways of finding a way forward. The most compelling aspect of The Tidal Model to me is the way in which it is framed to be accessible to nurses and the people they are working with (Barker, 2000; Barker \& Buchanan-Barker, 2004).

Similar to Watson (2005a) Barker and Buchanan-Barker (2004) emphasize a spiritual dimension which underpins The Tidal Model. I expand on this further under the following heading because spirituality is also central to my facilitative work.

\section{Spirituality and nursing care in mental health}

In Spirituality and Mental Health: Breakthrough Barker and Buchanan-Barker (2004) offer an interpretation of spirituality as something which links us with the past, giving us a sense of belonging and interconnectedness. This involves a sense of place and grounded-ness. These ideas are particularly pertinent in Celtic and Maori cultures. An 
example of Barker and Buchanan-Barker's ideas on this are revealed in the following excerpt:

The ground - which serves as the canvas upon which we trace the metaphorical journey of the heart; which serves as the shadow catcher for each living movement; which serves as the drum for the dancing rhythm of our footfalls - is the great servant, but also is the great teacher; yet another paradox (p.xix).

In this statement, they describe the importance of grounded-ness to access a sense of self-awareness. Barker and Buchanan Barker (2004) propose that the reductionism of mental illness by medicine and psychology has denied this sense of connection and spirituality, instead attempting to replace it with medication and psychological techniques, such as cognitive and emotional therapy. Like Newman (1986), they suggest that instead of trying to get rid of disorder or illness, it is necessary to return to the core being to explore more deeply the meaning of the inner tension, or in their words, "the various struggles which life scatters upon the path, have been put there for a purpose" (p.xxi). Whilst I agree with these sentiments, I believe there is a danger of superficiality if a process of deep self-exploration and reflection does not occur to enable the person to connect with a sense of spirituality; in order to make sense of suffering. Suffering need not be avoided; rather, suffering becomes a platform for a deeper sense of awareness and learning. I believe the movement to try and bypass suffering, through quick fix prescriptive processes, emphasizes a human tendency to avoidance and the resistance of pain, loss, and death. A facilitated exploration of tensions inherent in life's struggles, using a dialectical approach, does not seek solutions or cures, nor propose an easier pathway. Instead, such exploration invites an acknowledgment of all facets of life and encourages a sense that all of these experiences have meaning, pointing to a cyclic process that all life is involved in; nothing is wasted.

Barker and Buchanan-Barker (2004) suggest that psychiatry and psychotherapy seek to support this journey towards meaning using a "historical - pathological approach" (p.8), delving into the past to discover origins of pathology. Alternatively, a spiritual approach is likely to unearth deeper meanings in the spiritual crisis, which may be presenting as a psychological deterioration. Rather than curing or seeking to alleviate 
the disturbance, both therapist and client, in a human-to-human encounter with openness and humility, discover possibilities for transformation and transcendence. Paradoxically, this journey can really only be taken alone, and facilitation at best can mirror the unique process that the person is showing.

Barker and Buchanan-Barker (2004) indicate there is a dichotomy between individual experiences of suffering and social, medical, and psychological constructions of suffering and the human condition. Thus, theorizing can lead to a sense of loss of self and trigger a human need to search for this lost-self. I believe this search, for many, can become a hedonistic journey that can be equally vacuous. It is my view that many have fallen into this trap, for example those who seek pathways to rapid enlightenment in the avoidance of struggle and the pursuit of pleasure. However, Caroline Myss, a Medical Intuitive (1997), offers the view that a focus on the self is a necessary part of an evolutionary transformation process that is precipitated by an awareness of the need to change. Myss (1997) describes a four-stage process of self-awareness. This begins with revolution, or the recognition that something has to change, followed by involution, or a period of reflection which leads to a focus on the self, or narcissism. Narcissism tends to have negative connotations in psychiatry, implying a strong sense of entitlement and focusing on self at the expense of social relations. In Myss' description of narcissism, the focus is on coming to a sense of feeling 'okay' about oneself - being worthy and valuable as a human being. From there, a process of evolution or personal growth can occur.

Barker and Buchanan-Barker (2004) suggest that the personal relationship with the self is the 'core crises' in mental illness that can only be resolved through selfawareness following a period of reflection. It is important to realize that there is no panacea for distress. Facilitation can support the person to allow things to evolve; though a journey into the self, described by many mystics and sages, remains a mystery invoking a sense of awe and humility, as discoveries and insights are made through direct life experience. In a sense, this is the crux of a dialectical approach, which supports the exploration, reflection, and synthesis of insights made about the tensions that exist within everyday life experiences. The question remains: Is this a spiritual approach? If so, how is it different from psycho-social approaches? 
Brandon (2004) makes a distinction between a spiritual approach as engaging in a search for essential humanity, meaning a sense of interconnectedness with others, and a bio-psycho-social approach, which tends to be individually focused, seeking causation and focusing on curing or helping. I suggest a dialectical approach is looking for synthesis between these aspects and does not exclude anything.

The basic tenets of these models provide theoretical frameworks that are expansive enough to encompass facilitative and counselling roles for nurses in mental health but as Barker and Buchanan Barker (2005) suggests the emphasis in mental health nursing nowadays is often on pathology and medical aspects rather than the healing nature of relational nursing and caring. I discuss influences, tensions and potentials of counselling and facilitative roles in nursing under the following heading.

\section{Counselling and facilitation roles in nursing}

Counselling educator and writer Tim Bond (2002) addresses and delineates counselling, psychology, and psychotherapy in primary care contexts, demystifying the preciousness surrounding counselling. This creates an open space for a preliminary discussion of facilitative and counselling roles for nurses.

Bond (2002) suggests that the term 'counselling' lends itself to ambiguity and confusion. This confusion has to do with function. For example, some may consider that being the recipient of counselling means getting advice about something, which could be true in some situations. Whereas, the canons of most forms of professional counselling specifically excludes advice giving (Bond, 2002). Although there are benefits in certifying counselling as a profession, the utility of a counselling role could become unnecessarily inaccessible to those who need it. As Bond (2002) suggests:

Counselling and helping are synonymous and complementary ways of offering assistance in everyday life that ought not be colonized as a basis for forming a new profession (p.3).

With respect to nursing in counselling roles, Bond notes that nurse educators, such as Burnard (1988), find that nurses resist the use of counselling and facilitation roles with 
patients and tend to succumb to didactic advice. Burnard (1999) has taken up this issue, writing extensively on this subject in an attempt to engage nurses on the topic and connect them with the meaning of the facilitative role of counselling. The fact that nurses still struggle to take this on board can perhaps be understood by considering the origins of counselling and psychotherapy and the territorial barriers which surround them. According to Bond (2002) the history of professional counselling and psychotherapy came under the umbrella of psychiatry and Carl Rogers was one of the people (being a psychologist) who sought to change this. In spite of Roger's breakthroughs, with regard to the medical acceptance of professional counselling, there are still boundary tensions between psychotherapy and counselling. Considering the historical roots of these tensions, psychotherapy, with the exception of Gestalt and existential therapies described later in this section; tends to have a closer alliance with medicine and a focus on pathology and treatment. Counselling, on the other hand tends to have a humanistic focus, based on psychology (Bond, 2002). I wonder if these tensions have, in some way, influenced the difficulty nurses may have in accepting facilitative/counselling roles as they straddle the borders of medicine and psychology, especially in mental health contexts.

Bond (2002) suggests some of these difficulties could be resolved by delineating professional counselling from the term, counselling skills. Bond holds the view that counselling skills are not exclusive to professional counselling, as 'skill' pertains to behaviour, whereas counselling, in the professional sense, encompasses accountability and formal contracting. Counselling skills can be needed anytime, anyplace, and are likely to be particularly helpful in times of distress and crises, especially in health-care settings that nurses inhabit. I am inclined to agree with Peplau (1952) that the interventions and counselling support of nurses can assist people to gain important insights in the vulnerable moments of their lives.

Bond (2002) addresses some misconceptions about the application of counselling and counselling skills by challenging some assumptions of counsellors seeking to guard their professional status. For example, some counsellors may have the assumption that using counselling skills in ad-hoc or informal ways is less important than formal counselling sessions with a certified counsellor. Instead he suggests that the application of these skills in demanding acute situations, such as emergency services, 
although adding to the degree of difficulty of the health professional's primary role, can be very beneficial for clients. Bond refutes notions that health professionals, such as nurses, cannot counsel. Instead he puts forward the view that counselling by health professionals can be very beneficial for clients in primary care settings because of the immediacy of their need. However, he does not suggest that all health professionals take on a counselling role, although he promotes appropriate training and supervision for this type of work, if they choose to take on dual roles.

As I reflect on the views of Bond (2002); Burnard (1988); Peplau (1952); Barker and Buchanan (2005); Cameron et al., (2005); and Crowe and Luty (2005), it seems to me that the counselling and facilitative role of the nurse is ideally formalized, for clarity. In the past, as stated previously, nurses have tended to borrow extensively from other practice disciplines' theoretical constructs and practices to gain counselling knowledge. This sometimes leads to their defection to psychotherapy or counselling and the loss of valuable skills where they are needed, embedded in the day-to-day world of nursing practice. To be fair, there are many potential reasons for this, such as, validation of skills in a medical culture. For example, General Practitioners (GPs) in $\mathrm{NZ}$ are politically appointed gatekeepers for A.C.C. ${ }^{13}$ counselling. Another political obstacle around validation is that members of Associations of Counselling and Psychotherapy are the only people who are mandated by the Government to provide affordable subsidized care for counselling in NZ. It seems a paradox that nurses are taking on increasingly complex roles in practice with little recognition for the actual level of skill or further education that they have, especially as a counselling role is expected in role definitions of NPs and registered nurses (RNs) (MOH, 2002; Nursing Council of New Zealand (NCNZ), 2004).

My experience in mental health developed at a time of a close association with developing models of psychology, psychotherapy and psychiatry. The theories and practices of Jung (1933, 1963); Rogers (1957); Perls (1969); Frankl (1973); Yalom (1985); and Maslow (1973) all had a direct influence on my thinking on the subject. I summarize their collective contributions to my understandings of psychotherapy and counselling under the next heading.

\footnotetext{
${ }^{13}$ New Zealand's Accident Compensation scheme.
} 


\section{Influential psychotherapeutic theories on mental health}

I became interested in Carl Jung a Swiss psychiatrist and founder of analytical psychology, because of his integration of spirituality into psychotherapy. Early on in his development he was mentored by Freud in the world of psychoanalysis. Their association was close for some years but came to a bitter end as Jung developed controversial theories about the human nature of consciousness. Most notably, he developed a theory about the collective unconsciousness. Jung did not subscribe to Freud's $(1960 ; 1965)$ pathologizing trajectories on the nature of consciousness, which focused on mental mechanisms, repression of desire; or his atheist viewpoint.

A dialectical concept of male energy (anima) and female energy (animus) were incorporated in Jung's (1971) understanding of the collective unconscious, and he proposed that male energy unconsciously hold female aspects and female likewise hold the male energy, which people subconsciously attempt to integrate.

In Jung's theory of the collective unconscious, he posited a universal system of archetypes, otherwise known as the objective psyche. These archetypes common to all, are experienced in the dreaming phase of the sleep cycle and provide a means for the psyche to integrate the conflicts embedded in the multidimensional aspects of the mind (Jung, 1970). To Jung, these archetypes represented universal patterns and symbols, which he explored further in the drawing of mandalas and the use of the IChing in his work in therapy (Wing, 1979). The notion of an underlying life pattern and an implicit universal order underpin his belief in manifestations of synchronicities which have some resonance with nursing theories (see Rogers, 1971; Krieger 1981). These views may have contributed to his being marginalized by peers, and the scientific fraternity, and being thought of as a subscriber to magical thinking and myth. I wonder whether these views still exist in modern day proponents of medically based psychology, who seldom refer to his insightful work.

Jung (1971) also formulated a theory of personality types, the opposites of extraversion and introversion. Based on four basic functions of consciousness, sensing, intuition, feeling, and thinking; these functions are lived out in the attitudes and energies of either introverted self-reflection or externalized extraversion in waking consciousness. Jung (1971) worked through configurations which typify each person's 
natural inclinations or ways of being. Each person who manifests the extrovert or introvert attitude will repress its opposite but live it in the dream world in the form of archetypes. These types were refined to develop a system of personality typing known as the Myers-Briggs Type Indicator (MBTI), conceptualized by (Myers and McCaulley, 1985). Jung also identified the conception of the false self or persona, and the shadow self which people attempt to keep hidden from others and themselves.

Jung lived out his theories engaging in deep self-reflection, meditation, and the study of dreams. He proposed that the spiritual quest is the most likely way for a person to access and realize their innate potential and create wellbeing. He devoted a great deal of time to the study of both Eastern and Western religions and concluded that these religions share the same basic tenets.

I was not introduced to Jung during my nursing education but, serendipitously, I have been drawn to his work in my personal spiritual quest, and explorations of the MBTI, dream work retreats, and mentoring. I find many of his ideas resonate with both contemplative Christianity, which I practised for nearly thirty years, and Buddhism, which I now practise; and a dialectical approach.

Another person who was influential in my development of the relational aspects of nursing was the work of Carl Rogers who also integrated humanistic spirituality into his work. Rogers born in the US, is arguably the most known and enduring theorist on the nature of interpersonal relations. Rogers built his theories from the influences of education and theology. He was renowned for his humanistic perspectives and creating a foundation for counselling and psychotherapy, which found resonance with US nurse theorists in mental health fields, such as Peplau (1952) and Travelbee (1971). The hallmark of Rogerian counselling is the creation of a confidential caring, respectful, and relational, environment, with emphases on the self-determination and inherent potentials of counsellees. Rogers (1957) posited a role for psychotherapists, which in essence, facilitates the change and transformation processes of the individual using a non-directive approach. The means for this facilitation process was the sincerity, 'or unconditional positive regard', for the person in therapy. Rogers valued the qualities of intuitive knowing in his work with people and upheld the spiritual 
nature of interpersonal work (Arnold, 2007). I expand on the facilitative and dialogical nature of his theory development under the next heading.

Another form of psychotherapy introduced to me in the early days of my work as a nurse, was Gestalt therapy. This approach described through the lens of Fritz Perls below has undoubtedly led to my interest in the dialectics of communication. Frederick Perls born in Berlin, Germany, was a Jewish immigrant to the US. He was another humanistic therapist who challenged the basis tenets of psychoanalysis and pathologizing theories by developing Gestalt therapy. Although the basic meaning of Gestalt, according to Encarta, UK (Online 2007) is a holistic configuration of thoughts, feelings or experiences; Gestalt therapy, with the influence of Perls, came to be associated with the 'here and now'. Perls and Stevens (1975) describe Gestalt therapy as an experiential, existential, humanistic therapy. Gestalt is dialectical in the sense that the aim of therapy is to access one's inherent potential, through the process of integration. The emphasis is on raising self-awareness of feelings, needs, intuitions, and senses, through focusing on the immediate moment. Gradually, through honest engagement with other group members, people become aware of tensions and conflicts, resistances, avoidance, and obligatory and false selves. People experience inner conflict of opposing selves in the Gestalt. In Perls (1975a), the dialectic between these opposing selves, "Topdog and Underdog" (p.5), manifest internally and in the environment. Perls (1975a) explains that while these aspects of self remain in a dualistic polarity, "[t]hey will easily fight and paralyse each other. By integrating opposite traits we make the person whole again. For instance, weakness and bullying integrate as silent firmness" (p.7).

Like Jung, Perls found the content of dreams to be valuable existential messages and encouraged persons to act out remembered dreams as though it was happening in the moment. There are no interpretations from the therapist; rather, a facilitated awareness of the significance of the person's inaccessible self. The emphasis of Gestalt is different from the counselling approach proposed by C. Rogers, in that the facilitation of the therapist is focused on keeping the person on task in the present moment, 
observing and noticing the paradoxes and projective identifications ${ }^{14}$ that show up. Gestalt is action orientated, involving all aspects of the person in the process of becoming an authentic self. Perls (1975b) emphasis in therapy is "[t]o achieve that amount of integration which facilitates its own development" (p.52).

As I read and reread collective works on Gestalt therapy I realize that some of the tenets such as: dialectical process orientation, a focus on the present moment, and the significance of remembered dreams, have been absorbed into my work. I reengage with these tenets in Part Three of this thesis. Gestalt therapy led to my interest in the meanings people ascribe to their experiences of life, and existential psychotherapies.

Two existential authors are important to the underpinnings of my work. They are Victor Frankl and Irvin Yalom. Frankl (1987) who was a Jewish Austrian neurologist, psychiatrist, and psychoanalyst, developed a form of existential therapy, known as Logotherapy, from his experience of being in Auschwitz concentration camp in the $2^{\text {nd }}$ World War. In his compelling text, Introduction to Logotherapy, he expounded on the search for meaning that people go through when they try to make sense of suffering. He was particularly interested in people with depression and suicidal tendencies. Frankl developed a way of supporting people through reasoning and talk, (logos) to heal, (therapy) by finding meaning in their existence so that they can continue living. Frankl strongly influenced Joyce Travelbee's (1971) Interpersonal Aspects of Nursing theory; and it was my study of her work that illuminated Victor Frankl's inspiring work to me.

Irvin Yalom (1985) was a son of Russian immigrants to the US, who grew up in relative poverty to become an eminent existential psychiatrist and psychotherapist. I came into contact with his work in clinical practice in mental health in the 1980s-90s. His book, The Theory and Practice of Group Psychotherapy, was an essential reader for the practice of group psychotherapy. Yalom, although steeped in the scientific paradigm of psychiatric medicine, prized the uniqueness of the individual and their

\footnotetext{
${ }^{14}$ Projective identification (PI) is a process whereby a person will project unconscious aspects of self onto another so convincingly that the other will take on the projection as their own. The projection will usually be either positive or negative aspects of the self that are denied or avoided. The objective of the therapist in Gestalt is to notice the PI and facilitate a conscious awareness of repressed aspects of self to achieve a healthy integration (Perls, 1975).
} 
search for meaning. This search and exploration of one's fear of death is the basis for his work. His existential approach, which was not based on religious or spiritual practice, encouraged people to face their fears of death in order to live a richer, more authentic and appreciative life. These approaches were also the basis of the theoretical assumptions of another strong influence on nursing; Abraham Maslow.

The authentic and appreciative life was certainly a theme attributed to Maslow's Theory of Human Motivation (1943). Born in US, a son of Russian Jewish immigrants, he was considered the father of humanistic psychology. Maslow's theory posited a hierarchy of human needs, ranging from physiological, environmental, social, emotional, and spiritual, which serve as the basis for motivation and are also necessary for survival. For example, if a person's basic physiological needs for food and oxygen aren't met, it is difficult for people to be motivated to seek to have needs met emotionally, such as self-esteem. Conversely if needs are met, they cease to be a motivating force, allowing people to address higher needs. According to Maslow (1943) experiences of deprivation in the early stages of development may trigger a neurotic fixation in that area of need, motivating the person to continually make certain that the need is met. For example, an early experience of poverty may motivate the person to continue to be frugal with resources, even if they become very wealthy.

According to Boeree (2006) Maslow focussed on the human potential movement in his later years and inaugurated transpersonal psychologies, taking psychology beyond analysis, behaviourism, humanism and existentialism; towards Eastern philosophies and the practices of meditation, deeper understandings of consciousness, and parapsychology. Maslow's work has been, and arguably remains the basis for conceptual frameworks of needs assessment for nurses. Although I find his theory of motivation interesting and a useful basis for assessment, like Krieger (1997) it is his latter interests that I resonate with at this time.

Although these authors sparked the growth of humanistic and existential psychotherapy and counselling, nurse theorists such as Watson (1979); Benner and Wrubel (1989); and Newman (1986); carried the momentum of caring forward in nursing, stopping short of specifying counselling roles and the preparation of nurses as facilitators; although facilitation is implicit in their writing. More recently Welch 
(2005) in gathering perceptions of nurse-patient relations, finds that the nature of these important relationships is not specified adequately in nursing mental health texts. I wonder whether nurses' concerns about territorial flare-ups with Associations of Psychotherapy and Counselling have contributed to the vagueness about relational aspects of nursing and the reluctance of nurses to embrace counselling or facilitative roles in their practice.

It is these ambiguous issues that I intend to tease out in this thesis, by delineating both counselling and facilitation as nursing roles. I do this as part of a dialectical inquiry and reflective research method and design to show patterns of DNFT in praxis. I believe the counselling role of the nurse is actually better described as facilitative, as it covers broader parameters than counselling or psychotherapy tend to do. These parameters not only relate to counselling skills that provide a supportive exploratory dimension, but also include teaching and learning, the dialectics of support and challenge, and imparting advice. To develop these skills, nurses need to go beyond theories about psychology and counselling and delve into the particulars of facilitation and dialogical theory which I discuss in the next section.

\section{Facilitation and dialogical philosophies}

Facilitation of transition is complex and multidimensional, with transitions themselves being unique occurrences in people's lives that need to be further studied, so that the nursing facilitation of diverse transitions can be identified, clarified, and evaluated for future refinement of nursing practice (Meleis et al., 2000). From a philosophical perspective, the tenets of facilitation are embedded in theories on dialogue. There are a number of philosophers and theorists that specifically address dialogue; such as, Carl Rogers, Paulo Freire, Hans-Georg Gadamer, Jurgan Habermas, Martin Buber and David Bohm (Smith, 2001). Many of these authors are found scattered through the collective works of nurse authors, especially the ones I have focused on in this thesis. At this point however I think it is valuable to briefly consider the diverse perspectives of these authors, and to clarify the meanings I have derived from them that I take with me into the work of facilitation.

As I stated previously C. Rogers has had the most enduring influence on the relational aspects of nursing, especially in mental health (see, Peplau, 1952; Travelbee, 1971; 
Barker \& Buchanan-Barker, 2005). Most notably he has infused nursing, psychology, and counselling, with the caring humanistic elements of relational work. Much of the crafting of the therapeutic relationship was done by Rogers in his capacity as pedagogical theorist and psychologist. The central tenets that emerged from his writing on the subjects of counselling, facilitation, and learning, are authenticity and congruence. To explain further, the most successful therapeutic or teaching alliance is to be genuinely oneself; not holding back ones values and beliefs. In addition to authenticity, there is acceptance; and the ability to have empathic concern for the person, as well as being able to enter the person's world without judgment and fear (Rogers, 1957).

I find his work particularly helpful as he derived much of his therapeutic philosophy from the study of education, learning, and spiritual practice (Thorne, 1992). C. Rogers upheld the importance of developing theory from authentic experience and the belief that each client has the potential to find their own solution in an enabling therapeutic relationship (Rogers 1957; Smith, 2007) Kirschenbaum, and Henderson (1990), summarized Roger's ideal humanistic qualities and intentions for relationships in the facilitation of learning under three headings. First, the most basic quality was seen to be realness, and meeting people on a person-to-person basis. Second, is the notion of 'prizing' the ideas and feelings of the learner and offering acceptance. Respect and trust was regarded as important, thereby showing the person that they are trusted to find the solution to their line of inquiry. Third, Rogers' proposed empathic understanding of persons, and seeing things from their point of view; without judgment. Rogers' emphasis in a facilitative role was on engagement and exploration in a non-directive way. He made a departure from the interpretive styles of psychoanalytic predecessors to maintain a focus on the person, rather than the technique (Smith, 2007).

These themes of facilitation identified by C. Rogers show up in Rosa Zubizarreta's (2002) qualitative interviews with group facilitators in her Dynamic Facilitation thesis, Facilitating Democracy: The Evolving Practice and Theory of Dialogue. The focus of her research is on patterns for facilitation in group situations. In her research findings, common themes for successful facilitation include: Listening deeply, authenticity, empathy, 'looking for gems', and the expression of emotions. They also 
include facilitators learning to sense the moments to be inclusive and the moments to challenge. These are important aspects of dialogical skills that are worth bearing in mind for a dialectical approach to the facilitation of transition. Zubizarreta found that when there was a balance in the facilitation moments of participants; facilitators noticed a process of unfolding for persons and possibilities emerging that were not seen before. Conversely, when facilitators adopted a forcing, leading approach, groups closed down and did not find their own insights. Facilitators talked about 'getting out of the way' of those they were helping to get the most inspiring results in the work of facilitation.

Another frequently mentioned philosopher on the subject that is applicable to facilitation and nursing relationships, referred to in nursing texts is Martin Buber. Buber, an existentialist, puts forward a thesis on human existence as real encounter and the 'I-Thou', mutuality of human existence which is a prerequisite for meaningful dialogue. He posited that for the most part, relationships usually reveal an ' $I-I t$ ', connection, viewing the other as an object. This sort of relationship is typified in nursing and medical contexts when people speak of patients in terms of diagnostic labels. This type of behaviour, in my view, holds the person at a distance and can be a way of nurses protecting the self. I previously referred to Gadow's (1980) work who addressed this tendency for nurses. Barker and Buchanan-Barker (2004) emphasize the I-Thou approach, and humility in relationships with people in their care that draws on the work of Buber, among others. Buber believed the ' $I-I t$ ' is especially evident in societies which hold a materialistic analytic view, leading to the devaluing of human existence. Buber's theoretical constructs were lived out in the religious context of Jewish philosophy and religion (Zank, 2007).

Also inspired by religious tenets, this time Catholicism, is the Brazilian educationalist, Paolo Freire. Freire was motivated by a sense of injustice and economic inequality, to develop a theory of education and learning that held the central tenets of dialogue at its core. Freire posited knowing as a process of developing values and beliefs in the context of social engagement, encounter; and through discussion, reflection, and critique. Freedom and discovery of potential is the product of education, which in poverty stricken areas is seen by Freire as the only means to transcend these conditions and reach out to opportunities. He believed the transmission of learning 
could only meaningfully come about through a facilitative egalitarian approach to learners, which similar to C. Rogers ideology, involved the Christian values of love and respect. These views resonate with Buber's notion that most learning occurs when the facilitator is being themselves, acting out the spontaneity of their own life (Smith 2001). Reaching consensus in the dialogical encounter of discussion, is not about peaceful agreement according to Freire, rather it is fleshed out in the struggle of conflict with honest reflection and critique. In this way struggle and conflict becomes the means for growth and change (Freire, 1974; 1985; 1998).

Jurgan Habermas, social theorist and philosopher, emphasizes reciprocity, and symmetry in dialogue, which isn't necessarily egalitarian. In an interview with Stephens, in the Los Angeles Times Magazine (1994) Habermas admitted he believed that freedom is the basis of unrestrained emancipatory dialogue; to overcome egocentric and ethnocentric perspectives, and search for an expanded, more hopeful view of the world. Like Freire, Habermas does not think consensus is something that can be imposed, rather there needs to be mutual trust, respect, a willingness to listen; and to risk conflict (Smith, 2001).

Hans-Georg Gadamer, hermeneutic phenomenologist and philosopher, posited a dialogical theory, or conversational theory as he called it, that asserts the importance of the person's 'horizon of understanding' or 'prejudices and assumptions' in conversational encounters. In order to have open dialogue there needs to be a desire to learn from the other in the 'to and fro' of conversation, about how they see the world; and to seek an understanding of their viewpoint. Similar to Freire and Habermas' views, agreement is not necessarily reached, in this process (Gadamer, 1989). His offerings on the subject of dialogical theory, in my view, take me only to the edges of the cognitive mind.

Gadamer's phenomenological hermeneutics have been referred to many times in nursing research (see Walters, 1994; Geanellos, 1998; Conner, 2004). Margaret Conner (2004) in Courage and Complexity in Chronic Illness was informed by Gadamerian hermeneutics to write about her reflective practice and her dialogical relationship with a person, to make meaning of journeying through chronic illness. Conner's reflection on this dialogical relationship reveals the intensity and closeness 
of caring with, for nurses; especially in long-term situations. Conner concludes that relational work that is intense over a long period of time requires advanced nursing skills. Drawing on the work of Carol Montgomery (1993) Conner suggests that,

In my view her (Montgomery) qualities are competencies that emanate from our being as a person in nursing, grounded in personal and moral knowing and are honed in practice. They are not learned interpersonal techniques that can be turned off an on at will (p.91).

I share Conner's views on this point, thus I turn to others such as Bohm, to take me closer to the essence of shared understandings of the meaning of dialogue.

David Bohm covered the span of quantum physics, consciousness, philosophy, and dialogue, and is referred to frequently in unitary paradigms of nursing. He is cited as an influence in both Rogers' and Newman's theories, especially his holographic theory and postulation of an implicate order. Bohm's views on dialogue integrates holography and an implicate order as part of the dynamic of communication. Bohm, Factor, and Garratt, (1991) were particularly interested in the idea of the reconstruction of personal meaning in the context of large group dialogues, and offered the viewpoint that dialogue allows an immediate mirroring and reflection of the content and process of thought, which they termed "collective proprioception".

In order to describe the essence of these group dialogues, Bohm et al., resorted to negation. For example, dialogue is not considered to be discussion or debate, because each of these types of group activities looks for a solution to a problem. Neither is dialogue analytical or focused on fixing or removing something. I find these forms are frequently used in work with persons in mental health. Bohm et al., (1991) in their online debate, postulate, learning and the transcendence of impasses can, and often do, take place without resorting to problem solving. Dialogue is revealed by Bohm et al., as an awakening energizing process, going beyond argument, and capturing the spirit of mutual affiliation and the merging of consciousness. Bohm's hope, traced in the reading of his works, was that persons could maybe glimpse an implicate order through the lattice work of their thoughts. 
Facilitative efforts, drawing on the theories and ideas of C. Rogers, Buber, Freire, Gadamer, Habermas, and Bohm, need to be as capacious and allowing as they can be, risking the potential for chaos to emerge, whilst at the same time holding the context of the dialogue in focus so that a true exploration can occur. The recurring pattern running through the thread of these distinct viewpoints on dialogue is the movement towards freedom and an expanded awareness about the nature and meaning of being human.

Zubizarreta (2002) and Smith (2007) both wonder about the balance between an empathic focus on the person and the need to see the viewpoints of both the facilitator and the person. Zubizarreta (2002), drawing on the ideas of Burbules' (1993) dynamic facilitation, suggests that a dialogical approach is a more likely to surface the creative tension between inclusiveness and critique in the facilitative relationship. Zubizarreta raised the potential for the shadow sides of these aspects to emerge if the balance isn't held between these facets; the shadow sides being enabling and combative. The ability to hold the balance in this tension is described as a having a "skillful discussion". However, it is important to bear in mind what one is trying to achieve in this type of facilitative discussion. For example, is it practical and goal orientated? Or, are the person and the facilitator going for meaning which would align with a freeform agenda-less type of dialogue? These are important issues for me as a DNFT as I have often found that I move between aspects of these identified polarities, especially the dialectic of support and challenge. I return to the theories and philosophies of facilitation in dialogue in the discussion chapters of this thesis.

In Table 4, I summarize facilitative dialogical aspects of this review which inform my practice. 
Table 4: Facilitation influences for DNFT

\begin{tabular}{|c|c|c|}
\hline Qualities & Aims & Focus \\
\hline $\begin{array}{l}\text { - } \text { Mutual respect } \\
\text { - } \text { Authenticity } \\
\text { - } \text { Openness } \\
\text { - } \text { Exploratory } \\
\text { - Compassion } \\
\text { - Listening skills } \\
\text { - } \text { Mirroring }\end{array}$ & $\begin{array}{ll}\text { - } & \text { Raise awareness } \\
\text { - } & \text { Surface tensions } \\
\text { - } & \text { Look for patterns \& } \\
\text { meanings } \\
\text { - Surface person's potential } \\
\text { - Instill hope } \\
\text { - } \quad \text { Support and challenge }\end{array}$ & $\begin{array}{ll}\text { - } & \text { Present moment } \\
\text { - } & \text { Person's issues } \\
\text { - } & \text { Integration } \\
\text { - } & \text { Transformation }\end{array}$ \\
\hline \multicolumn{3}{|l|}{ Influences } \\
\hline $\begin{array}{l}\text { C. Rogers, Bohm, Watson, } \\
\text { Barker, Peplau, M. Rogers } \\
\text { Newman }\end{array}$ & $\begin{array}{l}\text { Jung, Frankl, Yalom, Freire, } \\
\text { Newman, C. Rogers, M. Rogers, } \\
\text { Parse }\end{array}$ & $\begin{array}{l}\text { Perls, Jung, C. Rogers, } \\
\text { Barker, Peplau, Newman, } \\
\text { Parse }\end{array}$ \\
\hline
\end{tabular}

I take these aspects of facilitation forward into shaping a dialectical inquiry methodology in Chapter Four. In doing this I integrate Eastern and Western philosophies that inform my thinking on dialectics. The influences of Buddhist philosophy especially influence my understandings of dialectics thus I foreground the tenets that influence my approach to DNFT in Section Three.

\section{Section Three: The influence of Buddhism on my nursing practice}

This review has so far revealed philosophical influences and discourses that inform my nursing knowing, creating a lens from which to view a deeper heuristic reflection of the practice of DNFT in supervision, peer review, and case review. I specifically include the philosophy of Buddhism, delineating to the Nichiren Daishonin school of thought. This forms the background to my philosophical development. I do this because I believe Buddhist thought is often variously referred to in nursing theory, particularly by schools of unitary and integral / holistic thinking. In Western schools of nursing philosophy and thought, I believe there is a tendency to globalize Eastern philosophies and religions. It is therefore my intention to clarify the particulars of philosophies that influence me, so that the reader can find the resonance and dissonance of my thinking with the various philosophies and schools of thought, that 
influence nursing in particular, and health services in general. I reiterate that my inclusion of religious thought is not intended as a colonizing influence; rather, it is an attempt to reveal the embedded-ness of self in nursing work, which I argue is a humanitarian professional service. I start with an overview of Buddhism under the next heading.

\section{An overview of the history of Buddhism}

I offer a brief overview of Buddhism so that the reader is familiar with the school of Buddhism that influences my approach to dialectical philosophy. In doing this I take up the comments made by Barbara Sarter (1988) below, in which she reviews Philosophical Sources of Nursing Theory, drawing from the work of Rogers, Newman, Parse and Watson.

It is time that serious attention is paid to the formal systems of thought of the East, both ancient and modern, so that an accurate interpretation and application, rather than vague references, can be made (p. 59).

To understand the development of the ancient philosophy of Buddhism, I refer to the writings of Chandra Wickramasinghe (1988) and Daisaku Ikeda (1988; 2003). In doing so, I hope to clarify some of the teachings that illuminate the nature of the lifeforce, suffering, and the notion of death.

Shakyamuni Buddha expounded his enlightenment over 50 or so years, developing a profound and expansive philosophy about the nature of life, the reason for suffering, and the relationship of humans with each other and with the environment. It contained the intricacies of medicine, health and wellbeing, and life and death. Set in a cultural context of India, which at that time was embedded in Hindu religion; Shakyamuni proposed a middle path, between the extremes of ascetic practice and self-indulgence. He posited that all humans have the potential to attain enlightenment. Following his death, details and interpretations of the practice of Buddhism led both to the spread and hybridization of these teachings, across the diverse countries of Asia. As interpretations were made by scholars throughout the ages, esoteric rituals were 
developed, and ancient temple worship and offerings derived from Hindu practices became common (Wickramasinghe, 1988).

Buddhism does not espouse a divine omnipotent being, in its teachings; rather, it focuses on the intrinsic essence of Buddha nature in each living being. This essence shows itself in the state of enlightenment of human beings. It is to this state of enlightenment that the philosophy of Buddhism interpreted in diverse ways; becomes relevant in the present age.

Nichiren Daishonin, frustrated with the many practices of Buddhism, embarked on a process of study and meditation and expounded a practice around 1253, which holds that the essence of Shakymuni's teaching in the Lotus Sutra is contained in its title, Nam-myoho-renge-kyo. This phrase refers to the mystic law of the universe; in other words, the unseen law of the universe. Nichiren proposed that chanting this title brings a person into rhythm with the mystic law of the universe, revealing the essence of Buddha nature inherent in each person, and is a way for people to attain enlightenment (Ikeda 1988).

Nichiren Buddhism was contemporized in the $20^{\text {th }}$ Century by a Japanese educational reformer Tsunesaburo Makiguchi. He sought a paradigm shift in the education system in Japan, from rote learning to critical thinking. He strove to develop ways of teaching that would unleash the person's potential. This led him to the teachings of Nichiren Daishonin, and a desire to conceive a philosophy that would transfer educational principles into value creation for the betterment of human society and peace. Josie Toda, also a teacher, joined in this practice and committed himself, along with Makiguchi, to educational and religious reform. They formed a society entitled the Soku Kyoiku Gakkai (SKG) (Value Creating Education Society) and attracted membership of mainly educators (Bethel, 1994).

When Japan became involved in the $2^{\text {nd }}$ World War, the government of Japan incarcerated those who opposed their views. This included Makiguchi and Toda. Makiguchi died in prison. Toda survived and was released in 1945. On his release, Toda expanded the SKG beyond the educational system and into the broader society, renaming it the Soka Gakkai (SG) (Value Creation Society). The movement grew 
rapidly in Japan, and at the time of Toda's death in 1958, Daisaku Ikeda led the movement, becoming the foremost proponent of Nichiren Buddhism in the Western world. Ikeda interprets the writing of Nichiren Buddhism proposing that Buddhism embodies humanism (Bethel, 1994).

The renaissance of Buddhism, in the contemporary context, has occurred in the West in a number of different ways and comprises many schools of Buddhist philosophy. For example Buddhist influences underpin the integral work of Boeree (1997); Johns (2004a) Wilber (2007a); Rowan (2007).

The basic tenets of Buddhism that relate with unitary and caring theories, and philosophies of nursing, include: The interdependence of people and environments; the humanistic quality of compassion; the value and worth of people and their environments; and the belief in the inherent potential that each person has to bring about changes in their lives. I take these forward into my work with people as underlying principles of practice included in Table 5. The dialectical principles which underpin Buddhist thought also show some compatibility with unitary schools of nursing theory, and dialogical, psychological, facilitative, learning and education theories, previously reviewed. In the next section I discuss the influence of the Buddhist philosophy on constructs of health.

Table 5: Basic Buddhist principles for practice

\section{Buddhist principles for practice}

- Interdependence of people and environments

- Humanistic compassion

- Belief in inherent potential and worth of each person

- Belief that each person has the potential to change

\section{Buddhism and health}

A state of complete wholeness and health is not proposed in Buddhist teachings because of the inevitability of the cycle of life and death. According to Buddhism, the real origin of suffering is the attachment to being in a static non-changing state; for 
example, desiring youthful beauty and health. Tibetan Buddhist Sogyal Rinpoche (2002), in his epic text the Tibetan Book of Living and Dying, highlights the Buddha's universal teaching on change: "There is only one law in the universe that never changes - that all things change, and that all things are impermanent" (p.29). The lifeforce; however, is considered to be eternal.

Shakyamuni's teachings were prolific on the subject of health, illness, and healing, and much was written about the causations of illness and ways of managing health. T'ien-t'ia (538-597), a Chinese scholar synthesized some of these teachings and the major causations of illnesses into three main groups (Ikeda, 1988; 2003). These are: Physical illness, mental illness, and illness related to karma.

\section{Physical illness}

The first group focused on the physical body, specifying disharmony in the four elements, earth, water, fire, and wind, manifesting in disorders of solid (body mass), liquid (bodily fluids), thermal (heat generating systems), and gas (respiration). The causations of these disorders were thought to be due to poor diet, poor posture, irregular meditation, and the attack of demons. Attacks of demons were not malevolent beings, as once thought, rather they were likely to be the attack on the body's immune system by viruses and bacteria, or the effect of externally generated stress (Ikeda, 2003). To explain further, the interconnectedness of human beings and the environment relate to the five elements; Earth, water, fire, wind, and space / ether. These elements constitute all aspects of the physical world of persons and physical structures. For example, the element earth constitutes all natural physical structures of the external world. In the body, earth refers to the structural aspects of the body such as bones, teeth, skin, hair, nails. Water refers to the natural external environment of the seas and water ways. In the body it refers to blood and bodily fluids. Fire in the natural environment lies deep within the earth, the basis for volcanic action. In the body it refers to heat regulation and digestion. Wind refers externally to the wind and air that we breathe and internally to respirations and metabolism (Ikeda, 1988). Space in Buddhist interpretation integrates and brings other elements into harmony. The space element, sometimes referred to as ether or etheric, also refers to the energy field shadowing the physical form (Mookerjee, 1982; Brennan, 1993; Ozaniec, 1994; Wilber, 2007a). 
Ikeda (2003) interprets Nichiren's teaching of the five elements as being synonymous with the five characters of Myo-ho-ren-ge-kyo implying a unity of essence between the environment, the body, and the Mystic Law. T'ien-t'ia integrated the unity of mindbody-spirit suggesting that for health, persons need to engage in five regulatory activities: Eating, sleeping, posture, breathing and thinking (meditation) (Ikeda, 2000). The balance of the elements of earth, water, fire and air is evident in the work of Nightingale (1969) in her promotion of nutrition, cleanliness, warmth, and fresh air as essentials of life and the return to health. The balance of mind-body-spirit is also a feature of Watson's theories and philosophies which extends to interdependence with the environment; encompassing self, other, society, and the physical environment. According to Watson (2005 a,b) in 'caritas nursing' nurses become a compassionate energy field through reflective practice and Mindfulness, not only concerned with human beings but with the earth it-self. This view is different from predominant Western ideas in which human beings and their environments tend to be viewed as separate entities with human beings having dominion over the environment. In Eastern and indigenous thought, for example Maori, there is an interdependent relationship between persons and their environments (Durie, 1998).

\section{Mental Illness}

The second group related to mental function, described as the work of devils, or in current terms; negative aspects of the mind that prevent people from developing a strong life-force. Illnesses of the mind range greatly in severity, from mild to severe. Mild disorders of the mind were thought to be caused by the three poisons of greed, anger, and foolishness. A common example of this is an attitude or belief that one's life has no purpose or meaning. In this state, the person lives in ignorance of their inherent potential, or the potential of others. Being in this state of life often precipitates a search for happiness in the form of cravings, and desires such as a hunger for food, substances, sex, power, or wealth. This cyclical pattern holds the person in a state of selfish stagnation and dualistic thinking, where the person segments experiences into good and bad, externalizing both their dissatisfaction and happiness. This cyclical state of being can lead to illness of the emotions (TWND, 1999; Ikeda, 2003). 
Little is written about the contemporary practical application of Nichiren Buddhism to mental health, although I found the work of psychologist Karen Dockett (1993) integrates Nichiren humanistic Buddhism into the practice and understanding of psychology. She especially emphasizes the importance of self responsibility and challenging negativity through Buddhist practice. Docket proposes that the Buddhist way is to see crisis and stress as an opportunity to grow and transform. She believes this goes beyond psychological therapy which tends to focus on behavioural modification and cognitive efforts to develop an internal locus of control.

\section{Illness related to karma}

The third group is a severe group of illnesses of the mind concerning the realm of karma. In Buddhist terms, karma relates to a person's present condition being a culmination of past thoughts, speech, and action, not only pertaining to this life, but the many life cycles the person has been through. Essentially, the law of karma is a manifestation of the universal law of cause and effect, or the Christian teaching of reaping what we sow. Karmic diseases can manifest in either the emotions, or the body, and tend to be immune to traditional healing methods, energy work, or medicine. According to many religious practices, including Buddhism, the only way changes can occur to the karmic pattern is through an awakening of spiritual understanding. This awakening demands that a person takes responsibility for the issues and problems they face, that they assiduously practice meditation to raise their life-state, and that they serve others with compassion, without expectation of reward (Gurudev Shree Chitrabhanu, 1982; Brennan, 1993; Sogyal Rinpoche, 2002; Ikeda, 2003).

Sogyal Rinpoche (2002) puts it like this:

Because the law of karma is inevitable and infallible, whenever we harm others, we are directly harming ourselves, and whenever we bring them happiness, we are bringing ourselves future happiness (p.98).

Nichiren Buddhism directly addresses the issue of karma change through the recitation of the mantra Nam myoho renge kyo. This mantra has deep meaning. To elaborate; 
Nam means to devote oneself. Myo means hidden or mystic and has three components, which are: to open (to the true nature or essence and full inherent potential); to be endowed (complete with all the necessities of life and wisdom), to revive (to revive and manifest inherent potential and Buddha nature that tends to be dormant without active spiritual practice.). Ho refers to aspects of life which are seen; the manifestation of life. Myoho symbolizes the dialectic of seen and unseen, negative and positive, and light and day. Renge is analogous to the lotus blossoms, revered by many Eastern religions as symbolic of sacred truth, because they flower and seed simultaneously, providing a metaphor for the principle of cause and effect underpinning karma. Lotus blossoms grow in muddy swamps, symbolizing the potential for change and growth to emerge from difficult conditions in life. Kyo means sound, speech, or teaching.

According to Ikeda's (2003) interpretation of Buddhist Sutras "the voice is the vibration of the whole living entity; it reveals a person's being and character" (p.183). My understanding of chanting is that of a harmonious vibration for tuning the instrument of the energy field, raising the life-state to equilibrium, and opening up to one's full potential. In doing so, the energy field is mobilized to re-pattern negative karma held; thereby, enabling renewal and unearthing Buddha Nature. Although this may seem a simple matter, Nichiren reveals two aspects to the practice of chanting: one is for self development, or 'human revolution', as Daisaku Ikeda puts it, and the second aspect is to practice for others through teaching, acts of compassion, and promoting peaceful living within humanity and the environment.

Chanting is a practice that most religions share in common for similar reasons; to come into harmony or agreement, to awaken to the spiritual aspect of life, and to communicate a sacred message. Chanting is a call. For example, in Maori culture, a female elder calls people to the meeting house with a song or chant. Similarly, a metaphor given by Nichiren to describe chanting as a call is as follows:

When a caged bird sings, birds who are flying in the sky are thereby summoned and gather around, and when the birds flying in the sky gather around, the bird in the cage strives to get out (TWND, 1999, p.887). 
This statement implies chanting as a liberating function. Spiritual practices, whether they are chanting, prayer, or meditation, address the part of self which taps into deeper layers of consciousness. These layers of consciousness have been described in different ways by religious teachings and cannot be understood fully in the language of science. I expand further upon these layers of consciousness in the next section. Consciousness cannot be discussed in isolation. Therefore I reveal the realms of existence that embodies consciousness. I include the main themes of Nichiren Buddhist constructs of illness and recovery in Table 6, which are drawn from Tien T'ia's writings (Ikeda, 2003). In this thesis I use the words conventional medicines to refer to scientific methods of medicine throughout the ages; and traditional medicines to refer to what would now be regarded in $\mathrm{NZ}$ as complementary and alternative medicines.

Table 6: Nichiren's classification of Buddhist views on illness and approaches to recovery

\begin{tabular}{|c|c|c|}
\hline Causes of ill health & Manifestation & Buddhist approach \\
\hline $\begin{array}{l}\text { 1. Disharmony of } 4 \\
\text { elements }\end{array}$ & Physical illnesses & $\begin{array}{l}\text { Posture, breathing, diet, sleep, } \\
\text { meditation. Responds to } \\
\text { conventional \& traditional } \\
\text { medicine. }\end{array}$ \\
\hline $\begin{array}{l}\text { 2. Anger, greed, } \\
\text { foolishness }\end{array}$ & Mental illnesses & $\begin{array}{l}\text { Develop deep respect for self } \\
\text { and others. Meditation. } \\
\text { Responds to psychotherapies, } \\
\text { conventional \& traditional } \\
\text { medicine. }\end{array}$ \\
\hline 3. Karmic & $\begin{array}{l}\text { Can be physical mental, or } \\
\text { environmental. Illness } \\
\text { process remains progressive } \\
\text { unless change occurs } \\
\text { through re-patterning and } \\
\text { spiritual practice }\end{array}$ & $\begin{array}{l}\text { Take responsibility for ones life } \\
\text { condition. Spiritual practice for } \\
\text { self and others. }\end{array}$ \\
\hline
\end{tabular}

The integrative nature of Buddhist philosophy places an emphasis on context to understand aspects of the self and the social and physical environment. I expand on this below. 


\section{Buddhist ideas about context: The three realms of existence}

Three realms of existence in the Buddhist teachings of Nichiren Daishonin place the individual in relationship to others in a socio-cultural context, which in turn exists in a place or land. These realms are based on the Buddhist principle of dependent origination $^{15}$ and the idea that the physical environment mirrors the life-states of the individual and society (TEBDC, 2002). This view of life is evident in Maori health models, especially Te Whare Tapa Wha - Te Wheke - Nga Pou Mana (Pere, 1984 \& Durie, 1998). These models collectively encompass themes of health as related to unseen energies, in which mind, body, and spirit are inseparable. Individuals are viewed in contexts of wider social systems inclusive of family, cultural heritage, environment, and land-base (Durie, 1998).

From a nursing perspective these principles underpin many theories of nursing across the range of unitary, simultaneity and dimensionality models which emphasize the importance of the inclusion of contextual issues in health assessments (Parse, 1992). Like Parse, I wonder whether these aspects are sufficiently integrated in dimensionality models to capture a sense of the whole as would be implied by Buddhist, Maori, and unitary ideas about human beings and their environments. I argue that, to be able to meaningfully achieve this integration in nursing assessments, there needs to be a philosophical understanding of interdependence, and the implications of it in health-care contexts.

In the following section I review the Buddhist integration of the context of the individual and their social and physical environments.

\section{The realm of the individual: Mind-body-spirit}

In the realm of the individual, persons come to know through five components (skandhas, Sanskrit, Skt) of mind-body-spirit, namely: Form, perception, conception, volition, and consciousness (Ikeda, 2003; TEBDC, 2002). Although I may refer to dimensions of mind-body-spirit, the five components represent an integration of dimensions showing that these components, as they apply to human beings, need to be viewed as a whole. To explain further, form pertains to the realm of the individual

15 "A Buddhist doctrine expressing the interdependence of all things" (TEBDC, 2002, p.110). 
referring to physical dimensions, including the sense organs making up the Buddhist understanding of five aspects of consciousness.

Perception involves the interpretation and integration of the sensory system through both the neurological system and the spirit in the sixth layer (Skt, mano-vijnana) of consciousness. In the sixth layer of consciousness ideas are formed and judgments are made about information coming in from the external world. If there are any impediments in any of the five senses, inevitably this will lead to altered perceptions and misinterpretations of stimuli being received. The person's ability to perceive is affected by the filtering, figure-ground, and perceptual abilities of the nervous system. Individuals perceive things in different ways, depending on their unique configurations of form (TEBDC, 2002; Ikeda, 2003).

Conception is the creation of thought forms in response to perceptions, and consists of the judgments about the outer world in the conscious waking state. More sophisticated interpretations of thought forms and emotions are processed in the seventh layer of consciousness. The seventh consciousness (Skt, mano-consciousness), is referred to in Nichiren Buddhism, as being the inner experience of the world, sense of self-identity and ego, spirituality and moral conscience. The potential for self-awareness is within this layer of consciousness. The seventh layer of consciousness is the focus of interest in schools of psychology, psychiatry, and mental health nursing in diverse ways. Especially understanding the means by which persons respond to the world and their volition to partake in it. Volition, from a Buddhist perspective, is the will and intention to act on conceptions and perceptions (TEBDC, 2002; Ikeda, 2003).

Maslow's writing on this subject elucidated the psychological aspects of volition linking it to spirituality in his descriptions of self-actualization. Maslow expanded on this later in his life with his conceptions of the transpersonal dimension (Boeree, 1997; 2006).

Much of contemporary thought on the subject of consciousness in psychology is influenced by the theories of Freud who with his neurology background, attempted to classify layers of the conscious and unconscious mind in his conception of the ego, superego, and the id (Freud, 1960; 1965). The spiritual aspects of consciousness were 
also explored by Freud's contemporaries Jung and Roberto Assagioli; founder of a psychoanalysis called psychosynthesis ${ }^{16}$.

In a Buddhist view of the seventh consciousness, the ego identity is conceptualized as a lesser self, which tends to dichotomize aspects of life, categorizing them into good and bad, permanent and temporary, self and other. This dichotomizing function of the ego mind creates an illusory system in human beings. From a Buddhist perspective this can set people on a path of suffering and a tendency to carve out a permanent and static image of self and life; seeking permanence in the material world (TEBDC 2002; Ikeda, 2003). It is the dichotomous ego mind that creates the perception and conception of a separation between self and other, environment and humankind. Buddhist philosophy challenges these perceptions and conceptions as delusional, because, in the urge to create a permanent static identity of self, persons lose sight of the true self which lies at a deeper layer of consciousness. As Ikeda (2003) puts it, "Our attachment to the self of the seventh consciousness confines us to a small cage within the vastness of life, and our inherent wellspring of humanity remains untapped" (p.157). To clarify, there are two selves in Buddhist thought, the lesser self and the greater self, or, ego mind and Buddha Mind.

In this thesis I refer to the Buddha Mind with a capital $M$ to distinguish the Mind of the greater self from the lesser mind of the ego self. Tapping into this greater self facilitates the mastery of the ego self, which is often beleaguered by the vicissitudes of day-to-day life, and the emotions and thoughts that accompany them. According to Ikeda (2003) Shakyamuni helped people to master the negative aspects of these shifting thoughts and emotions through meditation and a form of creative visualization. This is similar to meditations, such as visualization, used in some psycho-therapies and nursing practices (see Assagioli, 1967; Barrett, 2003).

In Nichiren Buddhism, the meditation for observing the Mind of the greater self is through the practice of chanting. It is believed that chanting penetrates all layers of

\footnotetext{
${ }^{16}$ A way of achieving harmony within the human personality, the body and the psyche, which comes from the psychoanalysis and psychotherapy tradition (Assagioli, 1967).
} 
consciousness and raises the life-state, enabling a rapid process of transforming negative and karmic patterns (TWND, 1999).

To explain the vicissitudes of shifting cognitions and emotions influenced by the perceptions and conceptions of the mind, Chinese sage T'ien-T'ia in Great Concentration and Insight, revealed a teaching known as Ichinen Sanzen. The principle of Ichinen Sanzen (3000 realms in a single moment), reveals the capacity for a person to manifest any one, or all, of ten possible life-states at any moment in time (Ikeda, 1988; 2003; and Causton, 1995). Although it is not within the scope of this thesis to fully explain the intricacies of this profound teaching; an overview of the three realms, ten life-states and ten factors elucidates the potential for persons to shift from one state to another. In the philosophy of Nichiren Buddhism based on the writings of T'ien T'ia, people do not transcend one state and move on to another in a stepwise manner; instead each person could potentially experience any one of these states in the moment. Each state has both negative and positive aspects, which I explain in the following section.

\section{Ten life-states}

The ten life-states encompass the diverse ways that people perceive and form ideas about their worlds. They include: Hell, hunger, animality, anger, humanity, heaven, learning, realization, bodhisattva, and Buddha nature.

Hell refers to a state of misery usually generated in response to something happening in the environment, for example, the loss of a loved one. It can also refer to an internalized state of misery when a person erroneously perceives themselves to be bad, unworthy or unlovable. This state of hell often accounts for the distortions that occur in mental illness (TEBDC, 2002; Ikeda, 2003). On a positive note, experiences of them and transcendence, can motivate people to empathize with others and can form the background for helping (see Conti-O'Hare, 2007).

Hunger refers to a state of yearning. This yearning can motivate the person to seek relief. For example, to satisfy the hunger of an unmet need; or it may motivate the 
person to search for a deeper meaning in life. On the negative side this may mean the person has an insatiable need that may translate into an addiction for money, food, sex, power, which is cyclical. Conversely it can motivate the person to strive to improve their situation; for example, find a mate, or survive a famine (TEBDC 2002; Ikeda, 2003).

Animality represents the mentality of the law of the jungle. For example, in the event of a disaster a person may resort to selfishness not thinking about the needs of others. Acting in this way the underlying tenets is 'every man for himself' or 'survival of the fittest'. On a positive note, the instincts of parents could motivate them to perform heroic acts to save a child. Animality is instinctual and a basis for human survival. Basic instincts to seek for food, shelter, and procreate, are necessary for life (TEBDC, 2002; Ikeda, 2003).

Anger refers to a state when a person sees the need to have control and to be seen to be better than others. Driven by ego, persons may trample on others to have things their way. Conversely anger can lead to motivation to change things or bring about reform. A state of anger characterizes a dualistic cosmology, thus, persons perceive a sense of separateness, and polarized thinking. Social action based on anger often involves war or social revolution. Underpinning this state is a sense that one way of thinking is right and another way of thinking is wrong (TEBDC, 2002; Ikeda, 2003).

Humanity refers to a state of concern and care for others and the environment. In humanity the person has developed the capacity for empathy, self-reflection and a sense of interdependence. This state may motivate the person to work for the good of social change and the environment, in a dialogical and consensual way. The negative aspect of this state is that the person, having reached a state of self control and mastery, may go into a 'comfort zone' and lapse into inactivity (TEBDC, 2002; Ikeda, 2003).

A state of heaven is an experience of profound happiness and peace. Although heaven is a desired state, the person can easily succumb to complacency and take this state for granted. Happiness in this state is relative, depending on the external environment. An example of this could be, having harmonious relationships with others and good 
health. This state of heaven can change, for example, when people are in conflict with others, or experience a change in their health (TEBDC, 2002; Ikeda, 2003). These six states are mainly influenced by the external environment. The seventh and eighth states represent a desire for enlightenment characterized by learning and realization.

Learning is a receiving state, usually involving a relationship with a mentor and teacher. The person is motivated to learn and develop their potential. The negative side to this is that the person may go inward and become egocentric, losing touch with the practical world and value knowledge over humanity (TEBDC, 2002; Ikeda, 2003).

Realization is an act of synthesis and integration through learning and thinking through. In realization an illumination of insight occurs, leading to enlightenment. For most of us realizations happen in cycles of transitions. Realizations can lead a person to awaken to their Buddha nature or on the negative side it can also lead to a state of arrogance and conceit (TEBDC, 2002; Ikeda, 2003).

Bodhisattva is a compassionate state of enlightenment which motivates the person to teach and help others to grow and realize their essential Buddha nature. The negative side to this state occurs when persons do not learn to facilitate others to help themselves, thereby becoming personally drained and unable to initiate change processes in others.

Buddha nature is the manifestation of real self. It is not a transcendence of the other states according to Nichiren, rather, the Buddha lives permanently in a state of pure joy having the capacity to forebear all sufferings and transitions. In Nichiren's teachings, based on the Lotus Sutra, all people have the capacity to tap into Buddha nature especially in the course of meditation which leads to the observation of the Mind or Spirit. (Causton, 1995; TWND, 1999; Ikeda, 2003).

T'ien-T'ia proposes in his interpretation of the Lotus Sutra, that all people have the potential to respond from any of these life states and that each state mutually possesses all of the other states. That means that coming from a position of hellish misery a person has the potential to access their Buddha nature or any of the states in between. Examples of this fact often manifest in times of great suffering such as a disaster when 
some individuals emerge as heroines or heroes surpassing their hellish situation to help others. In this way ordinary individuals may manifest the compassion of a bodhisattva (Causton, 1995; Ikeda, 2003).

These ten life-states in essence, resonate to some extent with Maslow's (1943) hierarchy of needs, in the sense that the achievement of the needs of each state, enables to person to be motivated to achieve higher levels of being. The mutual possession of the ten life states goes beyond hierarchies. As explained, there are both negative and positive aspects to these states. A dialectical approach surfaces the tensions within these mutable states, searching for an integration that enables movement and value creation.

As I live and observe these life-states, changing from moment-to-moment in my life, I develop a deeper awareness of the motivations and actions that come from perceived unmet needs, the obligatory self and the real self. Within each of these states there are tensions which can be synthesized to become what Newman would refer to as a 'choice point', shifting the emphasis from a sense of external locus of control, or powerlessness, to internal locus of control, where the self becomes the creator of the life pattern, or the author of the story (Newman, 1986; 1994; see also Docket 1993; Neimeyer, 2001a; Romanoff, 2001).

Those who struggle with life long patterns of an intrinsic nature such as a tendency to look at things from a negative viewpoint may not find movement or a sense of choice in a dialectical process. To understand the deeper patterns at work, T'ien T'ia in his teachings described these patterns or tendencies as ten factors of life explained next (Ikeda, 2003).

\section{Ten factors of life}

The ten factors refer to the factors of life that each person has which unlike the changing life-states; remain consistent throughout the life span of the person. These are: Appearance, nature, entity, power, influence, internal cause, relation, latent effect, manifest effect, and consistency from beginning to end. 
Each person has an appearance that is unique, distinguishing them from others. This relates to the physical form. Intrinsically persons have a certain inherent nature. This is manifested in the personality of the person. From a Buddhist perspective this refers to the spiritual dimension or 'Mind'. Entity manifests as both appearance and nature revealed in the life states described above. This is often referred to as the essence of the person. The appearance signals this essence as the person seems to radiate a presence which may be seen by others as positive, negative, or neutral. The personality or nature confirms this presence revealing the entity, essence, or spirit, of the person. Appearance, entity, and nature, all relate to the reality of life (TEBDC, 2002).

Power refers to each persons inherent potential to act. Depending on the life-state the person is manifesting; this may range from a position of powerlessness as in a state of hell, when a person feels immobilized by their emotional state, or power, as in a state of humanity when the person has the ability to change social conditions for others. Influence refers to thoughts, speech, and actions that cause inherent power to manifest. For example, the combination of thoughts, words, and action, enable a person to carry out a project. Put together these factors represent the component of volition. The next four factors relate to the principle of cause and effect and how the actions we take shift us from one of the ten life-states to the other (Ikeda, 2003).

Internal cause is a latent cause that each person has which is inherent. This relates to Karma. The relation is the trigger for the producing an effect. For example, a person may be physically abused by another and may respond with anger. The physical abuse is not seen to be the direct cause of this anger but the person's life tendency based on the above factors. The reaction of anger in this case is an example of a latent effect or bringing out the effect of some aspect lying dormant internally. When the conditions are right this latent effect becomes a manifest effect or consequence of the internal cause and the latent effect; revealing the karmic cycle. In the above example of abuse this may unleash a response manifesting in any of the life-states. It could manifest as feelings of unworthiness and induce a state of anguish (hell), or it could become anger motivating the person to become a terrorist, or, it could inspire the person to help others who are abused, in a state of humanity. There is no set timing for this it may take many lifetimes for the manifestation of a latent effect, or due to a transformation in the person to bring forth their Buddha nature, the manifest effect will be very 
different than if the person is in a state of hell. Power, influence, internal cause, relation, latent effect, and manifest effect, all refer to the functions of life (TEBDC, 2002).

The last factor, consistency from beginning to end integrates the other nine factors. None of these factors occur in isolation; all work together making up the whole which includes the person and their environment. According to TEBDC (2002); "All nine factors thus consistently and harmoniously express the same condition of existence at any given moment" (p.668).

These factors of life resonate with some psychological constructs, for example, understanding the personality and volition addressed by the work of Jung, Assagioli, and Maslow, but they are largely ignored by science. The scientific stance was critiqued by Assagioli (1967) who stated "[t]here exists no reason why sexuality should be scientific and love not" (p.3). Scientific evidence does suggest that the manifestation of inherent traits can be brought about by a trigger. An example of this may be a person's tendency to develop a mental illness when a high genetic susceptibility is coupled with a stressful environment. This could lead to the manifestation of intractable depression or psychosis (Kaplan, \& Sadock, 1998). This explains a mind-body understanding of the ten factors.

These aspects posited in Buddhism are the basis for self responsibility in relation to situations and states that people are in. There are no victims in Buddhism in this sense. Each person, even in the harshest of conditions, is seen to have the potential to change it through the surfacing of their inherent Buddha nature. Ikeda (2003) indicates that from a spiritual perspective, we have the potential to alter the course of our lives through creating a different pattern. Whilst this is possible, it is very difficult to achieve without a means for developing a deeper level of self-awareness and awareness of Buddha nature.

It is my view that modern mainstream psychology and mental health nursing practices tend to focus on strengthening the ego self in the form of cognitive re-patterning and emotional release. In these trajectories, in many cases, the existence of a greater self is denied. I suggest that gaining access to deeper layers of consciousness could be 
thwarted in therapy that focuses solely on the cognitive and emotional aspects of experience. Buddhist philosophy offers the view that deeply held intransigent patterns lay in the eighth consciousness. To explain further, the eighth (Skt), alayaconsciousness refers to the inherent storehouse of all present and past memories and experiences. It also contains the seed of the effects of present and past actions that manifests when the conditions are right (karma). This understanding is the basis for causality (TEBDC 2002; Ikeda, 2003).

The eighth consciousness is not confined to the present incarnation and corresponds with psychological theories such as, the Jungian conception of the collective unconscious, and archetypes, accessed in the dreaming cycle of sleep (Jung, 1970; see also Assagioli, 1967). Just as neurologists and branches of psycho-neurology are discovering, memory and the storage of memory is more complicated that was ever imagined. Rogers (1971) drew extensively from psycho-neurologist Karl H. Pibram and David Bohm's conception of the brain as holographic, containing electrical patterns of memory that greatly influence cognitions. Ikeda (2003) suggests that on a basic level the memories stored in the eighth consciousness influence the perceptions and conceptions of the other seven. This will also affect the volition and ability to act and respond in the world of experience.

Much of Western science denies the possibility of a memory bank of previous incarnations, instead directing its attention to the present one, implying that there is no continuity of a life cycle. Ikeda (2003) often shares an analogy made by his mentor Josie Toda in the following to illustrate this point:

According to medical science, over several years, every cell in our bodies, ...[i]s replaced. On that basis, ...[y]ou could argue that you are not liable for a debt from five years ago...Still the debt collector will come without fail. Similarly, we have no choice but to take responsibility for our past actions and the karma we've created (p. 159). 
The concept of karma effectively influences all aspects of a person's life within the five components, thus contributing to the persons', physical, mental, and spiritual configurations, and unique patterns. The purpose of spiritual practice is to facilitate repatterning in the cycle of life. From a Buddhist perspective, the first seven layers of consciousness are absorbed into the eighth consciousness in the transition of death and gradually merge with the ninth consciousness. Ikeda (2003) in his integration of Buddhist Sutras posits:

During the transition from sentience to insentience, our capacity to respond to external stimuli becomes latent and our lives become fixed in whichever state we have established as our basic tendency (p.160).

This statement implies that the cycle of embodiment of consciousness is the season for re-patterning and changing accumulated unhelpful patterns over many lifetimes. The teachings of Buddhism suggest that the means for doing this is through tapping into the ninth consciousness.

According to Buddhist texts, especially writings of T'ien-t'ia and Nichiren Daishonin, the ninth (Skt), amala-consciousness is the basis for all life functions, completely free from negative effects of present or past memories or actions (Causton, 1995; TEBDC, 2002). The ninth consciousness is the pure life-force energy and the greater self, referred to previously. In this thesis other names used for the ninth consciousness are: Core essence, Buddha nature, Mind, observer Mind, or spiritual essence, depending on the context. Ikeda (2003) reveals the importance of the ninth consciousness in the following:

Tapping our inner wisdom, compassion and life force is crucial. The full value of the nine consciousnesses concept is demonstrated only when one practically brings forth the ninth consciousness, or Buddhahood (p.163).

In this way the ninth consciousness is linked with the person's facility to access compassion for others, intuitive knowing, and life-force. 
In the realm of psychology and psychotherapy, the work of Assagioli in his development of psychosynthesis comes close to Buddhist understandings about the nature of consciousness as described above, although he does not subscribe to any religious means to surface the 'higher self' (Assagioli, 1967).

So that the reader has a snap shot of these complex ideas I include Table 7 , to summarize these aspects of mind-body-spirit.

Table 7: The person in context

\section{Three realms}

1. Individual -5 components, 10 life-states, 10 factors, 9 consciousnesses $=$ mind-bodyspirit

2. Social realm - collective body of individuals

3. Land and place - environmental context

Buddhist writings view all of these aspects as a whole, thus T'ien T'ia synthesizes these aspects of the life-force as the Ichinin Sanzen (TEBDC 2002; Ikeda, 2003). I discuss ideas about life-force below, including Maori, Hindu and Buddhist ideas.

\section{Life-force}

Life-force is variously referred to in literature, depending on the context. Each culture appears to have a name for life-force. For example, India refers to life-force as prana; the source of life, China, names it ch' $i$; energy that is present in all things (Brennan, 1993). In Aotearoa, the Maori term for life-force is mauri, meaning the essence or lifeforce of both animate and inanimate objects. Mauri binds body and spirit together in life (National New Zealand Government Library, 2006).

Energy patterns have been identified throughout the ages which are often referred to as chakra systems (Krieger, 1981; Brennan, 1993; Myss, 1997). The chakra system of energy fields is thought to originate from ancient Indian knowledge at least 4000 years ago. This energy system originates from the base of the spine to the crown of the head, aligning with the main endocrine glands. This enables spiritual essence to penetrate 
aspects of mind and body consciousness, infusing them with life. Each centre is symbolized by a lotus flower providing a metaphor for the principle of cause and effect. The chakras are thought to be transformers of energy that make up and integrate mind-body-spirit. This Eastern energy system is a highly developed and intricate, identified to support health and enable growth of consciousness and enlightenment. Western cultures, especially science, have largely ignored this knowledge, instead focusing on tangible measurable aspects of the body (Woodroffe, 1919; Mookerjee, 1982; Ozaniec, 1994; Krieger, 1997; Brennan, 1993; Myss, 1997; Gordon, 2002; Wilber, 2007a). The configurations of these subtle systems have some variations in ancient and modern literature. In this thesis I discuss only seven chakras associated with the body, although there are at least five relating to the spirit that are referred to by Brennan (1993), and Gordon (2002).

Myss (1997) refers to seven chakras in Anatomy of the spirit, integrating knowledge and understanding of the Hindu chakras, the Christian sacraments, and the Kabbalah tree of life. The word chakra means treasure, or, wheel treasure. It also symbolically represents teaching that subdues the power of earthly desires and false beliefs (TEBDC, 2002). Myss (1997) interprets the chakras as a seven fold system representing stages of development from the physical world to spirituality.

In the past, knowledge of the chakras was transmitted by experienced teachers or masters who supported others to attain enlightenment through various meditative and yogic practices, which enhance spiritual growth (Woodroffe, 1919; Mookerjee, 1982; Ozaniec, 1994). Nowadays as interest in the spiritual dimension grows in the Western world, information about the chakra system abounds. Although this has removed some of the secrecy surrounding this knowledge, practitioners warn that those attempting to gain instant health and spiritual awakening; and use this system to heal others without awakening deep compassion, can be detrimental and dangerous to health. Each chakra although distinct, serves an aspect of physical function, and forms part of a whole picture which synthesizes the physical, emotional, social, and spiritual aspects of people, with the elements of earth, water, fire, air and space / ether. In this way the chakras are collectively viewed as the universal energy field UEF of the life-force itself (Mookerjee, 1982; Brennan, 1993; Ozaniec, 1994). 
These views have some resonance with Rogers (1971) who in a nursing context, framed life-force as humans and environment evolving together. This was the basis for Rogers' theoretical title The Science of Unitary Human Beings. Krieger $(1981 ; 1997)$ drew extensively on the chakra system, or as she termed it, the "human vital energy field", to guide her in the TT process. Krieger (1997) defined therapeutic touch as follows:

Therapeutic touch is a contemporary interpretation of several ancient healing practices that are concerned with the knowledgeable use of therapeutic functions of the human vital-energy field...[h]ealing is concerned with the conscious, full engagement of the therapist's own access to vital-energy flows in the compassionate interest of helping another person who is ill. Healing, then, can be thought of as a humanization of energy (p.16).

Each chakra is associated in some configurations, for example, Brennan (1993) and Gordon (2002) with a rainbow colour, and physical, mental, psychological, and spiritual aspects of growth (Myss, 1997; Brennan, 1993). There is also an association of each chakra, with one of the five elements. The basic functions of each chakra are synthesized in Table 8 with references to the insights of (Myss, 1997; Brennan, 1993). 
Table 8: Energy centres (chakra systems)

\begin{tabular}{|c|c|c|c|c|c|}
\hline NO. & $\begin{array}{l}\text { Predominant } \\
\text { Colour }\end{array}$ & Physical & Emotional/social & Spiritual & Element \\
\hline 1 & Red & $\begin{array}{l}\text { Base of the spine, rectum, } \\
\text { legs, and feet, adrenal } \\
\text { medulla activated in the fight } \\
\text { and flight response. }\end{array}$ & $\begin{array}{l}\text { Associated with sense of } \\
\text { security and survival. Also with } \\
\text { tribal or social connections. }\end{array}$ & $\begin{array}{l}\text { Spiritual principle of } \\
\text { oneness or the } \\
\text { interdependence of life. }\end{array}$ & Earth \\
\hline 2 & Orange & $\begin{array}{l}\text { Sexual organs, large } \\
\text { intestines, bladder, pelvis, } \\
\text { lower vertebrae, appendix. }\end{array}$ & $\begin{array}{l}\text { Power and control, creativity, } \\
\text { sexuality. }\end{array}$ & Respect of others. & Water \\
\hline 3 & Yellow & $\begin{array}{l}\text { Stomach, small intestines, } \\
\text { liver gallbladder, kidney } \\
\text { pancreas, adrenal cortex, } \\
\text { spleen, middle vertebrae. }\end{array}$ & $\begin{array}{l}\text { Trust, fear, self confidence, care } \\
\text { of the self. }\end{array}$ & Self respect, self love. & Fire \\
\hline 4 & Green & $\begin{array}{l}\text { Heart, lungs, shoulders, arms, } \\
\text { breast, thymus gland, thoracic } \\
\text { vertebrae. }\end{array}$ & $\begin{array}{l}\text { Emotions of love, hate, anger, } \\
\text { loneliness, and sense of } \\
\text { belonging. }\end{array}$ & $\begin{array}{l}\text { Compassion and } \\
\text { forgiveness. }\end{array}$ & Air/wind \\
\hline 5 & Blue & $\begin{array}{l}\text { Throat, thyroid, parathyroid, } \\
\text { trachea, cervical vertebrae, } \\
\text { mouth, teeth. }\end{array}$ & $\begin{array}{l}\text { Expression, will, } \\
\text { motivation, autonomy, and } \\
\text { learning. }\end{array}$ & $\begin{array}{l}\text { Having faith enables } \\
\text { action based on choice. }\end{array}$ & $\begin{array}{l}\text { Ether/ } \\
\text { space }\end{array}$ \\
\hline 6 & Indigo & $\begin{array}{l}\text { Eyes, nose, ears, nervous } \\
\text { system, brain, pineal gland. }\end{array}$ & $\begin{array}{l}\text { Ability to reflect on experience, } \\
\text { learning, and synthesize } \\
\text { information. } \\
\text { Emotional intelligence and } \\
\text { control. }\end{array}$ & $\begin{array}{l}\text { Intuitive knowing, } \\
\text { wisdom, openness to } \\
\text { others. }\end{array}$ & All \\
\hline 7 & Violet or white & $\begin{array}{l}\text { Musculoskeletal system, skin, } \\
\text { pituitary gland }\end{array}$ & $\begin{array}{l}\text { Courage, kindness, selflessness, } \\
\text { can see the broad spectrum of } \\
\text { life. }\end{array}$ & Altruism & All \\
\hline
\end{tabular}


My exploration of these energy centres is strongly influenced by my understanding of the interconnection of humans and their environment as coevolving energy fields. This is a notion strongly purported by Rogers (1971); and Krieger (1981). Rogers (1971) proposed that:

Man is a multidimensional energy field whose boundaries extend beyond his visible mass. The human field occupies space-time, including the past and future as well as other dimensions (p.222).

Although Roger's SUHB did not specify the organization of the energy field, her theory was spacious enough to encompass aspects which apply to quantum physics and also to wisdom traditions such as Buddhism.

Nichiren Buddhism, in my reading of it, does not specify a structure for the intake of universal energy, for example, the chakra system, but directs its teaching to the five elements: earth, wind, fire, water, and space, and the nature of consciousness. Nichiren, in his writings, links the five elements to the characters of Myo-ho-ren-gekyo (TWND, 1999).

According to Ikeda (2000) Buddhism regards the life-force of the body as the entity of the Buddha, or the treasure tower. In Nichiren's orally transmitted teachings, the Ongi Kuden, each of the characters of myo-ho-ren-ge-kyo relate to an area of the body, similar to the chakra system. Myo is the head, ho is the neck, ren, is the chest, ge is the abdomen, and kyo is the legs (TWND, 1999; Ikeda, 2000). Nichiren's refers to seven kinds of treasures, relating them to the seven characters of Nam-u-myo-ho-ren-ge-kyo (TWND,1999). The $u$ is not usually pronounced and is therefore often not included; however, its presence makes up the seven characters. The meaning of the seven kinds of treasures according to Nichiren is: " [h] earing the correct teaching, believing it, keeping the precepts, engaging in meditation, practicing assiduously, renouncing one's attachments, and reflecting on oneself' (p.299). In other Buddhist scriptures the treasure tower is symbolized by seven jewels which are: Gold, silver, lapis lazuli, seashell, agate, pearl and carnelian (TEBDC, 2002). This also corresponds with some modern day associations of energy fields, the body, and the healing power of crystals 
(Stein, 2004). In Nichiren Buddhism, chanting is the key to unlocking the reality of life and raising the life-state of the Buddha nature.

It is evident in the Buddhist texts that attention to mind, body, and spirit, are essential to health. The spiritual practice of chanting is related to the body and mind. Jewels of the earth and sea represent the interdependent relationship of persons with the environment (dependent origination) (TEBDC, 2002).

The aspects of Buddhism pertaining to the mind-body-spirit have been discussed in this section and represent my foundational knowledge on this subject which I synthesize in the discussion section of this thesis.

\section{Summary}

This chapter, comprising three sections is a foundational synthesis of nursing, facilitative, dialogical, psychological, and Buddhist theories and philosophies that influence my practice. Unitary, humanistic, and Buddhist philosophies that uphold the integrity of the nurse and the person being nursed are included.

People are viewed contextually as individuals and social beings, existing within an environment or land-base. Like Rogers, Watson, and Krieger, I believe individuals include mind-body-spirit incorporating the UEF. I draw on Nichiren Buddhism and the syntheses of Myss and Brennan, to understand that the UEF is inclusive of layers of consciousness, and components of life. The UEF has an interdependent relationship with the human and non-human environment which I understand is a mirroring effect. Along with Bohm, it is my view that each person has the potential to develop, grow and make sense of patterns that show up in this mirroring process. I resonate with the ideas of others such as Carper, Gadow, Munhall, C. Rogers, and Barker, that in a dialogical relationship of mutual respect, openness, authenticity and compassion; an atmosphere is created for possibilities of change and growth to be facilitated and for healing to occur. Facilitation is an exploratory, non-directional, process that paradoxically can expand the boundaries of counselling while at the same time adhere to its basic tenets. I share the views of Freire and Habermas that this dialogical process is not necessarily egalitarian or straightforward, and like Newman and Parse, I 
see the potential for expansions of consciousness and human becoming in nursing work.

Not all of the ideas presented here in this initial discussion about the development of my understanding of nurse facilitation would be regarded by the diverse authors I refer to in this chapter as compatible. Nevertheless each and every author has made an indelible impression on my developing philosophy. I take these threads forward into Chapter Five to explain the theoretical and philosophical basis of the research philosophy, method, and design that I use to elucidate the work of DNFT and into the body of my work in Part Two. These ideas are further synthesized in Part Three. 
As I frame up the research methodology, method and design of this thesis I return to the original questions that guide this inquiry to search for congruence and resonance (see Chapter Two, p. 29)

In asking: What patterns emerge in the practice of dialectical nurse facilitation of transition? I am not only searching ways to explore patterns but I am also looking for the integration of knowledge and practice. In this chapter I include the dialectical philosophical and epistemological foundation of the research process and its application to my nursing practice. The dialectical inquiry in this thesis is inspired by both Western and Eastern philosophies.

To cover the exploratory and reflective aspects of this thesis I have divided this chapter into three sections. In Section One I trace Western interpretations of dialectical philosophy and give an outline of my application of dialectical reasoning in this thesis drawing on Rowan's (1997) dialectical inquiry. I describe how dialectical philosophy becomes a foundation for nursing praxis.

In Section Two I review the Buddhist concept of the 'Middle Way' and Taoism as they relate to dialectical philosophy. This synthesis of dialectical philosophy forms the basis for my application of dialectical inquiry to the reflective heuristic research method and design in Section Three.

\section{Section One: Western philosophies of dialectics}

In the West, dialectical philosophy is thought to originate from Heraclitus who was a Greek philosopher living around the era of Shakyamuni Buddha. It was thought that his writings influenced philosophers such as Plato who quoted from fragments of his work (Harris, 1994). Harris interprets the fragments of Heraclitus writings from the Greek language, revealing a philosophy of cycles of nature, life, death, and the paradoxical universe. Central to Heraclitus' thinking was the unity of opposites. An example relevant to my way of looking at dialectical philosophy from Harris's 
interpretation is: "It is by disease that health is pleasant, by evil that good is pleasant, by hunger satiety, by weariness rest" (p.47). Rescher (2002) credits Heraclitus as being the originator of process philosophy which looks to change processes as the real ontology. After Heraclitus; Aristotle, Socrates, and Plato, applied dialectics to argue contradictions through rhetorical dialogue and persuasion. Later Hegel, who resonates more closely with Heraclitus, focused on the contradictions within the mind itself and consciousness (Kaufmann, 1965).

\section{Hegelian dialectics}

Georg Hegel in Phenomenology of Spirit conceptualized dialectics as a synthesis of objective and subjective, cognition and emotions, in what he describes as a "circle of reciprocities' (Kaufmann, 1965). To explain further, nothing is discounted; rather, all aspects of a situation, being, or system, are considered in the dialectical process for the purposes of unifying them rather than attempting to arrive at a formal conclusion. According to the writings of Hegel, unity is found in the rhythm existent between object and subject (Kaufmann, 1965). Hegel used the metaphor of the cycles of a fruit tree to illustrate the absurdity of seeking a true or false position in life. For example, when a bud becomes a blossom, using the true-false trajectory, the bud is refuted by the blossom and when fruit forms, the blossom becomes an artifice to the true nature of the tree which is to fruit (Kaufmann, 1965). Rather than going for fixed positions in philosophy, Hegel's view of dialectics was about the individual making meaning out of the experiential world of polarities, so that they could move towards freedom and fluidity. This life-long process of transformations and change through conflict and frustration brings the person to selfhood, in the philosophy of Hegel (Hegel, 1971; Wood, 1998). In this sense, the dialectical perspective is integral (Linehan, 1993; Rowan 1997). To give an example in relation to nursing, Newman (1986) posited health as a conscious synthesis of life's contradictions, ambiguities, and paradoxes, towards transformative awareness through pattern recognition. This awareness does not discount disease processes, suffering, or death; rather, all things that human beings experience bring opportunities for movement and transcendence. 
Hegelian idealism became the subject of critique and refutation by philosophical descendents who in their writings expanded dialectics into the social world in an attempt to challenge inequalities in society (Marx \& Engels, 1968). This gave rise to the emergence of materialism and the basis for socialist philosophy popularized by the works of Karl Marx described briefly below.

\section{Material dialectics}

Karl Marx's material dialectics was developed as an antithesis to Hegelian philosophy which he regarded as idealistic and metaphysical. Instead Marx applied dialectics to the contradictions within the tangible world of social and political systems. Marx refuted Hegel's idealism and his focus on the regions of the philosophy of mind. An excerpt (below) from a letter to his father signals his growing antithetical philosophy to Hegelian dialectics and the gradual proselyting of a new social philosophy (Rühle, 1928).

[I] sat up night after night...[e]xperiencing both objective and subjective perturbations; and in the end I found that my mind had not been greatly enriched, while I had neglected nature, art, and the world...[A] curtain had fallen, my holy of holies had been shattered, and new gods had to be found for the vacant shrine (p.12).

Disillusioned by what Marx experienced in his early focus on the interior workings of thought and reasoning as philosophical development, he began to expand the notion of dialectics to the exterior social world. I include another excerpt form Marx's letter to illustrate this development. "Setting out from idealism, I proceeded to seek for the idea in the real itself" (Rühle, 1928, p.12). This began a search by Marx in the experiential world of the external environment.

Freedom, emancipation and enlightenment were the intentions of both philosophers, however the application of Marxist critical material dialectics in socialist politics in my view, reveals a dualistic tendency of erroneous and right (leftist) thinking to 
surface, inspiring the violent revolutions in Europe and China to communism in the $20^{\text {th }}$ century. Because of this, Marxist philosophy tends to have a mixed reception, although I think it is fair to say that his philosophy is also the foundation for emancipatory praxis based on dialectical thinking. This is especially evident in Freire's work referred to in Chapter Four $(1974 ; 1985 ; 1998)$. Freire placed an emphasis on the dialogical aspects of dialectics in educative settings. Dialogical aspects of dialectics have been furthered in the fields of psychology (see Linehan, 1993; Rowan, 1997) and communication theories (see Baxter \& Montgomery, 1996). I expand on these influences to relational dialectics in the next section.

\section{Relational dialectics}

Relational dialectics tends to shift the emphasis of dialectic reasoning to the discovery of tension patterns within relationships and the search for resolutions (Baxter \& Montgomery 1996). These authors posited that close relationships require a balance between 'connectedness and separateness', 'predictability and spontaneity', and being open to the other while at the same time having the need for privacy; similar to Parse's theory (see Baxter, 1988; Parse 1992; Baxter \& Montgomery, 1996; 1998). Linehan (1993) also suggests the basis of dialectics is on interrelatedness, and context. In transition, one could say that a dialectical perspective draws on the contextual issues of the human and non-human environment and the tensions that occur within that milieu. In the facilitation process of transition, I consider that insights are made through the exploration of these tensions, so that transformation can take place. Exploration of tensions takes account of what Linehan terms the dialectical principle of polarity. This principle is echoed in science, according to Linehan (1993), who uses the example of a single atom that holds the balance of both positive and negative charges. If one were to apply this to disease, one would have to say that within disease there is also non-disease. If we take the dualistic view that only non-disease is desirable, we discount the so-called negative aspect of ourselves and its potential to assist us in the process of transformation and wellbeing.

In the spirit of Heraclitus, inherent in the concept of dialectics is the potential for change. Science holds that change is the only constant. Rogers (1971) concept of 
unitary beings saw change as the dynamic underpinning all life in a process she termed 'helicy'. Rogers (1971) proposed a nursing theory that is open to possibilities and that recognizes that the "[r]esolution of health problems is directly related to the dynamic innovative potentialities of life to transcend itself' (p. 222). Linehan (1993) suggests it is "tension that produces gradual change, punctuated by spurts of sudden shifts and dramatic movement" (p.34). I would add that it is the awareness of tensions through exploration that motivates the movement of ideas and paradigm shifts. In this sense, the facilitator acts as a 'change agent' by facilitating exploration in a dialogical process. This is a process that Linehan refers to as 'dialectical persuasion', or exploring the tensions in the context of a therapeutic relationship. Linehan (1993) believes "the spirit of a dialectical point of view is never to accept a final truth or an undisputed fact" (p.34). I do not think she means to imply that one should not search for truth in a situation but that truth is always evolving; and therefore, cannot be finite or absolute. In Linehan's work with people with borderline personality disorder, where the notions of right or wrong, good or bad are often rigidly held views leading to a sense of impasse; the process of dialectics has the potential to free the person up from this position. Underpinning Linehan's work is the philosophy of Buddhism, although she does not specify the particulars of its influence.

I offer a synthesis of dialectical Western philosophies in Table 9. This shows the theories of compatibility and divergence from the various schools of dialectical thought. I find that I resonate to some extent with aspects of each. For example, the nature of my dialectical nursing practice is process orientated which is the basis for my reasoning of the dynamics that go on in the relationship. I draw on relational dialectics to find inner tensions, congruence, and contradictions in the relationships with the people I see. This also includes material dialectics in the exploration of sociopolitical alienation, although my focus is on the development of inner change rather than external emancipation. 
Table 9: A synthesis of Western dialectical philosophies

\begin{tabular}{|c|c|c|c|}
\hline Origins & Hegelian & Material & Rela \\
\hline 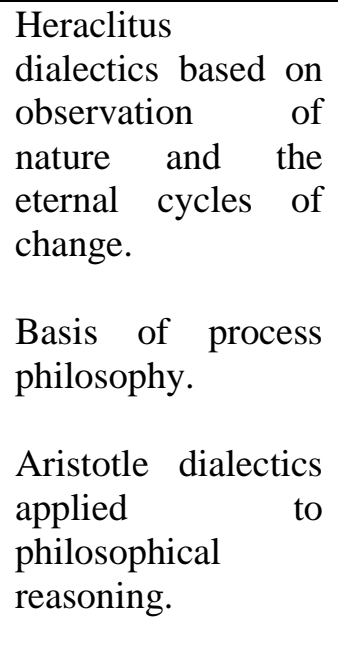 & $\begin{array}{l}\text { nature and } \\
\text { philosophical reasoning } \\
\text { to the interior world. } \\
\text { Focused on self- } \\
\text { awareness. } \\
\text { Unity of contradictions. } \\
\text { Looks for essence of } \\
\text { self. } \\
\text { Personal transformation } \\
\text { has a flow on effect to } \\
\text { society. }\end{array}$ & $\begin{array}{l}\text { Looks for } \\
\text { contradictions \& } \\
\text { alienation in socio- } \\
\text { political world. } \\
\text { Goes for social } \\
\text { emancipation and } \\
\text { revolution. } \\
\text { Employs a critical } \\
\text { dialectic. } \\
\text { Externally focused } \\
\text { on tensions in } \\
\text { society. }\end{array}$ & $\begin{array}{l}\text { Focused on } \\
\text { interrelatedness \& } \\
\text { context. } \\
\text { Goes for resolution of } \\
\text { social and inner } \\
\text { tensions and } \\
\text { contradictions. } \\
\text { Looks at internal and } \\
\text { external } \\
\text { contradictions. }\end{array}$ \\
\hline
\end{tabular}

\section{Rowan's influence on this dialectical inquiry}

Western dialectical philosophers such as Hegel intellectually sought a deeper understanding of the 'space between' negative and positive poles by attempting to clarify it in relation to human experience and the nature and essence of the self. Rowan, in making sense of Hegel's dialectical philosophy, posited levels of thinking and moments and cycles of questions as a dialectical methodology for research (Rowan, 1997).

Rowan did not propose a recipe for dialectical inquiry; however, he suggested a number of configurations for social science research using the principles of dialectical philosophy and encompassing material and relational dialectics. I now describe these in relation to the topic of study. Rowan believed there are three things that researchers should bear in mind in dialectical research. These are: alienation, social change, and the research cycle. These three concepts, outlined below, are interwoven into my adapted version of Rowan's (1997) three levels of dialectical thought; six moments of being; and six cycles of questioning, explained in Section Three (see p.129-139). 
Alienation comes about whenever reduction of human actions occurs. When people feel alienated there is a sense of isolation and disconnection. Alienation could occur in relation to participants if they are not actively involved in the research process, and can also apply to the researcher if consultation does not take place at multi levels - in this case with participants, and supervisors. Alienation can also occur if the researcher is not responsive to the research process and content.

Social change is the by-product of dialectical research (Rowan, 1997). The underlying question here is: Does the research make a difference to the researcher, participants, and the subject being studied? For example, changes in practice for the researcher, raised awareness in the participant, and an opening to new understandings in the nursing field nationally and internationally.

I describe aspects of Rowan's dialectical research philosophy under the headings: Primary level thinking, existentialism, phenomenology, social level thinking, and realized level thinking, as a preliminary to a more detailed explanation of my application of it in Section Three.

Primary level thinking

According to Rowan (1997) primary level thinking, is subjective, emotional and personal. This idea is similar to Carper's (1978) conceptualization of aspects of nursing knowledge as 'personal knowing'. Carper (1978) believes personal knowledge, '[p]romotes wholeness and integrity in the personal encounter' (p.20). In Jacobs-Kramer and Chinn's (1988) interpretation of Carper's patterns of personal knowing; reflection and self-examination are the ways in which we develop awareness of our authentic self, as distinct from the 'disclosed self', or as Rowan would put it, the self we reveal at the social level. It is through this self-reflective process that selfawareness is possible for congruity between the genuine self and the disclosed self. Both personal knowing and primary level thinking require reflection on subjective, emotional, and existential aspects of experience. Therefore the philosophies of existentialism and phenomenology, briefly described below, are important in surfacing primary level thinking. 


\section{Existentialism}

The key concern in existentialism is to make sense of one's existence. Examples of existential questions are: Who am I? Why am I here? These questions, for many people, may be formed briefly in the quiet moments of commonplace existence in dayto-day life. Mostly, they are likely to come up in times of transition, or crises; especially in matters of life and death. For some, these questions can precipitate a crisis, sometimes known as an existential crisis. This is often the time that people seek support and guidance, either turning to or against religion. Existentialism has been the subject of exploration by a number of philosophers such as Keirkegaard and Nietzche, in the $19^{\text {th }}$ century, and Buber, Jaspers, Sartre, Husserl, Heidegger in the $20^{\text {th }}$ century (Moran, 2000). The standpoints of these theorists are vastly different. However, they all acknowledge the importance of subjective experience to inquire after the nature of the meaning of human existence and consciousness.

In nursing, Travelbee (1971); Watson (1979); Gadow (1980); Parse (1981); Newman (1986); Benner and Wrubel (1989) among others, address the issue of existential meaning in their respective theories.

\section{Phenomenology}

Phenomenology has been written about by philosophers interested in the conscious reality of human beings in their life-world contexts (see Sartre 1957; Gadamer, 1989; Heidegger, 1996). Munhall (1994) suggests the essential concepts of phenomenology pertain to embodied consciousness; which is the capacity of the person to experience the world through the sensory mechanism. This has some resonance with the Buddhist construct of the first five consciousnesses. Munhall (1994) proposes "At any point in time and for each individual, a particular perspective or consciousness exists based on the individual's history, knowledge of the world, and perhaps openness to the world" (p.15). Perception relates to the person's ability to interpret the consciousness raised by sensory information. It is the perception of the person's experience, which informs about individual experience. What one is seeking to do as a researcher, in capturing the essence of that experience, is to represent the personal perception as accurately as possible. 
The search for meaning, through the exploration of perceptions arising from personal experience, provides an opportunity for growth, ideological shifts, or as Newman (1986) puts it, expansions of consciousness. It seems fitting that nurses become involved in this exploration with people; after all, many of the occasions in which people come into contact with nurses are at crises and dying moments. The sad fact in many of these occasions is that the opportunity to explore these questions is missed, due to the often acute focus of nursing work. If it isn't missed, it may be passed onto others, such as counsellors or psychologists. The 'now' moment gets overlooked because of waiting times. It is my view that existential dilemmas are best explored and reflected upon when they arise, if there is to be a shift in consciousness. The exploration of existential dilemmas in a dialectical process is the basis of 'human becoming' (Parse, 1992).

Walker (1996) in his synthesis of the theories of Parse and Watson proposes that "Humans must grapple with ultimate meaning, the discovery of life's purpose. But meaning also refers to personal confrontation with each moment of everyday existence" (p.990). Existential meaning was linked with personal freedom by Sartre (1957), who believed that authenticity and freedom of choice are the challenges we face. These challenges are experienced in social contexts highlighting Rowan's (1997) social level of thinking.

\section{Social level thinking}

In order to reveal an authentic self, it is important to know whether social norms are being adhered to in an obligatory way and to what extent people perceive they are free to be themselves. For example, one of the social tensions that I experience in shaping this research process is in the role of nursing itself. Public and other health professionals' perceptions are often different from nurses' perceptions of their role. The question that arises for me, from tension in the social context, is - do all of these perceptions support a role for nurses facilitating transitions? Social level thinking requires a socio-political context and explanation of the tensions that exist, such as the pressure to conform to social norms or to be involved in reformation. Deciding whether or not to conform is often determined by the person's social need to be accepted. In Rowan's (1997) summation of social level thinking, one could continue 
to seek approval; thus, maintaining the status quo, or, move into realized thinking. To stay in the social level eventually creates tension that can lead to realizations and reformations. Without tension in the social level, there is unlikely to be any breakthrough in thinking or change.

\section{Realized level thinking}

According to Rowan (1997) realized level thinking is the key to self-awareness and a growth in consciousness, which cannot precede the initial ideological shift brought about by tension in the social level. Rowan further suggests that if we try to go to a state of open awareness before we make a shift in our thinking, through a synthesis of subjective experience, the awareness is distorted by un-interpreted emotional responses, coming from primary level thinking. Realized thinking; therefore, is the synthesis of emotional experience with objective meaning making. It enables us to make constructive use of experience without getting trapped in the emotional responses brought up in the primal memory of it. For me, realized level thinking made sense when I applied the principles of the Buddhist understanding of the five components, in relation to the development of enlightened consciousness, explained in Chapter Three (TEBDC 2002). Reaching realized levels of awareness can sometimes lead to arrogance and contempt for those who may still be making sense of primary level experience. It could also lead to an overvaluation of subjective emotional experience versus intellect, and become dichotomous thinking (Rowan 1997). Raised consciousness, I suggest, can create a dialectical tension between knowledge gained primarily through learning, and wisdom acquired through both learning and deep reflection on experience. I believe the latter involves transcendence from egoist states, arising from knowledge through learning and realization, especially if it is selforientated.

I would argue that the clarification of the essence of self does not occur entirely within an emotional and cognitive loop and ways of knowing as implied by the work of Carper (1978) Linehan (1993) and Rowan (1997). Thus I find that the philosophy of the Buddhist 'Middle Way' takes me closer to the spiritual realm of human experience. Dialectical principles are also the basis of Taoism. I expand on these philosophies, as they pertain to dialectical ideology in Section Two. 


\section{Section Two: Eastern philosophies of dialectics}

The dialectical principles which underpin Buddhist and Taoist thought also show some compatibility with unitary schools of nursing theory, and dialogical, psychological, facilitative, learning and education theories previously reviewed. In this section I discuss the influence of 'the Middle Way' Buddhist philosophy and Taoism on my view of dialectics.

\section{The Middle Way}

The meaning of the Middle Way is in essence a spiritual concept transcending the notion of duality and in a Buddhist sense signifies the mystic law of life (TWND, 1999). There are at least three main interpretations of the Middle Way in Buddhist philosophy based on Shakyamuni's Sutras (it is important to bear in mind that over the span of Shakyamuni's teachings he gradually unfolded aspects that were expedient for the time and the ability of his students to understand, therefore these interpretations represent the gradual insight into the deeper meaning). First, the Middle Way, briefly explained in Chapter One, can refer to a rejection of the two polarities of austere and hedonistic practices, and instead embrace a doctrine of the eightfold path ${ }^{17}$ (TEBDC, 2002).

Second, the Middle Way can refer to non-substantiality, expounded by Nagarjuna ${ }^{18}$ (around 150-250). One of Nagarjuna's four treatises on the philosophy of Buddhism was entitled The Treatise on The Middle Way. In the Treatise, also known as the Madhyamika Doctrine, there is a passage known as the eight negations ${ }^{19}$ which clarifies non-substantiality (TEBDC, 2002). Embedded within Nagarjuna's teaching on non-substantiality is the concept of dependent origination which holds self and environment in a synergistic and interdependent relationship.

\footnotetext{
${ }^{17}$ The eightfold path refers to the principles of attaining freedom from suffering. These paths include: Right views, right thinking, right speech, right action, right way of life, right endeavour, right mindfulness, and right meditation (TEBDC, 2002).

${ }^{18}$ A revered $13^{\text {th }}$ successor of Shakyamuni Buddha

${ }^{19}$ The eight negations relates to the principle of the true nature of all things and are: Neither birth nor extinction, neither cessation nor permanence, neither uniformity nor diversity, neither coming nor going (TEBDC, 2002).
} 
Third, T'ien-T'ia reclassified them and posited the superiority of the Lotus Sutra. T'ien-T'ia proposed that the Middle Way is neither temporary existence nor nonsubstantiality, but has the qualities of both. T'ien-T'ia integrated the doctrines of nonsubstantiality, dependent origination and the Middle Way, developing a practice of meditation based on these tenets, to lead people to enlightenment (TEBDC, 2002).

The Middle Way according to Nichiren Daishonin does not denote a point between two poles but refers to the mysterious and elusive quality of the changing cycles of life and death, going beyond a sense of permanency (TWND, 1999). In other words birth and death are not beginning and end points. Rather, they are moments in an ever changing cycle. Although this implies a concept of eternity, eternity is not seen as a permanent state.

Many of the threads of Buddhist philosophy of the Middle Way find resonance with nursing philosophies based on energy fields, especially Rogers (1971). Rogers principle of integrality resonates with the Buddhist philosophy of dependent origination. The main point of difference is Roger's rejection of causality and determinism (Rogers, 1971). The Buddhist philosophy of Nichiren Daishonin also rejects determinism whilst at the same time holding the principle of cause and effect central to its tenets. Ikeda (2003) clarifies the differences in some scientific understandings of causality and the Buddhist understanding, which transcends time and space. Ikeda (2003) explains these differences as follows,

People sometimes equate causality ...[w]ith determinism, the belief that there is no free will. This is likely from their conception that a given cause must inevitably produce a given effect, which one can do little about. The deterministic view, however fails to account for our potential to alter the meanings of our past deeds through the causes or actions we initiate from now on (p.180).

The potential to alter the course of cause and effect is central to the practice of Nichiren Daishonin's Buddhism, and in fact remains firmly embedded within the diverse schools of thought in Buddhism. In the West, I think it is fair to say that there 
is a tendency for people to converge Eastern ideas relating to dialectics. I look at Taoism as an example of this.

\section{Taoism}

Taoism comes from ancient Chinese philosophy and has some resonance with dialectical philosophy and the Middle Way. Similar to the writings of Heraclitus, the Tao is based on two laws governing physical change in the universe. One law, known as polar reversal shows in the nature of all things and beings, there is an opposite. For example, in life, the physical body has both the properties for growth and degeneration. The second law, known as periodicity, manifests in cycles and rhythms, for example, the changing seasons (Wing, 1979). Wing (1979) defines The Tao as a "[w]ay or gate through which all things move" (p.12). Chinese philosophers use the metaphor of water to explain the Tao. For example, water is always flowing, wearing down resistance, filling deep wells, and continuously flowing on. A Taoist way of living is to find a harmonious path of least resistance (Wing, 1979). The concept of good and bad does not exist in Taoist ideology; rather, all dualities are interdependent on one another. This is represented in the Yin-Yang symbol. Yin represents negative, and Yang represents positive. Yin also represents female, and Yang, male.

These polarities and their symbols are the basis for the Book of Change or I Ching, supposedly authored by an ancient ruler of China, Fu Hsi, who, as legend has it, based 64 hexagrams of the I Ching on the patterns revealed on the shell of a tortoise (Wing, 1979). His writings were later expanded by the philosophers and sages; Lao Tzu and Confucius, among others. The Book of Change hexagrams were the basis for universal archetypes described by Jung (1970) in The Archetypes and the Collective Consciousness. These archetypes according to Jung dwell in the regions of the unconscious mind, performing an unsolicited and uncensored synthesis of the ego self and the real self.

The notion of moving towards harmony through a pathway of least resistance is not a view agreed upon in Nichiren Buddhism. The mystic quality of the Middle Way of Nichiren Buddhism is the vital discovery of the life-force itself or the real self. This discovery is related to the realization of inherent potentials, giving people the power to bring about these potentials. This is an energizing process rather than a peaceful one. 
In this sense, from my own perspective, I would tend to include the notion of harmony and peacefulness with the experience of joyfulness. Joyfulness, as I understand it is the highest state of wakefulness, or enlightenment which can accommodate all things, so called good-bad, life-death; incorporating harmony and turbulence all-at-once.

In summary, Nichiren Buddhism focuses primarily on the Lotus Sutra as a synthesis of the other sutras, emphasizing a specific practice to reveal Buddha nature. Whereas Taoism turns it attention to the rhythms of nature and the cyclic aspects of life and death. It does not posit a pathway to enlightenment other than living by the laws of nature and searching for harmony between the natural polarities existent in all life.

\section{Surfacing patterns for dialectical inquiry}

A review of Eastern and Western philosophies of dialectics, especially, Hegelian, Marxism, Middle Way and Taoism, is woven into a dialectical inquiry for research and relational dialectics for facilitating transitions. The study of Western and Eastern dialectics surfaces polarities and paradoxes in the philosophies that I have explored. Examples of this include the polarity of Hegelian internal transformation and Marxist external revolution. Relational dialectics achieve some integration between these poles by seeking a resolution of inner and social tensions. Both Heraclitus and Taoism look for a universal law in nature. Buddhism finds this universal law existent in each person; the discovery of which leads to enlightenment. In the weave and warp of these divergent ideologies I find a pattern for the individual, the social context, and the interdependence of self and environment, which I thread into the method and design of the thesis in Section Three, and the practice of DNFT itself. I describe these patterns below.

The pattern of the individual

Integration within transitional cycles of life and death in people makes up my understanding of the physical, emotional / cognitive and spiritual self. Within a facilitated integration, people have the potential to surface the meaning of these cycles through conscious awareness and self-reflection. Western dialectical philosophy influenced by Hegelian thought has a way of reasoning and integrating the internal paradoxes and contradictions, thereby raising awareness within the individual. Eastern 
influences such as Buddhism and Taoism tap into the universal patterns to reveal a deeper layer of integration which occurs in the Ichinen Sanzen or life-force itself.

The pattern of social context

The development of Western dialectics from a way of working out contradictions in the interior consciousness to working with contradictions in the social and political context was furthered by the work of Marx and Engels (1968). To some degree the emergent patterns of social order and disorder have been explored by Rowan in the social level of thought. Baxter and Montgomery (1996) posited a theory of relational dialectics and Linehan (1993) conceptualized a way of working with tensions known as dialectical behavioral therapy which I find helpful in both my work and research process.

From an Eastern perspective, Nichiren Buddhism extends the realm of the social context embracing the inextricable relationship of people with one another. I use the word inextricable here because in a Buddhist sense, the connections between people in the social world are linked by the principle of karma, and transcend time and space. For example, my study of dialectics links me with the philosophies of people past, present, and future that explore these ideas and practice them. On that basis I do not suppose there are any random connections between people and ideas.

The pattern of interdependence between the individual, social context and the physical environment

From a Western perspective Heraclitus, Hegel and Marx sought to work out their understanding of dialectics by observing nature. In a philosophical sense, the pattern of interdependence between the individual, social context and the physical environment is found in the tenets of Buddhism, and Taoism. In Aotearoa this pattern is embedded in the culture of Maori, reflecting a deep spiritual relationship with the land-base. In Nichiren Buddhism the land and living conditions reflect the life-state of the individual and the community, emphasizing the importance of the interconnectedness of the people and the places they live. Within this thesis this interrelationship underpins transitional work and is embedded in my individual, social, and environmental context. 
I take these three patterns of dialectics into the method and design of this thesis in Section Three so that my practice of DNFT can be revealed.

In Section Three I integrate dialectical philosophy into my way of inquiry which pertains to both the method and design of the research process and also the practice of DNFT. I explain how I draw on theories about self-reflection to make transparent realizations about practice from the supervisory process. These provide the basis for the research method and design.

\section{Section Three: A dialectical heuristic design for research}

In this section, I explicate the dialectical heuristic design I use to address the what, why, and how of my role as a researcher and as nurse facilitator. The design of this thesis incorporates a deep reflection on journals from practice supervision, peer review, and case notes from DNFT work, providing the basis for an in-depth exploration of praxis. The method I use includes: data collection and analysis, ethics, and relevance with reference to the work of Rowan (1997); Moustakas (1990) and Carper (1978). Practice supervision, peer review, and case review in the context of nursing, and with respect to this thesis, are detailed in this section. I expand on Rowan's (1997) levels of thinking, integrating primary, social, and realized levels with Carper's (1978) patterns of nursing knowing in the following section.

\section{An integration of levels and moments of dialectical inquiry with nursing ways of knowing}

The acquisition of knowledge in relation to nursing was the subject of Carper's (1978) theory on the Fundamental patterns of knowing. Carper posited four patterns of knowing from "[a]n analysis of conceptual and syntactical structure of nursing knowing" (p. 13), which I have alluded to so far. These are: Empirics, the science of nursing; Aesthetics, the art of nursing; Personal, knowing self; and Ethics, the moral aspect of nursing. I have gradually uncovered aspects of her contribution to the epistemology and ontology of nursing which I continue throughout this thesis. At this point I embed aspects of these four patterns into my dialectical inquiry described in Section One, to hold the relevance of developing nursing knowledge within a 
dialectical inquiry framework. Table 10, clarifies my integration of these levels of thinking and ways of knowing into this inquiry.

Table 10: Clayton's way of integrating feelings, thoughts, process and content, based on Rowan's dialectical levels of thought and Carper's ways of knowing

\begin{tabular}{|c|c|c|}
\hline Primary level & $\begin{array}{l}\text { Content } \\
\text { Personal \& Aesthetic knowing } \\
\text { Pre-understandings and } \\
\text { assumptions }\end{array}$ & $\begin{array}{l}\text { Process } \\
\text { Explore internal tensions and } \\
\text { paradoxes } \\
\text { Be aware of feelings } \\
\text { Be aware of intuitive knowing } \\
\text { i.e. gut reactions } \\
\text { Notice feelings of attraction and } \\
\text { feelings of distance and discord }\end{array}$ \\
\hline Social level & $\begin{array}{l}\text { Socio-political contexts } \\
\text { nationally and internationally } \\
\text { Ethical and moral concerns } \\
\text { Cultural context in Aotearoa } \\
\text { Religious contexts } \\
\text { Change consciousness }\end{array}$ & $\begin{array}{l}\text { Explore pressures to be in the } \\
\text { status quo, pressures to change } \\
\text { within self and external forces } \\
\text { Notice the difference between } \\
\text { freedom of thought and being } \\
\text { real, and obligatory tendencies } \\
\text { in self and others } \\
\text { Be aware of feelings of } \\
\text { alienation } \\
\text { Be aware of responses to } \\
\text { political cultural and religious } \\
\text { movements }\end{array}$ \\
\hline Realized level & $\begin{array}{l}\text { Insights from reflection on } \\
\text { practice, theories, philosophies } \\
\text { and empirical evidence from } \\
\text { research }\end{array}$ & $\begin{array}{l}\text { Synthesis of personal knowing } \\
\text { with extant theories and } \\
\text { philosophies. } \\
\text { Notice resonance and } \\
\text { dissonance. } \\
\text { Be aware of contradictions and } \\
\text { tensions within established } \\
\text { theories. } \\
\text { Be aware of own philosophical } \\
\text { voice }\end{array}$ \\
\hline
\end{tabular}


I now explain how in the context of this thesis I ascribe the infiltration of Rowan's (1997) research methodology with reference to Carper's (1978) work into the practice world of DNFT as a praxiological process. An example of praxiological inquiry from a nursing perspective is in Margaret Conner's (2002) doctoral thesis. She employed a praxiological inquiry process to show the integration of research as nursing praxis, in her reflections of the dialogical relationship with a person living with chronic illness, inspired by Gadamarian hermeneutics. In her understanding and synthesis of praxiological inquiry she showed an ongoing dialectic within nursing between the notion of praxis and practice. Conner revealed a tension in nursing literature of trajectories that emphasize a theory and practice gap in nursing and those that look for unity and connection in their conceptions of nursing as praxis. Reflexivity and reflective practice were seen by Conner as the way into uncovering the praxis of nursing without succumbing to prescriptive theorizing in nursing.

In a similar way to Conner (2002), I integrate Rowan's dialectical philosophy and Carper's patterns of nursing knowing, to reflect the nature of my experience in shaping a dialectical framework for facilitating transitions as described in the next section. Although others including: Jacobs-Kramer and Chinn (1988); White (1995); and Johns (2004b) have extended Carper's patterns of nursing knowing, I chose to focus on the four patterns she proposed to enable me to make a transition from the complexities of dialectical praxiology and philosophy to nursing. This helped me to find a way to explicate my nursing knowing in language and conceptual frameworks already familiar to nurses. I include Table 11 in 6 parts to show my integration of dialectical philosophy to the research and practice of DNFT.

\section{Six moments in a dialectical research cycle}

Rowan's (1997) six moments in the dialectical research cycle flow on from the three levels of thinking, and philosophies of existentialism and phenomenology. They are: Being, thinking, project, encounter, making sense, and communication. These 'moments' are adapted, in this thesis, to reflect the nature of my experience in shaping a dialectical framework for facilitating transition. Descriptions and meanings of the six moments follow, along with my adaptations. 
Being is multidimensional, reflecting the human experience of being in the world and living life. Rowan draws on the philosophy of Martin Heidegger's phenomenology, specifically his major work Being and Time (1996), which describes the experience of 'Being-in-the-world' as everything we see or hear, rather than in our conscious knowing. It is embedded in our culture as memory, and our perception and interpretation of memory. In this thesis, 'being' is my lived experience as a human being, as a nurse and as a nurse facilitator of transition, in transition. It incorporates Carper's (1978) notion of personal knowing, “[b]roadly characterized as subjective, concrete and existential (p.20). It is the unearthing of my authentic self, which is making contact with other selves in transition. In that process masks are removed, as growth in self-awareness is taking place in the synergy of supervision, peer review, and practice. This aspect of self-awareness constitutes the creative expression of the art of nursing, referred to by Carper as aesthetics. At this point I embed aspects of these four patterns into my dialectical inquiry alongside Rowan's work to hold the relevance of developing nursing knowledge within a dialectical inquiry framework.

Table 11: Clayton's dialectical self questioning process in research and practice, based on Rowan's dialectical moments of a research cycle and Carper's ways of knowing

\begin{tabular}{|l|l|}
\hline Part 1: Being in research cycles & In practice (personal \& aesthetics) \\
\hline $\begin{array}{l}\text { What have I come to know about nursing } \\
\text { transition dialectics \& facilitation? }\end{array}$ & Am I being real? \\
Am I aware of my own agendas? & Am I aware of my internal responses? \\
Why am I in this field? & Am I aware of inherent tensions? \\
$\begin{array}{l}\text { Am I taking responsibility for my } \\
\text { feelings? Am I aware of inherent } \\
\text { tensions? }\end{array}$ & Am I in the present moment? \\
Do I feel supported? & \\
\hline
\end{tabular}

According to Rowan (1997) Thinking, is an introspective process of gathering data, perceiving, conceptualizing, and looking for patterns and points of reference. It is a consciousness-raising activity, which draws on both subjective knowing and factual 
information. Thinking comes from the information which is brought to light in 'being' and what is already known and written about by others. In this thesis I think about nursing theories and philosophies, about nursing roles, ethics and socio-political contexts, such as new nursing roles in Aotearoa. Thinking incorporates Carper's (1978) empirical and ethical knowing as I review the development of nursing epistemology through an examination of nursing research. At some point, thinking is not enough and something has to be done. Rowan (1997) terms this 'project' because it comes about through the firming up of ideas in the thinking moment.

\begin{tabular}{|c|c|}
\hline $\begin{array}{l}\text { Part 2: Thinking in research } \\
\text { cycles }\end{array}$ & In practice (empirics, ethics) \\
\hline $\begin{array}{l}\text { Do I have the resources? } \\
\text { Am I focused? } \\
\text { Am I motivated? } \\
\text { Am I reading widely? } \\
\text { Is there congruity between the question } \\
\text { and the method? } \\
\text { Am I reflective and reflexive? } \\
\text { What is the relevance of this to me, to } \\
\text { others and the nursing profession? } \\
\text { Am I keeping up with research? }\end{array}$ & $\begin{array}{l}\text { Am I making sense of patterns? } \\
\text { Am I aware of contexts? } \\
\text { Do I explore belief systems, values, and } \\
\text { thought patterns with people? } \\
\text { Am I able to apply theoretical frameworks to } \\
\text { practice? } \\
\text { Do I have highly developed assessment } \\
\text { skills? } \\
\text { Can I facilitate learning in others? } \\
\text { Am I questioning my process in supervision } \\
\text { and peer review? } \\
\text { Am I open to learning? }\end{array}$ \\
\hline
\end{tabular}

In the project moment, plans are made for the implementation of practice, in my case, the practice of nurse facilitation of transition. For the purposes of this thesis, I have adapted this moment from project to doing. I do this because doing reflects the active phase, which in this situation is not specifically a project; rather, it is an action being taken that is evolving and does not necessarily have an end point. Doing includes both planning and implementation. Thus, it involves the description of the application of theories of nursing into the day-to-day world of practice (Carper, 1978). 


\begin{tabular}{|c|c|}
\hline Part 3: Doing in research cycles & $\begin{array}{l}\text { In practice (empirics, ethics, personal, } \\
\text { aesthetics) }\end{array}$ \\
\hline $\begin{array}{l}\text { Do I have the resources, the finance, the } \\
\text { backing? } \\
\text { Do I invest myself? } \\
\text { Do I understand the socio-political } \\
\text { context? } \\
\text { Do I exclude anybody? } \\
\text { Do I reflect on my nursing practice? } \\
\text { Do I know my limitations? } \\
\text { Do I allow things to evolve? }\end{array}$ & $\begin{array}{l}\text { Do I focus on the person and their transition? } \\
\text { Do I notice paradoxes, tensions, and patterns } \\
\text { in people I work with? } \\
\text { Do I check them out? } \\
\text { Do I allow the session to evolve? } \\
\text { Am I flexible in my approach? } \\
\text { Do I address transitions in an integral way? } \\
\text { Do I follow cues? }\end{array}$ \\
\hline
\end{tabular}

This leads on to the fourth moment proposed by Rowan (1997), which he terms 'encounter'; in my case, engagement with people in transition and with my practice supervisor and peer reviewer. Carper (1978) proposes that personal experiential knowing through encountering people in a therapeutic context "[p]romotes... engagement rather than detachment" (p.20). This moment is experiential; therefore, I adapt Rowan's term encounter to experiencing.

Experiencing involves encountering and being with those in transition. As a facilitator, it includes an active process of supporting change, which, as stated previously, includes a philosophy of anam cara, supportive mentoring, and kalyanamitra: a process of noticing and addressing avoidance, resistance, and the false self. 


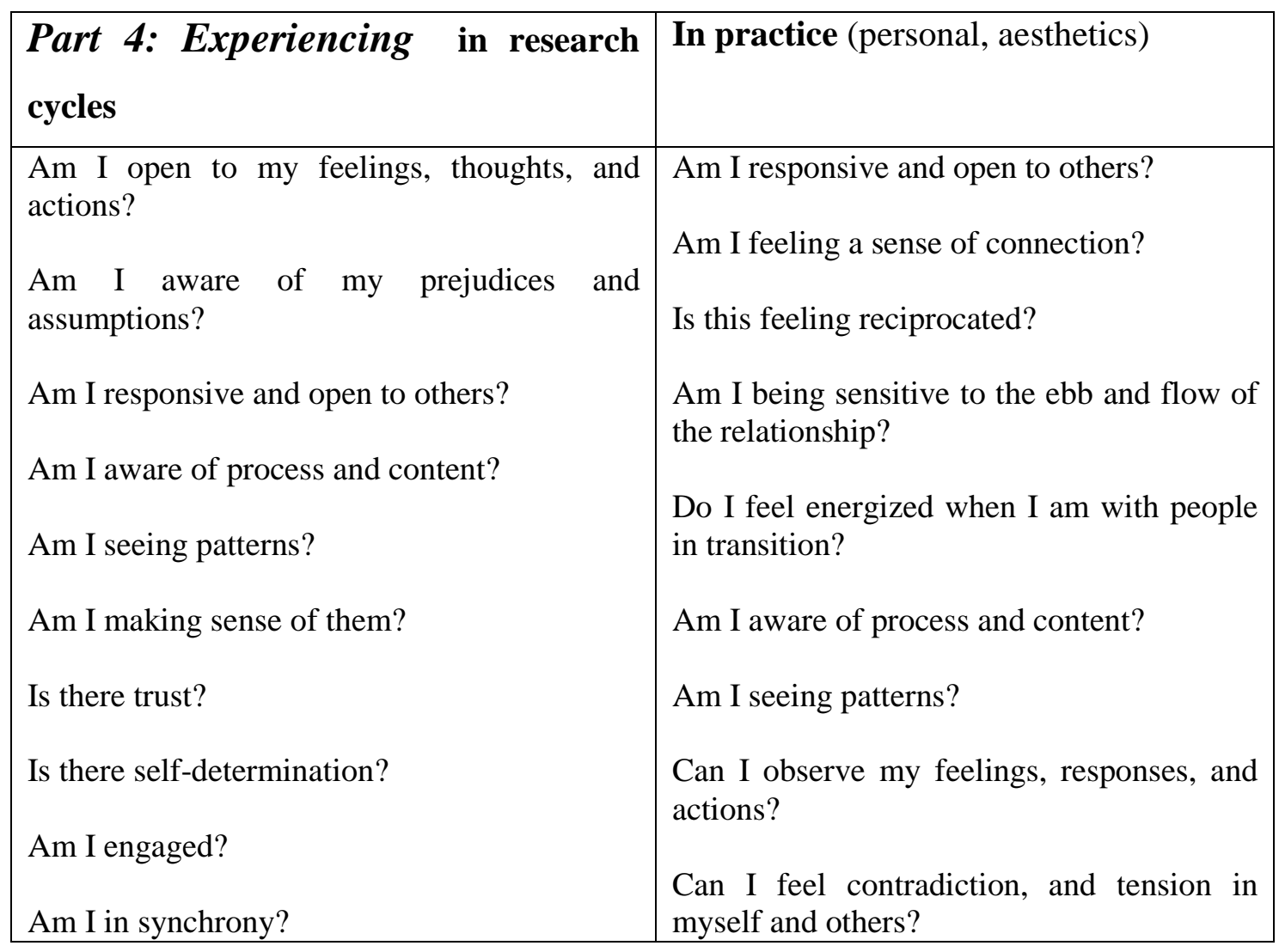

Moments of doing and experiencing, at some point, have to be processed and evaluated. Usually this involves integrating being, thinking, doing, and experiencing, through reflection' and empirical and ethical analysis. Rowan (1997) calls this 'making sense', which is the fifth moment.

I have renamed making sense as integrating, because in this thesis it involves a synthesis of all of the four moments. Integrating involves the bringing together of stories of practice, reflective synthesis, and literature reviews encompassing all aspects of nursing knowing. It is an existential moment, where phenomena become evident from supervision and case reviews, and where consciousness is raised and realizations become apparent. From here the moment of 'communicating', Rowan's (1997) sixth moment is achievable. 


\begin{tabular}{|c|c|}
\hline Part 5: Integrating & $\begin{array}{l}\text { In practice (empirics, ethics, personal, } \\
\text { aesthetics) }\end{array}$ \\
\hline Am I integrating skills for analysis of data? & Do I 'walk the talk'? \\
\hline $\begin{array}{l}\text { Have I reached saturation point with the } \\
\text { data? }\end{array}$ & $\begin{array}{l}\text { Am I reflecting on my practice? } \\
\text { Am I addressing both process and content? }\end{array}$ \\
\hline Can I pull this together? & Am I aware of my thoughts and feelings? \\
\hline $\begin{array}{l}\text { Does it make sense? } \\
\text { Is reflection bringing about new awareness? }\end{array}$ & $\begin{array}{l}\text { Am I noticing incongruities between words } \\
\text { and action? }\end{array}$ \\
\hline $\begin{array}{l}\text { Does analysis bring about consciousness in } \\
\text { a meaningful way? }\end{array}$ & Am I picking up on paradoxes? \\
\hline What new patterns are forming? & Am I exploring tensions and conflicts? \\
\hline $\begin{array}{l}\text { Am I seeking clarification from } \\
\text { participants? } \\
\text { Is the data relevant to them? }\end{array}$ & $\begin{array}{l}\text { Are control patterns being attended to? } \\
\text { Am I taking responsibility for my feelings? } \\
\text { Do I go away from the session feeling } \\
\text { energized by the work? }\end{array}$ \\
\hline $\begin{array}{l}\text { Am I raising awareness about paradoxes in } \\
\text { a meaningful way? }\end{array}$ & \\
\hline $\begin{array}{l}\text { Do the findings resonate with other } \\
\text { literature on the subject? }\end{array}$ & \\
\hline
\end{tabular}

Communicating is possible when there has been enough time to digest the realizations that have occurred. I understand communicating to be the 'show and tell' moment of the research process. It involves telling the story of practice and explaining the underpinning theories and philosophies. It is a moment of clarity, where others get to hear about the work of DNFT. It is also a moment of release, into the evolutionary phase of discourse and critique. 


\begin{tabular}{|l|l|}
\hline $\begin{array}{l}\text { Part 6: Communicating (all aspects } \\
\text { of knowing in research cycles) }\end{array}$ & $\begin{array}{l}\text { In practice (empirics, ethics, personal, } \\
\text { aesthetics) }\end{array}$ \\
\hline $\begin{array}{l}\text { Am I keeping people 'in the loop'? } \\
\begin{array}{l}\text { Will this work be relevant to nurses in the } \\
\text { practice area and to those in transition? }\end{array}\end{array}$ & Am I engaged? \\
$\begin{array}{l}\text { Could it be published? } \\
\text { Can I say what it meant for me? }\end{array}$ & Am I in synchrony? \\
$\begin{array}{l}\text { Will communicating make a difference to } \\
\text { others? }\end{array}$ & Am I reflecting feelings and ideas? \\
$\begin{array}{l}\text { How will this research be seen by those I I listening actively? } \\
\text { respect and care about? }\end{array}$ & $\begin{array}{l}\text { Am I looking for clues of raised awareness } \\
\text { in the person? }\end{array}$ \\
$\begin{array}{l}\text { Am I energized by it? } \\
\begin{array}{l}\text { Does it bring about raised awareness about } \\
\text { nurse facilitation, dialectics and transition? }\end{array}\end{array}$ & $\begin{array}{l}\text { Is there clarity? } \\
\text { Do people know what to expect from me? }\end{array}$ \\
\hline
\end{tabular}

Underpinning these self questioning processes in dialectical moments of research and practice there are another layer of questions proposed by Rowan which addresses the rigour of dialectical research methodology. I expand on this in the following.

\section{Questions to address rigour}

Rowan's (1997) describes six types of questions related to the levels and moments of thinking which I find helpful in addressing my role as both DNFT and researcher. These are positivist-efficiency, addressing validity and rigour; alienation-authenticity, addressing the role of the researcher; political-patriarchal, addressing the sociopolitical context; dialectical, addressing the paradoxes and transformations; legitimacy, addressing the appropriateness of the design; and relevance, addressing whether the research will be valuable to practice. In Table 12 below, I reframe these six types and state them as questions, which I address at each moment of the research process, and the practice of DNFT.

Table 12: Clayton's adaptation of Rowan's six questions, to guide dialectical reflection and dialectical inquiry process 


\begin{tabular}{|l|l|}
\hline Rowan & Clayton \\
\hline Positivist-efficiency & Is it workable? \\
\hline Alienation-authenticity & Is it real? \\
\hline Political-patriarchal & Is there equality? \\
\hline Dialectical & Is it dialectical? \\
\hline Legitimacy & Is it ethical? \\
\hline Relevance & Is it relevant? \\
\hline
\end{tabular}

Is it workable? This question addresses the research process itself, especially in relation to congruency. In this thesis, the question of congruency refers to the research design applied to the research question. It engages cognitive, meditative, and reflective processes, of the researcher to question whether this research is going to answer the question being posed. The refining process to arrive at a research design involves an exploration of the overarching processes of qualitative research. Morse and Richards (2002) suggest that qualitative research is appropriate when one is trying to research something that little is known about and when one is inducing knowledge. In my case, I want to reveal and describe my perspective of DNFT from the inside out. In order to do this, I need to explore it myself and bring it to informed consciousness, as distinct from knowing about it without synthesis. This involves openness to data that surfaces from reflecting on supervision, peer review and case review, and discovery, rather than reduction. It also involves experiencing and processing patterns, rather than primarily focusing on content. Qualitative research goes for depth, detail, and the complexity of human experience, which the question of this thesis calls for (Morse \& Richards, 2002; Roberts \& Taylor, 2002).

Being workable also involves attending to practicalities, such as resources including human resources, such as supervision, support, money, facilities, and access, as well as intrinsic qualities, such as personal motivation and skills.

Is it real? Being real addresses issues of authenticity, previously described. It also requires an exploration of covert and overt agendas, assumptions, and prejudices. For 
example, I ask myself why I am doing this research process now, in this way with this subject? Being real involves becoming transparent, in as much as one can, bearing in mind that in all things there is an element of mystery. The notion of openness is important here.

Is there equality? This question involves an exploration of the relational aspects of the research process, and the subject being studied. It pertains to Rowan's notion of the social level. Here, I look at the assumptions I make about others; for example, in relation to gender, ethnicity, age, or sexual orientation. I ask myself if I am excluding anybody, and if so, why? This relates to Rowan's ideas about alienation, referred to in the early stages of describing these research processes. I also explore my own experiences of exclusion, in relation to the subject and the research process.

This question also addresses political issues existing in external environments. Again, it relates to both the subject and the research process. For example, does the sociopolitical context condone the work of nurses supporting people in transition in health services? Or, are these methods of doing research accepted?

Is it dialectical? This question requires attention to issues of conflict, contradiction, and resistance. I ask myself whether these issues are being worked through in all the moments of the research process, and whether they lead to transformation and raised consciousness, both for myself, and potentially, for others. It also requires an honest reflection of paradoxes and tensions, which are surfacing; thus, addressing the possibility of censoring, either of the insights made in transformation, or of others I am relating to.

Is it ethical? Issues pertaining to the ethical processes of the research and subject of study include application to Ethics Committees, detailing the involvement and consent of participants. It also includes processes of approval, which are presented as appendices of this thesis. Ethics asks questions such as: What are the legalities of the research? Are there risks? If so, to whom? And, do the benefits of this research outweigh the risks? Legitimacy comes in here, as well as an assessment of the limitations of the research. People who had engaged in transition work with me and who gave permission for me to review the case notes, were given a summary of our 
work together. Exemplars were chosen from these summaries which made clear the process of facilitation, and which highlighted the main patterns emerging from personal reflections made in supervision. Participants, which included the practice supervisor and peer reviewer, were given written information (refer appendices $\mathrm{C} \&$ E) explaining the research process to them. This was also explained verbally. Participants were invited to sign a consent form (appendices D \& F) to be involved in the research. Those giving permission for case notes to be reviewed were assured of anonymity and confidentiality. Participants were informed that they could disengage from the research process at any time up until the write up of the thesis.

From an ethical standpoint the implications for the participants and the researcher are considerable, including risk of exposure and embarrassment (Stake 1994). Strict attention needs to be paid to the ways in which the data is managed, and how anonymity and confidentiality is protected. Limited access to the data is essential and in this situation, case notes are also protected by the legal requirements of the NCNZ (2004) for acceptable nursing practice and the New Zealand Health Information Privacy Code (1994). A summary of case notes and emerging patterns was given to participants who gave permission to review notes. They were invited to check accuracy of interpretation and clarify meanings and patterns emerging. In this research, exemplars of participants' experiences were kept to a minimum because the focus is on the process of facilitation itself. When exemplars were used, pseudonyms for participants were chosen, in a conjoint way, to protect anonymity. Demographic information was altered along with specific details, which could identify the person or breach confidentiality. This data serves as a triangulation of the self-reflective process involved in refining DNFT in theory and practice. I give specifics of my ethical considerations later in this chapter. Confidentiality also applies to the autobiographical aspects of this thesis which incorporates experiences from my primary family. In my sharing of stories I include the reflexiveness of my experiences from my perspective only.

Is it relevant? In addressing relevance I examine my research process to determine whether it relates to the 'so what' of the research. Here I ask questions, such as: Will 
answering the question bring about raised awareness? Will theory relate to practice? Will the findings be meaningful and understood by nurses? Will it make a difference?

In the following section I explain how I integrate these levels, moments and questioning processes with my method of self-reflection.

\section{Self-reflection}

An example of the benefits of deep self-reflection to reveal the depth of being, doing, and experiencing, is provided by Clark Moustakas (1997). In his heuristic self-study of loneliness, Moustakas discovered an interconnected process by opening himself up to the lonely experiences of hospitalized children. He immersed himself in the essence and meaning of that experience, described as follows:

I had gone 'wide open', at moments ceasing to be a separate individual, but wholly related to the other person, leaving something behind of my own intuitive vision and comprehension, while at the same time, taking something away (p.112).

Heuristics is defined by the UK Encarta Online Dictionary (2005) as "A method of solving a problem for which no formula exists, based on informal methods or experience, and employing a form of trial and error". For the purposes of developing a way of tracking this process, Moustakas (1990) described six phases of a research process, identified in Chapter One, as: Initial engagement, immersion, incubation, illumination, explication, and creative synthesis. He proposed that this process could lead to revelations of individual depictions of perceptual experience and add to the human story of lives lived in unique ways; while at the same time connecting to universal human experience. It invites the reader to vicariously experience the author's view.

I adapt Moustakas six phases of heuristics to my process of self-reflection in order to come to know and explicate to others, the deeper regions of the work of DNFT as follows. 
Initial engagement relates to my passion for, and subsequent engagement with, the facilitative role as a nurse with people in transition, to the formation of a research question which shows the way to a deeper exploration of the nursing role. This leads naturally to immersion, or in my case, the discovery of existing nursing knowledge on the subject, to the reframing and narrowing of the scope of the question being addressed. A period of incubation is suggested by Moustakas to allow a deeper awareness to emerge - to come to know more clearly how to approach the issue and gain insight. This insight appears as an illumination as self-awareness is heightened, and meanings and patterns come into view. Explication is the examination process of what has come to light and what it means to be in the lived life context of DNFT. Creative synthesis follows with core patterns being articulated in artistic ways.

In his summation of the process of heuristic research, Moustakas (1997) concludes: I now believe in such a process of searching and studying, of being open to significant dimensions of experience in which comprehension and compassion mingle, in which intellect, emotion and spirit are integrated, in which intuition, spontaneity, and self exploration are seen as components of unified experience, in which both discovery and creator are reflections of creative research into human ventures, human processes, and human experiences (p.216).

These words of Moustakas show congruence with Rowan's dialectical levels of thinking and moments of being. Thus I integrate and adapt Moustakas' heuristics with dialectical moments of being, doing and experiencing to my reflections of supervision and peer review, under the following headings: Attraction, engagement, immersion, meditation, expanding awareness. I am also influenced by Carper's (1978) ways of knowing in the thinking, integrating, and communication research cycles to address the application of heuristic reflection with nursing framework development. Each phase is highlighted in italics, explained below.

Attraction refers to my choice to focus on transition. Attraction to transition, as a nurse and as a human being, came about through experiences both in the nursing practice 
and personal life. It was through these experiences that I developed a fascination with unique transition processes that occur in human beings, much as Moustakas (1997) did with loneliness. Being fascinated and attracted is much like falling in love. The 'subject' becomes the centre of one's world. Not attending to it would lead to it becoming a hidden obsession, wondering about it, but not addressing or engaging in it.

Engaging or engagement follows attraction and is the subject of my supervision sessions. In the supervisory process, I discuss and reflect on what is going on for me when I work with people in transition in a facilitative nursing role, using a dialectical approach. For example, what patterns do I see immerging, how do I relate to them, how do I address them, and how do I deal with my own parallel processes. I am influenced by Johns' (2004b) self-reflective journaling process and apply uncensored writing, as a starting point to entering into a dialogical process with the reflections and texts, described more fully in this chapter. I work out my understandings about transitions in relation to the mirroring that the supervisor provides; journaling the feelings and realizations that are going on in supervision. This requires immersion.

Immersion is like plunging into a deep well. As I go into the depth of the work that I do, nobody can really come with me. At the deepest point, I meditate on journals and case reviews, reading and rereading. I search for emerging patterns through a process of rewriting. Patterns and summaries are meditated upon with participants, as I surface for air and clarity before I plunge in again, this time to read extant literature in order to search for both resonance and dissonance with the patterns I see forming.

Meditation in this context is allowing the mind to rest and drift into deeper consciousness. My experience of it is like stepping into a universal library in a dream state and fetching an insight that seems to well from an unknown, but familiar, source. This is not an immediate process, which is why Moustakas (1990) presented it as an incubation phase. It is the basis of a phenomenological notion of 'coming to know' or things 'coming to light' in expanding awareness.

Expanding awareness fits with Rowan's (1997) notion of realization, previously explained, and the influence of Margaret Newman's theory of HEC. Insights coming into conscious awareness are written after reflecting on supervision sessions and peer 
review. As journaling is a matter of course for me after supervision, I did not set a time frame for this. However, it is important to address the dilemma that all qualitative researchers have to face; that is, deciding when I have enough data to start making sense of it. I use Moustakas' yardstick; which is to reach saturation point so that no new patterns emerge after journaling. This also applies to the literature review regarding dialectical facilitation of transition in the nursing context. According to both Moustakas (1997) and Johns (2004b) a deep literature analysis, critique, and review, prior to interpretation and writing of reflective material, is not advisable, because to do so contaminates the authentic experience of the researcher.

Expanding awareness refers to the reflective process of stories, arising from the journals shared in the dialectical moments of thinking, integration, and communication. Expanding awareness emerges in my stories and poems in the journaling process, prior to engaging in, and studying in depth, the stories of others or the case reviews. When resonance is achieved between personal experience and literature, communication through creative synthesis, explication can occur.

Explication involves illuminating insights made through the journaling process and case reviews; the writing and rewriting process, and the reading and integration of extant knowledge. This explication moment of the thesis uncovers meanings and praxis of DNFT in Chapters Eight and Nine. The creative synthesis and explication is crafted to show patterns for nursing knowing of DNFT and is guided by the work of Carper (1978), taking account of writings of Jacobs-Kramer and Chinn (1988); White (1995); Johns (2004b); and Johns and Freshwater (2005).

Communication of supervision, peer review, and case review involves finding creative ways to explicate patterns in a cohesive description, and the interpretation of my unique experience and perception of exploring transition. Table 13 reframes Moustakas' heuristic phases to show my adaptation of them for the purpose of this study. 
Table 13: Clayton's adaptation of Moustakas' phases of heuristic research

\begin{tabular}{|l|l|}
\hline Moustakas & Clayton \\
\hline Initial engagement & Attraction \\
\hline Immersion & Engagement \\
\hline Incubation & Immersion \\
\hline Illumination, & Meditation \\
\hline Explication & Expanding awareness \\
\hline Creative synthesis & $\begin{array}{l}\text { Creative synthesis \& } \\
\text { Explication }\end{array}$ \\
\hline
\end{tabular}

\section{Ethics, data collection and synthesis}

Following ethical approval from the Human Ethics Committee Victoria University of Wellington, (Appendix A), permission was gained from participants (Appendix D \& F). Journals were written, in an uncensored style, following practice supervision and peer review sessions over two years from March 2005-March 2007. Although, for the purposes of this thesis, I set a time frame of two years; intensive journaling is influenced by patterns emerging in journals written over 30 years of nursing practice. At times, I included excerpts of earlier journals in my reflexive process to track the origins of current thinking. Entries in my journals were written about my subjective experiences in supervision and include my impressions of the key patterns of the session. In this process, my cognitive domain was suspended as I adopted an attitude of openness to intuitive knowing of the experience of being a DNFT. After two years, I read the journals and identify patterns of thoughts, feelings, content, and process of DNFT. The journals are read again and aspects which relate to key patterns are rewritten. Patterns are reflected upon in a meditative way to allow insights to surface in expanding awareness. An integration of subjective writing and objective synthesis are done as I reflect on the patterns revealing transitional processes and the dialectical processes for nurse facilitation.

\section{Selection of participants}


Six participants for case review were chosen from the following three categories: loss, changes in the person's life world, and adjustment to diagnosis of disease for themselves or significant others. Selection was made carefully, bearing in mind the level of adjustment to the transition, the sensitivity of the issue being facilitated, and the time lapse of my work with the person. From these reviews, exemplars were written that augmented emergent themes from supervision and peer review. In order to reduce the risk to participants of the research process superseding the emphasis in sessions, or creating an artificial dynamic in the relationship; people were invited to be participants retrospectively. In some cases this was during the closure stages of their work with me, and in others it was after they have completed their work with me. Having said that, the closure process for transition work has a tapering quality and for most of the participants, further work was being done during the research process.

\section{Case review}

Case notes were reviewed, with permission (Appendix F), and a summary of facilitation given to the participants who checked the summary for accuracy in a onehour session with the researcher. The participants had time to reflect on the summaries, and follow up sessions were offered for co-construction of exemplars. The wording of the co-constructed exemplars was strictly adhered to. Pseudonyms were chosen in this interview to protect the identity of the participants. The exemplars were integrated into the explication and creative synthesis of the self-reflective process, as I communicate the praxis of DNFT in this thesis.

As I immersed myself in patterns revealed in journals and exemplars a deeper layer of processing took place. In this time, I met with participants to review and refine exemplars and journal findings. I explain the process of reflection I use in Table 14, below, and follow with a literature review of supervision and peer review to bring clarity, and make transparent, my understandings and integrations of this subject, in the context of this thesis. 
Table 14: Self-reflective processes to elicit patterns of nursing knowing

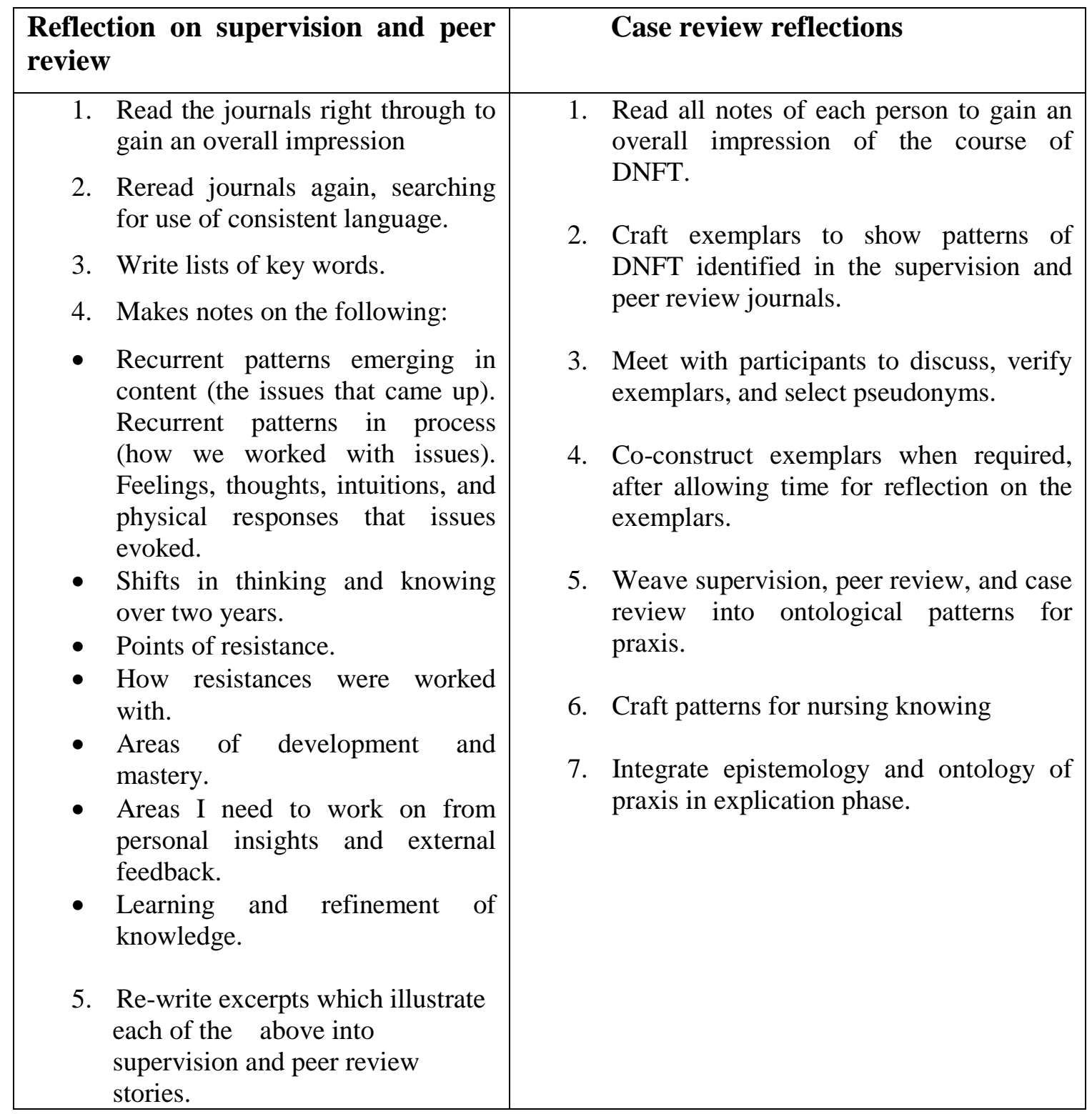

As supervision is variously described, I explore ideas about practice supervision in the next section that specifically pertains to nursing.

\section{Practice supervision: A process for reflection}

My first introduction to supervision, in the context of practice, was at the beginning of the 1980s when I was working in a mental health institution. At that point, the term used was interpersonal supervision, and the concepts were largely borrowed from psychotherapy. It was Mike Consedine, an early colleague in the 1970-80s, who translated these concepts into the mental health nursing context for me and who was a passionate proponent of supervision for nurses. Consedine (2004) highlighted the 
value of supervision to enhance practice, encourage reflection, and to promote change. The relationship between the supervisor and supervisee is seen as crucial to fulfilling these functions; a relationship not unlike that which occurs in a therapeutic context.

Parallels are drawn, by Fulton and Oliver (2001) between supervision and psychotherapy. Thus, the skills for supervision rely on psychotherapeutic expertize, especially giving attention to transference and counter-transference in the development of increasing self-awareness of the supervisee. The term transference was coined by Freud, to describe a tendency to transfer earlier experiences onto the present situation (Yalom, 1985). One example of transference in supervision could be the supervisee responding to the supervisor like a previous authority figure, not bearing any relationship to the current situation. Recognition of transference to the astute supervisor is 'grist for the mill' and provides a valuable opportunity for the supervisee to work through previous experiences and develop more self-awareness. Countertransference refers to unconscious feelings engendered in the supervisor, nurse, or therapist, which prevent them from addressing issues that are raised in sessions. An example of this could be when the supervisor has had experiences of abuse, which remain unresolved, and the supervisee brings up similar issues with the view to exploring it further. If the supervisor does not recognize and attend to their countertransference, they may avoid or block an exploration of the issue and therefore sabotage the process. The mechanisms of transference and counter-transference are powerful and frequent occurrences in communication; thus, supervision is desirable in occupations that rely on the interpersonal skills of those who work in them. This point has gradually been accepted by nursing management structures in Aotearoa NZ, leading to a growth in the area of supervision in the last twenty years.

Bond and Holland (1998) indicate that it is necessary for the supervisor to have a high level of expertize to ensure that the focus is on the facilitation of self-awareness and interpersonal skills to cope with the emotional aspects of nursing. This is not always straightforward because of a tendency by nurses to avoid talking about situations that did not go well, especially if supervision is linked to performance processes or the supervisor has a management role. Johns (2004b) raises an issue connected to this tendency, which he refers to as self distortion. In this situation, the practitioner may reflect on only part of the experience with the supervisor concealing other aspects to 
avoid judgment and anxiety. Self distortion could also occur because the practitioner has a blind-spot about their practice; for example, when they cannot see aspects of their practice because they are habitual patterns. This raises issues of safety for the practitioner in supervision. Consedine (2004); Bond and Holland (1998); MortonCooper and Palmer (2000) emphasize the importance of the supervisee choosing their supervisor so that there is a relationship of trust and mutual respect, providing an enabling environment for safe exploration of issues.

The facilitative role of the supervisor is emphasized by Morton-Cooper and Palmer (2000); a viewed shared by Bond and Holland (1998), who offer a lengthy, but comprehensive, definition of supervision, as follows:

Clinical supervision is regular, protected time for facilitated, in-depth reflection on clinical practice. It aims to enable the supervisee to achieve, sustain and creatively develop a high quality of practice through the means of focused support and development. The supervisee reflects on the part she plays as an individual in the complexities of the events and the quality of her practice, this reflection is facilitated by one or more experienced colleagues who have expertise in facilitation and the frequent, ongoing sessions are led by the supervisee's agenda. The process of clinical supervision should continue throughout the person's career, whether they remain in clinical practice or move into management, research or education (p.12).

The term clinical supervision, in this quote, is frequently used in nursing texts. As stated by Bond and Holland, the use of the word clinical is potentially linked with medical model approaches; thus, I use the word practice supervision in an attempt to distance myself from that connotation.

The themes of reflection and facilitation in the above definition are shared by authors so far mentioned. These themes are discussed extensively by Johns (2004b), who emphasizes guided reflection through journaling and the importance of the supervisor hearing the supervisee's stories of practice. According to Johns, these stories provide an opportunity for anxieties and conflicts to be faced and for misperceptions about 
oneself to surface. Supervisors are in the position to facilitate the exploration of new possibilities for practice, and at the same time, to notice aspects of practice that are outmoded and lacking validity. Supervision affords an opportunity to explore meaning, inspire commitment, and provide the impetus and courage to make changes where required (Johns, 2004b).

I selected a supervisor with longstanding expertize in the field of counselling in transition, grief, and loss. Although not from a nursing background, my practice supervisor has experience supervising and teaching nurses; thus, is familiar with the orientation of my work. Our work is contractual and regular, specifically addressing my practice. The parameters of the research components of supervision are explicated in (Appendices C \& D). I journal my experience of supervision immediately after each session. The process I use is one of the intuitive methods of reflection: writing without censoring, outlined in Bond and Holland (1998), referred to in Table 14. Broad patterns are identified after reading, rereading, and rewriting reflections from the journals. The identified patterns form clusters showing how dialectical facilitation of transition in my work takes place.

\section{Peer review}

The process of peer review is similar to supervision, except the emphasis of peer review for me is on the mutual discussion about practice by a peer, who works in similar areas with comparable skills. Peer review, in the context of this thesis, is undertaken with a colleague engaged in similar mental health practice contexts, after an explanation of the research process along with an information sheet (Appendix C) is given and consent (Appendix D) is signed. I already have an established professional relationship with this peer review colleague, spanning ten years. In this time, we have been informally discussing themes arising in our practice, which pay attention to spiritual paradigms for nursing practice. I include Table 15, below to highlight the differences between practice supervision and peer review. 
Table 15: Comparisons of practice supervision and peer review

\begin{tabular}{|c|c|}
\hline Practice supervision & Peer review \\
\hline $\begin{array}{l}\text { The practice supervisor is a person with } \\
\text { expertise in the field of grief and loss. } \\
\text { The supervisor's role is to address } \\
\text { practice issues of facilitation of } \\
\text { transition only. } \\
\text { The supervisor is aware that the } \\
\text { researcher keeps a journal of supervision } \\
\text { sessions to support a self-reflective } \\
\text { process that will form the basis of the } \\
\text { findings for research. } \\
\text { The journal notes are a reflection of the } \\
\text { researchers insights about practice } \\
\text { through supervision and do not include } \\
\text { the opinions or views of the practice } \\
\text { supervisor. } \\
\text { A disclaimer is included in this thesis to } \\
\text { protect the views and opinions of the } \\
\text { supervisor. }\end{array}$ & $\begin{array}{l}\text { The form of the peer review sessions is a mutual } \\
\text { interdependent process involving the exploration } \\
\text { of nursing practice in two similar fields, where } \\
\text { both are registered nurses with similar } \\
\text { qualifications and expertise. } \\
\text { The researcher has two mutually interdependent } \\
\text { roles, as both facilitator and participant. The } \\
\text { structure of these sessions is less formal than } \\
\text { practice supervision although time frames are } \\
\text { adhered to. } \\
\text { The peer reviewer is aware that the researcher } \\
\text { keeps a journal of supervision sessions to support } \\
\text { a self-reflective process that will form the basis of } \\
\text { the findings for research. } \\
\text { The journal notes are a reflection of the } \\
\text { researchers insights about practice through peer } \\
\text { review and do not include the opinions or views } \\
\text { of the peer reviewer. } \\
\text { A disclaimer is included in this thesis to protect } \\
\text { the views and opinions of the peer. }\end{array}$ \\
\hline
\end{tabular}

\section{Literature review}

After the completion of reflections and exemplars, I wrote Chapters Six and Seven detailing my interpretations of these reflections and interpretations. I then returned to the literature to seek resonance and dissonance with the findings. Literature relating to a dialectical approach, nursing relationships with clients, facilitation, counselling, grief, loss, transition, integral approaches, Nichiren Buddhism, reflective processes, nursing theories, supervision, heuristic and dialectical research, energy fields in health care, nursing, and education was sought, comprising Chapters Eight and Nine. The literature search includes the following databases and search engines: Cumulative Index of Nursing and Allied Health Literature (CINAHL); MEDLINE; PsychARTICLES; Health and Biological Sciences Journal Finder, and Google. 


\section{Summary}

The design for this philosophical, theoretical, and ontological inquiry encompasses dialectical philosophy, providing the basis for both DNFT as a praxiological process and the research design. Praxiological process is revealed through the explication of dialectical reflection. This reflective process informed by heuristics and nursing knowing illuminates dialectical tensions and the synthesis of these tensions into a coherent nursing framework for my nursing practice. Addressing the workability, authenticity, equality, dialectic, ethics, and relevance of this research, attends to the rigour, ethics, and the significance of the praxiological process and the research design.

Patterns emerging from reflective journals, after practice supervision and peer review, were augmented by exemplars from case review, written from the facilitator's perspective and validated by those who experience facilitation. Practice supervision and peer review are well established processes in mental health nursing to support, challenge, and enhance the nurse's insight into practice, through a skilled process of reflection, exploration, and feedback. Supervision and peer review, therefore, provides a vehicle that enables the ontology of praxis to emerge. 


\section{PART TWO}

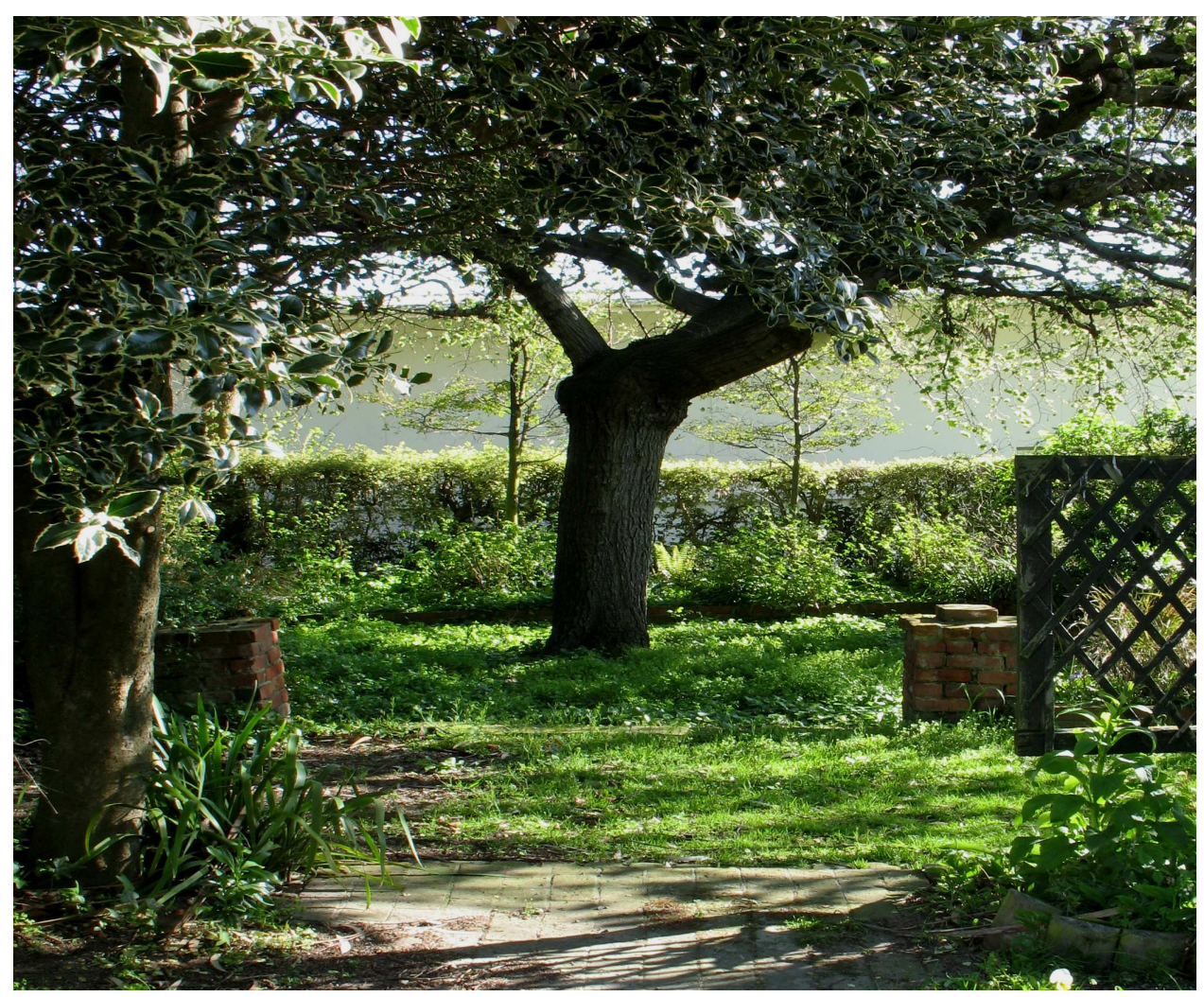

It is time now to strip ourselves down to the core

To sit inside our core selves and to be real, no matter what

It is time to clear out the clutter of our beings and in our lives

Stripping away anything that no longer resonates with our core selves Solara ${ }^{20}$

\footnotetext{
${ }^{20}$ This writing was given to me as a gift from a friend. The origin of it was not disclosed. I discovered it was a statement made in an interview by Joshua with Solara in 1996. Retrieved November 27, from http://www.v-j-enterprises.com/solara.htm
} 


\section{CHAPTER SIX}

\section{Epiphanies in Personal Knowing}

In the period of transition, briefly described in Chapter Three, I had begun a process of integration and synthesis of my professional role as an educator, nurse, and a traveller making sense of my own transitions. I had also highlighted the need for selfawareness, because of the potential for grief and facilitation to trigger negative memories or vicarious experiences of loss in the facilitator. It is for this reason I include relevant self stories of transitions that form primary, social, and realized levels of thinking and show my integration of these experiences into the development of an empathic therapeutic use of self.

The importance of self-awareness and transcendence of difficult experiences in nurses and its impact on health care, is addressed by Marion Conti-O'Hare (2007) in, The Nurse as Wounded Healer: Finding the Essence of the Therapeutic Self. She described the significance of the nurse's becoming aware of their own traumas in the following statement,

Nurses and other health professionals become wounded healers after recognizing, transforming, and transcending the pain of trauma in their lives. In the search for wholeness, traumatized individuals may pass from the stage of the walking wounded to wounded healer (p.1).

Conti-O'Hare's writing brings to light the vulnerability of nurses who work with people going through trauma and crisis. I suggest that without self-awareness, nursing work can trigger personal trauma and crises. Paradoxically these triggers if attended to can enable an opportunity for deeper understandings of transitional processes which can be beneficial to the therapeutic relationship.

I begin with three personal stories of transitions, spanning two decades, which led to my attraction and engagement with the process of transition. These stories were pivotal to a transformation in the way I view life and death. 


\section{The dark night of the soul}

It was 1989 I was thirty four and in limbo. We were relocating from the North Island to the South Island in Aotearoa NZ. Married and a mother of two daughters, I was returning to Dunedin, Otago - the place of my birth. I had a feeling of excitement as I drove into Dunedin at dusk with my daughters. The lights of the city appeared like jewels. Hopes of a better life ahead rose in my heart.

Moving was an attempt to search for a better life - a more meaningful future - access to city, culture, and learning. I was not prepared for the swathe of grief and loss that greeted my arrival. The gloom of depression that had slowly crept over my life as I battled with failing health and a troubled marriage, deepened in the harsh Otago climate.

I struggled to connect with people, organizations, clubs, and churches. One of my friends, who relocated to Dunedin at the same time, was dying of cancer, leaving three young children behind. At her death, the small light of hope in my heart for a better future flickered, threatening to be extinguished. I started to retreat; and therein, began a deep search for a sense of meaning and a feeling of connection.

I took myself often to a place I remembered from my early childhood, when we lived under Mt Cargill. I gazed out to the harbour blankly, noticing the changing scenes each time I visited. At times I could barely see the beautiful harbour, due to the dense mist hanging over the sea. On occasions the sea was grey and choppy, and large black clouds hung threateningly in the sky. Other times, the harbour shone like a mirror, reflecting the shapely outline of the Otago Peninsula, with a soft golden glow hovering over the harbour cone mountain. Watching these changing scenes showed me that nature, like human experience, has many moods, and that nature reflects the universal law - life is in a constant state of flux.

Set adrift, it is like night-time on the vast ocean

I perceive I am alone

Ifeel separate - cut off

It seems interminable

It feels hopeless 
Days and nights stretch out before me endlessly

I miss being connected

I miss a sense of awe and the presence of God

On this journey of the dark night of the soul I became a seeker, voraciously gathering up books and experiences of individuals who have battled great odds and transcended them. The following experience accelerated this learning.

\section{Finding spirit in the midst of tragedy}

Aramoana is the entrance to the Otago Harbour. I shuddered on our first visit to the small village, consisting of some houses and small cribs. I don't know why, but I felt a sense of foreboding.

I remember November 1990 and the terrible tragedy that took place in Aramoana. I felt immobilized by fatigue that day, as I gazed out of the window in our Port Chalmers house. My heart felt heavy. From our living room, the town of Port Chalmers was visible and also the road that connected Port Chalmers with Careys Bay, Deborah Bay, and Aramoana. In the afternoon I saw a succession of emergency vehicles make their way hastily through the town - followed by the sound of helicopters. News of a manhunt leaked out.

Thirteen people died in the massacre initiated by a troubled young man, isolated from the world because he had perceived others as threatening enemies. Among the dead were two members of my extended family: my cousin and his daughter. I duly visited my cousin's open coffin at the Otakou Marae. He was brought there, not because of any Maori lineage, but out of respect for his efforts, to render Aramoana free of a proposed aluminium smelter, which threatened the habitat of the Albatross at Taiaroa Heads. This visit was a turning point for me. I sat accompanied by my family next to his coffin and allowed my thoughts to drift to nothingness. I became aware that whilst his shell like body showed evidence of his violent death, his spirit was vibrant and alive. We communed in the language of spirit. He was pleased to see me and spoke to me of my family's heritage as seers and encouraged me to develop this gift. He urged me to step out of my comfort zone of past belief systems and trust that a new pathway would open up to me. 
This experience heralded a slow growing awareness that I had allowed my life to become too small. I had limited my self with beliefs, dogmas and learning. I started a process of opening to a spiritual journey. Over time this led me through a valley of letting go - letting go of my marriage, Christian dogmas, and unsupportive friends. Coming into contact with fellow travellers seemed to happen serendipitously as I found Sherpas to guide me through the unknown terrain of deepening spiritual awareness. I found an awakening of spirit and I developed a deep awareness of the continuity of life that transcended the fear of death. I share my experience of this in the following story.

\section{Saying goodbye to my mother}

My mother died in August 1998. Two days prior to her death I had attempted to ring her to say hello, but was told by my father that she had a cold and was in bed. I did not want to disturb her and I ran a deep hot bath scented with herbs from the garden. I lit a candle and allowed my mind to drift into a meditative state. I closed my eyes and I became aware of a vision of drifts of pink flowers floating to the ground. The thought of my mother came to me and a peaceful feeling that all was well. The next day I was at work preparing for a class when I received a phone call from my brother to say that my mother was very ill and had been taken to intensive care, he wasn't sure of the prognosis. I sat at my desk reflecting on what to do and remembered my vision. I made immediate plans to leave for the long journey from Dunedin to Nelson by car. My youngest daughter accompanied me.

It was 3am when we arrived at Nelson hospital. The night shift workers, who were waiting for our arrival, hurried us along the corridor to intensive care where a nurse led us to my mother's bedside. The nurse told me she felt that my mother was waiting for us to arrive. My mother's physical state belied the rate of her heartbeat. There was no time to be lost. I sat beside her bedside and held her cold hand. She did not respond physically, but I felt her spirit quicken. I took a bottle of rose oil and anointed her between the eyebrows. An Ancient hand guided me as I spoke a blessing. She released her spirit and the heart monitor drew an even line across the screen. The nurse put her hands on my father's shoulders and told him gently that my mother had passed away. The nurse removed the unsightly tubes and monitors and we sat with mother watching her as the dim night light softened her features. Her face 
transformed and she seemed to look forty rather than her seventy six years. We sang to her spirit and prayed. My father kissed her on the forehead and whispered 'bless you' for the last time. We sat feeling the presence of her ethereal body hovering over her physical shell. We all felt strangely peaceful and returned home at dawn.

As we lowered her body into the ground a few days later I stood with a bucket of pink chrysanthemums allowing them to drift in over her coffin, as in my vision. Family and friends showered her with pink flowers before covering them with brown earth.

My mother's passing led me to a pathway of heightened psychic awareness often described by those who have experienced the death of loved ones. Following her death and for at least two years afterward I was aware of a feeling like a warm cloak upon my shoulders. This was particularly evident to me when I was experienced something difficult or painful. I began to associate this feeling with the presence of my mother.

These experiences that I have shared were part of a gradual change process for me which included, growing up, separation, my children growing up and leaving home, leaving my family home, finding a new partner and embracing Buddhist philosophy. I felt supported in spirit through these transitions and developed an awareness like the dawning of a new day that I was no longer alone, that I was not separate, and that no matter what, I am connected to the universal heartbeat. I knew I would never feel a dark shadow pass over my soul again. Deeply etched into my spiritual awareness was a sense that past sufferings had given me a foundation to enter into a different experience of the craft of healing. That these experiences of transition would enable me to do the work that I had always suspected I would do, but wasn't ready for until now.

These experiences of transitions although unique to me have elements of the universal patterns which are often described by those in loss, grief, and transition. That loss and transition is a time of chaos where reorganization and the shaping of new identities have the potential to begin. It is a critical time as the person can succumb to the weight of the task before them and retreat into illness or depression - or bravely step forward with hope and begin the process of change and transformation. Although for many this is a pathway they travel alone, for others, negotiating their way through the labyrinth 
of chaos and disruption is best facilitated and supported by a person who understands the territory.

Understanding the territory of transitional journeys is not enough in itself to support those in transition as each situation and person is unique in their experience of the world. It is my view that facilitating transitions, as a nurse, is a skilful activity which encompasses deep self-knowledge and experience of interpersonal processes, counselling skills, and the ability to mirror processes without smudging the images perceived by the person.

In Chapter Seven, I take these integrations of personal knowing forward into the world of practice. 


\section{CHAPTER SEVEN Being-Doing-Experiencing Nursing Praxis: A \\ Heuristic Reflection of Dialectical Nurse Facilitation of Transition}

This chapter is divided into two sections and comprises research patterns of practice supervision, peer review, and six case reviews revealing the being doing and experiencing of my nursing praxis. Transitional moments are identified in both Sections One and Two, explored through my work with those experiencing: loss through death; adaptation to disability or illness; loss of relationship, work transitions; and seeking a deeper understanding of self, especially spiritual dimensions.

In Section One, I explicate foundation patterns underpinning DNFT, basing them on exemplars from the reconstructed stories of practice supervision, peer review, and the case reviews of Charles, Rose, and Lilo. These exemplars reveal and elucidate my growing awareness of patterns revealing nurse facilitation in praxis. Exemplars are derived through processes identified in Chapter Five. This includes giving information to participants, obtaining consent, and selecting pseudonyms. Contents of exemplars are negotiated over a period of weeks and months to allow time for reflection and mutual agreement. Participants are invited to co-create aspects of the exemplars so that there is agreement between my interpretation and their experience of DNFT. These are decided in hourly sessions. In some cases other sessions are arranged to negotiate content.

For the most part, the process of co-creation and negotiation of exemplars is mutually experienced as an added bonus to the work of facilitation, allowing a deeper reflection of transition. The text is written in an interwoven style with the patterns identified (italics and bolding) determining the order of exemplars and journal writings.

In Section Two I include reflections from my supervision and peer review journals, along with the case reviews of Sophie, Grace, and Faith, to integrate patterns identified from my experience of the transitional moments of those I see in my practice. Sophie spontaneously offered artwork to augment exemplars that pertained to her experiences of transition. Most of these works were retrospectively reflected upon 
in our sessions together. Sophie chose to do this as a process of making meaning of previous patterns occurring in her life that she linked to the transitional work we did together. In this process new insights came to light in significant transitions that had occurred over some years. This was approved by The Victoria University of Wellington Ethics Committee, and consent forms were altered to accommodate the inclusion of artwork with the text (refer Appendix, B). Understandings about transitional moments also came from my prior knowledge of the relationship between change processes and health, and my synthesis of theories about loss, grief and transition.

In Sections One and Two I include exemplars and artwork from case reviews as insets. Nursing intentions and patterns for facilitation are synthesized from the literature review of nursing theories and philosophies in Chapter Three, and Four, and personal knowing in Chapter Six which resonate with the praxis of DNFT. They are also based on meditations on my experience of being a facilitator.

\section{Section One: Foundation patterns for nursing praxis}

It is apparent from the supervision journals that transitional work draws extensively on knowing that is distinct from scientific, cognitive, or emotional ways of knowing. This knowing also integrates 30 years of being in the field of nursing and learning to view my life experiences through a nursing and personal life experience lens. I therefore draw on my personal knowing and include excerpts from personal journals. Patterns related to spirituality underpinning practice, stand out as being central to nurse facilitation of transition and appear consistently throughout the reflective journals. I highlight patterns in italics.

\section{Being grounded and connected}

Being grounded is a term often used in mental health to mean having a sense of perspective, 'having your feet on the ground', or 'being down-to-earth'. Basic, practical, taken-for-granted things tend to give us a sense of being grounded. For example, taking a walk in the fresh air when perplexed or confused about something 
tends to help people to make a connection with the environment and help gain perspective of themselves in the scheme of the larger whole.

My belief in the significance of being grounded and having a connection to the land relates not only to the philosophy of Nichiren Buddhism's three realms, but also to being embedded in the bicultural context of Aotearoa NZ. I share a reflection from my personal journal about my experience of having a connection to the land and of working with a person for whom this was a central issue.

My daily habit is to walk my dogs. As we were plodding our way through the golden leaves of English oaks in my neighbourhood, I paused to study the environment. I noticed borders of native trees dispersed with species brought over by ancestors from the British Isles. As trees jostle with each other, I ponder my entry into this land that I have such a strong connection to. I was born under the shadow of Mt Cargill. From the place of my birth I looked out to the Otago Harbour.

My mother's ancestors settled in the city of Dunedin, in the Otago region, in the late part of the $19^{\text {th }}$ Century. They were from English / European descent, bringing with them the strong traditions of a middle class family. My father, although adopted, shared with me his blood ancestry. They were of English descent, arriving in NZ in 1860, bringing with them the traditions of the English legal system. My great, great grandfather infiltrated these ideas into early New Zealand colonial life as an elected parliamentarian. This tradition was followed by his son, my great grandfather, who served on the NZ Legislative Council in the early 1900s. Their way of life was privileged, and my father was critical of them for not fully integrating into New Zealand life, because they commuted between $N Z$ and England.

My father was born and raised in England, immigrating to NZ in his 20s. He largely rejected his ancestor's lifestyles, choosing a simple, non-materialistic life based on Theosophy and his mentor, Jiddu Krishnamurti ${ }^{21}$. I was part of a family of eight children, raised on a rich diet of vegetarian food, and literature.

\footnotetext{
${ }^{21}$ Jiddu Krishnamurti (1895-1986) was an Indian philosopher, writer and mystic who rejected any spiritual and psychological authority. He posited that the only way to come to truth was through the mirroring of relationship to persons, nature, and ourselves. He engaged in dialogues with, scientists, leaders, and thinkers such as David Bohm, believing the only pathway to peace is fundamental change and the ability to observe one's mind (Krishnamurti foundation of America, 2004).
} 
Growing up in the culture of 1950s conformist NZ, our lifestyle was unusual, and even considered subversive by some, as my father was a conscientious objector and opposed any participation in warring acts.

I, like many of my Pakeha (fair skinned) contemporaries, struggled to know my cultural identity, triggering a need to travel to England in my early 20 s to retrace the steps of ancestors, and to be reconnected with the 'mother country'. The journey, on reflection, raised more questions than answers, and it wasn't long before I missed the azure skies, the aqua coloured seas, and the sound of native birdsong. I felt drawn back to Aotearoa $N$, the place that I call home.

Part of my education, as a nurse practising in NZ, was to understand the relationship between the indigenous people, (Maori), and the manuhiri (visitors). Aotearoa NZ was founded on the Treaty of Waitangi in 1840 - a Treaty agreed to by British ancestors and Maori iwi (tribes), although not all iwi were signatories to this Treaty. The Treaty of Waitangi set up a relationship with two peoples, Maori and manuhiri. Thus, the Treaty of Waitangi addresses biculturalism, forming a participatory partnership relationship, ensuring protection of land and resources for Maori, and the self determination of iwi to own and utilise land and resources. In itself, and for its time, it was an emancipatory document for Maori, and is the subject of continued debate and legislation to this day. My experience of the Treaty of Waitangi is that it provides a vantage point, from which I can view myself and others, from the position of my cultural identity. As a Pakeha woman of English and European descent, in communication with Tangata Whenua (people of the land), I bring with me my ancestral heritage, customs, and values. Although I do not necessarily subscribe to all of the customs and values of my ancestors, I have come to an understanding of their position within the socio-political contexts of their times. I carry forward my views and the integration of the migration and transition of my ancestors into the present moment in my role as a transition facilitator. It is for this reason that I have become fascinated by stories of descendents of migrants, as I notice a recurring pattern in the transition work, to look back at ancestral connections to make sense of experiences of transition. This was so in the following case exemplar. 
Turangawaewae (having a place to stand)

Charles came to me following the sudden and traumatic loss of his wife in an accident. As, bit by bit, the story of his loss unfolded, the underlying theme of cultural identity came into the foreground. Charles's story revealed a family history of struggle and triumph as two cultures became integrated in early New Zealand life. Deeply embedded in his psyche was a sense of his Maori heritage, although easily concealed by his Pakeha exterior. He had traced his history back to a South Island Maori chief, and themes of his present situation were strangely similar to stories he had heard of his history. Making sense of his wife's death brought up issues about land and tapu (sacredness, protective elements of people, places, animals plants, events, and social relationships). He kept returning to notions of a breach of tapu preceding his wife's death. Although in his present expression of cultural values, tapu could easily be marginalized by the European aspect of his culture, deep within him he felt the need to address tapu. We talked about tapu and the significance of it in his Maori lineage. We explored possibilities for addressing this through karakia (incantation, prayer).

The experience of the death of Charles's wife had reconnected him strongly with a sense of himself as a young Maori warrior with a deeper understanding of taonga (treasures of his lineage) and tikanga (customs and values) of Maori ancestors. It had also emphasized his sense of belonging to the land on which he had planned to build a house with his wife. This land was a place that connected him with his Maori ancestors.

It is my sense that this journey into Charles's heritage, and reclaiming aspects of ancestral values, has the potential to take him forward into a coherent understanding of his self-identity and the place where he stands, providing a foundation for resilience in the face of adversity. 
Having a sense of connectedness, or oneness follows on from this sense of cultural connection, and connection to the land. Oneness was the life state experienced by Shakyamuni Buddha in his experience of enlightenment (Hochswender et al., 2001). This is an experience commonly held by those who embark on a search for a deeper understanding of self as a human being, and self as spirit. Having a sense of oneness, for me, was experienced in the transitions I shared in Chapter Six, as an integration of the dualistic notion of self and other. A sense of oneness is embedded in the culture of Maori; however, in European culture, individualism and dualistic notions of self and others, body and mind, physical realm and spiritual realm, are abound. This sense of separateness and aloneness is the basis for many human fears, especially fears of death. I believe it is these fears that lead to the difficulty, for some, to move through transition. In one of my earlier supervision sessions, I sought to understand more clearly how I had come to this position in my story of becoming involved in transition. I share an integration of my journal excerpts, in the following section.

\section{Moving from alone to all-one: A mutual process}

In the supervision session, I chose to look at the dialectical process, which became apparent to me in my decision to choose to work independently, facilitating transitions. The dichotomies I faced, and still do, are: Do I go it alone or with others? Is this a business or a way of life? Do I stay in the system or get out of it? I realized that, in many ways, I had adopted these dualities in order to manage the social tensions I experienced, which are to some extent inherent in the New Zealand health system, referred to earlier in this thesis as the mechanism of denial. As early British pioneers to $\mathrm{NZ}$ dug through fallow ground and experienced great hardship to become settlers in another land, I realize that to some extent that is what I do. My choice to work with transition was envisioned at a much earlier time in my nursing career but the reason that I did not do it then was because I had a sense of isolation. Others had not stepped forward to work in this area from the nursing profession solely, and the conditions did not seem right. Referring to Rowan's (1997) ideas about transformation in the social level, it seemed, for me to work in this area, there had to be an integration of my subjective experience of transition and my learning about transition, to have the courage to break through a minimalist attitude in the social health context with respect to loss and transition, to bring about this vision. For me, it 
came about in my epiphanies about interconnectedness in the experiences of the death of family members that I shared earlier.

Moving from the place of alone to all-one comes about for me when I tap into this sense of oneness, as I link with others, who share the consciousness of life as a process of travelling through transitions, to discover deeper awareness of self as part of a universal thread. It is this integration of dualism and living with paradox that I share with those who see me as a transition facilitator. We mutually hold these tensions and work on the integration of them into new understandings and personal growth.

The meanings I ascribe to mutuality - looking at it through a spiritual lens - relate to the interconnectedness of beings. To explain further, I am often astounded by the frequency at which people come into my life in serendipitous ways. Buddhist philosophies refer to this as a karmic relationship. The principle of karma is explained in terms of cause and effect. For example, if I set a cause to work with people in transition, those people who most need my approach to it are drawn to my practice. What may be described in other settings as coincidences or chance meetings are not considered so from the perspective of a spiritual lens. Because we are being mutually drawn to each other's energy field, each exchange of information in the encounter is beneficial to both. In other words, there is a potential for mutual growth. At times, the process of mutual benefit is not perceived as such, when negative dramas unfold in sessions, challenging both nurse and person. I share the following excerpt, integrated from my supervision journal, to illustrate this point.

\section{Working with negative tendencies in others}

I discuss my work with two persons, seen individually, who were manifesting emotions of anger and impulsive behaviours. Although both of these people were at different ages, stages, and issues, each was operating from an external locus of control and seemed to be expecting me to reclaim their lost identities. I noticed a tendency I have to become goal orientated, controlling, and powerful in the face of this behaviour. I was asked in supervision to consider what arrangements I would be likely to make if I was marooned on a desert island with either of these people. This question enabled me to consider the relationship in a mutual beneficial way. It is about two people sharing 
skills on the even playing field of survival. As a facilitator, knowing what I know about human behaviour, understanding the potential for both of these people to be 'loose cannons' I realize the most important thing for me to be is authentically myself. As both of these people reveal a pattern of premature closure in relationship; for example, a tendency to harm themselves and others; in order to survive I would need to keep things open and be hopeful, in other words, build bridges to walk over, rather than to burn.

In this reflection, my awareness grew about the importance of attending to the process of relationship with persons I work with, modelling potential aspects of relationship with self and others, which keep things open and move them forward, rather than leading to brokenness and closure. I was asked in supervision what I considered to be the main principles underpinning this modelling. On reflection, I realized the most important aspects of relationships are to treat people with respect and be real. By being real and respectful the true identity of self is revealed; thus, uncovering layers which conceal the real self. I am real in the hope that I get honesty from the person. I am respectful so that I am respected. That way we are in mutual process.

In the case of both of these people over time, especially when I was able to let go of my need to work through identifiable measurable goals, I noticed a gradual interest in universal philosophy that each individual shared in the sessions. This occurred after several sessions of exploring recurring personal patterns and processes. An exploratory approach is process orientated, distinct from a goal oriented approach which tends to focus on content. To explain further, I encourage the person to talk about their experiences of self in relation to significant others. When stories are shared, I notice recurring patterns of behaviour in the stories, relating to the story teller and their perceptions of others. My noticing is like a mirroring process. As I mirror, using the counselling skills of reflecting feelings and clarification/paraphrasing, the person can nod to it, refute it, or refine it further. When each person in the above example felt connected back to the universal thread of human experience, they individually disengaged and their need for support abated. As facilitator in these situations, I acted as a conduit to the connection of self-with-self and self-with-other through a mirroring process; thus, breaking the cycle of isolation. 
Although in the above example I could not say that major issues were resolved for these people, I can say that processes and patterns were explored. In facilitation, the attention is on process, rather than content. If I try to control the process and become goal/content orientated in relationship to interpersonal issues, it is easy to turn away from self and focus on a set of suppositions, which tends to lead away from selfidentity. Working with people who have an external locus of control continually presents a challenge for me as a facilitator, to be grounded in my own self-identity as a nurse, and be clear about what I can and cannot do. In discussions in supervision, the theme of self-care comes up regularly and helps me to remain grounded in my statutory principles for practice as a registered nurse, and to examine my spiritual principles for self-care.

\section{The importance of self-care}

I am aware that people who are grieving, especially when they perceive their grief to be externally generated, not only have a tendency to blame others for their situation but also to attempt to borrow energy from others in order to deal with their pain, rather than taking responsibility for their own renewal. This is a situation which requires close self monitoring, as energy leeches can lead to burnout in susceptible people. As a Buddhist, I attend to my self-care by the daily practice of chanting. I do this when I wake up in the morning and again in the evening, and at any time when I need to tap into my inner wisdom about a situation. The Nichiren practice of chanting is a centering meditation for observing the mind, to call forth one's highest wisdom, or Buddha wisdom, and to come into rhythm with the universal law. In this process of chanting, I am also seeking to raise my life-force, renew energy, and deal with my own deep layers of consciousness, which work against these principles. Chanting also serves to remind me that each person has inherent Buddha nature; therefore, each of the people I see has the potential to overcome their difficulties and to find their own solutions to the issues they are facing, from within. Although this is my identified selfcare practice, I do not think it is the only way to care for self. Thus, I suggest that all nurses who work in the interpersonal area consider a form of self-care that facilitates energy renewal. As facilitator, my role is to maintain a focus of personal empowerment and self responsibility for the person. This has caused me to reflect, in supervision, on the dance that I do between science and spirituality. 


\section{The paradox of being goal oriented and allowing things to evolve}

In spite of a growing use of the Strengths Model, Solution-Focused Therapy and the Recovery Approach in mental health, which focuses on positive aspects and potentials; risk management is once again the focus of secondary and tertiary care for mental health (Chandler \& Mason, 1995; Rapp, 1998; MHC, 1998). This I believe has occurred in the interests of political expediency fuelled by media attention of rare but serious situations involving those with mental illness. This trend represents a pendulum swing in mental health and a return to a biomedical focus. A biomedical focus approach tends to be problem orientated, where the parameters of nursing input is narrow, focussing on diagnosis, treatment, and measurable outcomes.

For example when I was working as a mental health nurse in public services I found I was frequently engaged in a search for what is wrong and how to deal with it because of the expected outcomes of the health service. This was done using problem-solving processes, which involved formulating a series of goals from which to measure outcomes. In this approach, my role as a nurse and the people I worked with were clearly defined. My role as a nurse was identified as the health promoter/provider, and the person in care was perceived as the sick one. Each time we met the stated diagnosis; risk factors, goals, interventions, and outcomes were addressed and became reinforced. This allowed little room for other aspects of the person to be revealed, such as mastery and wellbeing, or for things to evolve. A 'them and us', 'sick and well' 'Iit', dichotomy was maintained. I noticed that people in care learned to show sickness as a basis for relationship; and saw me as a knowledgeable other. As a nurse my own humanness and vulnerability was carefully concealed behind shields of so-called professionalism in the interests of maintaining acceptable professional boundaries. I felt this set up artificial relationships of power and control, sometimes leading to a feeling in both parties that something was being missed. I noticed that I experienced this tension, stated at the beginning of my supervision reflection, when I adopted a powering, forcing approach. I found I tended to get regression from the person and left the session feeling as though I had done most of the work.

This does not mean that I negate the need for nurses to address risk factors. The focus of facilitation is on the surfacing of the tensions in the session, which sit in the foreground of the person's life, the focus being on patterns and processes. This 
approach is most likely to generate a genuine response and an honest exploration leading to self responsibility and adjustment of negative patterns. Agendas for outcomes can be put aside to allow for the emergence of evolutionary shifts in consciousness which taps into a deeper spiritual layer of processing than can occur in the limitations of a biomedical focus.

\section{Looking at life through a spiritual lens}

Allowing for the emergence of evolutionary shifts in consciousness is consistent with looking at life through a spiritual lens. This is one of the focuses of peer review. As we are both nurses working in mental health; this way of viewing health and wellbeing is chosen as a way to facilitate a deeper awareness of self in relation to others and the environment. In doing this, tensions become evident in relation to spiritual ways of viewing the world, and the NZ mental health system, which tends to privilege medicocentric approaches, placing emphasis on the management of risk as a bottom line parameter for care and treatment. To clarify this difference, looking at it from a spiritual lens within peer review, a person is seen as the principal author and creator of their life. If the person is suffering, the suffering generated, has an internal source, rather than being seen as something that happens upon the person through bad luck, or primarily external causes. Facilitation of health from the perspective of a spiritual lens; therefore, involves an exploration of the realm of personal choice and self responsibility, as well as the tensions that exist in the external environment. Personal choice and self responsibility were patterns identified in the following exemplar, relating to my facilitation work with Rose.

\section{Archaeological dig: A metaphor for self exploration}

The themes of self exploration and self responsibility, among other things, were reflected upon over a period of two years by Rose, a young woman in her $30 \mathrm{~s}$ in recovery from a fluctuating mental health state, primarily involving her mood and cognitions. Rose has been receiving medical treatment since early adulthood. There is no doubt that a medical approach has been beneficial for the stabilization of her mental state. It did not however, address her life from a spiritual perspective, which was her reason for working with me in addition to 
her primary care team. In the sessions Rose spoke about her attraction to archaeology, which she was exploring in a course of study. The archaeological dig became a metaphor for her search for what she was hoping to find in her own life. This search involved an exploration of her own sense of identity through considering her cultural background from a heritage with a Christian basis.

She acknowledged that these influences had a significant impact on her views of the world and her sense of spirituality. Faith and hope were identified as being important in the sessions and a driving force for her struggle to maintain wellbeing. Having a sense of connection with others was an area that she sought to work on. Rose did this by considering how she could integrate with the community through work and recreation. Although this is something she always has to work on, her sense of not being alone is important to her. Rose's belief that there is a God is a great comfort. It is part of a belief she has gathered, with her perception of life and spirituality, along with an understanding that there is a middle way, a place of balance, a place of reason, humanity, rationality, understanding, and of good intent. In her own perception of spirituality on exploration, Rose revealed some tensions in the outworking of her beliefs in her life. She recognised a tendency to do 'emotional labour'; for example, listening to people put her feelings aside, and feeling she 'should' be able to make everything alright for those people no matter what she felt about it.

At times of un-wellness, Rose did not feel strong enough to fully express what she felt, and it seemed at those times that her real self was being veiled by the mists of illness. She noticed the potential to be misunderstood and misrepresented. Clouds rolling in occluding her real self seemed a fitting metaphor at these times; conversely, sun coming out represented becoming well again and being able to show the essence of who she is. 
Rose, in the process of dialogue over time, was seeking a more direct route to her inner self. We discussed viewing life from a spiritual lens, rather than an inherited construct of spirituality. In viewing spirituality this way, she was able to put forward the view that being self responsible was important, along with stability, integrity, humility, and having a sense of interconnectedness. Rose identified that she valued honesty and respecting self and others. She saw this way of viewing the world as different from having a sense of obligation to others and trying to please others by putting on a mask. Becoming more open to herself and others, through self acceptance, was an area she sought to work on in the sessions. This involved, not only openness to her deeper feelings, but also an acknowledgement of the hopes and dreams that had been lost in the process of her fluctuating health. Taking this forward into the present moment and opening new chapters, dreams, and hopes, involved a combination of envisioning and stepwise planning.

Over time, in my practising a goal oriented approach, I have come to the realization that allowing things to evolve is an antithesis to goal setting. Instead, I have been discovering and living with the paradox of planning for the future, whilst at the same time allowing things to evolve. Part of the process of allowing things to evolve seems to involve a period of reflecting on past patterns; symbolized by the archaeological dig, and making space for new possibilities. This was the subject of a peer review session.

\section{Reflection on releasing stored energy}

The notions of the importance of the archaeological dig and the releasing of stored energy came up in peer review, when we were discussing our experiences of being engaged in renovating activities and finding spaces for stored belongings, especially those which pertained to the self. Looking at it through a spiritual lens, we mutually came to the conclusion that archaeological digs, renovations and clearing storage, are the externalizations of an inner process of change. Releasing stored energy was mutually discussed as being freeing but cannot be done until a process of readiness 
has been reached. In this process, it seems as though an emotional release precedes cognitive processing and that both are needed for dialectical integration. This process cannot be forced externally or shaped by others. Thus, the synergenistic role of facilitation is crucial, along with the understanding that each person is responsible for their life journey. As an example, I recalled an early experience when my father introduced me to energy fields. He was teaching me by negation, and although I was only six, I sensed that he was attempting to shape my understanding in a certain way, and that he was also attempting to exclude some schools of thought in the process. This closed means did not have congruence with the subject he was teaching me and I rejected it at that time, not really fully understanding why. I now see that it was not so much the content of what he was teaching me, but the process which was unhelpful to my learning at that stage. I was not able to proceed forward with the learning of energy fields until the conditions were open and exploratory. This did not happen for me until I reached my 40 s.

The notion of allowing things to evolve came about for me in a nursing education context, in the synergy of teaching. I became aware that I had made significant shifts in my thinking when I was propelled back into the theory of communication in nursing, while teaching undergraduate first level nurses in the early stages of writing this thesis. I began to unpick nursing theories in mental health nursing as I reflected on my evolving knowing. Themes of Munhall's (1993) ideas about unknowing emerged, as I reflected on this change, and the following words of John's (2004a) mindfulness echoed in my mind.

I do not pretend to know. Indeed, I eschew knowing, because once I think I know then I am at risk of closing my mind to other ways of seeing and being. Worse, I may become attached to my knowing and resist attempts to view in other ways. Worse still, I may impose my restrictive frameworks on others, especially if I set myself up as an expert and teacher (p.19-20).

I reflect on these ideas in the following excerpt from my personal journal. 


\section{The emergence of energy facilitation}

I am struggling with the concept of emptiness. I notice this when I teach beginning students, as I struggle to make a connection with them. I become aware of a tension that I hold when I attempt to discuss theories about communication in the nursing curriculum. I realise that in my journey toward becoming a transition facilitator, I have emptied myself of many of the theories about interpersonal relationships that have influenced me in the past. They no longer seem relevant to the processes I now use. This feeling was like 'being cast adrift'.

I am aware that I am reaching out to another way of knowing. In this experience, I begin to notice new processes occurring in myself. In my practice, I begin to hear much more than the person is telling me with words. I start to see underlying patterns in their energy field. I refer to my knowledge of chakra systems I had learned about from my father, and later a spiritual mentor, who taught me to work with the auric field and the chakra system, and writers such as Myss and Krieger. When clients ask me, I use what I know to scan their chakra systems with my hand. I begin to notice resistance and blockages and I see, in my Mind's eye, the possible reasons for sluggishness or overactivity, information that I check with the person. In this experience of mindfulness, I experience emptiness to my own knowing. I am able to tap into a deeper level of communication from the spirit energy of the person. In this situation I bypass their censor and my censor and find a deeper pattern of energy. This experience of tapping into the deeper pattern of energy revealed a tension for me, which is about being part of a profession that has a set of theoretical constructs - and being a facilitator of transition tapping into deeper layers of consciousness. I begin to question - am I a nurse? Can I be a nurse in this evolving knowing-unknowing dynamic? I experience discomfort and ungroundedness as the integral quadrants of Being come into alignment. For several days I feel doubtful - uncomfortable. I refer to a quote which I had recorded in my journal in 2005 by Bhagwan Shree Rajneesh (1974),

If the technique fits you these three things come up... Rather than becoming more at peace you become more disturbed, this is an indication that it is right for you. Peacefulness indicates adjustment to an old pattern - to society to family. Meditation will not help as an 
adjustment, only as a transformation. Harmony or peace does not necessarily mean peace and harmony with society or friends. The harmony is with the universe. Then the deep harmony flowers between you and the totality - then silence - but first you must be disturbed. It the technique fits, it will make you aware of everything that you are, your anarchy, your mind, your madness. Everything will come to light. Darkness becomes more apparent. For the first time you will encounter yourself as you are. You would like to put the light off and go to sleep again. It is fearful. This is the point when a teacher or mentor is helpful - by reassuring you that this is just the beginning and not to be afraid. Do not escape from it. At first light it shows you what you are, and if you can go on and on, it transforms you toward what you can be (p. 49$50)$.

As I consider this, I realize my reflection is about dealing with tension in the social level of nursing and community ideas about what is acceptable practice. Much of nursing practice seeks to ameliorate pain, whether it is emotional or physical. There is often an association of dis-ease as being bad or needing to be fixed. Rajneesh reminds us that it is our disturbance that will ultimately lead to harmony if we can just be-fullywith-it. DNFT does not attempt to eliminate disturbances; rather, they are given full play as variables, teased out in the situation that the person is in. Facilitation involves exploring ways that painful experiences can be integrated into the person's life, so that they become part of the backdrop for new stories to emerge. The self-identity becomes sharper, and the person feels more at-ease with a changing world, trusting that they have what they need to go on. My noticing patterns in the energy field become a tool for this exploration. As patterns show up I can check them out with the person, as a beginning point to a dialogical exploration. This type of exploration, in my practice, is only done when the person indicates a willingness and desire to explore energy fields. In these cases, I explained what I did and saw in a transparent way, encouraging the person to be involved in the process rather than be a passive recipient of it. Energy facilitation was part of my work with Lilo, Grace and Sophie. 
Being able to notice patterns in the energy field is dependent on my ability to go within and trust inner wisdom. This is similar to Krieger's (1997) notion of tapping into inner knowing in her centring process, prior to therapeutic touch (TT). Tapping into inner wisdom is a process that requires an understanding of self, in a broad sense, as an amalgam of emotions, cognitions, socio-cultural connections, and spirit. Nurses who choose to work in this way ideally have a deep awareness of all of these aspects. I offer a reflection from supervision in which I notice processes in myself that lead to tapping into inner wisdom.

Tapping into inner wisdom

I discussed my noticing of a growing awareness I had when working with people. I experience this as a sense of detachment. I was unsure about this newly identified feeling, as it did not correspond with a sense of being removed from the situation or being objective, which in the past had been an effort. On exploration in supervision, I identified a sense of flow. I realized, on reflection, that this is a state of egoless-ness being in the moment and fully-with the story of the client. In contrast, being ego-based is having the need to control, set goals, and achieve them in a certain way. I become more aware why focusing on outcomes, is an antithesis to enabling things to evolve and for healing to occur.

In this flowing, gliding state, intuitive insights surface easily as inner wisdom, enabling me to respond appropriately, without judgement, and for the person to proceed with their story, knowing that they are heard and understood where they are now. Insights coming up from inner wisdom also arise in the person, as they recognise patterns of their life story. It is these insightful moments that provide the seed for new stories to emerge, as the person claims authorship of their life story and the possibility for new chapters to be created.

This feeling of gliding is not always with me. In my discussions in supervision, I realize that it comes about when I can own my anxiety about a situation and allow it to rest as I open up to the other. An analogy that comes to mind is the attitude I had as a child when opening up a book for the first time. There are no expectations, just a sense of curiosity that leads me into the story. On reflection, the stories that were most 
compelling were the ones that rung true, connecting me with shared hopes, dreams, and aspirations of the universal human story.

In meeting the other, I meet myself. In this process, the need for solutions does not exist - just the story and being heard - as the mirroring process reveals the potential for more stories to unfold. I expand on this in the following exemplar.

\section{Reconnecting with self}

This process was apparent in my work with Lilo, who had reached an impasse with her health and recurrent negative patterns in her relationships with men. My work with Lilo, over time, opened up an exploration of patterns through noticing the words she used to describe her life. One of the significant phrases Lilo used in her initial session was the sense that she had of "lurching through life". I kept on coming back to this with her - echoing her words. On reflection, a memory surfaced for Lilo about her relationship with an older brother, in an experience she had when she was just learning to walk. Her brother had offered to take her for a walk, and she did not really want to go. She remembers him pushing her as she "lurched" forward with each reluctant step. In a sense, this relationship carried on with him and others, especially the men throughout her life. In the sessions, over time, it became apparent that her life had been lived by others' expectations, and that in some ways, she had let go of her own knowing. Others had been authoring her story and shaping her character, and that sense of reluctance to move, and a feeling of lurching had become a main pattern for her.

Coming home to herself as author of her life story became the focus for the sessions, rather than her negative health patterns. This process involved journaling between the sessions in a non-censoring way. In this process, insights, dreams, and reflections came up and were opened up and explored in the sessions. As an artist, Lilo began to notice 
different and surprising symbols and patterns emerging in her paintings.

A break-through in Lilo's reconnection with herself, as principal author of her life, came about after a session in which I scanned her energy field. Lilo was interested and somewhat sceptical of this possibility, but recounted an experience in the past, in which she had benefited from energy healing. In the sessions, I had noticed her attraction to stones and crystals in the room. I asked Lilo if she wanted to learn about her energy field using a quartz crystal pendulum. I scanned the seven chakras with the pendulum and told her my understanding of each chakra and insights I had, as I identified each one. I showed Lilo how to find the energy and work with each chakra with her hand and retest them. It was evident that there was a significant block in the energy of her $3^{\text {rd }}$ chakra and over activity in her $4^{\text {th }}$ chakra. Informed by the work of Caroline Myss, and insights from inner wisdom, I wondered whether the sluggishness of the $3^{\text {rd }}$ chakra was related to Lilo's self-identity and self-love, and the over activity in the $4^{\text {th }}$ chakra was her tendency to freely give to others at the expense of herself. This rang true for her, and I encouraged her to work with these chakras at home with her own stone. I encouraged Lilo to place her hand on her $3^{\text {rd }}$ chakra, and meet her real self - to hold her hand there while she gathered an intuitive sense of herself and the things that held her back.

When Lilo was able to do this in the quietness of home, she experienced a deep meeting with her child self and the recognition that most of her life had been involved in concealing this aspect of herself, so that it could not be judged or hurt. In doing this, she had closed off to aspects of herself as spontaneous, fun making, and energy creating, especially in relation to others. This meeting real self was a turning point for her - reconnecting her with herself as principal author and shaper of her life. 
Lilo continues to live with the vicissitudes of her energy levels and has developed gratitude for the stillness she is able to experience in times of rest. She has become more accepting of her need for rest and low stimulation. This has led to some alterations in Lilo's lifestyle and work patterns, which she continues to moderate as more subtle physical and emotional and spiritual needs are identified.

\section{Energy Facilitation}

Working with energy, using the chakra system, within nursing has been researched and practiced in the U.S., especially the practice of TT, pioneered by Dolores Krieger in the 1970s and HT by Janet Mentgen in the 1980s. There is little written about the use of TT or HT in NZ and it is difficult to find registered nurses working in this way within the health system. Although complementary therapies have growing support within the community in NZ (see MACCAH, 2004), they sit outside mainstream service provision, which is dominated by the medical model. Aside from traditional therapies used in Maori health care, which have the support by the Ministry of Health, in principle, because of the Treaty of Waitangi, (see MHC, 1998) this same support is not forthcoming in the non-Maori sector. It is difficult for people to obtain funding to access non-invasive complementary therapies. This does not match the growing demand for complementary therapies by the public, who have access to literature supporting these modalities. Increasingly, nurses are being exposed to such modalities in their undergraduate education. But education and training, especially for energy work such as TT, is not offered within postgraduate nursing education programmes. In my experience, the process of becoming what I would call an energy facilitator is not simple or straight forward because ideally those who are able to use it successfully and safely are usually people who have been involved in personal growth, which encompasses the mind-body-spirit.

My education in energy work sits outside nursing. As stated previously I began my introduction to the chakra system early in life. Although at that time I was unable to use it or develop any further knowledge of it, I came back to it in the mid 1990s when I began the practice of guided meditation. This practice involved an introduction to the auric field, the chakra system, the use of crystals, and support to develop energy 
sensitivity; in other words, learn to pick up the subtleties of energy through scanning the auric field with the hands, in much the same way that Dolores Krieger does (see Krieger, 1997).

One of my first uses of energy facilitation was with my father in 1999, when after the death of my mother, he developed heart failure. I share the following experience from my personal journal (1999).

\section{Retrospective reflection on energy facilitation}

My father was having difficulty breathing, especially at night, not only because of congestive heart failure but also because of emphysema. As he had introduced me to energy work earlier in life, I told him that I had been learning how to scan and channel energy for healing and asked him if he would like me to try it to relieve his distressing symptoms. At the time he was well-supported with medical treatment, but this was not helping him much at night when he was troubled by an increase of congestion. This problem had caused him considerable anxiety and prevented him from having a restful sleep. He was willing to give it a go trusting that this process was valid and safe. Before he was ready to go to sleep I scanned the energy over the body to get a sense of where the energy needed to be channelled, and as expected, following theories put forward by Myss (1997) about physical structures and their interface with the corresponding chakra, there was considerable blockage in the $4^{\text {th }}$ chakra, commonly known as the heart chakra. I channelled energy in the area of the chest for a few minutes and noted that his breathing had slowed down and he was more restful. He coughed for a short time and was able to expectorate sputum freely. Following this he was able to drift off to sleep peacefully and enjoy a few hours of uninterrupted sleep. Energy used in this way was not a replacement for his medication or inhalations and did not stop the expected course of his condition. It did, however, provide palliative care and relief from anxiety and enabled him to have more enjoyment in his day.

On reflection, I felt deeply moved to be able support my father in a culturally appropriate way before he finally passed away in 2002, having extended at least nine of his expected life spans; according to his GP. His passing came at the right time for him and has left me with no regrets about my time and relationship with him. 
Although I felt that a very tall and strong tree had fallen in my life when he died, I am left with appreciation for the values and spiritual principles that he shared with me, and for the example of his indomitable spirit in the face of hardship.

Deeper healing in my experience cannot really take place unless there is also an exploration of mind blocks, physical checks, and spiritual growth. This also requires the facilitator to have deep experience and wisdom generated from inner growth and healing work. For the safety of the facilitator and the client, ideally this is an ongoing process and requires the supervision of a mentor, in much the same way as practice supervision.

In my practice of energy nowadays, I am mindful that the use of this skill does not have the backing of my registration as a nurse. Therefore, to ensure that I fit within the bounds of safe practice I locate this activity outside my nursing practice being careful to let my clients know that I do not have 'recognized' qualifications for energy facilitation, and therefore they receive this part of my work at their own risk. I have found there is an increasing request for such work, in the context of an integrated approach. It is my intention over time to formalize this work in my nursing practice, in a way that is acceptable to my own growing understanding of energy facilitation and my spiritual practices. Energy facilitation is in my view, ideally a practice that involves the education and participation of the client as much as is possible, and is augmented by a mind-body-spirit assessment. Further, an energy facilitator does not purport to heal another in a passive way; rather, facilitation involves supporting the person to access their inherent potential in order to take responsibility for their own healing (Krieger, 1997; Myss, 1997; Gordon, 2002). Facilitation is a conduit to this process. It is my belief that energy facilitation can be learned by anybody who is prepared to take full responsibility for their life and to develop the wisdom to understand the deeper workings of the mind-body-spirit. It is difficult to facilitate healing energy when there is an ego investment in it or when it is not done with the attitude of compassion for the person. These factors make it challenging for energy facilitation to be set up as a course of learning in an institution where the parameters for completion are decided by some objective assessment process and when it becomes an issue of copywriting. Bearing these things in mind however, it is my vision that energy work will become a mainstream modality of nurse healing in 
Aotearoa NZ, readily available to those who choose it. I contend, like Dolores Krieger and Janet Mentgen, that nurses who have an integrative knowledge of health are ideally placed for this type of work.

\section{Recovery of spirit}

We discuss the limitations of working with the spiritual lens in mainstream mental health services and internal limitations of ourselves. The 'Recovery of spirit' is the name of a group process designed and facilitated by, my peer reviewer in the mental health context. Recovery of spirit explores opening up to the spiritual lens. Although this work is in some way impeded by the parameters of nursing practice in the mainstream identified above, it is possible to 'seed' an openness to the spiritual lens, which can be deepened in other contexts. To prepare for this work, we recognise the importance of uncovering the attachments of ego mind to familiar emotional responses and cognitive patterns of thought. In doing this, we discuss the most difficult patterns to change, for example, familial relationships. These relationships unearth a real difficulty in living the notion of taking full responsibility for all things that happen in our lives, including unhelpful family patterns.

Experiences are shared between us of familial patterns being mirrored in the work of facilitation in the form of transferences and countertransferences. A tendency to call in experiences and people which trigger our own repetitive unhelpful patterns is acknowledged in the peer review session. In supervision and peer review, there is an opportunity for a deeper understanding and recognition of patterns, coming to a point of readiness for change. Facilitating an understanding of this, in those who are uninitiated in viewing life from the spiritual lens, is difficult, especially if the people we work with are committed to the expectation that others will fix things for them.

We discussed the importance of developing the fitness of the 'observer', previously described as the egoless self. The observer is capable of seeing things as they are, with openness, recognising energy connections, and unique patterns of being. We mutually recognised that going into an observer role, or egoless state, enables a facilitation of an exploration of life through the spiritual lens. I expressed the view that developing the fitness of the observer is most likely to happen in the experiential world and the doing world, rather than the theorizing or cognitive world. Theorizing 
is the result of the fitness of the observer, rather than a precipitant. In the writings of sages and prophets, the wisdom of the observer mind is expressed in the form of parables, which tell of the profundity of every day experiences in real life.

I offer Table 16, as an integration of the foundation patterns that emerged for DNFT which become a basis for Chapter Eight.

Table 16: Foundation patterns for DNFT

\begin{tabular}{|l|l|}
\hline Patterns & \\
\hline Being \\
grounded & $\begin{array}{l}\text { Having a connection with the land } \\
\text { Being self-aware as a person and as a nurse } \\
\text { Being grounded in universal principles and the mutuality of life } \\
\text { processes } \\
\text { Caring for self for energy renewal }\end{array}$ \\
\hline $\begin{array}{l}\text { Being } \\
\text { connected }\end{array}$ & $\begin{array}{l}\text { Being connected with self-identity } \\
\text { Having a sense of interconnectedness with self, others, and environment } \\
\text { (oneness) } \\
\text { Tapping in to inner wisdom } \\
\text { Seeing patterns of energy with the mind's eye } \\
\text { Experiencing serendipity } \\
\text { Being aware of patterns and processes in mind-body-spirit }\end{array}$ \\
\hline Having faith & $\begin{array}{l}\text { Trusting the process } \\
\text { Taking risks } \\
\text { Taking responsibility } \\
\text { Looking for open doors and walking through them } \\
\text { Envisioning } \\
\text { Being hopeful } \\
\text { Keeping things open } \\
\text { Allowing things to evolve }\end{array}$ \\
\hline Being real & $\begin{array}{l}\text { Consistency of behaviour within professional and private settings } \\
\text { Honesty } \\
\text { Being accepting } \\
\text { Being respectful } \\
\text { Being a mirror }\end{array}$ \\
\hline
\end{tabular}

\section{Summary}

In my view, dialectical nurse facilitation of transition, seen through the perspective of a spiritual lens, is being grounded in mind-body-spirit, and wanting to be a real witness to the person's reality - being with the person in the moment - trusting that we will both go to the place that we need to go and it will be okay. Facilitation of transition also involves being mindful of professional parameters and working within them. The metaphor my supervisor used was "swinging on a trapeze with a net 
underneath". In my situation as a nurse in private practice, I adhere to the professional codes of conduct and ethics for registered nurses in NZ and the NZ Mental Health Act (1992); NZ Health Information Privacy Code (1994); and NZ Public Health and Disability Act (2000). To protect myself, I have insurance cover for my practice and have a contractual arrangement with the people I see, which addresses the selfmanagement of personal safety and health, the liaison with other health professionals, and a disclaimer (refer Appendix G).

In Section Two I expand on my role of DNFT as I make sense of the transitional journeys of those I work with and the processes that stand out for me as consistent patterns for transitioning.

\section{Section Two: Transitional journeys}

One of the statements I frequently hear on a first meeting with people I work with is the phrase, 'I hit the wall'. I call it reaching an impasse because it is a moment in the transition when previous patterns of dealing with situations no longer seem valid. The person feels as though they are stepping into new territory, often at a time when they are encountering a major loss, such as the death of a loved one, or a change in their life circumstances; for example, a relationship break-up, or coming to terms with a change in their health. These situations often leave the person with the feeling that they don't know who they are anymore. The following exemplar illustrates this process.

\section{Hitting the wall}

I met Sophie in a hospital when I was doing some relief work in the mental health field. I was asked to see a woman in her 60s who was recovering from acute abdominal pain. Sophie was in great distress and although she was having problems with her gall bladder, as I spoke with her it was evident that she had reached an impasse in her recovery from a broken relationship about 18 months earlier. Sophie's hopes and dreams for this relationship had been shattered, and she was not sure how she was going to go on. She chose to see me on a regular basis to try and piece together where it had all gone wrong and to search for a 
hopeful way forward. This work involved a combination of emotional catharsis (see Figure 1), energy work, and the retrospective exploration of reflective journals and artwork. Sophie reflected the exclusion of hands in this picture represented the powerlessness and anger she felt in situations of impasse. She said: "It took courage to paint this as I felt I had no right to be angry".

In the co-construction of these exemplars, Sophie felt her visual journals added an authentic dimension to her experience of facilitation work.

Figure 1: Releasing emotions.

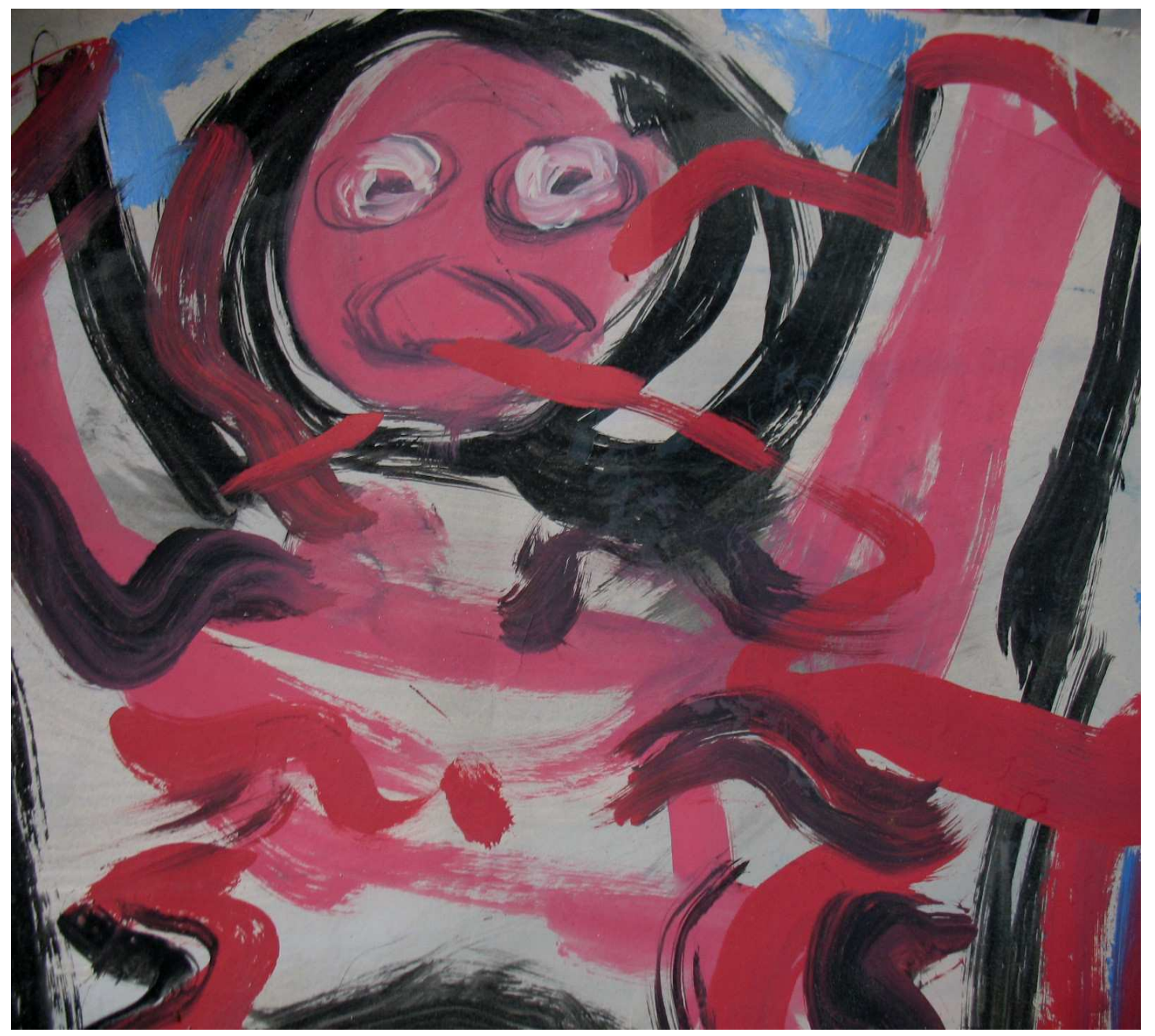

My work with Sophie, had elements of mutuality, connectedness, and serendipity that

I discussed in Section One. I expand on this in the following excerpt. 


\section{Experiencing serendipity}

Sophie often said to me that I had come in at the right moment to her situation of struggle, a helping hand - a listening ear - a puzzle partner. A rapport was struck easily, as we found resonance in the noticing of symbols and patterns that her life had created. I asked her if she had noticed any signpost when he left. "It's rather odd you should say that," she said, as she rummaged through her purse to find a piece of paper that had flown in the air and landed at her feet the day he had left. It was the title of a book "Where the Road Ends". She kept it, wondering if it signalled the ending of this chapter of her life. These symbols and patterns emerged as our explorations touched primary echoes as we moved from the foreground of her current experience to the background of the past; and were integrated in her art work..

\section{Discovering the many faceted self in imagery}

Sophie recalled a much earlier episode in her life when she had been hospitalized with appendicitis, following the untimely death of her father. In our early sessions together, Sophie spoke about the pastpresent, present-past as she took me through the labyrinth of her life story, in and out of memories, with humour and tears, artwork and poetry - sometimes shedding light on herself, sometimes enigmatic. Sophie is a strong pioneer woman - a survivor - owner of a small lifestyle block - living in a house she had built herself - a conservationist, her delicate feminine appearance incongruent with the witness that she bore of her daily lot. Art-work revealed more than words. The first work she showed me was a mirror on a dressing table a reflection (see Figure 2). She was planning to paint $\underline{\text { Him }}$ in the reflection. I commented that the reflection looked rather like $\underline{\text { Her }}$ and I wondered if perhaps she was really the focus now. Sophie replied that it was strange how the face had evolved, taking on a life of its own. On reflection this picture represented aspects for Sophie that created 
tension between getting it right artistically and expressing how she perceived her life at the time.

Figure 2: What's on the table for the future?

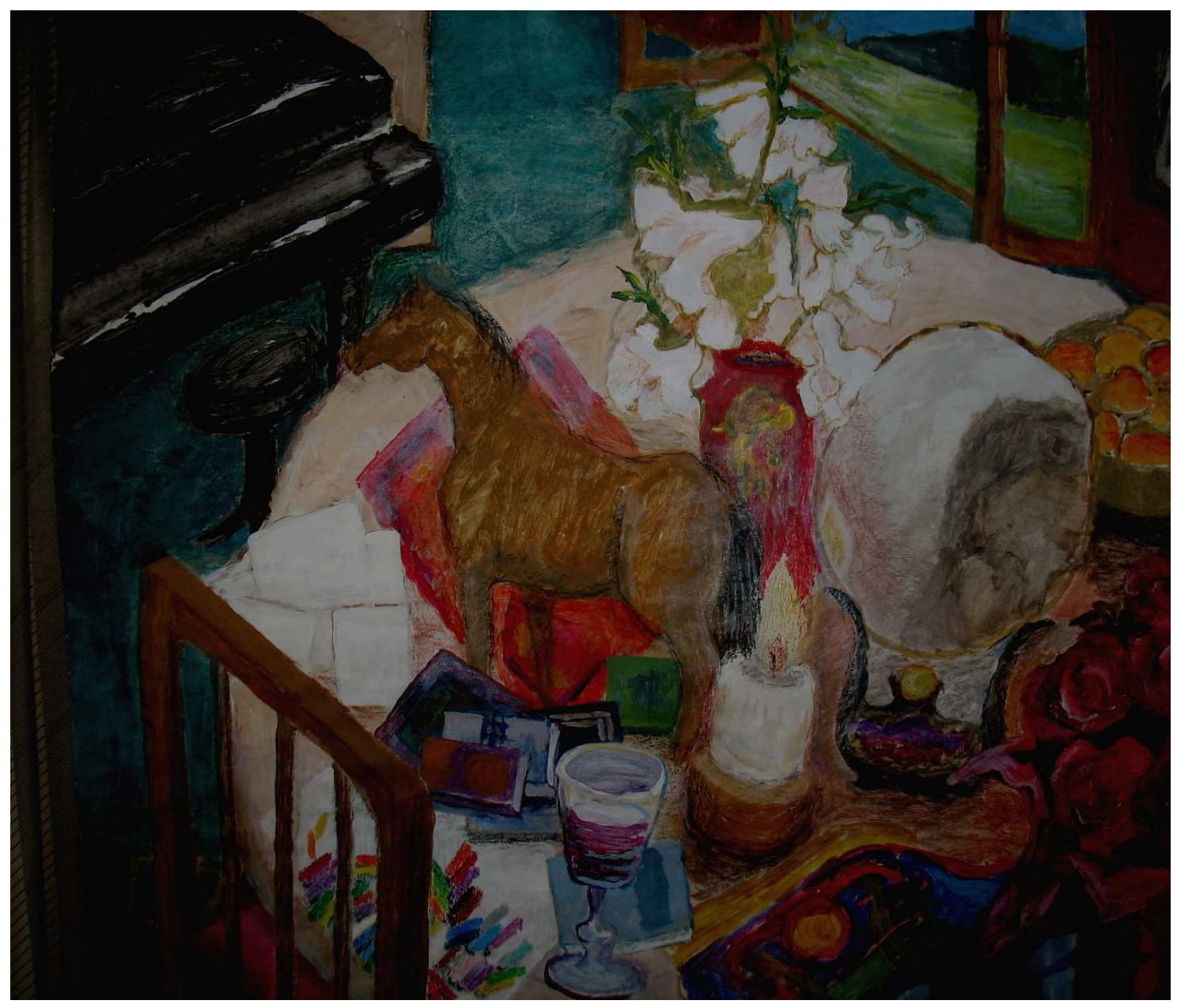

\section{Reflecting on facilitating change}

We discussed impasses and what keeps some people from seeking change. We talked about the role of the facilitator, the real work of transition - to reconnect self-withself, as in the above example, where the focus became the self portrait. Embracing self is the hardest of all tasks when it comes to transition, and the hardest to facilitate. We discussed self-care when lost selves seek other selves to lean on, or plug into, and rituals that can helpfully focus me as facilitator on myself as true self. Transferences and countertransferences are skilfully noticed as I tell my story of dual tensions experienced when I cross the bridge of transition with the people I work with. Parallel processes are brought to awareness, between facilitator and person, supervisor and facilitator, as energy is renewed and fresh insights emerge. 


\section{A search for change}

In the process of seeking change, Sophie brought free-form paintings and sketches she had done previously to the sessions. These meaningfully illustrate her change processes. In Figure 3 Sophie reveals the 'to and fro' of dialectical process as she searches to synthesize and make meaning of her situation. She expressed a feeling of being stuck and ambivalent when she drew it and was aware of censoring herself to please others.

Figure 3: The 'to-ing and fro-ing' in a dialectical process

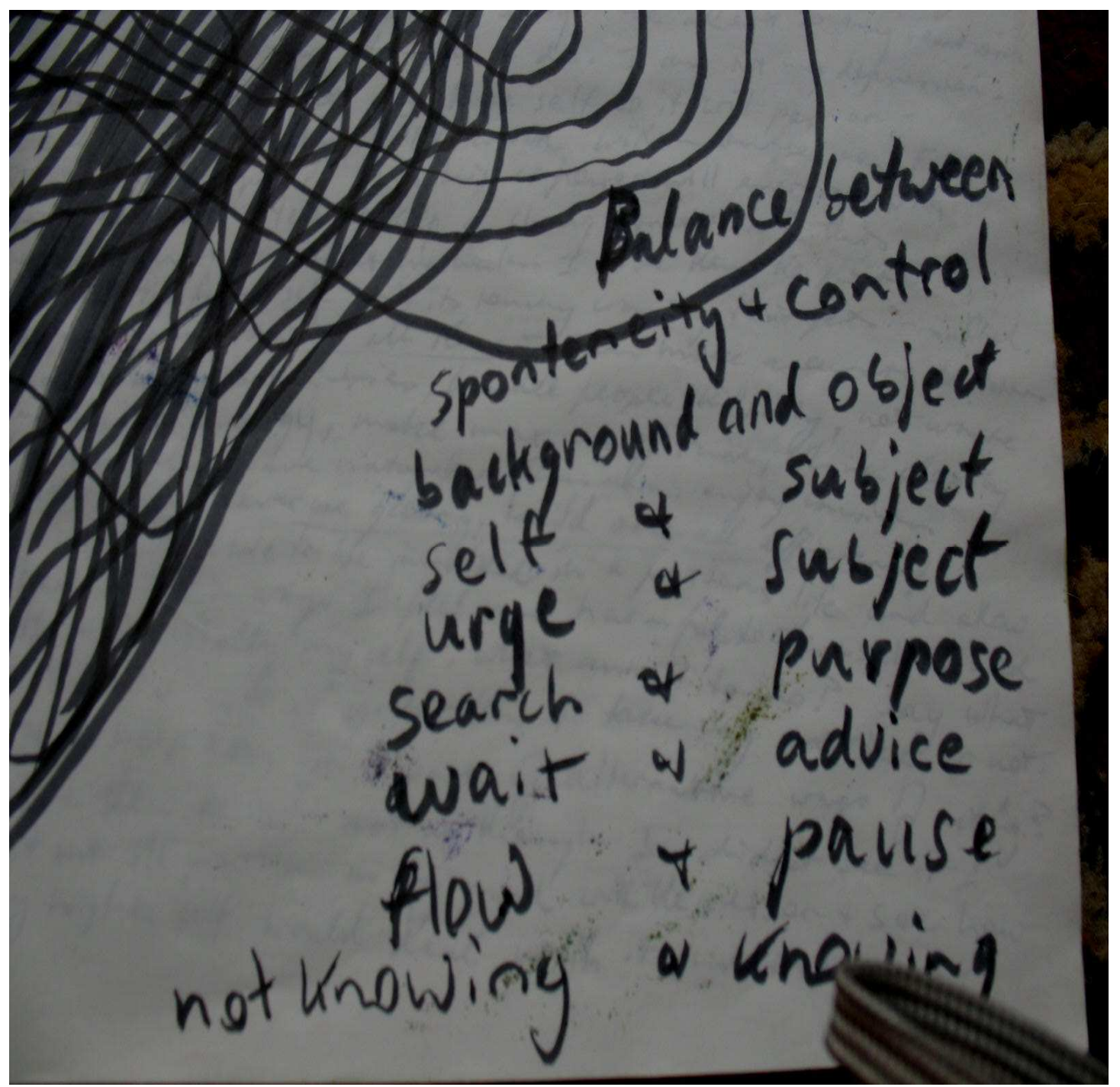


An embryonic process of change is depicted by Sophie in Figure 4, as new growth emerges from the core self and extends outward to form new patterns.

Figure 4: Embryonic forms

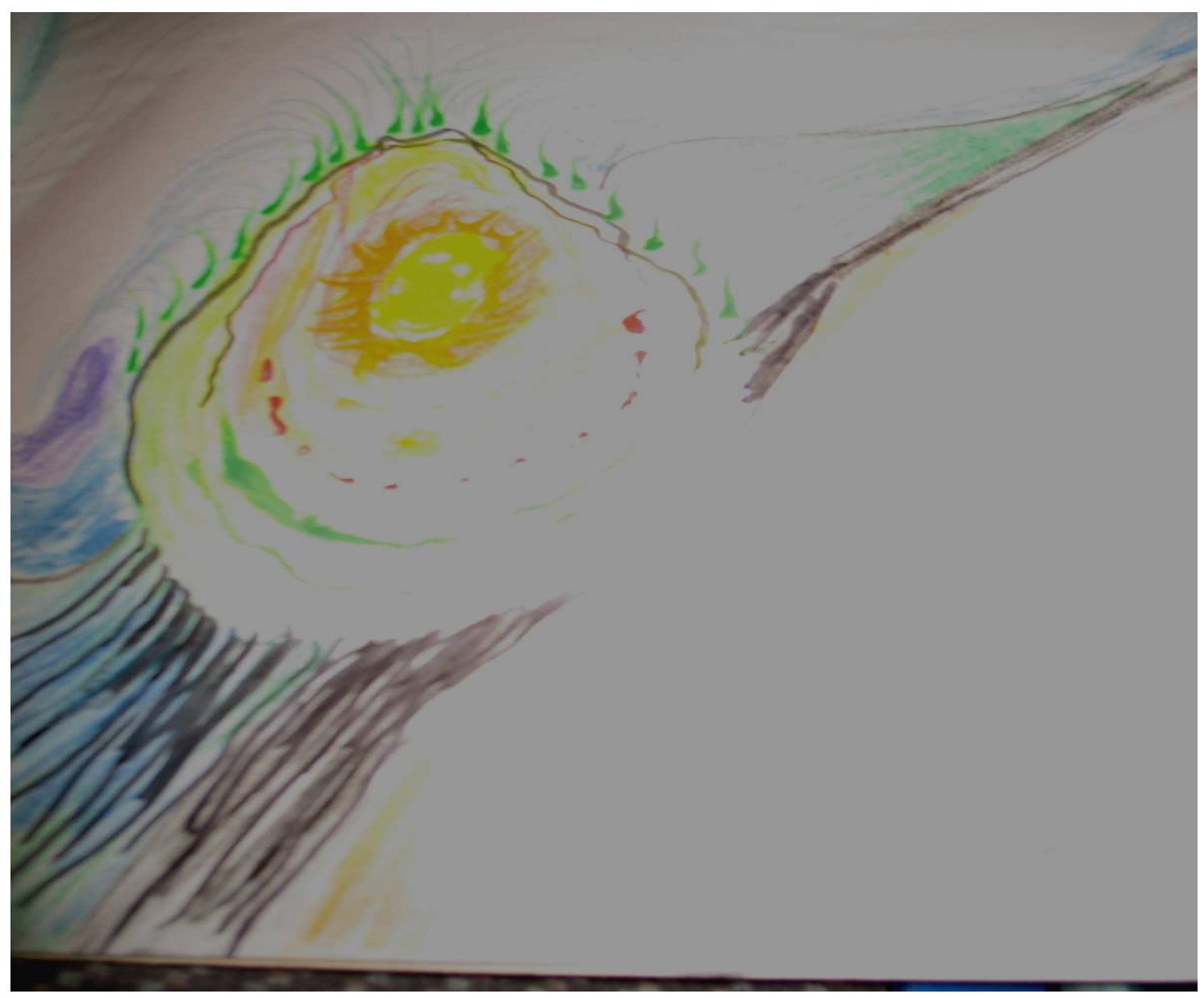

Being with a person in their impasse is a skillful balance between gentle processes of encouragement, coaxing, and confrontation and challenge. As in dance, perfect balance is held with honesty and respect. This balance has elements of anam cara and kalyanamitra (O'Donohue, 1997). Even then, the initial impasse may be traversed only to find the presence of internal and external resistance forces to present another wall to overcome, this one much harder than the first.

\section{Meeting resistance}

Meeting resistance was apparent, in the story of Sophie, as the presence of two noisy roosters made them-selves at home at her property. No 
matter what she did, she could not seem to capture them, and as they crowed loudly each morning into the day, she felt a cloud of defeat creeping over her newly found self. These roosters took on the symbology of troublemakers in her life that did not go away. Why did they stay when lovers, who she wanted, did not? I heard about the roosters for several weeks, and the plumbing problems, then another acute abdominal pain episode, and a brief visit to hospital. We looked at the pattern of this resistance within her, now reflected in her environment. It felt like push and pull for several sessions, and I suggested that the roosters will be caught when she is ready to come to know her saboteur. Soon after, Sophie came into the session smiling broadly, announcing that the roosters were GONE.

A rooster box ( see Figure 5), with its open case serendipitously found some time later by Sophie, is a metaphor for the departed rooster's symbolic ashes; and the significance of overcoming the problem identified in this story.

Figure 5: The rooster box

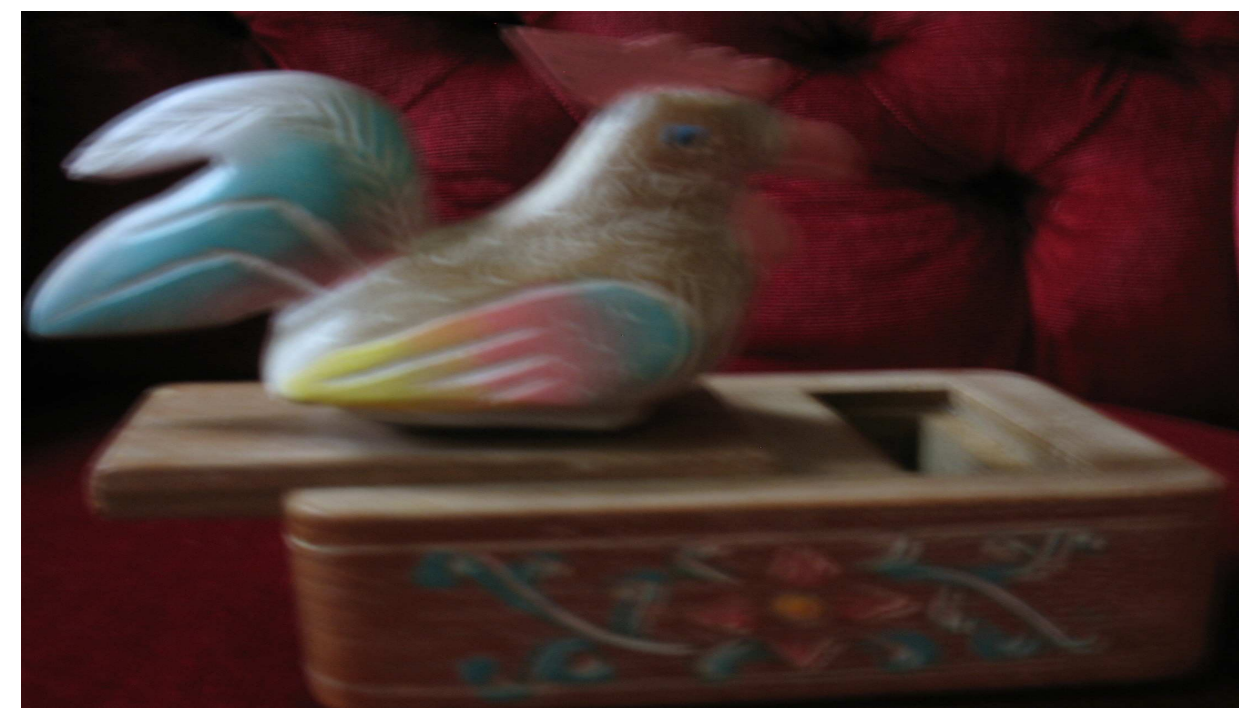

Meeting resistance is symbolized in Figure 6, by Sophie, as the dialectic of light and dark. As the tension mounts between two opposing forces, an opening is made, allowing a channel through the 
impasse. In Sophie's words, some force is necessary, depicted by the black lines resembling lightening.

Figure 6: Resistance forces

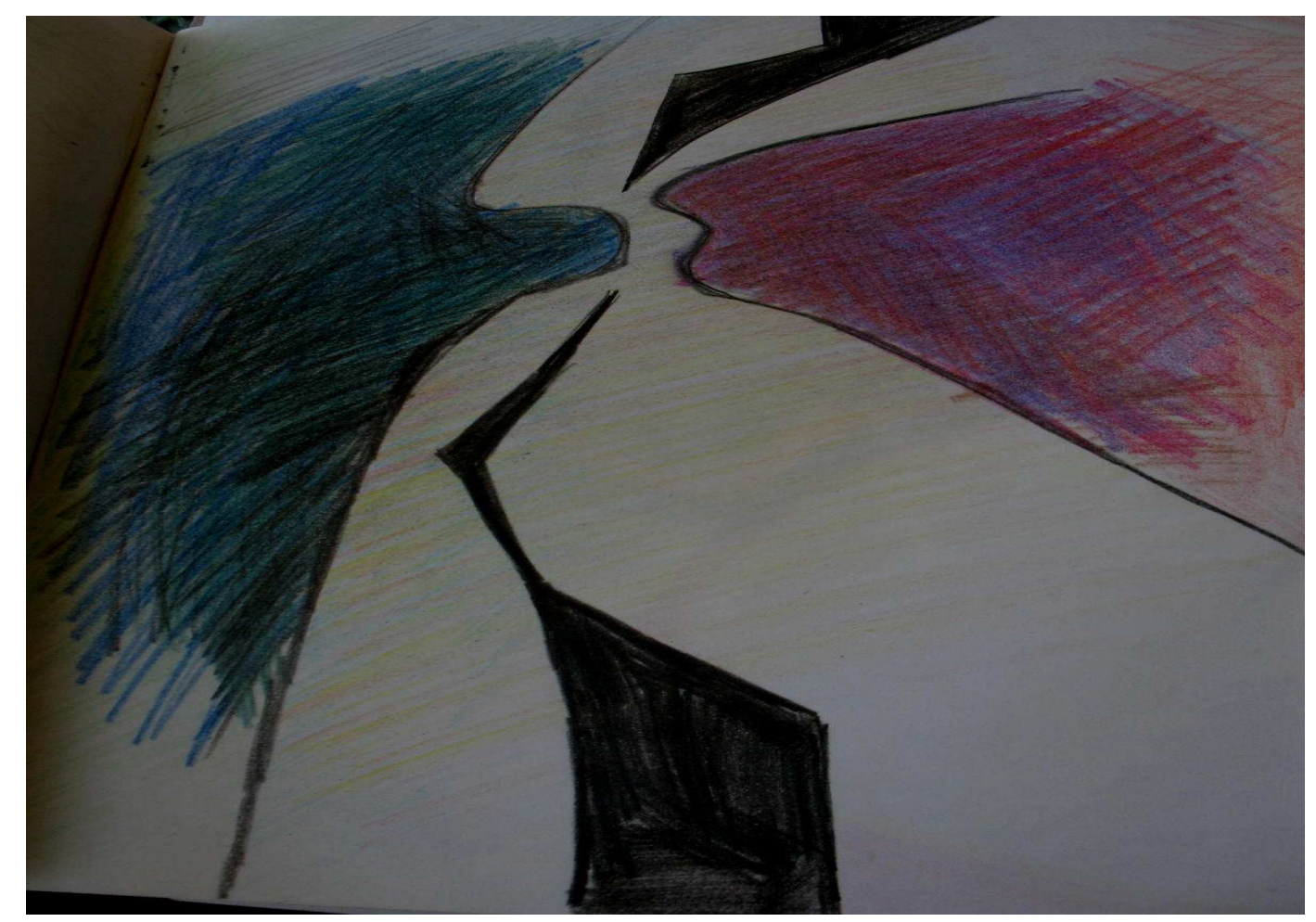

In the process of facilitation, I believe this lighten-ing can create an opening through both challenge and compassion, mentioned before as anam cara and kalynamitra. In Sophie's reflection of this drawing she said: "It seemed like I was breaking through a problem to see the light of future possibilities and to create a feeling of optimism".

Many of my supervision and peer review sessions have included discussions about a recurring pattern of resistance in transition work. Meeting resistance is a moment when some will disengage. It is the moment when the person is at risk of reverting to the comfort zone of known patterns, relationships, and habits, even though they are 
identified as undesirable by the person. Staying in the comfort zone can seem easier than exploring new pathways and coming to a deeper understanding of themselves.

The anatomy of resistance

I discuss two types of resistance, internal resistance and external resistance. Internal resistance becomes evident when there is an exploration of the inner tensions which exist in the person's situation and the discovery of paradox. For example, the person may recognise that an undesirable relationship is over and see the need to move on with their life, while at the same time still be highly invested in that person in their thoughts, habits, and life patterns. These paradoxes are noticed in the sessions as the person is encouraged to free up the energy they are holding, which often manifests as symptoms in the body, such as headaches or abdominal pain, as was the case with Sophie. This is a moment for meeting the internal saboteur, or the part of us that sabotages change. Meeting the saboteur occurs in many ways. One way of facilitation is by directly exploring and recognising paradoxes in the session, uncovering facets of the self that prevent progress, maturation, and growth. Other times, the exploration of contradictory facets occurs by exploring artwork as was the case with Sophie. In the process of exploration, there is an integration of memories and a conscious process of foregrounding and backgrounding life experiences. I share a powerful example of this process in the following exemplar.

\section{The foregrounding and backgrounding of dialectical integration}

At the end of a session, Sophie said she did a series of paintings which were about her relationship with her mother, revealing a deeper layer of grief for her that had been unearthed in the sessions. She said she didn't think they were very significant, but I encouraged her to bring them in if she wanted to explore them again. The following session, Sophie brought in the paintings which revealed an aspect of her identity that she had kept hidden from most people, even herself. The bold colours and male-like images of her at the time, revealed a layer of armoury she had been carrying for a long time. Figure 7 reveals dimensions of the 
sense of self that she had been grappling with over time. In Sophie's words "this picture depicted a reflective process of self-examination and coming to honour all aspects of myself". The central aspect of this painting shows the need to form a protective layer around the deeper parts of self.

Figure 7: A search for the integration of self

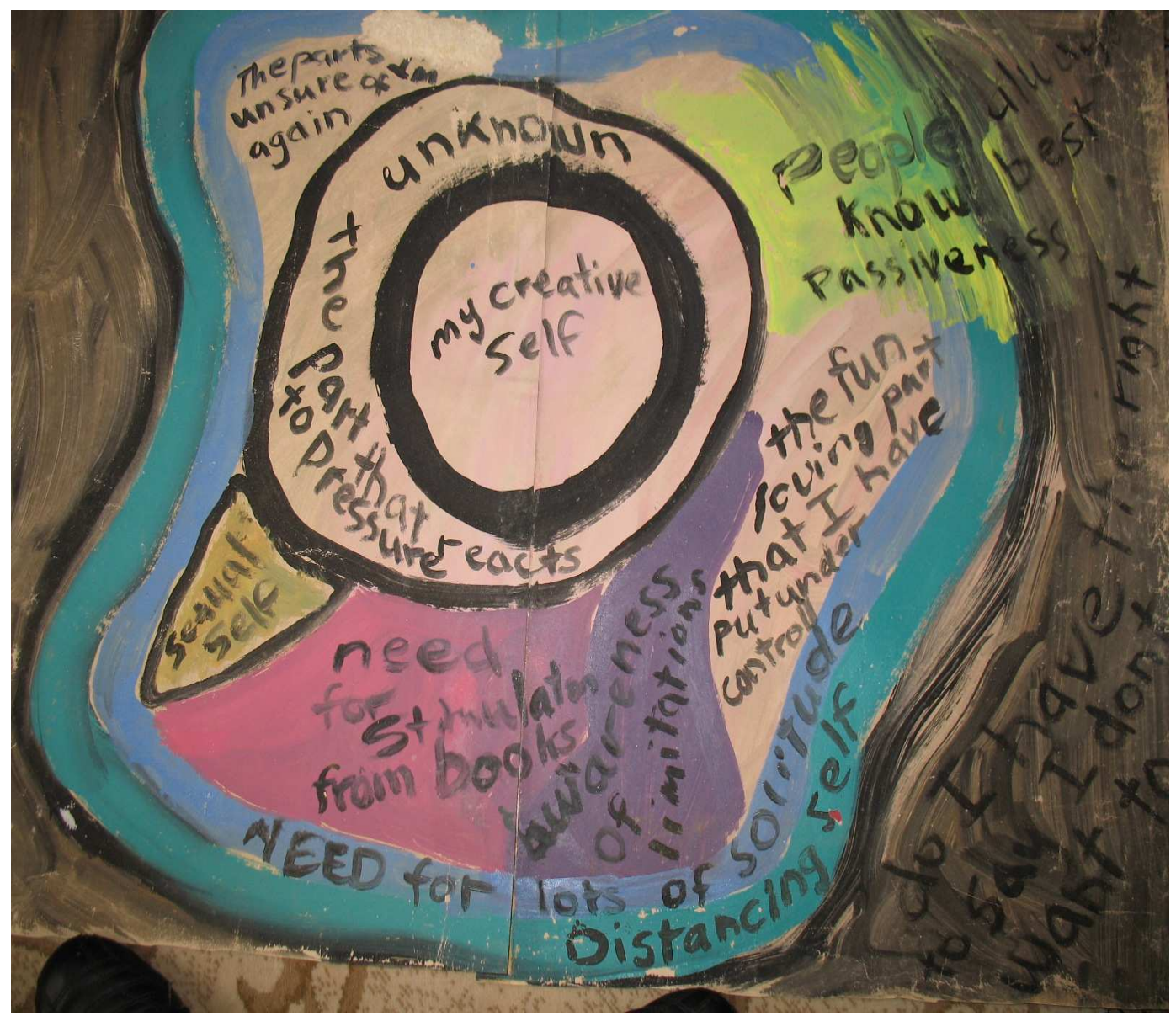

\section{Primary echoes}

The exploration opened up aspects of her relationship with her mother, which held primary echoes from her childhood. One of the paintings (see Figure 8) makes explicit Sophie's perception of others' opinions and its effect on her self concept, at a time in her life when she was faced with a number of social tensions. 
Figure 8: Perceptions and conceptions of self and others in moments of social tension

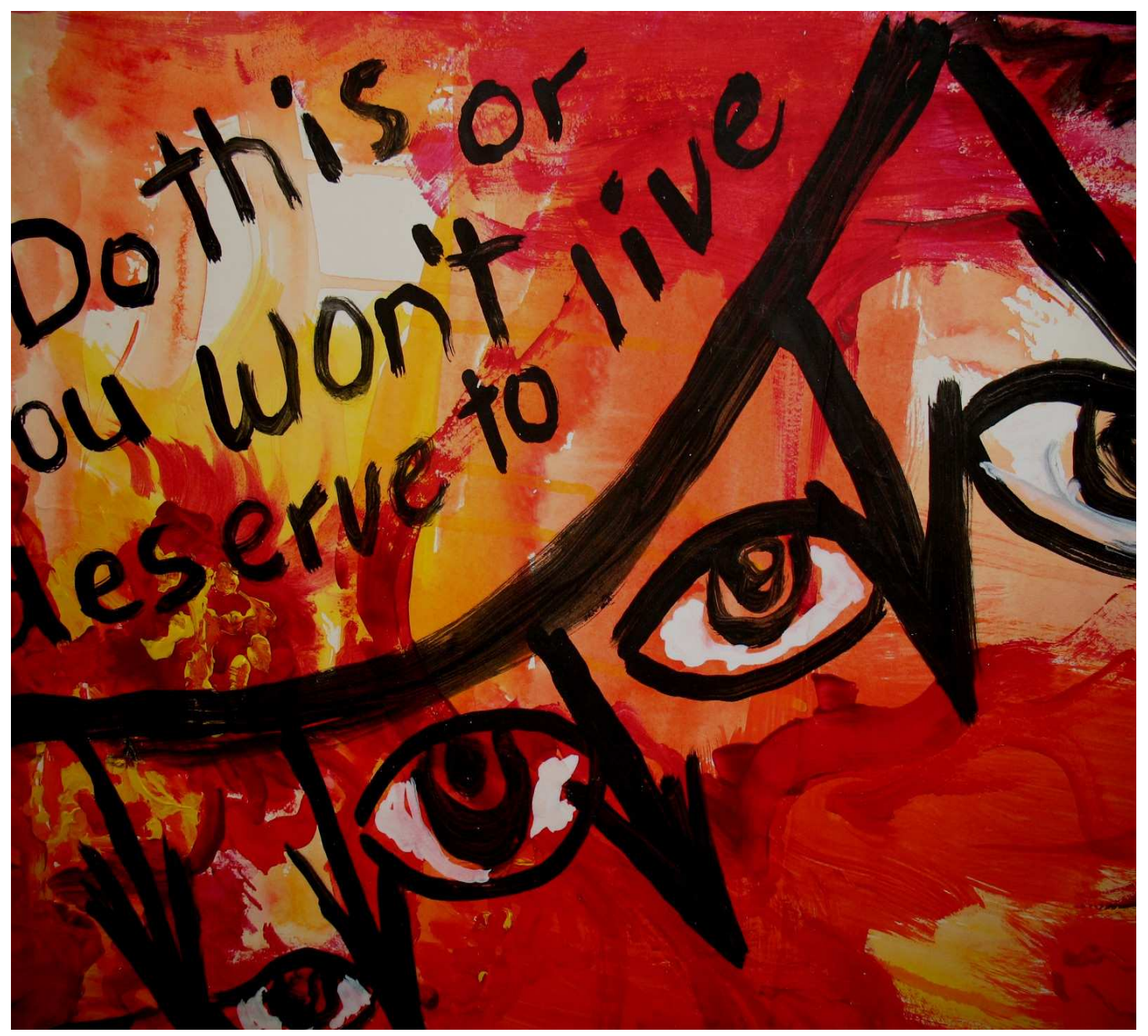

Integrating negative and positive primary echoes

The paintings were followed up the next week by the reality of an old photo album, which celebrated her mother and Sophie as young, beautiful, whole, and joyful. The jigsaw of the many facets of her personality was being fashioned into a durable and honest account of her life, through her many stages and transitions. In this process nothing is discounted, and all is acknowledged, owned, lived with, then backgrounded, when more present issues emerge again into the foreground. In more recent artwork, see Figure 9, a softer aspect of her personality emerged as she experimented, drawing portraits with eye shadows and face shadows on paper. According to Sophie, this drawing 
was influenced by artists who show the beauty and softness of the feminine self.

Figure 9: Finding a softer lens for viewing self

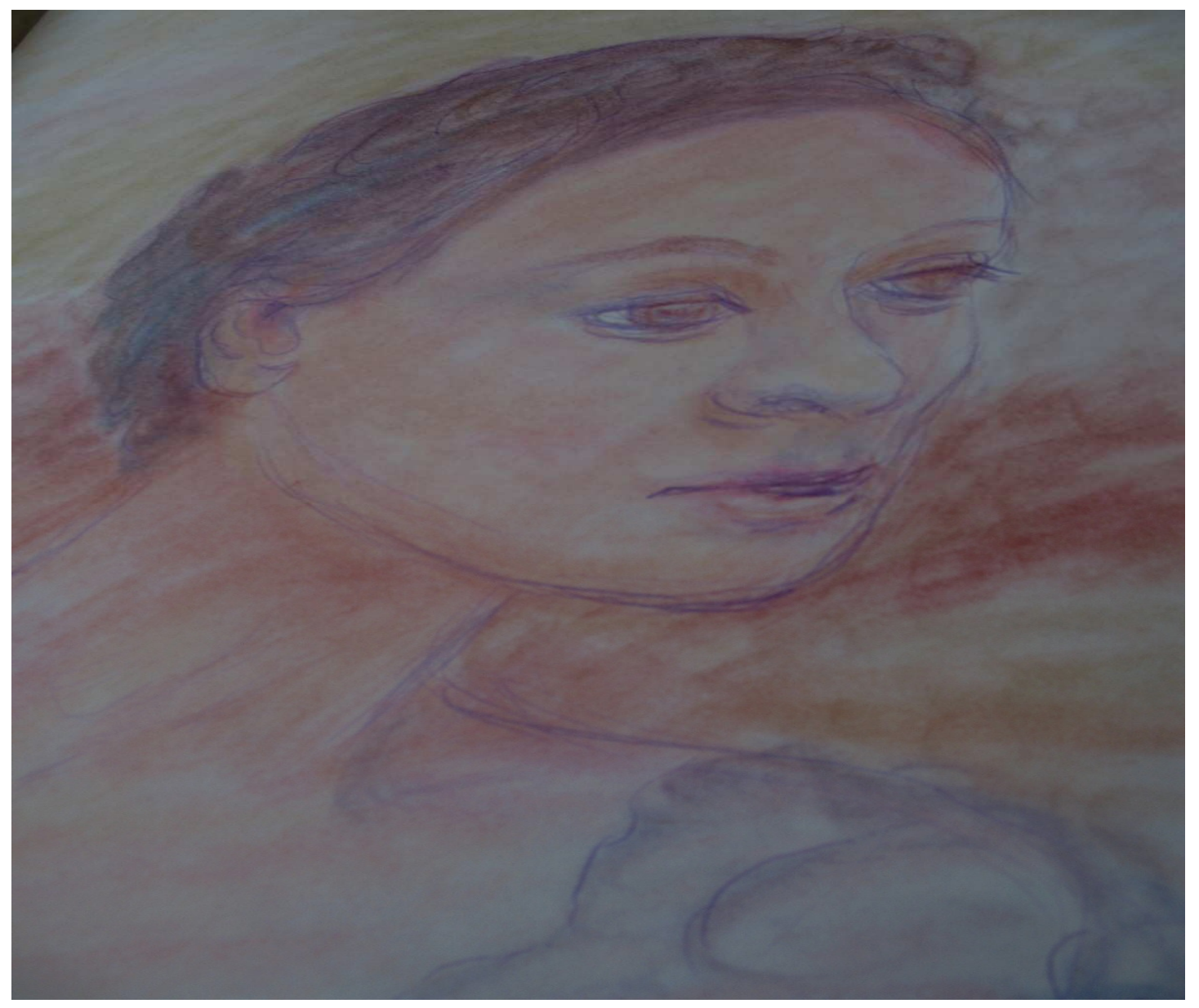

Working with energy was an important aspect of my work with Sophie during this exploratory process, explained as follows.

\section{Change: A process of energy re-patterning}

Sophie found it helpful to develop an expanding awareness of her energy field, especially to manage the pain located in the solar plexus area, which was diagnosed by the hospital physician as gall stones. An operation was suggested by the surgeon, which she did not want to have. In my work with her, I reiterated to her that the energy work was not a substitute for surgery but may help her to relax. My work with her 
involved an education of the chakra system. Sophie was instructed how to locate the area of blockage and gently work with her energy field at home. As time passed, her symptoms of pain abated.

At one of the sessions, Sophie brought in some free form drawings. Although she was not conscious of representing the energy field, they stood out for me as depictions of the pulsating energy field of the $3^{\text {rd }}$ chakra, or solar plexus, see Figure 10. This chakra is thought to energize the organs located in the abdominal area. In the emotional field, the $3^{\text {rd }}$ chakra relates to self-concept and identity, and is frequently sluggish in those struggling with inner change and selfesteem (Myss, 1997). When Sophie drew this with coloured pencils she said: "I was aware of searching for the light at the end of the tunnel and a sense of coming out of the darkness".

Figure 10: Discovering energy fields

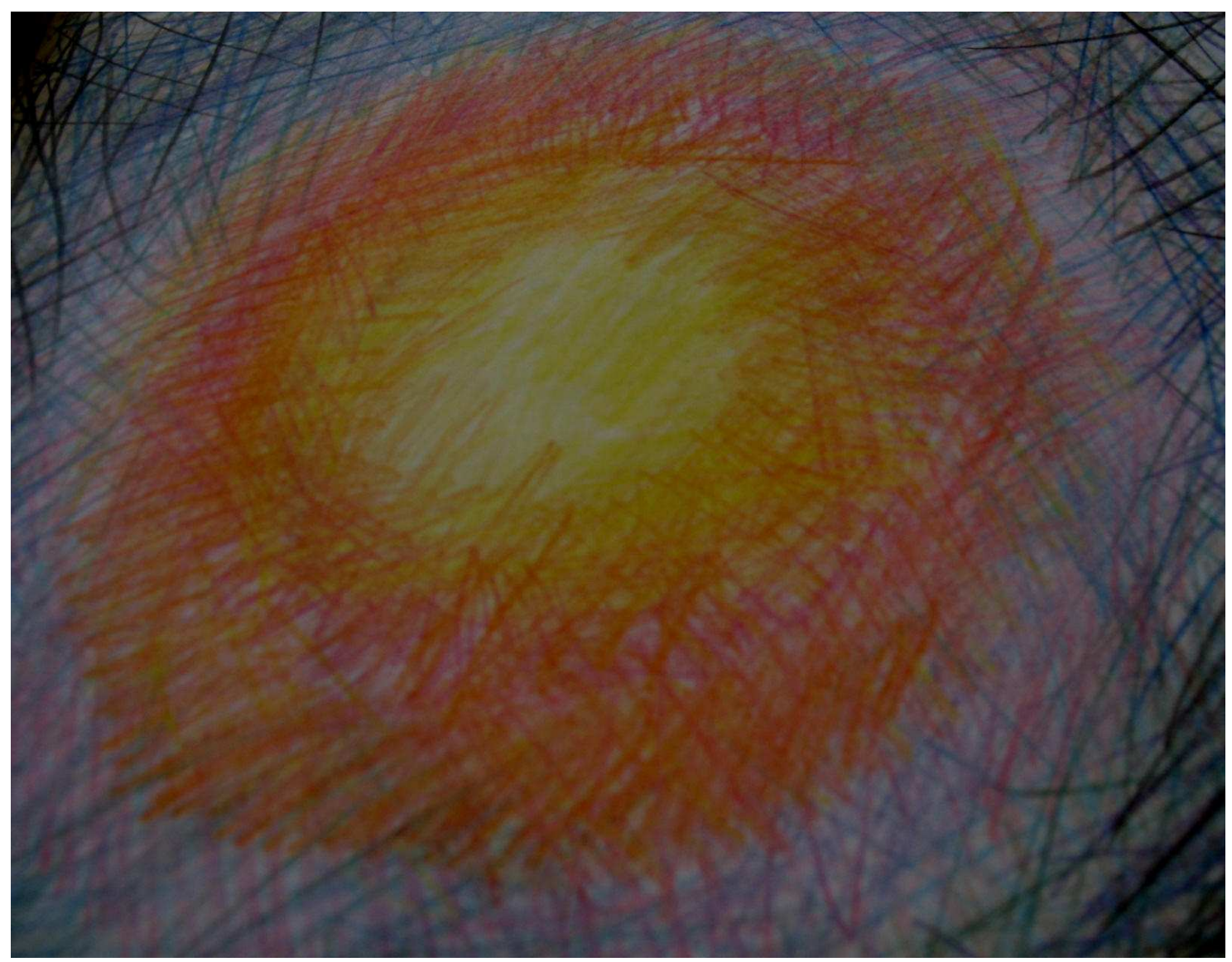




\section{Looking at external resistance and taking responsibility}

External resistance refers to the pressures coming in from others, such as partners, family, and friends, who may oppose evolution and change; instead, supporting the person to remain in the status quo. This is especially the case when the person makes changes in the way they choose to communicate with others. In these situations, assertiveness, learning to communicate and take ownership of ones thoughts, feelings, and actions, instead of blaming others, enables the person to take responsibility for their own transitional journey. As those I work with take ownership of their life journey the possibilities for new courses become possible. The patterns and colours for new courses were revealed in Sophie's artwork as a vibrant energy flow.

\section{Changing course}

Changing course and renewal is revealed in an abstract work by Sophie, in Figure 11, as an awakening of energy. The pink spiral superimposed on the watercolours seemed to signal a focus on the centre of her being and the awakening of the $1^{\text {st }}, 2^{\text {nd }}, 3^{\text {rd }}$, and $6^{\text {th }}$ chakras. To explain further, there was an awakening to grounded-ness, creativity, self-identity, and insight. The white opening according to Sophie represents mystery and becoming open to the journey. In her words it represents: "A feeling of excitement of something coming up that I am not aware of yet". 
Figure 11: Awakening

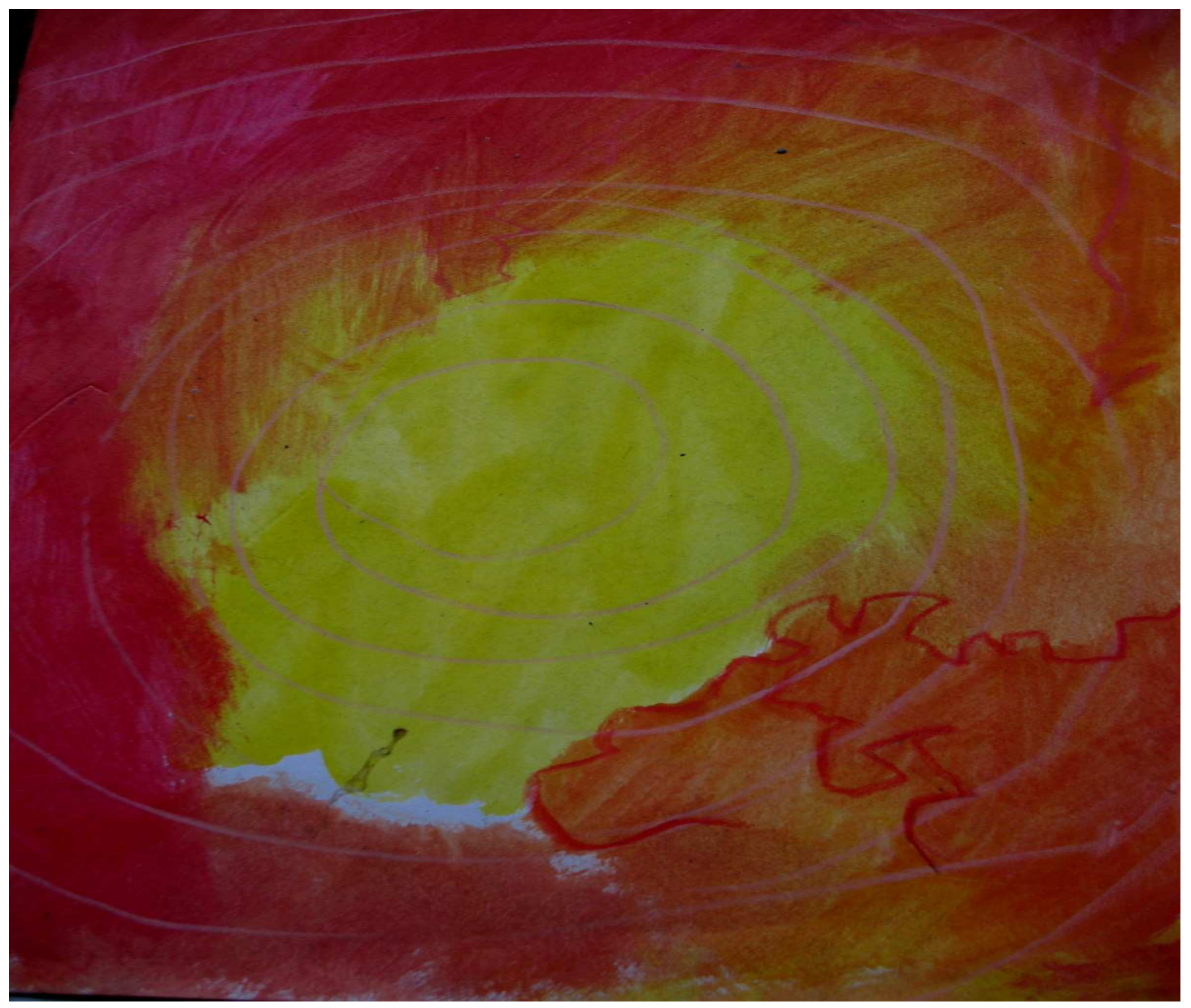

As she shared her story, many characters, lost and found, were revealed and then faded again, as she painted a large self portrait of herself; smiling, colourful, celebratory; acrylic on paper. In Figure 12, Sophie shows the multidimensionality and mystery of the growth process as she experienced it, which is revealed in colours and form. 
Figure 12: The many colours of transitions

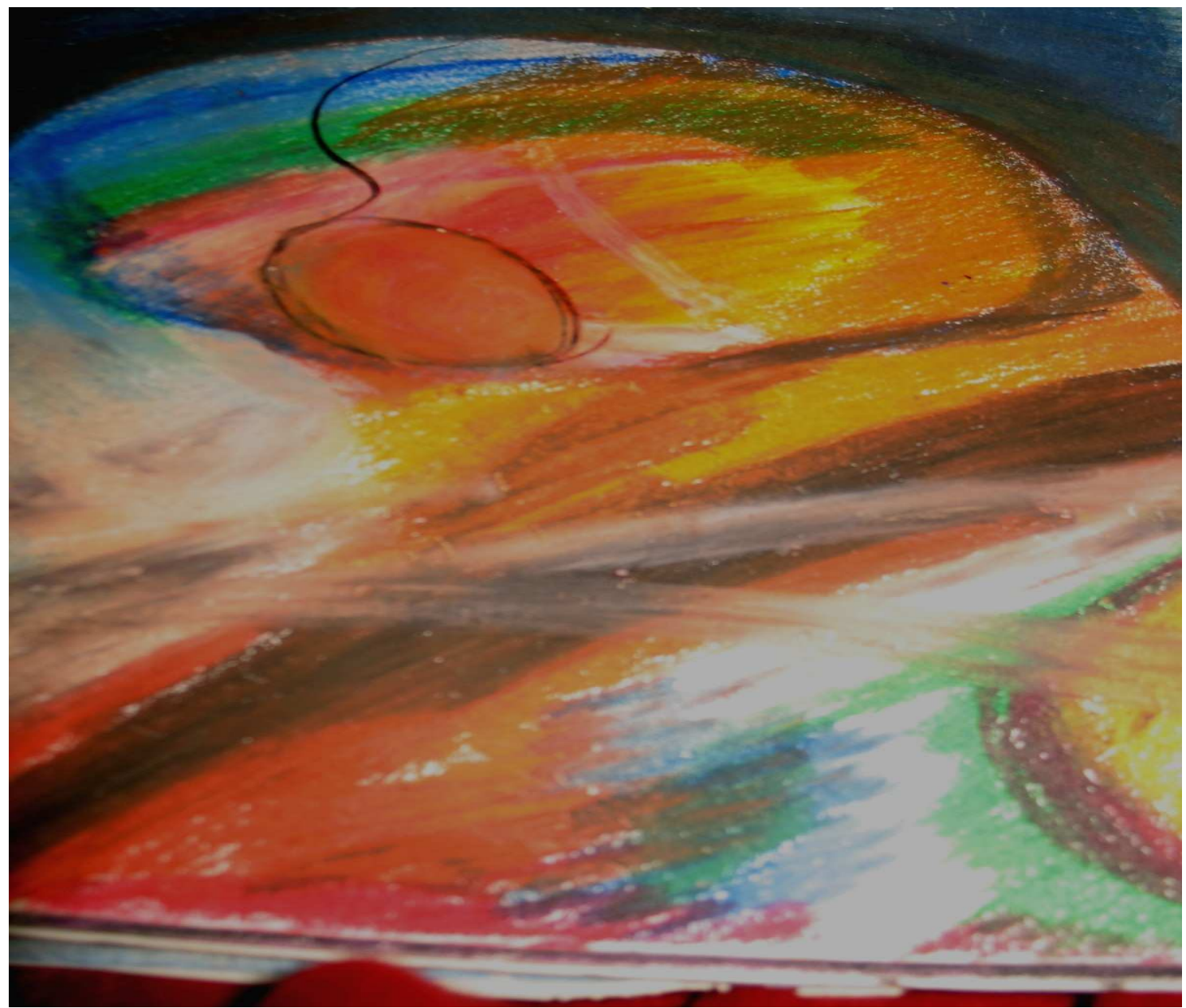

Finding internal power in the self and in relationships with others was also a pattern shared by Grace in the following exemplar.

\section{Locating inner power}

Grace was a young woman who came to me with the agenda of increasing her self-esteem. Grace had become aware that in her relationships, she struggled to make herself clear in communication and often found herself being reactive rather than responsive to those close to her. Her vision for the future was to work towards changing her life script from negativity, and isolation, towards positiveness and love. Grace identified spirituality as being an important part of her selfsearch and has been actively engaged in taking responsibility for her health through conventional medicine, Reiki, and naturopathy. 
Early in the sessions, Grace identified the need to come into her own power. Her early experiences in life, and in relationships, had undermined her sense of power and self trust significantly. Our work together involved learning about assertiveness. In particular, we were working on patterns of not feeling valued in communication. Learning to lead with 'I' statements and to own her feelings and thoughts was not easy. We developed the metaphor of not catching the ball of others' thoughts and emotions, as a way of separating her perceptions of herself from that of others.

Grace's decision to change in her style of communication was not always appreciated by those closest to her. It was at this time when she wondered if change was worth it.

\section{Living with paradoxes}

Internal resistance often manifests as external resistance as self and environment mirror each other, as in Grace's experience with others' responses to her changes, and the symbology of the noisy roosters in Sophie's story. The stronghold of resistances is broken when they are owned, acknowledged, and integrated into the autobiography of the person's life. There is no letting go, rather, paradoxes are lived with.

One of the snares I discussed in supervision about internal resistance is the tendency, that some people have in transitional moments, to try and banish the negative aspects of their experience and get to the positive aspects quickly; in other words, to seek a quick fix. This mechanism of avoidance and denial of negative aspects of life experience only serves to mask the reality of the situation and does not lead to any sense of integration. In this situation, a premature pathway to goal setting and solution focusing can distort the experience of transition and lead to further tension. If the person persists in their pursuit of quick fixes and miracles, we reach an impasse situation in DNFT. My role in this is to reflect the process that I see and invite the person to make a choice about whether to continue with DNFT, or take time out. In this situation I leave it open for the person to return when they are ready, or to 
consider other ways of working. Most often, when a person struggles with this moment of transition, they take breaks to integrate aspects of the transition work and come back when they are ready to process more. This was important in Grace's situation, as new learning was integrated before further work could be done. I left the timing of this up to her.

\section{Expanding life-force}

During the course of our work together Grace asked me if I would work with her energy fields. We discussed what I could offer and also the limitations of the work. I showed Grace how to find the chakras and explained each one. This was not new to her as she had worked with Reiki before.

In reading Grace's chakra energy, I discerned sluggishness in the $3^{\text {rd }}$ and the $5^{\text {th }}$ chakras, and overactivity in the $6^{\text {th }}$ chakra. This confirmed her diminished sense of self, and her difficulty in expressing emotions and thoughts. Overactivity in the $6^{\text {th }}$ chakra confirmed her tendency to have distortions in the perceptual field. For example, Grace often felt unfairly judged and rejected by others.

My initial energy work with Grace involved balancing the chakra energy fields, and ventilating in the emotional field. She experienced calmness and relaxation after the sessions. Following this, and subsequent energy work, she was able to express emotions more freely. Grace did, however, feel tired after the energy work and had feelings of nausea, which may have been related to this work. Another side effect was the surfacing of deeply held emotions of rejection and lability of emotions. This was initially a painful process for her, and she needed some reassurance from me that energy work tends to surface deeper patterns of being which manifest in the physical, emotional field as well as the energy field. Coming to a place of deep integration in this area takes time and adjustment. It was at this time I sensed some 
retrenchment and resistance as deeper patterns were surfacing. At this time, I offered her a session with more experienced energy facilitators. Grace was receptive to this; however, before it happened, she had released the tension herself through a vivid dream of deep peace and wellbeing.

Our work together spanned over a year and I was privileged to witness some shifts in patterns and improvement in Grace's wellbeing. Most notably, I saw a change in her sense of who she is. Grace was starting to come into her own power.

\section{Having faith and trusting the process}

At the core of both internal and external resistance is the emotion, fear. This includes fear of the unknown of change and fear of not having the resources to change. In another supervision session, I discuss the fear and doubt about trusting my inner voice, professional judgement, and level of support. This is especially so when I am dealing with people who are fluctuating in their ability to cope with life. It is at times when safety is an issue that I attempt to refine the balance between providing support and confrontation or direction. An example of this is directing a person to receive help when they are at risk, or when they are placing another person at risk. In this reflection, I considered in the supervision how I strike the balance between intellect, body, emotion, and spirit. If I am talking about being intuitive, one of the safety measures I use is to adopt a four pronged approach of attending to self, other, content, and process. In myself, I listen to my thoughts, my emotions, my senses, and my intuition or gut feeling. In the other, I encourage them to do the same and I look at the content, what is actually going on, who is involved, where, when; and process, how is the issue manifesting in the person, in others and in the environment. This process and my initial contract with the person (refer Appendix G), enables me to feel grounded in my professional practice as a registered nurse.

I get in touch with my resistance as I own my transitional moments of moving into this field as a nurse. In the supervision, I grapple with my fear of not being accepted as a 
nurse in the role I have forged for myself, and I wonder about its viability from a financial standpoint. I explore, with my supervisor, the underlying beliefs I have about change and renewal, and I realize that the basis for my persistence in this area of practice, is my unshakable belief that all experiences in life present an opportunity to grow, no matter how difficult they are. My optimistic philosophy stems from a transcendence of the internal and external resistance processes in the aftermath of major transitions, and an unshakable belief that although the structure of the body deteriorates over time, spiritual energy is always renewable. The fear of death is the deep-seated origin of fears leading to resistance, whether it is the fear of the death of a role, a physical function, a person, or oneself as identity and ego. Fear is an antithesis to spiritual renewal. Learning to live with the paradox of a decaying fragile embodiment of consciousness and the potential for continual evolvement as an energy form is the deeper aspect of transitional work. This deeper work is not the main focus of DNFT; it is frequently the result of it however, as at the completion of the work people often embark on, or continue with, their spiritual journey. I give an example of this in the following exemplar about Faith.

\section{Meeting real self as transition}

Faith came to transition work when she chose to leave a long-held career with children, to focus on her-self. Faith made this choice because she was close to burnout. Her decision to consciously prepare for this transition was made to circumvent a tendency to become depressed and avoidant when faced with change. Faith came to me to prepare for this transition and to seek reassurance that her leaving for this reason was a legitimate thing to do. We met regularly when she needed to, over the time of her leaving the job, and adjusting to new patterns and habits.

The cultural embedded-ness of the work ethic was so strong in her family background that it was difficult for her to accept that it was okay, for once in her life, to focus on herself. A cacophony of voices from her childhood created echoes in her mind. Such as: "Other people are worse off than you, they don't want to know your problems"; "the 
tough keep going", "you are weak and selfish if you give in to ill health"; "our family does not rely on outside financial help"; "work at whatever you can to put food on the table". Similar to my own experience of scurrying back to known roles, which I shared in Chapter Two, Faith did likewise. Most often her consultations with me were to explore the tensions that these feelings brought up. A deeper tension emerged as she explored a strong inner voice telling her that her main role as a female is to look after others, regardless of her own needs. On exploration, she had done this for many years in support of her husband who was living with a bipolar disorder, which eventually culminated in his suicide. Some sessions were spent uncovering grief work related to this. Over this time, it became clear to me that she had become stuck with some aspects of this deep loss, as thoughts became circular and negative. This led to a referral by me to her GP, with concerns being expressed that she may be suffering from depression and need the help of medication. Her GP agreed and tried her on a small dose of antidepressant. This helped to free up Faith's thinking and made it easier for her to focus on the transitional process.

As time went on, and her visits became less frequent, Faith focussed on a spiritual journey into the deeper regions of herself. She was gradually able to resign from her previous life script to care for others, and instead, make a choice to care for herself. Faith began practising a form of meditation to support her in this process and gradually developed the peace of mind to stay with the journey of change. At this stage, my role was largely one of reflecting feelings and thoughts; in other words, holding up a mirror so that she could see and hear herself more clearly, affirming the pathway she had chosen in midlife to come home to herself as spirit being, trusting that in taking this leap of faith she would not only survive, but flourish.

This exemplar shows two distinct patterns of moments of transition work, which are: changing course and finding real self. As the person changes course, questions start to emerge in the person, such as: Who am I now? How do I want to live my life? What 
are my values, and guiding philosophies? What is my life purpose? And what does it all mean?

As a DNFT, the cues that I notice occurring in the sessions, which show me these moments, often include changes in physical stature, speaking with more confidence, sometimes the clothes that they wear are different in colour and style, they come to report to me rather than to seek support, and they come to say goodbye because they are strong enough to continue the journey on their own. They seem to have a clearer sense of who they are. They, and I, leave the sessions feeling light and renewed as the synergy of energies ignites new frequencies. There is no time frame for this process of changing course and finding real self, but the doorway to this moment is usually by way of a meeting with the self saboteur and embracing real self. Sometimes the person comes to it and then runs back to previous understandings of self, gradually shedding masks, as they become more consolidated in standing in their truth. In these moments, facilitation takes on a different form. Rather than guiding, I notice new patterns and settle back to listen to new stories emerging. I summarize where I feel we have been and where I notice things are going now, commenting on the paradigm shifts that have been made and the new patterns I see emerging. Closure happens naturally in this process.

\section{Reflection on supervision and peer review about the process orientation of DNFT} On many occasions we speak about the work. Why do I do this? Who am I? What does it mean to be a DNFT. I have come to realize that at a deeper level, as I encourage and support others, I grow. As I learn to glide effortlessly in my work, leaving my ego behind and the fear of giving too much of myself away, I come to a deep and clear pool of renewal, a place of refreshment, and to the realization that transitional work touches the pulse of life itself, in its unending cycle.

In Table 17 below I bring together patterns that were revealed in these exemplars and integrate them with theoretical underpinnings from my reviews in Chapters Two, and Three. This forms the basis for further discussion of identified foundation patterns for nursing praxis, in Chapter Seven. 
Table 17: Patterns for transitional moments, nursing intentions and facilitation

\begin{tabular}{|c|c|c|c|c|c|}
\hline $\begin{array}{l}\text { Transitiona } \\
\text { l moments }\end{array}$ & Process & $\begin{array}{l}\text { Nursing } \\
\text { Intentions }\end{array}$ & Process & $\begin{array}{ll}\text { Patterns } & \text { of } \\
\text { Facilitation } & \end{array}$ & Process \\
\hline $\begin{array}{l}\text { Reaching } \\
\text { an impasse }\end{array}$ & $\begin{array}{l}\text { Things no longer fit. } \\
\text { Current philosophies \& beliefs do not seem to } \\
\text { help. } \\
\text { Person feels stuck (hits the wall). } \\
\text { Doesn't know what to do. } \\
\text { Central question } \\
\text { Who am I now? }\end{array}$ & Openness & $\begin{array}{l}\text { Openness to come to know the person. } \\
\text { Forming rapport and trust, getting } \\
\text { alongside, integrated assessment } \\
\text { (Appendix G). } \\
\text { Openness to patterns of being. } \\
\text { Allowing things to evolve. } \\
\text { Being spiritually based rather than ego } \\
\text { based. } \\
\text { Leaving things open. }\end{array}$ & Actively listening & $\begin{array}{l}\text { Non-directional. } \\
\text { Open questioning. } \\
\text { Hearing the story. } \\
\text { Hearing primary echoes. } \\
\text { Focusing on the present moment. } \\
\text { Echoing insights made. }\end{array}$ \\
\hline $\begin{array}{l}\text { Seeking } \\
\text { change }\end{array}$ & $\begin{array}{l}\text { Looks externally for signs. } \\
\text { Seeks guidance. } \\
\text { Looks internally for answers. } \\
\text { Wants to feel OK again. } \\
\text { Central question } \\
\text { How do I want to live my life? }\end{array}$ & Intentionality & $\begin{array}{l}\text { Exploration of tensions in self and } \\
\text { environment. } \\
\text { Support person to discover inner strength } \\
\text { and knowing. } \\
\text { Exploration of inconsistencies and } \\
\text { incongruity in the self. }\end{array}$ & Being a mirror & $\begin{array}{l}\text { Reflect feelings, } \\
\text { thoughts, words, and patterns. }\end{array}$ \\
\hline $\begin{array}{l}\text { Meeting } \\
\text { resistance }\end{array}$ & $\begin{array}{l}\text { Internal resistance } \\
\text { Health issues manifesting in physical, } \\
\text { emotional, or spiritual dimensions. } \\
\text { Coming to know the self saboteur - (inner } \\
\text { tensions and fears that arise). } \\
\text { Becoming aware of fear. } \\
\text { External resistance, social environment } \\
\text { unsupportive to change. } \\
\text { Central questions } \\
\text { What stops me moving forward? } \\
\text { How do I stop myself moving forward? }\end{array}$ & Compassion & $\begin{array}{l}\text { Empathic concern, understanding. } \\
\text { Offering Support. } \\
\text { Getting alongside. } \\
\text { Challenging incongruity with } \\
\text { compassion. } \\
\text { Building self esteem. } \\
\text { Expanding life force. }\end{array}$ & Giving feedback & $\begin{array}{l}\text { Includes: } \\
\text { Recurring patterns. } \\
\text { Moments of clarity, confusion, and } \\
\text { incongruence. }\end{array}$ \\
\hline $\begin{array}{l}\text { Changing } \\
\text { course }\end{array}$ & $\begin{array}{l}\text { Start to form new patterns of Being. } \\
\text { Routines and habits change. } \\
\text { May be open to new relationships and ideas. } \\
\text { Prepared to take responsibility for self. } \\
\text { Central questions } \\
\text { What are my guiding philosophies? } \\
\text { What is my life purpose? } \\
\text { What does it all mean? }\end{array}$ & Intuition & $\begin{array}{l}\text { Notice new patterns } \\
\text { Notice signposts } \\
\text { Listen to inner voice } \\
\text { Being insightful } \\
\text { Trust the process } \\
\text { Use an integrated approach taking } \\
\text { account of self, others, content, process, } \\
\text { intellect, emotion, body, spirit, } \\
\text { Follow up on hunches }\end{array}$ & Being a catalyst & $\begin{array}{l}\text { Facilitate Envisioning. Foregrounding } \\
\text { Backgrounding } \\
\text { Foster self responsibility } \\
\text { Facilitate teaching and learning } \\
\text { Emphasize free choice } \\
\text { Co-create new learning and new } \\
\text { stories }\end{array}$ \\
\hline
\end{tabular}




\section{Summary}

In my summary of this Chapter I reflect on these transitional journeys by recalling the story of Alice's Adventures in Wonderland (Carroll, 1873;1993). This story was one I read again and again as a girl and provides a salient analogy of the transitional cycle. It is the story of a dream of a young girl, and the many faceted aspects of self, acted out in the seemingly nonsensical manner of the dream-world. As facilitator, I sometimes feel like the white rabbit in the story of Alice in Wonderland, who acts as a catalyst for Alice to plunge into the deeper regions of her growing self-identity. Her journey is inspired by his appearance. When she reaches an impasse in her attempts to get through a doorway into another world after him, it is her curiosity that moves her forward with openness and a sense of wonder, about the journey. As she stumbles into unknown territories and new relationships, she gains strength, and Alice responds to each new encounter with the weird and wonderful characters she meets, with more confidence. Haughton (1998), in reviewing Lewis Carroll's Alice story, interprets Alice's journey as follows: [A]lice is caught up in a series of bad tempered dialectical duets which call into question or put into play the conceptual foundations of her world (xiv). I draw an analogy with facilitation, as I encounter each curious person in transition, searching for answers and a way forward. At times I challenge, and at other times I question, so that like Alice, the person emerges clearer about whom they are. This process is exemplified in the story of Alice's encounter with the powerful queen, who near the end of the story, orders Alice to be beheaded; whereupon, Alice strongly challenges all of the disagreeable identities she has encountered on her journey, including the queen. As she does so, she regains her stature and the identities rise in the air like a pack of cards, symbolizing the dispelling of her fears and delusions about their power over her. It is the moment of the queen's exhortation to Alice that she is able to break through the intellect and get to the heart of the matter, in Alice's case, her true self.

These reflections shared in this chapter provide a basis for creating a framework for DNFT praxis in Chapter Eight. 


\section{CHAPTER EIGHT Seeing Patterns: An Integral Approach to the Dialectical Nurse Facilitation of Transition}

In this Chapter I address the central question of this thesis to answer the question I posed in Chapter Two: What patterns emerge in the practice of Dialectical Nurse Facilitation of Transition? Patterns for my praxis of DNFT are presented visually and conceptually. This reveals a praxiological process, outlined in Chapter Five, showing how reflecting on research integrates theory and practice and becomes praxis? Praxiological patterns are not intended as a template for DNFT; rather, they give the reader a visual reference point to track a self-reflective and reflexive process from the annals of practice supervision, peer review, and case review, showing my life-world as a nurse.

One of the components of my central question was: Why is a personal exploration of the patterns of DNFT essential to an epistemological and ontological integration? I answer this question by communicating and explicating my thinking through and integrating understandings interpreted from being, doing, and experiencing. It is the being doing and experiencing of DNFT that shows the significance of a personal exploration, detailing the self-reflection and reflexive process.

This chapter creates the foundation for discussions in Chapter Nine on the third component to answering the central question of this thesis, namely: What is the significance of DNFT praxis for nurses nationally and internationally?

I begin by showing patterns of praxis in the following section.

\section{Being-doing-experiencing praxis}

In Figure 13, I depict the entry point of the relationship between myself as a nurse occurring at the intersection of crises and need on the persons part, in the context of a health service. In my situation this involves the motivation of the person to contact me to specifically address a transition they are going through. Sometimes this happens when the person is advised to seek my help from another health service, for example 
emergency mental health care or primary health clinics. Figure 13 shows the progression of the relationship as it commonly occurs, and the aspects that we work with. As with most of the patterns I reveal in this chapter the presence of a butterfly symbolizes change, movement, and an inherent potential in each person, to create a new pattern.

Figure 13: An overview of the work of DNFT

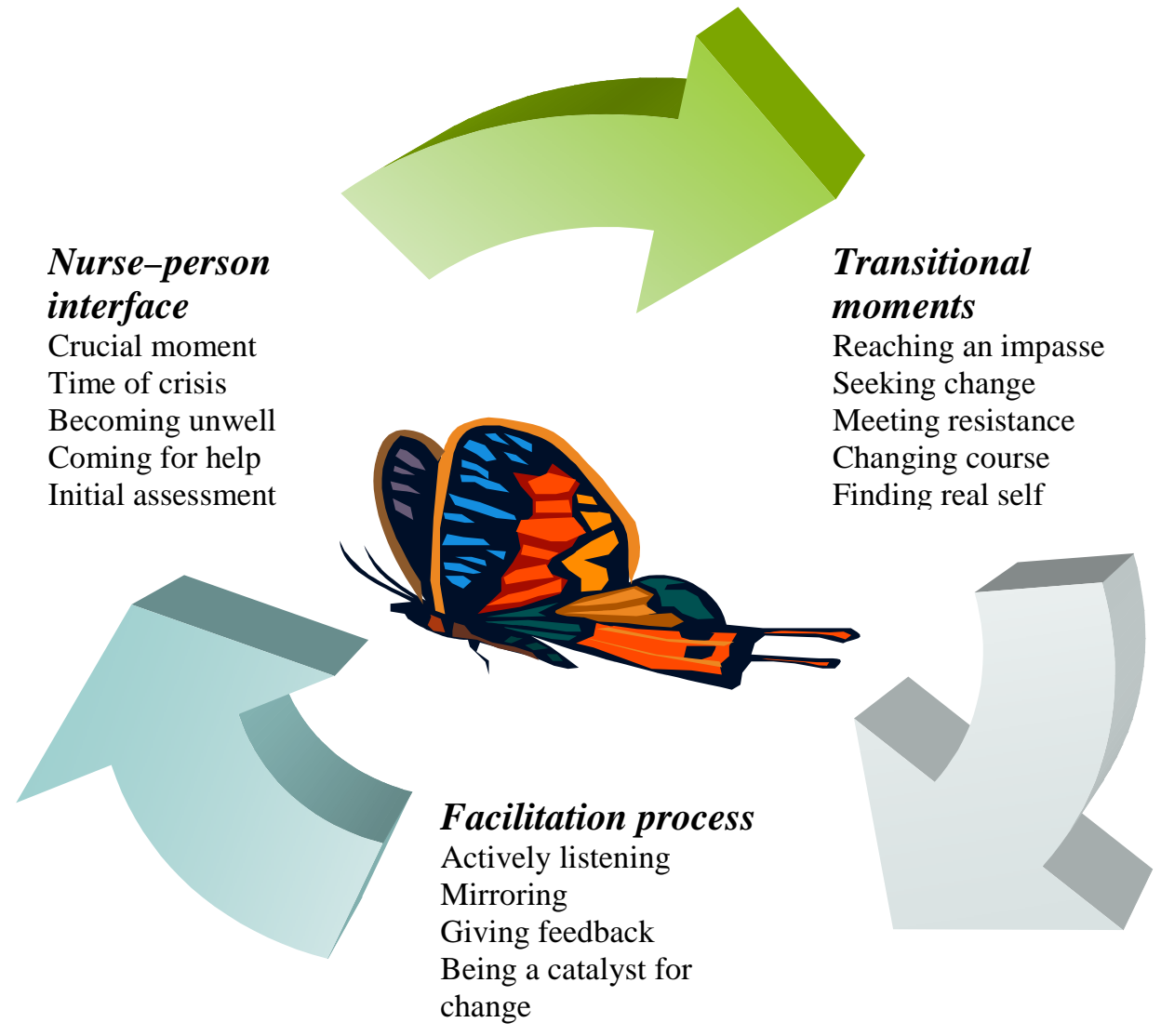

As was stated in Chapter Seven, in most instances, as we begin to work on the unique transitional moments of the person's life, there is to-ing and fro-ing, foregrounding and backgrounding movements as we weave in and out of the person's life story in search for patterns, meanings, and a way forward. These movements of to-ing and fro-ing, foregrounding and backgrounding, have resonance with the dialogical theory of Gadamer (1989). He viewed dialogue as a conversational engagement in a search for 'horizons of understanding' and the 'prejudices and assumptions' of oneself and others. In gestalt therapy the pattern of foregrounding is discussed by Perls (1975c) as a way of being aware in the present moment. Background is implied. As Perls 
indicates "Nothing ever dies or disappears in the realm of awareness. What is not lived here as consciousness lives there as muscle tension, unaccountable emotion, perception of others..."(p.71). These patterns reveal an antithesis in dialectical transition work to early theories in grief therapy outlined in Chapter Three that seek resolutions and encourage people to let go of the past. The emergent patterns of DNFT reveal a relational process which I unfold in the next section.

\section{Relational connections in DNFT}

Figure 14, shows the beginning of the relationship in DNFT depicted as multi- layered spherical symbols of nurses and persons with a two-way arrow, revealing unique patterns of being; coming together, each with their own understanding of how the world works, yet with a shared vision of change. As I seek to know the situation and life-state of the person through assessing dimensions of mind-body-spirit in the context of a health service; the person seeks a transition from an impasse situation. In Western health services, the response to this search has traditionally been in the form of intervention, which in itself seems compassionate. In my view, when a person does not engage actively in their process for healing, direct intervention can decontextualize the health issue from the person's life. Direct intervention can leave the person with an expectation that others are responsible for taking away the health issue, or providing a solution to the problem that they face. In this process, the person does not access their inherent potential to bring about a change in their life-state. In putting forward a pattern of nurses and persons as unique beings, it is my intention to facilitate an increasing awareness of the diverse potentials and options that the person has in their situation.

Figure 14: Nurses and people in transition are unique complex beings of mind-bodyspirit, each with infinite potential

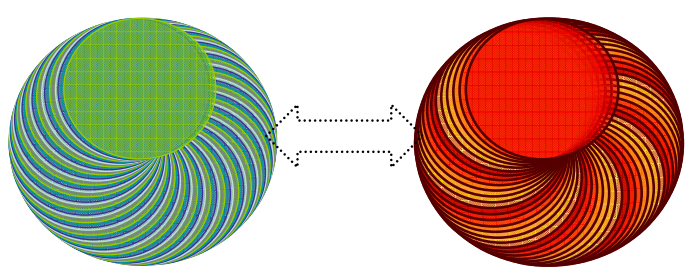


In the development of the relationship there needs to be an element of attraction which manifests as an open curiosity about each other to engage in the work. I do not subscribe to any prescriptions about how this comes about. As I stated in Chapter Seven, the meetings and terms of the relationship often happen serendipitously and take on a unique flow and cadence. This is especially so if the ego is freed up and the Mind of core essence / Buddha nature takes over. In this way people are free to be themselves, bearing witness to evolving being, experiencing, doing and thinking in the moments spent together. In an exploration of the notion of bearing witness Naef (2006 p. 149) suggests that "bearing witness constitutes a well articulated and particular way of caring" which specifies the meaning of caring. I do not have any agenda other than to meet the person with a compassionate heart, and an intention to create a healing space for the hour we spend together. The relationship has the quality of a heart-toheart relationship which in essence is like the anam cara, soul friend, of the Celtic world (O’Donohue, 1997; Gully, 1998; 2005; Watson 2005b). In the poetic words of Eleanor Gully (2005, p.142)

[T]wo souls meet if but for a fleeting moment

Two souls destined to meet in the moment

And in the moment there is change...

When we engage in this heart-to-heart anam cara energy connection as shown in Figure 15, potentials emerge forming an embryo of change, much like the embryonic form in Sophie's work (see Figure 4). It is this connection that takes us into the mutuality of transition work, described in the next section. 
Figure 15: Anam cara energy connection

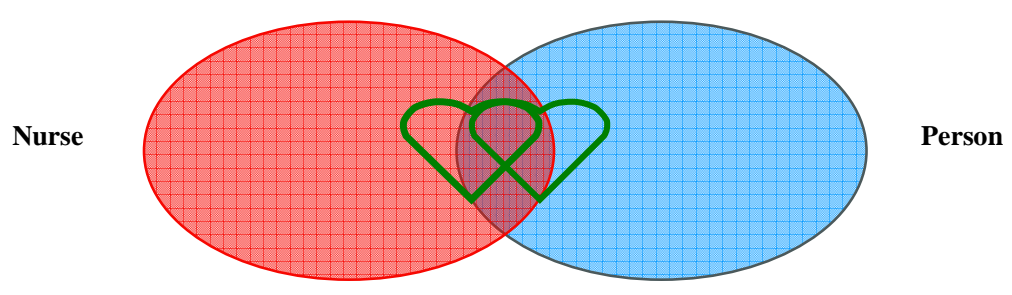

\section{The mutuality of transition}

As stated previously cycles of transition are common to all, for example, as people in transition seek enlightenment and freedom, so to do those who walk beside people in this process. In Figure 16, I integrate a pattern showing moments of transition with the heuristic process of self-reflection, and the dialectical process identified in this thesis. As people integrate new patterns they simultaneously release old patterns revealing more of their real selves. As they do so people feel lighter, depicted in Figure 16 as the transformation of the butterfly. 
Figure 16: All people are involved in ongoing cycles of transition

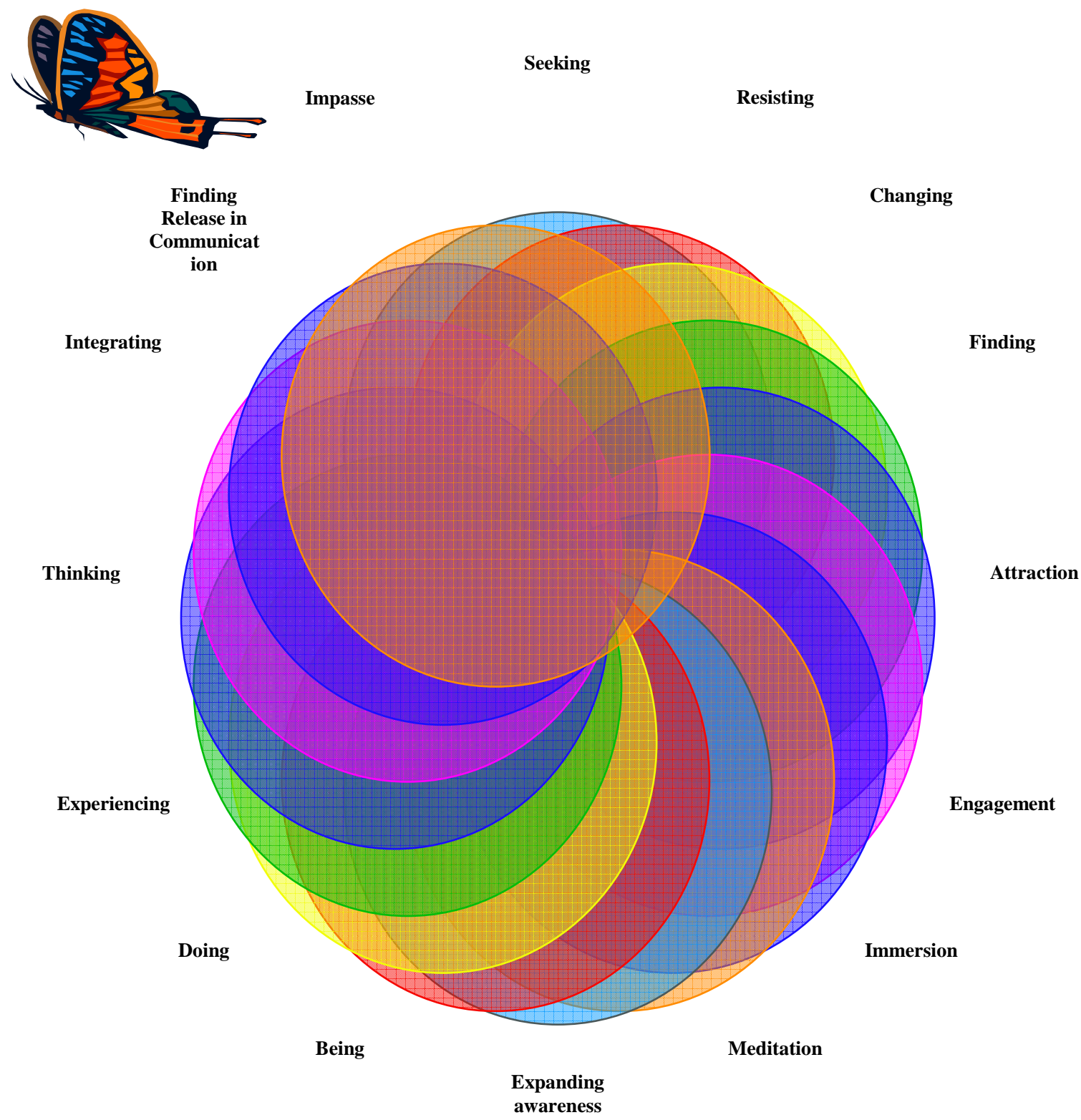

\section{Mutuality in 'caring with' and caring for self}

Mutuality with respect to nurse-person relationships is a subject that has been interpreted in diverse ways in nursing literature. Arnold and Boggs (2007) refer to the mutuality of agreement of the person's health problems and ways of working with them. Their emphasis is on the shared goals of the nurse and person, encompassing a relationship where feelings and thoughts are shared between them. Hartrick (1997) in describing mutuality in the nurse-person context includes the notion of appreciating 
the differences as well as similarities. Barker and Whitehall (1997) link mutuality with influence, indicating that there is a potential for nurses, persons, and significant others to be influenced to change in the 'caring with' process. Gadow (1980) draws a distinction between the mutual personal experiences of nurses and persons by classifying differences in terms of focus, intensity, and perspective. Newman (1986) proposes that both nurses and persons have the potential for expansions of consciousness as they engage in "[a] mutual relationship of pattern recognition and augmentation" (p.88).

Mutuality in my view is the aspect that leads to Barker's (2002) notion of humility in the 'caring with' process. It is a leveller, shifting a commonly held 'them and us' stance in health care settings which creates distance and hierarchical relationships; and does not allow a progression through walls of impasse. My belief in the mutuality of life process takes account of energy as renewable and ever flowing rather than something that has to be conserved and protected. This runs counter to views in nursing which posit the need to protect the self from being drained by others (TodaroFranceschi, 2001; Tanyi, 2002). Rather than an action of protection which is defensive, resistant, and often experienced as energy depleting; I find a renewal of energy flow when I attend to self-care, preparing myself to be present in the work. This self-care for me is a discipline not only involving spiritual practice for energy renewal but also attending to my own health needs. In Chapter Four I referred to the need to attend to ones health as engaging in five regulatory activities: Eating, sleeping, posture, breathing and thinking; based on a Buddhist viewpoint. Thought in this trajectory, involves the practice of living moment-to-moment in true presence. In these moments the three existences of past present and future become one, and time is illusory.

Self-care is a strengthening action rather than a defensive one. For example Ikeda (2000) in his dialogue with health care professionals integrates the mind-body-spirit by suggesting that the back is the crux of the body holding up the treasure tower of the entity of the Buddha Nature and "[t]he stomach (hara) is the mirror of the heart" (p.157). These aspects of the body are of particular interest to me as they represent the centre of our being and the core of our existence in embodied consciousness. They are the areas of the body that most frequently present in those I see, as being vulnerable, 
or as manifesting disease. In energy terms they represent the $I A M$ of self-esteem and the intentionality of the person. Working with the midline, hara, solar plexus, forms the core of DNFT, from an energy perspective. In Buddhist terms, each person is fully responsible for their situation, thus as a person working with others I keep this foremost in my mind. For example, referring to aspects of my work in Chapter Seven, when I go away from a session feeling depleted, I need to take full responsibility for this feeling, and my energy renewal. I do not do this alone as this is the basis for mentorship in the supervisory and peer review relationship, as I bring these real feelings to the sessions with an honest intention to transform them into learning and expanding awareness about the lived experience of DNFT.

\section{Transition work and self responsibility}

In my work with others, I encourage them to assume full responsibility for their lives by viewing themselves as the only one who can freely choose the life-course they want to take, from now on. This does not involve blaming the person for the situation they are in and dispassionately telling them they are responsible for it. Rather, it is about working in the present moment. If the person is suffering, for example, I as a facilitator will explore the options that they see open to them, and perhaps uncover the options they do not see but may or may not choose to explore, in order to progress. The focus is on choices and decisions, of the suffering person, not on attributing blame to externals, or, seeing people as flawed and needing to be fixed.

The analogy of the treasure tower in Buddhism supports my view that each person is a veritable storehouse of treasures waiting to be discovered. In this viewpoint there is always an answer to a problem, a way out of an impasse and hope of a way forward. To maintain my fitness to be a DNFT this clarity and optimistic stance must always be with me in the work, even though the situation that we are discussing in the work may be shrouded in mist.

The mutuality of transition extends into the patterns for facilitation itself as a mirroring of mutual growth which is the hallmark of transition work. I expand on this as I explicate the development of nursing knowing in the facilitation process in the next section. 


\section{Nursing knowing and facilitation}

As I integrate patterns of DNFT and my experiences of transitional journeys from Chapter Seven, I find a pattern inclusive of a mutual process of nurse and person depicted in Figure 17, as a circle, holding foundation patterns for DNFT praxis. These are identified as: Being grounded, being connected, having faith and being real. An octagonal pattern of the dimensions of facilitation identified as: Actively listening, being a mirror, giving feedback, being a catalyst, encompass nursing qualities of openness, intentionality, compassion, and intuition, within the mutual circle. This helps me to explicate a dialectical facilitation process that holds non-linear overlapping cycles of transition at the centre of DNFT. Transitional patterns identified from experiencing DNFT and integrating transition-loss-change literature that present consistently in my heuristic process are: Reaching an impasse, seeking change, meeting resistance, changing course and finding real self. These transitional patterns are shown in the centre of the octagon as overlapping circles.

For the purposes of clarity, in the following section, I examine each pattern of DNFT with a closer lens. To reveal the specifics of heuristic patterns of nursing knowing I refer to the theory of Carper (1978) namely empirical, ethical, personal, and aesthetic ways of knowing, with respect to critiques and updates put forward by Jacobs-Kramer and Chinn (1988); Munhall (1993); White (1995); and Johns (2004b). I explicate foundation patterns for praxis, nursing qualities, and the dimensions of facilitation. 
Figure 17: Patterns for DNFT

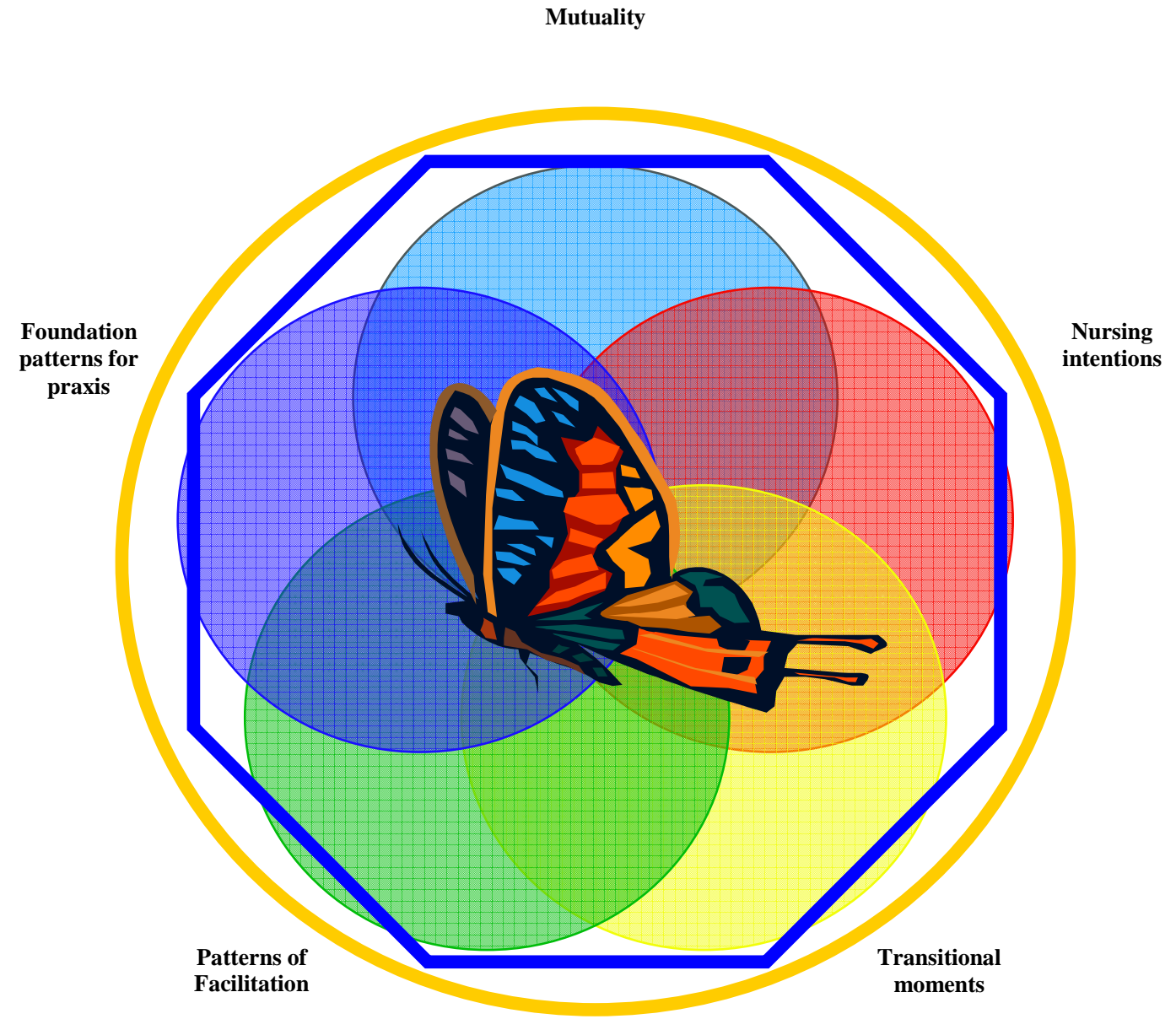

In Figure 18, I show the mutual interdependence of the qualities that come into the transitional work to be open to the journey of transition with compassion for self and other; intuiting wisdom for intentional re-patterning so that movement, flow, and creativity is discovered. The mutuality of nurse and person is symbolized by the golden circle. Each aspect is shown as overlapping non-linear cycles. In the centre, Core Essence depicts the emergence of spirit which holds each person's inherent potential. 
Figure 18: Qualities for transitions: A mutual process

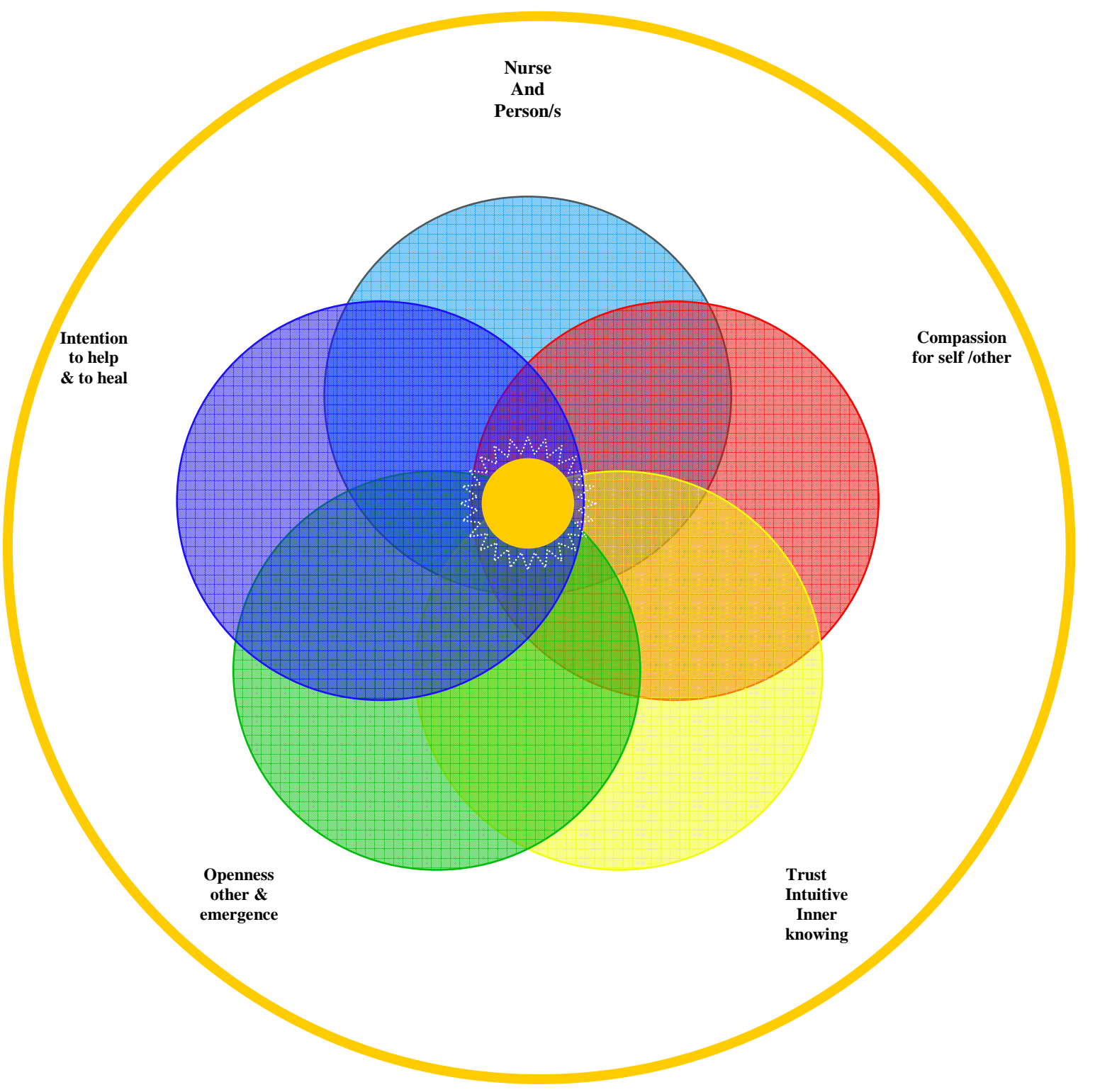

Empirical evidence of DNFT from the dialectical heuristic reflective design that I use reveals a mutual process between the nurse and person in transition. Gathering empirical evidence about the effectiveness of nursing interventions in my situation is largely a matter of ascertaining the perceptual experiences of persons being cared for in systematic qualitative and quantitative evaluations. It has not been the focus of this thesis to write up an evaluation of the effectiveness of DNFT; rather I make explicit experiential patterns for praxis, thus providing the basis for future evaluations of DNFT. Evaluations both formal and informal are an inherent part of my practice to ensure than I am responsive to the needs and expectations of the people I work with. 


\section{Becoming grounded in practice knowledge}

A mutual process depicted in Figure 19 shows the empirical value of self as a nurse being grounded in theoretical knowledge about nursing, loss, grief, and transition. Being grounded is self-knowing, and having a developing awareness of what belongs with me and what belongs with others. Being grounded in oneself is, I believe, a prerequisite for authentic relation which I identify as being real.

In the Aotearoa NZ context, nursing is embedded in a bicultural relationship between Maori and non-Maori. Thus I am grounded in the Treaty of Waitangi (TOW). Being grounded in the TOW requires an understanding of the basic tenets of this Treaty; to recapitulate, these are: Partnership, participation, protection, and self determination. These tenets relate to governance, equality, protection of cultural heritage, and the ability of Maori to self-manage aspects of resources, land and culture (Ramsden, 2002).

A Treaty relationship was exemplified in the reflection of my personal ancestral background and the ancestral background of Charles in Chapter Seven. Charles reclaims aspects of his cultural identity as a Maori in the process of grieving the tragic loss of his wife in an accident. This aspect of grounded-ness in the TOW underpins all other aspects of nursing in Aotearoa NZ and creates a position of 'Cultural Safety',22 for both nurse and people in the process of care.

\footnotetext{
${ }^{22}$ The term 'Cultural Safety' arose in 1988 in response to a young Maori student who questioned the importance of 'Cultural Safety' in respect of nursing education which could have been interpreted at the time as being a reflection of a colonising pedagogy. This issue was taken up extensively by Dr Irehapeti Ramsden in her Thesis: Cultural Safety and Nursing Education in Aotearoa and Te Waipaunamu, (2002) radicalizing not only nursing education but the way the Treaty of Waitangi and 'Cultural Safety' was viewed in the public sector.
} 
Figure 19: Foundation patterns for praxis: A mutual process

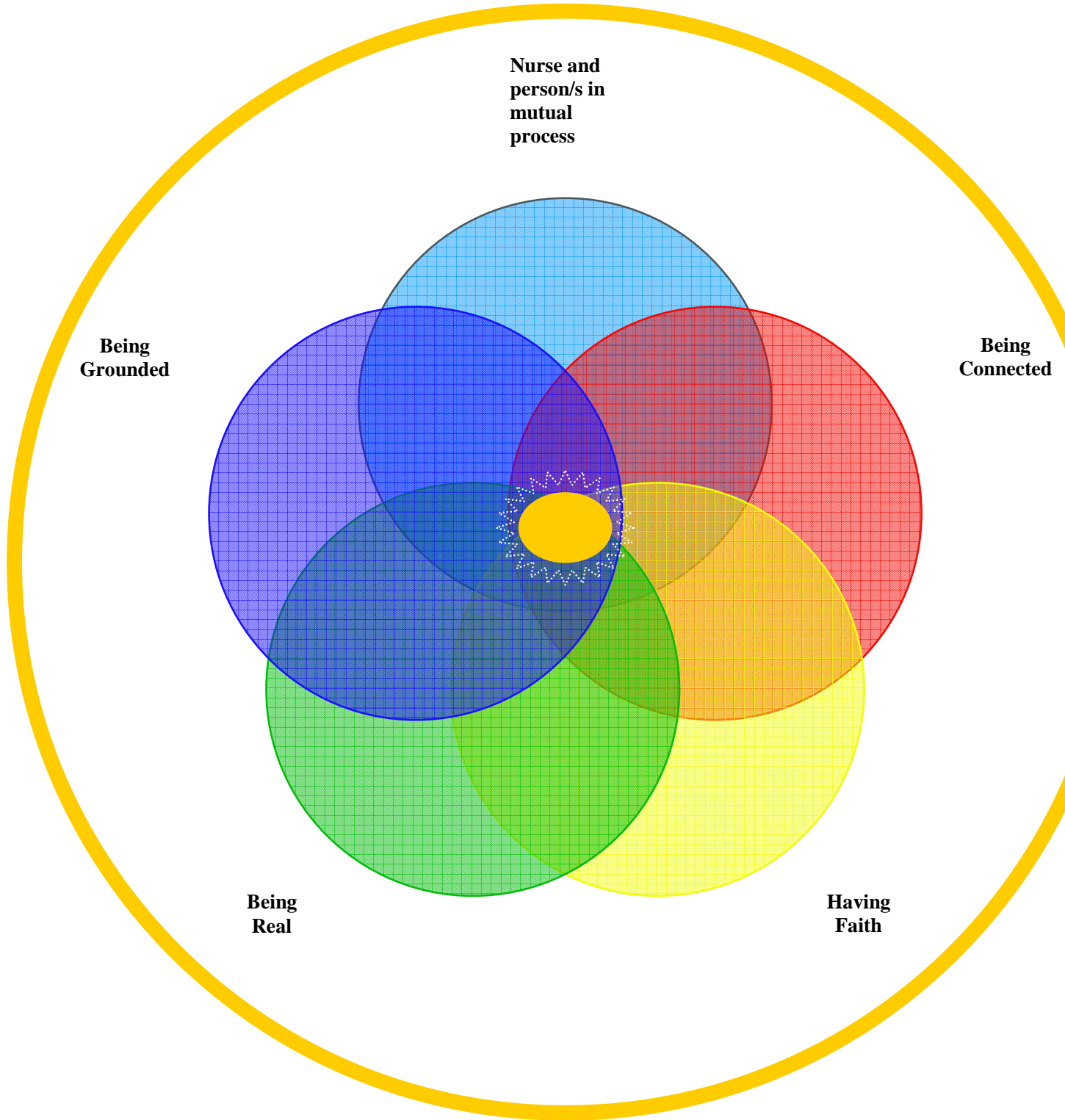

To explain further, 'Cultural Safety' addresses the way in which the TOW is embedded in the education, practice, and culture of nursing. Cultural safety in the grounded-ness of DNFT is an ethical as well as a socio-cultural concern (NCNZ, 2005). Coming to a place of Cultural Safety in nursing requires a heuristic exploration of a sense of self, and connection to people and places as well as the sense of self and places of others. In this thesis I explore my sense of self as a nurse by tracing my nursing ancestry. I find patterns of nursing knowing in energy field nursing theories that posit an integrated view of persons and health and wellbeing (see Rogers, 1971; Newman, 1986; 1994; Parse, 1992; Krieger, 1997; Barker, 2002; Watson, 2005a). I also find universal life patterns in my study and practice of Nichiren Daishonin Buddhism, (see Causton, 1995; TWND, 1999; Ikeda, 2003); 20-21 ${ }^{\text {st }}$ century studies of 
energy fields, (see Brennan, 1993; Myss, 1997; Gordon, 2002; Wilber, 2007a); and Maori models of health, (see Pere, 1984; Durie, 1998; Cram, Smith \& Johnstone, 2003).

When I reflect on the statutory competencies expected of RNs in Aotearoa NZ, I find being grounded in acceptable principles sets out an empirical systematic process for practice which involves nursing assessment, planning, case notes, practice supervision and peer review (NCNZ, 2005). This ensures a descriptive pattern for nursing practice that in Carper's (1978) words, "[i]s exemplary, discursively formulated and publicly verifiable" (p.15). Planning and implementation of nursing care in the DNFT context is implicit in the exemplars presented in Chapter Seven.

\section{Being grounded in ethics}

Although as a DNFT I may walk on the margins of traditional nursing practice, especially in relation to energy work, having cognizance of my statutory obligations as a $\mathrm{RN}$ is foremost in my mind; as is the ethics, safety, and health of the people that I work with. This is my reasoning for the inclusion of a disclaimer in the initial assessment form which marks the territory of my professional responsibilities and the responsibilities of people in DNFT work. It is also the reason that I seek permission from the person to liaise with other health professionals if there are indications of a deterioration of their health or safety (refer Appendix G).

A valuable aspect of this research process for those who were participants are the insights and affirmations which became a natural aspect of the negotiation process for inclusion of exemplars. This indicates the value of debriefing and formally evaluating work with people. All participants seemed to benefit from this process and in the case of Sophie; this led to a review of her journals and artwork which after ethical approval and consent, became a valuable adjunct to her powerful story of transition.

Being grounded in oneself

The personal and aesthetic ways of nursing knowing, in relation to being grounded, is shown in reflections from personal journals and poems. This includes my responses to, and reflections on, the stories and exemplars of persons I work with, and from practice supervision, and peer review. These self-reflective processes enabled me to explore 
my grounded-ness in my nursing-identity and to notice paradoxes such as: Setting definitive goals, whilst at the same time leaving things open to evolve; and fulfilling statutory obligations and competencies of RNs, whilst discovering vistas beyond recognised and validated practice in NZ; such as energy work. Although I have previously referred to the ground of energy work in existence Brennan (1993); Myss (1997); Krieger (1997); Hover-Kramer and Mentgen (2002); and Gordon (2002); my experience of energy facilitation is both similar and distinct from these works. I therefore include a backstage lens of my growing perceptual awareness in this field.

Personal and aesthetic knowing may be regarded by pragmatic circles in nursing and research as self-indulgent. Carper (1988) responds to criticisms of her perspectives on nursing knowing by highlighting the paradoxes inherent in the disclosure of personal and aesthetic knowing. According to Carper (1988) whilst practical concerns in nursing may show up as unclear and 'messy', scientific knowing does not address "[u]ncertainty, uniqueness, and conflict" (p.143). Carper (1988) draws on the work of Benner (1984), who writes extensively about the ability of the expert nurse to utilize scientific, ethical and personal knowing to address complex clinical situations. The ability of nurses to integrate plural ways of knowing in given situations is as Carper (1988) says, “[r]isky...but... necessary" (p.143). I find it is particularly necessary when I seek to expand nursing epistemology and ontology within the ground of nursing practice. In other words, grow nursing knowledge in cultural contexts. Surely the alternative is to gradually experience the erosion of the nursing profession, be eventually covered by the landfall of generic provisions of care and washed away by the dilutions of eclectic practice.

Some may argue that DNFT is not just the preserve of nurses. In this thesis I seek to illuminate DNFT praxis coming from the ground of nursing. I address this further in discussions about counselling and its interface with the nursing profession in Chapter Nine.

Being grounded implies an earthy connection which Starhawk (2004) believes is more than just a metaphor, it is the prerequisite for enabling energy to flow in the cyclical to and fro of interconnectedness. Delgado (2005) identifies the differences in Eastern and Western constructs of connectedness implying that Eastern thought links 
connectedness with spiritual practice, providing a basis for meaning and a sense of sacredness of life, whereas Western thought tends to link connectedness with a sense of justice and social responsibility. I would also add that the Buddhist understanding of dependent origination extends the notion of connectedness to include a relationship with the environment and all living and non-living beings. In this way of thinking the significance of inanimate objects becomes essential, valuing the importance of them to people in loss, grief, and transition; for example, transitional phenomena ${ }^{23}$, as exemplified by Sophie's victory box. The way in which I explore and discover connectedness in my work encompasses both Eastern and Western ideologies. In the following section I explore my evolving knowing and perceptions about energy connections

\section{Being connected: Perceiving energy fields}

Being connected to a sense of self-identity and feelings of interconnection with others and the environment is essential for both the nurse and the person being cared for. I believe being connected goes beyond a sense of belonging identified by Maslow (1943) as a basic human need; into the perception and conception of the human energy field (HEF) and UEF. Empirical evidence for HEF and UEF is gathering in nursing theory at least in a qualitative and theoretical sense (see Rogers, 1971; Adam \& Wright, 2001; Krieger, 2002; Hover-Kramer \& Mentgen, 2002; Geddes, 2002). I discuss the ways in which I gather evidence for HEF and UEF connectedness in the next section through the lens of intuitive knowing.

Seeing with the Minds eye: Tapping into intuitive knowing

I reiterate, the empirical evidence that I have been gathering through being, doing, and experiencing DNFT foundation patterns for nursing praxis, are not intended as proofs of the validity or superiority of this way of working, rather, it is my intention to reveal a way of discovering deeper knowing about being with those in transition, and becoming self-aware. As I grapple with the deeper regions of the being connected with the spiritual self, and release my fears of being believed about intuitive knowing, tapping into inner wisdom, and experiencing serendipities, I hear the resonant pulse of

\footnotetext{
${ }^{23}$ A concept introduced by the British psychotherapist Donald, W. Winnicott (1896-1976), and depicted in his writings as an intermediate space between objective and subjective reality. Symbolic transitional objects, for example, act as a metaphor for the changing reality of the external world, the inner reality of the external world, and the inner conception of what is personally experienced (Young, 1994).
} 
life itself and the words of Nichiren Daishonin (1999) repeated many times in his writings to seekers of truth "Rely on the law and not upon persons" (p. 105). Those who work with a spiritual sense of connection, intuition and wisdom such as Krieger (2002) also acknowledge a concept of universal law underpinning energy facilitation. Krieger (2002) links these aspects in the following:

The concept of fundamental order lies at the heart of TT. The process for healing is essentially concerned with correcting a state of imbalance through the intentional reorganising of dynamic function, feelings, ideas and motivation (p.27).

A sense of being connected underpins the recognition of unique patterns of being in a systematic assessment process, which where appropriate and accepted, will include the pattern of the energy field. This resonates with Rogers' (1971) view in which she reiterates the relationship of energy and the presence of a pattern in her statement:

An energy field is the basic unit of living things. It is a field which imposes pattern and organisation on the parts. It is a pattern and organisation that identifies man and reflects his wholeness (p.61).

In my work with people who specifically seek further clarification of the presence of a pattern in the energy field as a reflection of their life-state, I use a quartz crystal pendulum ${ }^{24}$ to initially determine the flow of the seven energy centres. This practice is not a divination or magical process but an ordinary manifestation of the universal law which exists in both sentient and insentient beings. Although some practitioners do this with their hand chakra through scanning the field a few inches away from the body, I find that the pendulum is able to pick up the field without the potential for my pre-judgement and augments the work of the hand chakra for discerning energy. Once having picked up the energy fields and discerned the flow, I intuit the areas needing further attention. In my work this usually provides the basis for meaningful discussion

\footnotetext{
${ }^{24}$ Quartz crystal is particularly sensitive to the energy field although metals and woods can be used.
} 
about the person's part in and responsibility for the issues needing attention in a dialogical process.

My preparation for this work is my daily practice of chanting to ensure the necessary level of self-care and expansion of life-state. As stated previously this is a practice for observing the Mind and for tapping in to inner wisdom. My experience of it is that it helps me to appreciate that I have access to inherent Buddha nature which is the lifestate I draw from in my work. In this way I am also mindful that each person who works with me has inherent Buddha nature even though they may or may not be aware of this. As a DNFT I remain mindful of the fact that it is my responsibility to take care of what belongs to me, and to encourage and support others that they are also selfresponsible. This is the intentional attitude to my work.

In this capacity I find resonance with the work of Johns (2004a) in his book Being Mindful, Easing Suffering, especially in relation to managing self. To explain further, Johns (2004a) describes five aspects of a healing attitude which include: Intentionality, compassion, non-attachment, wisdom, and equanimity. Johns' views on nonattachment provides a standard for approaching healing work with a sense of self that honours the uniqueness and individuality of self, whilst at the same time recognising our interconnectedness with those we work with. An attitude of non-attachment enables one to be in the presence of suffering with compassion, and recognise that one does not need to hold the pain of the other, identify with it, or take it on.

From my own perspective this attitude of non-attachment is not easy to achieve without a sustained and disciplined way of managing ones own life-state and renewing energy. I have found in my experience of intuiting the energy field of a person, I am momentarily able to feel the impact of the disturbance that they are experiencing. For example, in the case of anxiety I am able to experience the breathing pattern, or if there is pain I will feel the pain in the local area. This experience is described by Koss-Chioino (2006 p.885) as 'radical empathy' in which "[t]he wounded healer enters the feelings of suffering and distress of those persons", usually in the context of being a medium. When I adopt a state of non-attachment I am able to release that feeling and recognise it as part of the intuitive process without taking it on. This takes 
practice and discernment. It also highlights the importance of good supervision, support and daily spiritual renewal.

At this time in my practice I usually use the process of facilitation of energy as a form of assessment only. From here I will teach the person to work with their own field through, meditation, gentle rebalancing the energy centres, and or visiting a specialist in the area of energy facilitation. On occasions when I have discerned great distress or illness I have applied a form of healing which I call soothing the etheric layer; so that that the person is able to relax and focus on the process of re-patterning in the transition they are undergoing. This form of healing work, taps into the emotional dimension clearing the way for meaningful discussion with the person on their processes and patterns for managing stressful situations.

At all times in energy facilitation I am aware of my role as a catalyst for the person's inherent self-regulating and healing system to come into play. There is no room for any ego-investment in this process. Having said that, ego is with us at all times and in most individuals seldom leaves us in the physical realm of being. Ego is part of our sense of self-identity and is an important part of who we are. Having an egoinvestment in something simply means wanting to control something, or have something attributed to oneself. The attitude is like one of having pride in one's work in such a way as to subordinate the other in the process. It is very hard to adopt an attitude of egoless-ness when so much of our Western thinking honours achievement and dichotomises our experiences of life into, good and bad, right and wrong. In Chapter Seven I referred to my own experience of freedom from ego investment in a state of openness to the other, a feeling of tapping into a seemingly in-exhaustible flow of energy and a sense of deep compassion for the other. In this state I cannot say I am free of thoughts and feelings of power and control; however I can watch them with the observer or Buddha Mind and choose not to attach to them. In a state of compassion I can direct my intention in the DNFT work to a pathway of expanding awareness, internal power and self-responsibility for healing.

It is the integration of these aspects that enable me to have faith in the courses of action I take in the doing moments of my work. 


\section{Having faith in oneself and others: The essence of process orientation}

Faith is a word often associated with belief, especially in a religious context. Faith is also strongly connected with the notion of trust; or of a sense of having confidence in something or someone in the hope that something positive will emerge from it (Encarta Online UK, 2007). Having faith is a mutual pattern for facilitation and transitioning, showing up in my work which is the essence of a process-orientation. Process orientation in my understanding of it involves having a sense of intangible movement. Rescher (2002) depicts process philosophers as "those for whom temporality, activity, and change... [a]re the cardinal factors for our understanding of the real" (p.4), and thereby seek the metaphysics of ontology. Process-orientation is the means and manner in which I as DNFT and person as transitioner, go about the work. The process-orientation of having faith is evidenced by the continuity of the work that people do with me. To some extent the person takes a risk, trusting that addressing moments of impasse will in some way free them to the discovery of new vistas, possibilities, and potentialities in their situation.

Having faith is a step into the unknown and opening up to new pathways. Having faith draws on a sense of belief in oneself, others, and/or an ultimate force for positive energy that some may call God or higher self, and others may think of as Buddha nature, or core essence. It involves taking responsibility and having the courage to move forward. In DNFT work having faith is based on my assumption that each person has inherent strength residing in the Buddha nature of the real self. At times people develop defences to cover and protect the real self from being seen. It is my view that transitional moments create an opening for real selves to be revealed. In a real heart-to-heart connection of being, DNFT can foster an attitude of acceptance and respect, enabling tensions to surface in the mirroring process of DNFT. In intentional aspects of actively listening, and assessment, tensions are explored in the physical, emotional, and social self, to find the centre of the resistance tension leading to the impasse. Values and beliefs are also explored, in an attempt to reveal the extent to which the person has been sabotaging their journey to get to the impasse moment in their lives. This includes the extent to which the person in their social-cultural context bases their life story on the roles and obligations they perceive being imposed on them from the external world. These were identified issues for Rose, Faith, and Lilo, in Chapter Seven. 
The discovery of tensions can engage the person in a search for a deeper reality of life in which they become principal author and key player in their life story. This discovery of the central point of tension can lead to a transformation of resistance tension into creative energy necessary for freedom of movement and the discovery of new life-courses and real self. Therapy, treatment, teaching and learning may all be involved in this process. As a DNFT I may not be the person that deals with all of these aspects, to develop this freedom of movement. For example, in Faith's situation a mental status assessment and referral to her GP for antidepressants was an important step for Faith to free herself from a cyclic pattern of negative thinking that had emerged over an extended period of deep grief. Medical treatment along with the freedom of emotional expression and reasoning in our sessions, regular massages, to connect with sensory awareness, and the personal engagement in a meditative practice of her choosing; were all part of Faith's process of moving towards creative energy. Faith's proactive stance and willingness to take responsibility for her journey of transition was an important part of shedding aspects of self which stemmed from an obligation to others and perceptions of acceptable role enactments originating from her primary social experience of family.

Likewise in my work with Lilo, a realistic assessment of her physical and social needs as a person was important. As Lilo lived with fluctuating levels of fatigue for a significant period of her life; practical steps were considered to develop acceptance of self and her situation, to enable freedom of movement. Being able to reframe the fatigue from being limiting and burdensome, to become an opportunity for the discovery of deeper realizations of self in times of rest; freed up the emotional energy trapped in the experience of physical fatigue. This indicates an important distinction between the life-force as a spiritual entity rather than solely a physical / emotional entity. In Lilo's situation addressing the life-force of the energy field was a key to making this transition.

To explain further, the energy manifesting in the physical and emotional field is often thought to be synonymous with life-force. My own realization that this was not so, occurred for me when I examined the energy field of my father not long before he passed away. I found his energy centres to be vibrant and open even though his body was failing and he was close to death. I suspect that this was so because of his 
extensive spiritual practice over several decades. This highlights the importance to me of the necessity of spiritual practice and attention to the subtle layers of consciousness energy to attend to the life-force itself. This attendance to the life-force is the basis of most, if not all, of the wisdom traditions that address spirituality. No matter how flawed we perceive wisdom traditions to be, the discipline of attending to the eternal life-force is usually central to the tenets of these traditions.

The addressing of the life-force and the dawning of the realization of the cyclic nature of manifestation and latency, or, life and death, is at the core of addressing the fear of death that is at the centre of resistance tension which I expand on in the next section.

\section{Transforming resistance tension to creative energy: A compassionate act}

To simplify these process orientations I have conceptualised the DNFT work in Figures 20, 21, 22, and 23. At the centre in Figure 20, the relationship is depicted as a heart-to-heart connection with compassion and having faith being central to a process of an integral exploration of tensions within the self, others, and situation. In this connection a bridge is visualized which depicts the crossing of the negative polarity of impasse, towards an integration and transformation of resistance tension to creative energy. This part of the bridge is depicted as a climb, which in reality is the hardest part of the journey as the person struggles to overcome the obstacles of previous limiting patterns in the self, social world, and the environment. Meeting the resistance tension occurs at the highest point of the bridge and needs to be addressed before the person can take a more fluid pathway. Addressing resistance tension depends on the suppleness of the relationship.

Trust and safety is essential for the person to proceed on their transitional journey, similar to McEldowney's (2002) discovery through one of her participants of the importance of "[c]reating the safe space to be unsafe or vulnerable" (p.188). This can open the person up to discoveries which manifest as freedom to move, discovery of creativity, potentials, and hidden aspects of real self. These aspects are glimpsed by the person who may or may not choose pathways towards unlocking less restricted patterns of living. Self-responsibility and the courage to try new things provide the way forward for a more positive direction. It is not a matter of swinging from negative to positive poles rather; there is an acceptance that within each person is there is 
potential for both negative and positive ways of being. Finding the middle way of integration and transformation of perceptions of self, other, and situation, enables the experience of suffering or illness to become a vehicle for change, rather than a stumbling block or an impasse. For some this may open them up to a different experience of themselves in the world and recognition of spiritual energy which they are encouraged to take forward in whichever ways fits for them.

Figure 20: Bridging the negative - positive continuum: Finding a middle way

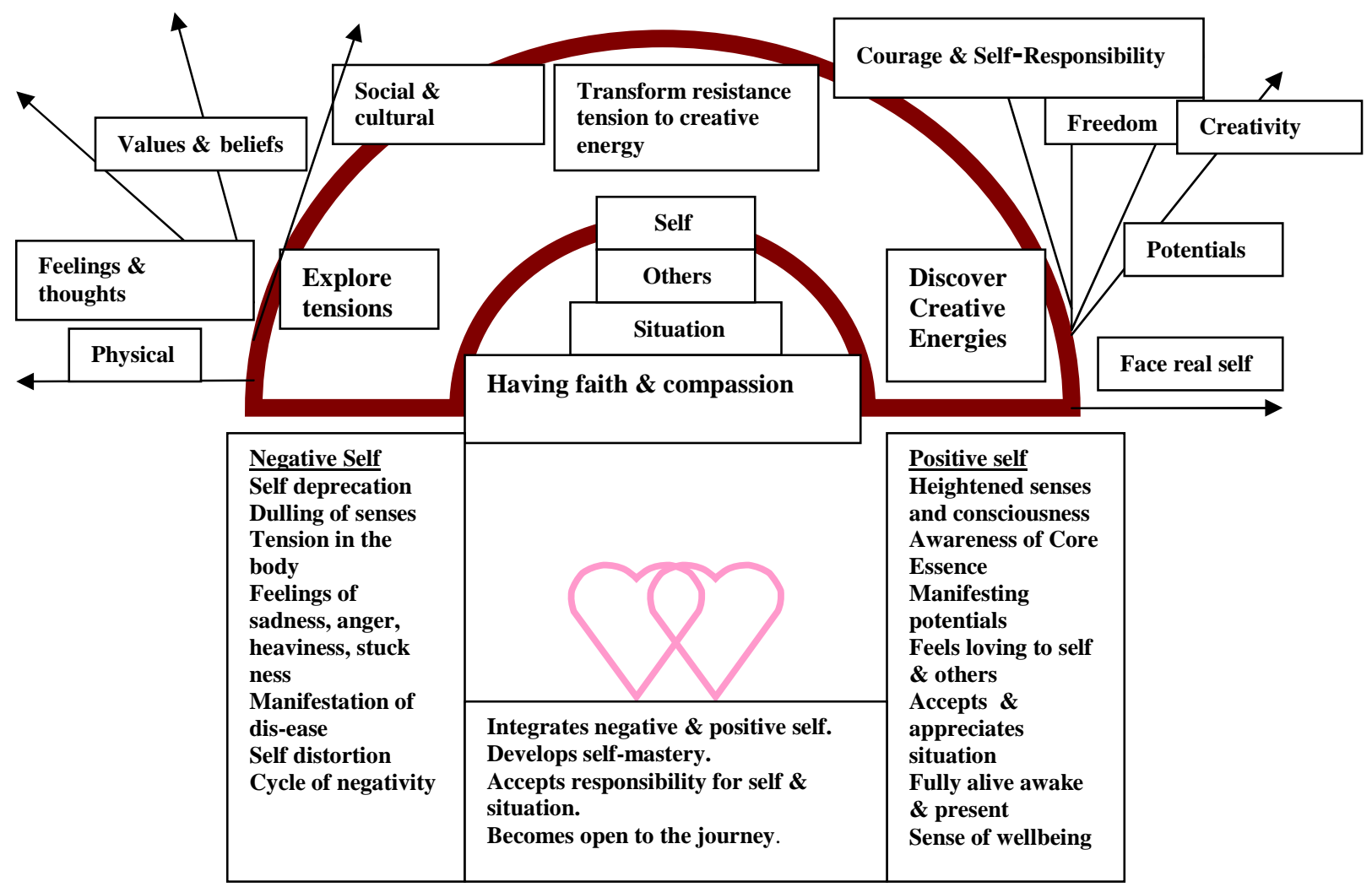

In Figures 21 and 22 I create symbolist patterns with inks on silk in an attempt to find the soft edge of transition facilitation showing the mists and colours of DNFT as it actually seems in the experiencing dialectic. These mirror the chakra colours, previously described in Chapter Four. 
Figure 21: Colours of change

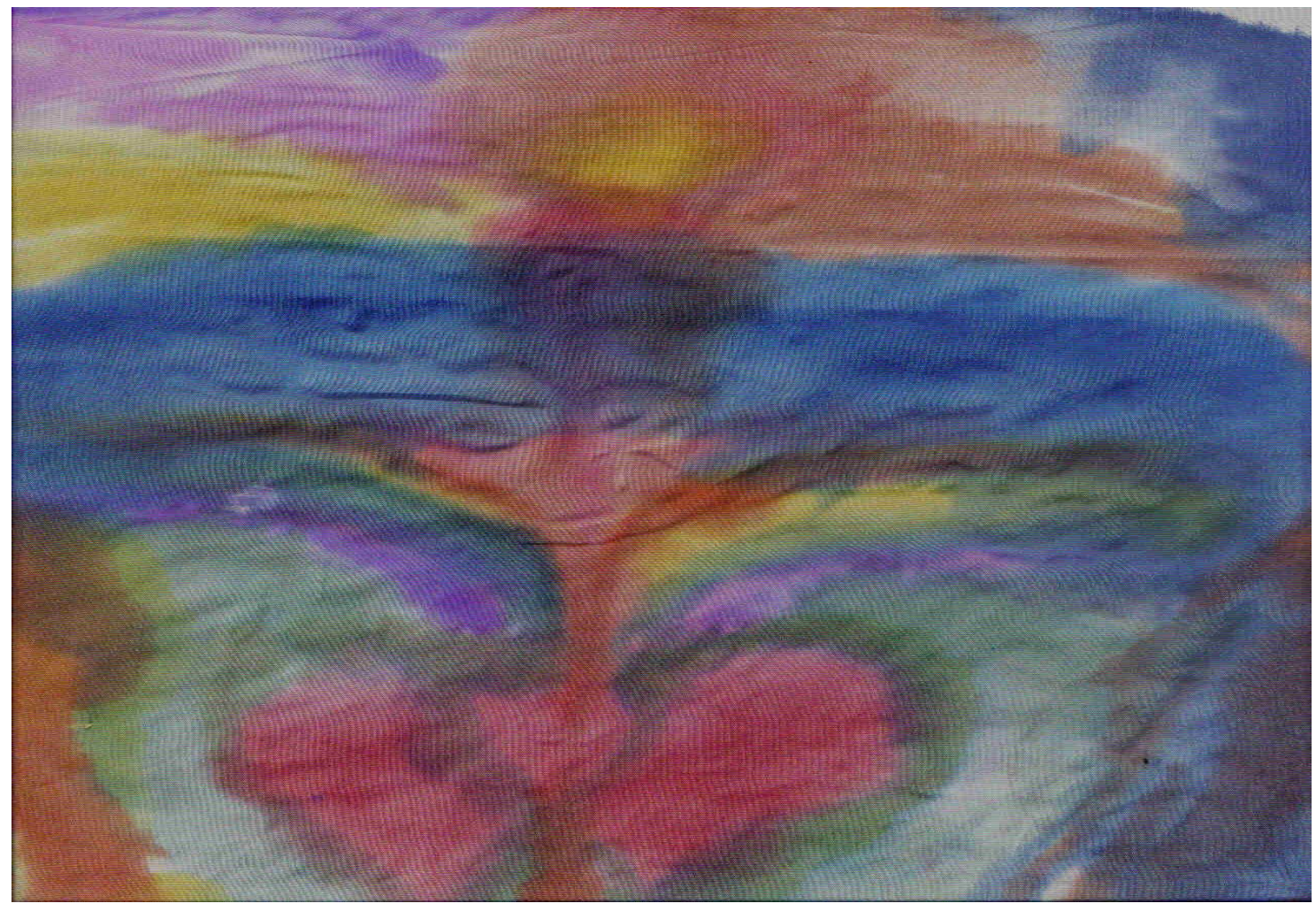

The heart-to-heart connection in Figure 21 shows red as the grounded-ness of the compassion in green. To progress in the journey the person needs compassion for self as they tap into inner wisdom to find insights into their impasse situation. The seven colours of the energy centres emerge and merge out of the heart-to-heart connection to provide a foundation for the bridge shown in blue. Red represents the Grounded-ness of each person in their understanding of lived life as individual-self, in relationship with others, and environments. Orange represents the volition to move forward challenging impasses and seeking change. Yellow represents the strengthened self emerging onto a firmer ground to move forward. The emerald colour surrounding the compassionate heart holds the relatedness of self and other/s in the cycle of growth and transition. The blue bridge represents the expression of feelings, thoughts, tensions, fears and resistances as the person climbs to the central point of their resistance tension. Shades of indigo and violet represent the emergence of intuitive inner wisdom and spirit as the journey of integration and transformation occurs. 
Figure 22: Finding core essence through the resistance tension

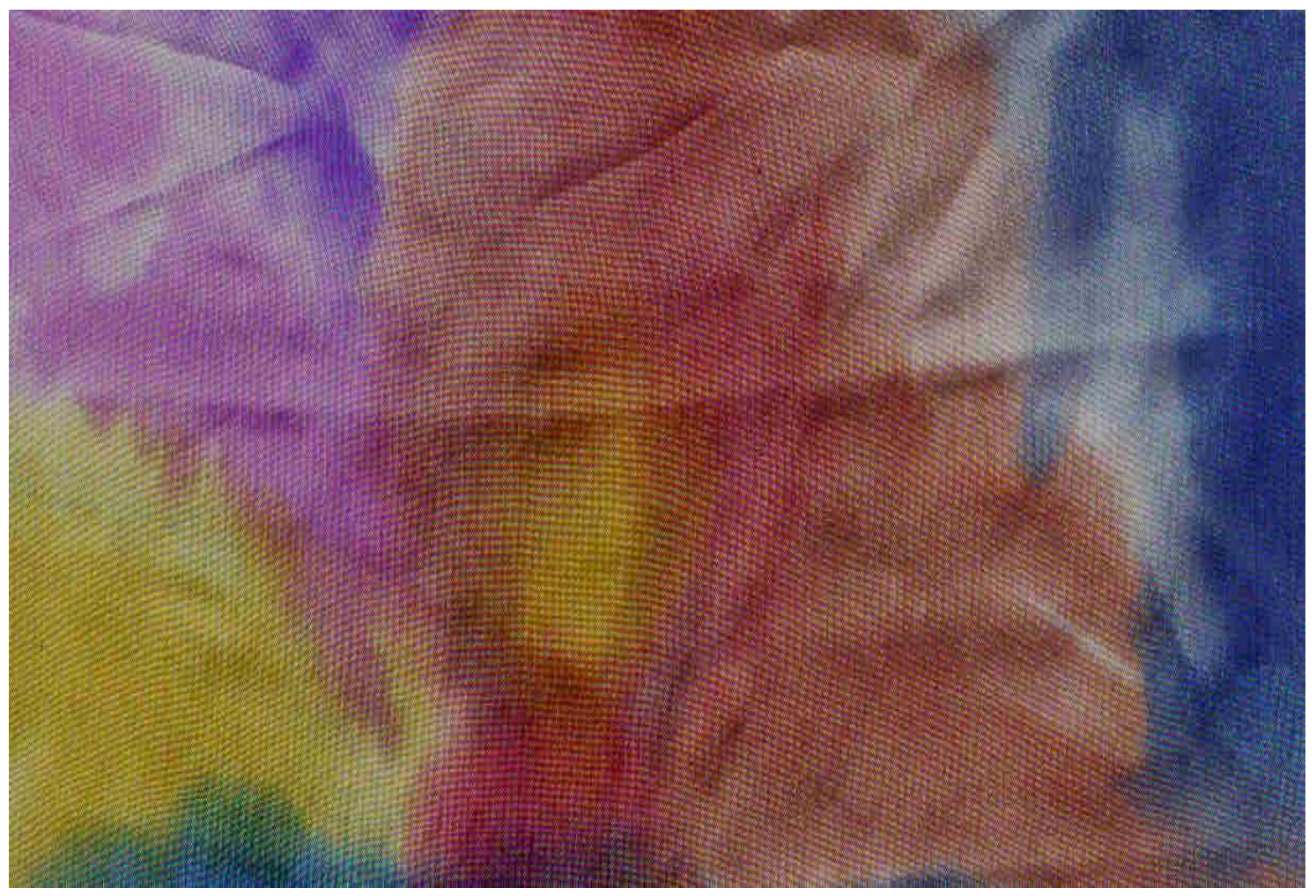

Figure 22, reveals the central point of the resistance tension showing the misting of core essence/real self which is at the centre of all cycles and aspects of life. To get to this centre and transform the resistance tension into creative energy requires processes which strengthen the self, and open up to the energy/spiritual dimension. A shift from resistance tension to creative energy requires that the person accesses the courage to take full responsibility for their life.

Figure 23, depicts this process in a more concrete way showing the polarities and integration processes that goes on in facilitation work. As experiences are shared in the session, the facilitation processes of openness, exploration and mirroring in a number of different ways, can free things up as possibilities and potentials are explored. 
Figure 23: Discovering the dialectics of tension: Transforming resistance to creativity

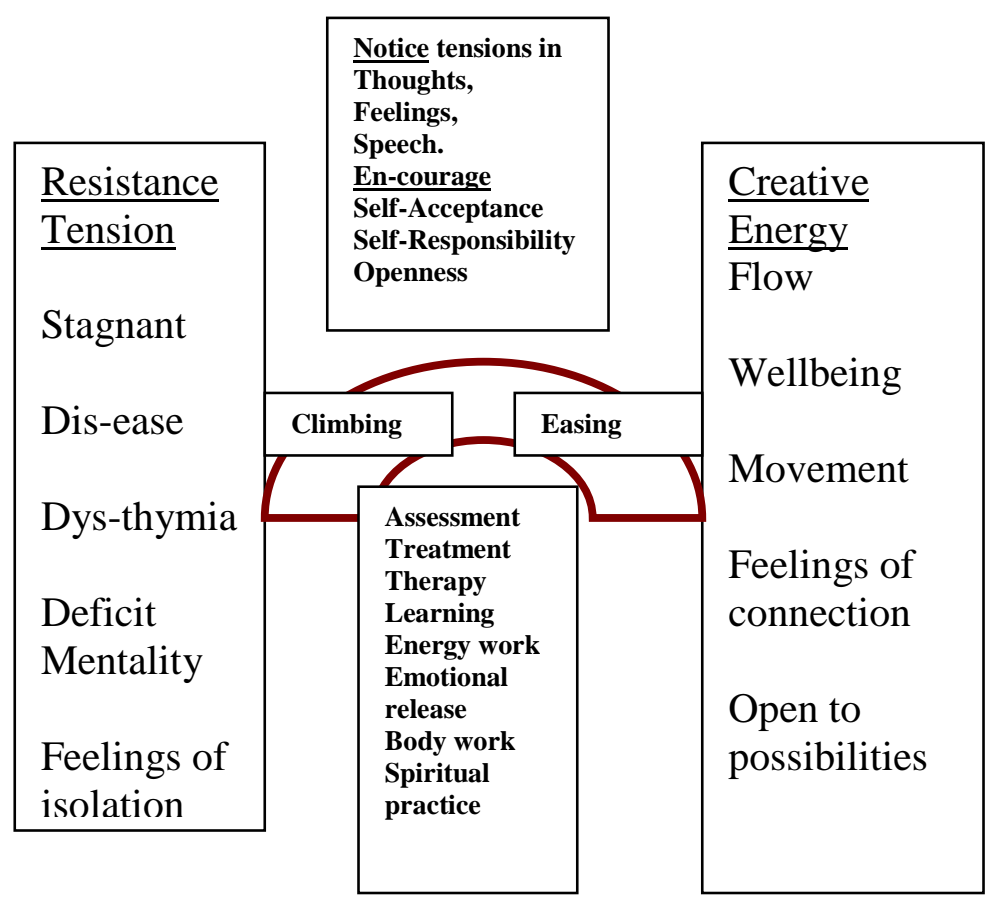

\section{DNFT as a dialogical process}

Actively listening

As shown in figure 23, the key to the doorway of the resistance tension is by way of a dialogical exploration of the lived experience of impasse in life-states, components of being, and seven consciousnesses. For some, this may present as a feeling of stagnancy as though progression is impossible. Impasse may manifest in a tangible disease form, or could be experienced in the emotions as dysthymia, a feeling of dullness, heaviness and lack of enjoyment of life. A sense of deficit may be experienced as though the person does not have the resources they need to get them through. As a facilitator, I establish a rapport of trust and engagement through the skills of actively listening to the person's story so that layers of impasse can be teased out in an assessment process. In this process of actively listening, thoughts, and feelings are noticed and mirrored to create an audible echo and image of the story of the person's experience of being. The time for this process is unique to the person and depends on their willingness to engage in the process of transition. As we progress, in giving feedback I reveal aspects of my real self to engage the real self of the other. 
This does not necessarily mean that I share my story; rather, the response I reveal shows the person that I connect with the universal experience of resistance and am willing to be with them in their transformation, reorganization, and reformation in their search for change. In transformation and reformation persons may find resistances in their internal and external worlds. They can discover the courage and confidence to try out new courses as they glimpse and open up to potentials of real self that until now in the darkness of impasse has not been apparent.

\section{Giving feedback}

In giving feedback through support and challenge, I use the metaphor of dance as I catalyse a way of treading lightly in the heart-to-heart partnership of relationship, revealing a new choreography of movement in the misty moments of life. People are invited to remove their heavy boots and try out lighter ones as we trip around the dungeon of their impasse in search for open doors and windows. When shafts of light are noticed and fresh air bursts in, warmth and movement happens serendipitously as the person risks rattling the heavy doors of resistance. Keys are discovered in the light of day and the call of life beckons as the person opens the doors to new possibilities in an act of faith.

This dance takes much practice as the person learns to feel the resistance tension in their body and to notice again and again the steps that lead to injury and the steps that lead to fluid movement. The finer points of this dance can only be accessed in spiritual realms as the person discovers the weightlessness of the energy field that invisibly shadows the denseness of physical self. These spiritual realms can take many forms as the person finds their own resonance with spirit self. Held by the elements of the grounded-ness of earth, the fluidity and cleansing of water, the movement of the wind, and the warmth of fire, the ethereal layers in space are anchored in life by the body and freed up in transition that is death.

Transitions are infused with meanings transforming fear into creative energy as the person is opened up to the worlds of discovery of movement, creativity, potentials; and the courage, wisdom, and compassion, to be real self. In a state of open awareness the person has the potential to perceive a reality of interconnectedness and a realization that they do not stand alone. 
The discovery of creative energy is similar to the theory of 'Flow' posited by psychology theorist Csikszentmihalyi (1990; 1996). In Csikszentmihalyi’s (1990) theory of 'Flow' a state of immersion, timelessness and ego suspension is achieved when a person is engaged in activities which have the right balance of challenge and skill. If the challenge is too high for the level of skill the person may experience anxiety and be unable to experience flow. Conversely if the challenge is too low for the level of skill, the person will experience boredom and apathy. Csikszentmihalyi attributes the ability to reach a state of flow to spiritual practices such as forms of meditation, the discipline of martial arts or practices that sharpen the attention and concentration, bringing the person to the present moment. The fine balance of the achievement of creative energy to be fully engaged with life, in my view, can be reached in the dialectical process which is not a search for peace and tranquility. Instead it is the bringing into balance both negative and positive aspects of life to a place of integration which creates the potential for movement rather than rest. In the words of Heraclitus, "Opposition brings concord. Out of discord comes the fairest harmony" (Harris, 1994, p.47).

As stated previously nurse facilitation is imbued with the qualities and intentions of compassion, intentionality, intuition and openness (see Figures $18 \& 19$ p. 216-218). These underpin facilitation processes of actively listening, being a mirror, giving feedback and being a catalyst. I synthesize the mutuality of patterns for DNFT in, Figure 24. Three aspects stand out as being central, these are: compassionate engagement, being a catalytic mirror and the interconnectedness of self, other, and environment. Other aspects cluster under these main headings. I expand of these aspects as I synthesize philosophies, theories, presented in this thesis, into the work of DNFT.

\section{Compassionate engagement}

From my perspective, at the heart of a compassionate engagement, is the desire for the happiness of the other person and the relief of suffering. Herein lays a paradox because suffering is inherent in life and we cannot avoid the many cycles of transitions that lead to suffering. From a Buddhist perspective, suffering is a perception, which at any moment can be transformed into a state of joy. The state of joy is not dependent on circumstances but it is dependent on the state of Mind, or the ability to access the 
real self. I do not experience this state as an end point; for me it is experienced as a moment of stillness and timelessness. In the present moment of stillness and real meeting in the warmth of compassionate engagement, time appears to stand still and for that moment all things are possible and the windows and doors of closed hearts and minds are opened, allowing light to come in. Compassion in relation to the Buddha is compared with sunlight; a great light in the sea of suffering appearing whenever there are people with seeking minds ${ }^{25}$ compassionate engagement may be understood as an attitude, or a way of being. The dialectic of sympathy and empathy (Travelbee, 1971); 'genuine unconditional positive regard' (Rogers, 1957); "showing one's inner energy, radiance of love, beauty, compassion and human presence" (Watson , 2005b, p. x); 'having concern' (Benner \& Wrubel, 1989). All of these ideas seem to capture some of the essence of compassion.

Buddhist meanings of compassion in the context of health encompass an altruistic intention to raise the life-state, or expand consciousness (Newman 1994). From a Buddhist perspective it is the bodhisattva way. At the seat of the meaning of the bodhisattva way of being is a sense of interconnectedness, or dependent origination. When one suffers we all suffer, when a person is relieved of their suffering and experiences joy, then through our interconnection, others will experience joy also. Helping, in this context is an energizing function, rather that a depleting one. In Ikeda's (2000) meeting and dialogue with nurses about the essence of nursing he shared a story about Shakyamuni Buddha caring for one of the monks who was ill. Shakyamuni was said to attend to all aspects of his care, washing him, changing his bedding, gently massaging the body, and offering encouragement. Gradually the monk recovered and his mind and body was filled with joy. Shakyamuni further stated as recorded in Bommo Sutra, cited in Ikeda, (2000) "Nursing the sick is the greatest of all good deeds" (p.206). Although this is a statement encouraging others to care for one another, a compassionate intention to care for others is not something that can arise out of a sense of obligation, which in itself is duty rather than compassion. Compassion radiates from the heart as a way of being, and precedes intention which is

\footnotetext{
${ }^{25}$ Taken from the Jigage (verse) of the "Life Span" which is a part of the Lotus Sutra, elucidating the self or "Oneself", which is the Buddha nature. According to Nichiren Daishonins's Buddhism, all people have Buddha nature and the teaching and practice of Buddhism is to enable each person to 'shine like the sun' (Ikeda's lectures on the Hoben and Juryo chapters of the Lotus Sutra, 2006).
} 
deliberate, involving the will. To me, intention is the willingness to act. It involves doing in the process of mirroring.

\section{The challenge of mirroring}

Another aspect of compassion that I have alluded to before is the idea of challenge. O’Donohue (1997) referred to a kalyanamitra or noble friend, as a person who compassionately illuminates aspects of the self which are unknown to the other. An example in psychotherapy is the Johari window ${ }^{26}$ (Luft, \& Ingham, 1955). I have found the most valuable way to challenge in transition work, is to mirror the person through actively listening, reflecting thoughts and feelings in sessions and through being real self; whilst at the same time calling the other to be fully who they are through the process of giving honest feedback. Shakyamuni Buddha is said to have called out to a youth that he met in a forest "Seek out your self! Seek out your self! Start digging at your feet!" (Ikeda, 2006). In other words, the best way to develop self-awareness, is in the moment, dealing with the situation at hand. One of the most common things to challenge is a delusion that the answers to the pain and suffering that persons are going through, is external to them. People frequently muse, for example, if only that person would be kinder to me, if only I had a better job, house, partner, things would be okay. In these musings person lose sight of their own power and the extent of their life-force, to manifest the things they need in their life in order to grow. Adverse conditions are seen as obstacles created by others to limit them rather than a vehicle for growth, transformation and expansion. I challenge by revealing my own expanded life-state and showing optimism and hope that all difficulties can be overcome. Eastern religions and philosophies of Buddhism use the Lotus flower as the symbol of growth and beauty coming from the muddy swampland, as a metaphor for the transformative aspects of growth coming from hardship or struggle (Dockett, 1993).

\footnotetext{
${ }^{26}$ A tool to develop an expanded awareness of self that incorporates unknown aspects of self and blind spots in addition to the known realms and facades.
} 


\section{Compassion interconnection and intuition: Becoming a catalytic mirror}

One of the aspects of compassion that links with the interconnection of self, other, and environment, is the quality of intuition. Intuition, in my view, is seeing with the Minds eye. It is the quality that is held up as being suspect and indefinable by the scientific world. To clarify the importance of intuition in expert nursing decision making processes Benner (1984) defines a intuitive grasp as a "[d]irect apprehension of a situation based upon a background of similar and dissimilar situations and embodied intelligence or skill” (p. 295). Although Benner does not think having an intuitive grasp of something in a nursing context has anything to do with mysticism, I agree with her view that intuitions that come to consciousness in the experiential world of practice, must be viewed in the light of deep knowledge and experience about the subject. As I have stated previously, intuitive insights in DNFT are viewed and discerned, bearing in mind the intellect, the body, and the emotions, within a sociocultural context (Carper, 1978; Rowan, 1997). Intuitions in the practice of DNFT are the integration of knowledge and wisdom, or, the integration between primary level thinking and realized level thinking in the social context (Rowan, 1997). For example, when intuitive insights come up for me in energy facilitation they do not in themselves convey the reality of the situation, nor are they the basis for a diagnostic interpretation of what may be happening in the life-state of the other. Rather, they need to be treated with humility and respect, as a signal to call the other to shed light on the sense they are making of the situation, to dig deeper to find the answers from within (Parse 1992; Barker \& Buchanan-Barker 2005). Intuitive insights in the context of DNFT are reminders and catalysts for me as facilitator to explore a territory in the other in the openness of a question, comment, echo, or sometimes; to share as a hunch that I have, so that the person can agree, expand on, or refute. This for me is the meaning of being a catalytic mirror. As I echo a word that they have said that stands out as significant, and reflect the feelings and thoughts that I see and hear; the other is inspired to see the subject at hand more deeply and find or expand on the meaning that may have hitherto been hidden. Being a catalytic mirror requires a grasp of the gestalt of the process that is going on in the transition work. The content of the conversation shows the colours of the pattern that is emerging. However to be a catalytic mirror, I need to see an impression of the whole which is the process-orientation, the content, and the pattern, all-at-once. The catalytic mirroring of DNFT surfaces the existent and emerging 
patterns through the integration of wisdom and knowledge, heart and mind, body and spirit, which is a mutual process. A catalyst is the medium and the mirror is the reflection, thus I as DNFT integrate the opposites of the wisdom and knowledge, heart and mind, body and spirit to be a facilitator/catalyst to the other reflecting/mirroring the patterns that I see.

In Figure 24, I show the creative synthesis of patterns of nurse facilitation with mutual foundation patterns of DNFT, and qualities and intentions of DNFT, with arrows showing a continuous flow of movement. Transformation and transition, represented by the butterfly, comes about through the discovery of courage and self-responsibility to find new courses, real self, and the freedom to move forward. 
Figure 24: Synthesis of the mutuality of Dialectical Nurse Facilitation of Transition

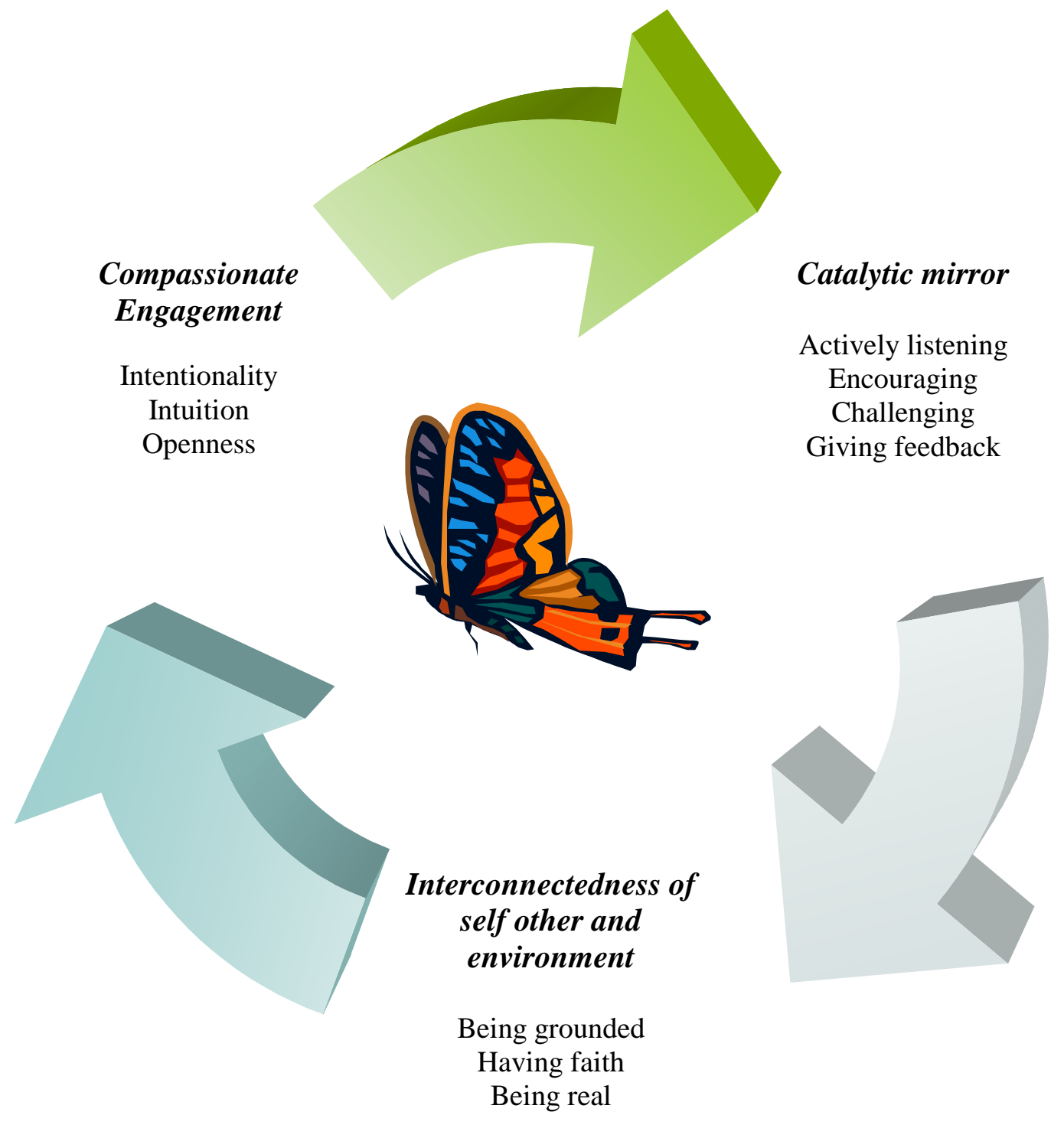

For the sake of simplicity, moments of transition are further synthesized to show three main movements that I see in DNFT work depicted in Figure 25, as overlapping non linear transitional cycles, from impasse through a process of searching to developing self-awareness, and in some cases; transformation. This transformation shows itself in the shedding of the false and obligatory self to reveal more of the real self. I also present this pattern as a variation to the more detailed one explicated in Chapter Seven, to show the potential for aspects other than those I have seen as moments, to reveal themselves. 
Figure 25: A journey towards transformation

$$
\text { Impasse }
$$

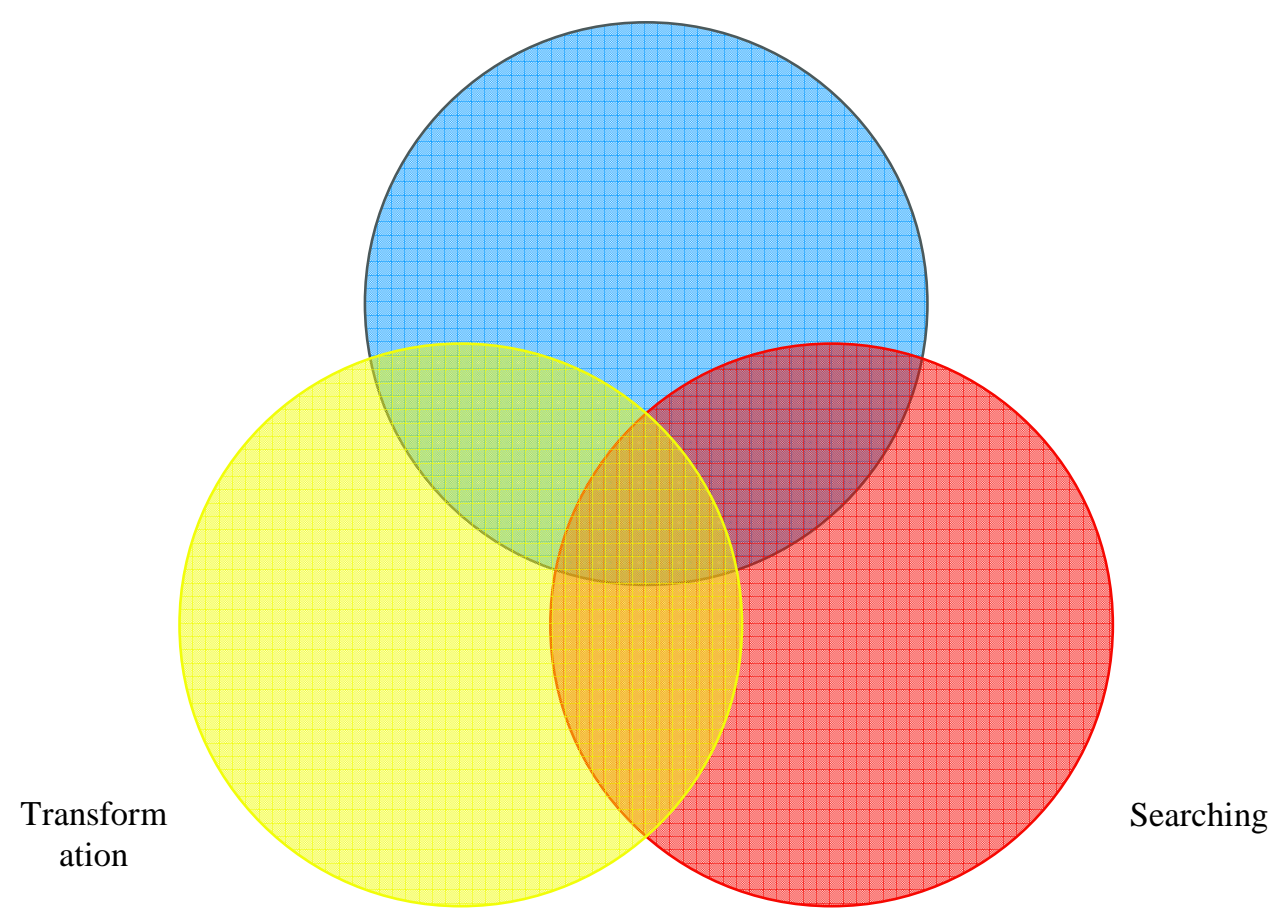

In these cycles depicted in figure 25 , the potential for transformation depends on the willingness of the person to engage in the transition and to have the courage and commitment to move into the unknown.

To explain further, impasses can seem like ever decreasing circles. Usually people are motivated to address them with me because their worlds have become narrow as they go around and around with an idea, or a situation. It can seem interminable. Others may have heard the story over and over, and distance themselves from the person, telling them to get over it, and move on. People often feel that they are playing the same record in their heads. The notes start to jar and there is a general feeling that they would like a break from themselves for a while. Impasse is a deeply uncomfortable experience. As facilitator I experience this impasse moment as a metaphorical 
minefield. It is imperative that I tread carefully with the person. My job as I see it, is to help the person find a way out, and to assist them in this process. In this minefield of potentially explosive emotions, often arising from distant primary experiences, the person seeks release. This moment is captured in the colourful and disturbing frankness of Sophie's paintings in Chapter Seven (see Figures $1 \&$ 8). Searching for a way forward is a mutual process. The person goes inward as I search for a way into their world. I tread lightly with a spotlight of collective insights to highlight the fears and internal and external resistance tensions that I see. As I en-courage, the person finds the courage and faith to step forward, risking a pathway to freedom of movement. This is an outward moment, opening the person to possibilities and potentialities which only they can access; and the beginning of a transformational pathway. As the person gains confidence and lightness of movement on their transformational pathway, their true colours emerge with increasing boldness as they learn to follow the possibilities that appear in their worlds. Memories and feelings of the many moments of transitions past and present merge into the colours of the self to create a deeper and bolder hue, dispelling the illusions of detachment and letting-go. This journeying through the impasses in transitions is a mutual integrative process leading to growth and expansions of life-states.

\section{Summary}

In this chapter I have synthesized patterns of being, doing, experiencing, DNFT, from reflections written in Chapter Seven. In my interpretation and explication of these patterns, cycles, and moments; I find resistance existing within my own evolving knowing. Especially about the intuitive aspects of nursing knowing, that is continually held up for critical evaluation in practice worlds that privileges narrow science as a standard for valid practice. As I look at the mounting evidence calling for integral approaches to health care, I begin to challenge the external resistances in nursing worlds. I discover freedom to see real patterns of DNFT that show the intimate practice world that characterizes nursing. These patterns form the aesthetic, personal, ethical, empirical, and contextual lived experience of practice, shaping the praxis of DNFT. I take these ideas forward in Chapter Nine to discuss the challenges and possibilities that identified patterns potentially offer the nursing profession, in national and international contexts. 


\section{PART THREE}

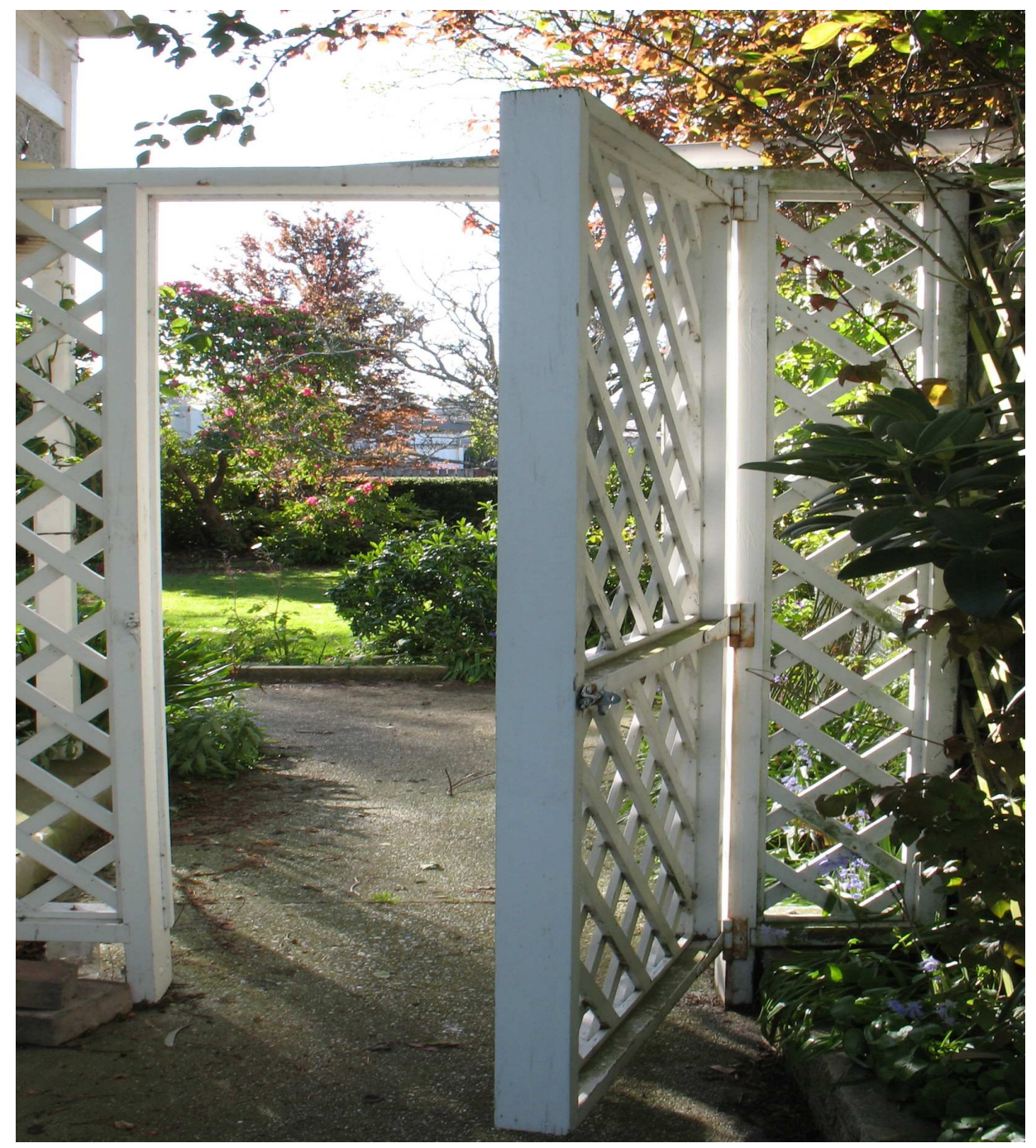

Through the lattice step lightly ${ }^{27}$

${ }^{27}$ (John Francis Waller, 1800's). From the folk song 'The Spinning Wheel'. 


\section{CHAPTER NINE Finding Resonance and Dissonance: Tapping}

\section{into the Collective Consciousness about}

\section{Transition, Facilitation, and Nursing}

I use the metaphor of a lattice gate to create an atmosphere of glimpsing and a sense that looking forward is in itself an act of faith as the full vista of the future is not apparent all-at-once. Instead it gradually unfolds in the proprioception of my vision, as the present comes into the foreground and the past fades into the backgrounded allowing the future to come into view. Hence the need to trip lightly so that the baggage of past ways of being does not create an impasse; or a feeling of heaviness for movement in a forward direction. I do not think that I can look forward in nursing with a sense of vision without scanning the nursing field, nationally and internationally, to get a sense of the distance travelled in nursing and the impasses that have been encountered along the way on the subjects of Dialectical-NurseFacilitation-of-Transition. It is for this reason in a heuristic process of expanding awareness and realization, I seek to further clarify, delineate and refine my understanding of DNFT by engaging with extant texts. I reveal my attraction to and engagement with, theoretical and philosophical constructs that expound on the nature of being and experiencing in change. In doing this I pick up themes from ancient and modern collective wisdom, from nursing, religion, and philosophy, to describe my expanding awareness of consciousness as it applies to mental health and wellbeing. The metaphor of a spider weaving a web is salient to the way I constructed durable threads onto which I formed patterns of the heuristic of DNFT, explicated in Chapter Seven, and conceptualized as patterns in Chapter Eight.

In this literature review, the threads of DNFT praxis patterns are strengthened by the collective consciousness so that I am able to catch the dialectic of transitions in their various states of metamorphosis. In choosing texts I seek both resonance and dissonance with insights made to create a discourse about DNFT praxis. I begin with the historical influence of Florence Nightingale, especially in relation to healing and facilitation, in the next section. 


\section{Florence Nightingale's legacy}

Florence Nightingale (1969), in her heuristic Notes on Nursing: What Nursing is and What it is Not, written in 1860, revealed a pattern of the interdependence of human beings and their environment in her perception and conception of nursing. I was inspired to write poetry following my re-reading of her personal journal account. I can't help feeling that in the flow of her Victorian pen, she was expressing a longing for something that she would have prescribed for herself. Nightingale's journal notes on nursing, I think, reveal the dialectics of a didactic matron, pragmatic nurse, and empathic mystic, as she explicates her understanding of the canons of nursing.

\section{Florence Nightingale's Healing Space}

Nurses step firmly and cheerfully into the sick room

With brightly coloured flowers

Faint scents

Bringing news of life

Reminders

Shafts of gold and silver light

Form a beam on the sick bed

Extending the healing hands of nature

A breeze flows in and out of the open window

Rhythms of life's breath

The fire glows

Warming cold hands and feet

No traces of mature midriffs encased

In crinoline expected

Rather

The gentle presence of the nurse

A constant companion 
In suffering moments

Keeping watch on nature's wisdom

Searching for signs of recovery

Nursing

An Art Act

Played out in the dramas of birth, aging, sickness, and death

Florence taps knowingly, or unknowingly, as the case may be, into ancient wisdom found in the philosophies of Hinduism, Buddhism, Heraclitus, and Hippocrates, namely; the four elements, earth, water, wind and fire, underpinning medicine and healing. In putting forward a view that the forces of nature hold the key to wellbeing with the help of the Divine, Nightingale (1969) reveals a facilitation pattern for nurses to be part of this healing dynamic. The "firm light quick step"(p.5), of the nurse is, I believe, her 'desiderata' for being a real presence in the healing space, grounded and connected to one's identity as a nurse, to do what has to be done and create a healing environment for nature and the will of the patient to do the rest. Humorous though her description may be, of the 'indecency' of 'crinoline', perhaps underlying her exclamation there is a principle reinforced in the aforementioned work of Gadow (1980); to keep the focus on the person rather than oneself in the healing dynamic. Nightingale explicitly alluded to the inappropriateness of overt displays of sexuality, a stance which finds resonance with ethical prescriptions of most counselling and psychotherapy practices in this age (see New Zealand Association of Counsellor's Code of Ethics 2007; Bond, 2002). Rather than revealing the aesthetic of the female form, she promoted the aesthetic of colour, aroma, and light, to engage the sensory system in awakening. This awakening would, in Nightingale's view, soothe frayed nerves and restore a connection with life easily forgotten in the shadow of suffering. This approach would find kindred spirits in current nursing complementary therapies, such as aromatherapy and colour therapy (Barrett, 2003; Johns, 2004a; and Gully, 2005).

Nightingale (1969) referred to nursing as an art - a mastery of both subjective and objective knowing, in an alliance with nature and the Divine - "To put the patient in 
the best condition for nature to act upon him" (p.133). Her explicit chastening of the narrow lens of science is eloquently expressed below,

[i]t is quite surprising how many men (some women do it too), practically behave as if the scientific end were the only one in view, or as if the sick body were but a reservoir for stowing medicines into, and the surgical disease only a curious case the sufferer has made for the attendants special information (p.125).

Nightingale advises subscribers to this view not to put aside observations and therapies extracted from the well of experience.

Of compassionate interpersonal relations, Nightingale warns against "[a]ttempting to cheer the sick by making light of their danger and exaggerating their probabilities of recovery" (p.96). Speaking of the tyranny of people imposing their advice on the vulnerable, Nightingale (1969) empathically states:

How little the real suffering of illness are known and understood. How little does any one in good health fancy him or even herself into the life of the sick person (p.102).

The inclusion of micro-counselling skills in some formal nursing education programmes addresses these lay tendencies; preparing to view the complexity of the nurse-person relationship, and the person's unique experience of illness as a core foundation upon which to base skilled nursing practice (Peplau,1952; Arnold \& Underman Boggs, 2007). Barker \& Buchanan-Barker (2005), in developing the Tidal Model, progress the aforementioned work of Peplau (1952) by explicating nursing in relation to interpersonal relationships, specifically in mental health. I expand on this under the following heading. 


\section{Metaphors for facilitation: The Tidal model}

In particular, Barker and Buchanan-Barker use the element of water in a metaphorical way, to lead into proposing a philosophical 'credo' for the day-to-day world of mental health nursing, emphasizing the caring and facilitative nature of the work. This metaphorical use of the sea has resonance with TWND (1999), in which Nichiren refers to Buddhism as "A ship to cross the sea of suffering" (p.33).

Barker and Buchanan-Barker posit four key principles underpinning the Tidal Model, interpreted by me as follows: To focus on the person in the context of their life world rather than the narrowed lens of a mental health problem; to develop an awareness of the constant of change; and to place empowerment at the centre of caring nursing practice. Caring is caring with, "[1]ike dancers united in the dance (p.23). Barker and Buchanan-Barker (2005) highlight the experiential nature of nursing work, honouring the unique knowing of the persons they work with, exhorting nurses to become learners encouraging people to teach them about their experience of being unwell. According to Barker and Buchanan-Barker, this teaching and learning, is through hearing the stories in caring conversations, over time. This is different from the contrivance of an interview, which tends to foster a power relationship, no matter how skillfully done. In contrast, Barker and Buchanan-Barker (2005) posit:

The Tidal Model emphasises the need to engage with the person, building a genuine human alliance that might begin to address the person's problems of living. The practitioner signals an intention to engage with the person rather than manage, treat or otherwise fix the problem, by opening a conversation with the least restrictive question (p.28).

The Tidal Model was introduced to NZ in 2000, creating an optimistic hope of a return to the essence of nursing. Jacquie Kidd (2005) located the Tidal Model in the Maori context of Aotearoa and spoke of the significance of the metaphorical associations of the model to Maori in the following: 
While water can be a powerful metaphor, it is also grounded in reality. In addition to returning to home waters for cleansing and renewal, water is used for symbolic cleansing of a person, article or place...[w]ater is a central theme to spiritual and physical life for Maori, and therefore the Tidal Model is a comfortable match in symbolic and metaphorical terms (p.4).

This statement by Kidd shows the resonance of the Tidal Model within the sociocultural context of Aotearoa, offering a way forward for mental health nurses in the climate of changes in governmental documents (MHC,1998; 1999; 2000; 2001; 2004; 2007).

Laurie Davidson (2002) shows a sympathetic alliance with the tenets of the Tidal Model. Nevertheless, he questions the need to burden the practice world with yet another model. Davidson wondered whether the Tidal Model was not just another take on the work of Carl Rogers, and why it needed to be posited as a nursing model when so much of it is transferable to other disciplines. Davidson (2002) noted a tendency by proponents of models to develop special language around them and prescriptive ways of implementation; and believed this was already starting to happen with the Tidal Model. I share his views on this, as I step in and out of the various theories, models, and philosophies that I review. I suggest that one way of avoiding this trap is to come home to oneself frequently, in a heuristic self-reflective process. Davidson emphasizes the need to understand the basic values system behind models, or better still, 'approaches'; for example the 'Recovery Approach', to hold the space open for diversity of application. That said, the basic value system that I see underpinning both the Tidal Model and the Recovery Approach is the humanitarian pattern of caring shared by a number of nursing writers (see Travelbee, 1971; Watson, 1979; Benner, 1984; Benner \& Wrubel, 1989; and Montgomery, 1993). I expand on their work in relation to caring in the next section.

\section{Finding the essence of caring}

Watson (1979) theorized about the nature of caring in The Science of Human Caring. Benner and Wrubel (1989) sought to uncover the invisibility of caring in nursing in 
their phenomenological research, Montgomery (1993) linked communication with caring in nursing practice. Barker and Buchanan-Barker (2005) note that although the intention of caring in nursing is to create a healing environment, paradoxically it can also lead to dependency if the dynamics of it aren't thought through. Caring as a healing dynamic is, therefore, ideally focused on change and growth, and this process is enabled by skillful reflective and reflexive nursing practice, embodied in empathic motivations. The quality of empathic responses also carries a feeling of vulnerability for nurses, highlighting the need for self-care and renewal.

Barker and Buchanan-Barker (2005); and Munhall (1994) emphasize openness to learn from the other in order to discover the person's needs rather than assume them. Mindfulness in the care of a distressed person is essential, which is different from prescriptive approaches so often associated with health-care (Johns 2004a and Barker \& Buchanan-Barker 2005). Being mindful, is described by Johns (2004a), as "[t]he exquisite ability to pay attention to self within the unfolding moment in such a way that one remains fully available to ease suffering and nurture growth" (p.18-19). I understand that mindfulness, in a relational context, is a compassionate nursing intention, incorporating being fully present and open to the other with full awareness of self, whilst at the same time, being available to hear the evolving story and emerging meanings revealed by the other person. Mindful presence goes beyond egoself into the deeper regions of spiritual emergence; like a meditation. From this vantage point, the observer Mind is able to watch the thoughts and responses of one's ego-self, whilst at the same time, hear and experience the other. This goes beyond language and words to the essence of being-ness where inner wisdom emerges and intuitive awareness is accessed. It is my view that a mindful compassionate intentional state brings to light primary level knowing in the energetic life-force, primary echoes, and life-states of the person held in the layers of, in the memory of the $7^{\text {th }}$ and $8^{\text {th }}$ consciousnesses.

I wonder if these important tenets of mindful compassionate interpersonal relationships, from the writings of Nightingale (1969); Peplau (1952); Krieger (1997); Johns (2004a); Barker and Buchanan-Barker (2005); Watson (2005); and MHC (1998; $1999 ; 2000 ; 2001 ; 2007)$, are now forgotten in the empirical turn of evidenced based practice (EBP), where quantifiable science again becomes the focus, and the long 
suffering person is treated to more subtle versions of advice. I refer to the current tendency for nurses to focus on setting appropriate goals with people, for a timely and efficacious return to health. This in itself could be helpful, or so one would think, if only the goals would actually come from the motivations of the person, rather than allknowing others. It is my view that a facilitative role leads to a less intrusive pathway of helping, as explored in the next section.

\section{Nursing and the facilitation of transition}

In contemplating the nurse's role in the facilitation of transition, I find that nursing has a natural affinity with transition by the very nature of the work. This view finds agreement from Joffrion and Douglas (1994); Schumacher and Meleis (1994); Meleis and Trangenstein (1994); and Meleis, et al., (2000) who put forward the view that the facilitation of transition is a nursing mission. Meleis et al., (2000) drew on transitions research in nursing contexts to develop a middle range theory of transitions, which has some resonance with my experiential work. To explain further, Meleis et al., (2000) specify the following in their emerging middle range theory: Types of transitions; patterns of transitions; properties; contextual transition conditions; and processoriented patterns of response. These types, patterns, contextual indicators, process orientations, and outcome indicators were wrapped within the therapeutic nursing facilitative relationship. Patterns of response, identified by Meleis et al., (2000), such as feeling connected, and being situated, show some resonance with my patterns of being connected and being grounded, but do not touch on the energy and spirituality that I found to be factors. Being connected and being grounded were also seen to be important for the facilitation of wellbeing, in persons with mental health issues, by Barker and Buchanan-Barker (2004). Joffrion and Douglas (1994) in their perception of facilitating self-transcendence in the bereaved found that feelings of connection encompass relationships, the environment, and spiritual dimensions. These perceptions of connection are seen to be important in the facilitation process.

Meleis et al., (2000) suggest that nurses need to be cognizant of patterns of significant transitions in person's and family's lives in assessment processes. Awareness, for example, relates to the person's perceptual knowing about the change process. Meleis et al were unable to resolve the tension identified between nurses and persons awareness of transitions, specifically whose awareness initiates the transitional 
process. This paradox is not so often found in my private practice, where people elect to come to me because of an awareness of impasse and the motivation to change. It is important to bear this paradox in mind when it is the nurse who triggers the transitional process through an assessment process, and when the nature of the transition has not reached the person's full awareness. This would have implications on facilitation, which begins with an inductive process, rather than being driven by the volition of the person. Clearly, this may impact on the level of engagement of person/s in their work with facilitators.

I suggest, in most cases in health-care contexts, the entry point of the relationship between nurses and persons are by way of meeting in crucial moments, when people are confronted with change. These changes usually relate to the person's physical and emotional selves manifesting as a disorder of some kind. Secondary to these situations, transitions occur in every aspect of the person's life. Although nurses may be tempted to focus on the most obvious physical and emotional disturbances presenting in health-care situations, the issues standing in the foreground in the person's perceptual consciousness, may actually be quite different. This was so in the case of Sophie in Chapter Seven, where her point of entry into the health service was a disorder manifesting in the physical realm. In her perception the pain was also keenly felt in the emotional and social realm.

Meleis et al., (2000) noted seeking and pro-action as signals of involved engagement in transitions. This resonated with my perception of the seeking moment in fully aware transitional processes. Seeking change in the context of my work also takes account of the volition to seek answers, meanings, and reasons for the impasses that occur. This seeking process was also described by Feilden (2003) who found a process of searching for meanings and answers, in the lived experiences of those bereaved by suicide.

According to Meleis et al., (2000) it is important for nursing assessments to include aspects in the person, community, and society, which can either facilitate the transitional process, or inhibit it. In the patterns that I saw, I identified both internal and external resistance as inhibiters of the transitional process, which relates to the personal and socio-cultural-political world. The resistance mechanism of defence is 
evident in many of the theories of loss and grief, and in Gestalt psychotherapy, previously discussed (Neimeyer, 2001a \& b; Perls, 1975a \& b). Rowan (1997) locates these mechanisms in primary and social level thinking. The internal and external resistances are both inhibiting and transformative in my experience. To explain further, resistances in the self and environment are seen to create impasses in transitional processes and have the potential to become transformative when people develop an awareness of what have, hitherto, been largely subconscious processes.

In my experiences of facilitation, awareness frequently represents a turning point in the facilitation of transition process, preceding movement, changing course, and discovery of real self. These patterns resonate with the nursing work and theories of Meleis' et al., (2000) 'critical turning points', Newman's $(1986,1994)$ 'choice points' and moves towards freedom; and Fielden's (2003) 'creating a different life world'; forming a collective pattern of nursing insights into change processes. Each of these patterns holds the relational aspect of nursing work central to facilitating transition representing the being, doing, and experiencing of my nursing praxis.

\section{The being-doing-experiencing triad of facilitating transitions}

In my work with people in transition, I locate the praxis world of nurse facilitation in the being, doing, and experiencing triad of a dialectical approach, which is sometimes problematic when it comes to explicating the work. This is because the being and experiencing aspects of nursing are often hidden and mysterious, and can only be located through research using qualitative methods. The doing of nursing is much more likely to be shown in quantifiable aspects. At this time in nursing, the emphasis is to produce material evidence of practice efficacy in the health and business worlds, especially in the socio-political arena of funding for health services. I posit that this quantitative focus veils nurses' true worth and skillfulness which is best revealed in the being and experiencing moments of nursing.

Paradoxically, while the skills of nurses may be hidden to socio-political influences and dominant cultures in health worlds, the public, since Florence Nightingale's time at least, view nurses with admiration. It could be said that the public have an obsession with both nurses and doctors, if the ratings of popular television programmes such as British 'Casualty', United States (US) 'Grey's Anatomy' and NZ 'Shortland Street', 
are anything to go by. I wonder if these programmes, in some way, assuage the public appetite for hidden mysterious elements of the health-care experience, by showcasing life-death, loss-change dialectics. I suggest that the experiential world is the place where these secrets are kept, and it is only through phenomenological, heuristic, reflective, or narrative means, that aspects of the experiential world and the dialectic of change can be revealed.

\section{The dialectic of change}

The experiential world of nurses as change agents, or facilitators of transitions, as I prefer to call them, was written about extensively by Newman (1990), who drew on Young's (1976) stages of human evolution and Prigogine's theory of change (Prigogine, Allen \& Herman, 1977). Both Young and Newman hypothesize that humans come into embodied consciousness from another state of consciousness, which is free from the constraints of perceived linear time and space. This embodiment is an experience of struggle, limited by time and space, in which persons become identified as an individual or ego-self. This ego-self strives for power in the social world and self-determination within it. At transitional moments and turning points, when the ego-self experiences restrictions, the person searches for a way forward, beyond the boundaries and limitations they have experienced so far; opening to moments of potential transformation and a return to freedom. This journey from struggle and confinement to freedom is much like the moments I notice in the person's journey from impasse to changing course. The time of resistance represents a to and fro dance of ambivalence, as the person searches for a way forward. This to-ing and fro-ing is expressed, in more complex language, in Parse (1992), as rhythmic patterns of 'revealing-concealing', 'enabling-limiting', while 'connecting-separating', mentioned in Chapter Three. Newman (1990), in explaining this difficult moment in change, refers to Prigogine's theory as follows:

If the force of the fluctuation is great enough, the structure is forced to change and moves through a temporarily chaotic situation to a new higher order. Transformation takes place as the system moves far from equilibrium. The action at the critical point of the fluctuation has the potential to go in a number of directions, and it is impossible to know 
which way it will go. But at some point one direction takes over and a new order is established. In this new order new rules apply (p.40).

Moments of choice and self-determination at critical points are emphasized by Newman, as times of potential transformation and expanding consciousness. This expanding consciousness is not seen to be entirely on the physical or mental level but also having to do with a person-environment interaction. The direction that the person goes shows itself as an emergent pattern and could be disorder, wellbeing, life, or death. Nurses facilitate an awareness of these emergent patterns in the context of an authentic relationship of trust; supporting the person to make the accompanying organizational adjustments to accommodate change (Newman, 1990). This facilitation process, proposed by Newman, is resonant with DNFT in the transitional moments in each of the case exemplars and emphasizes the need for nurses being real to establish a trusting therapeutic milieu.

Another proponent of change processes and pattern-seeing influencing my work was psychotherapist Virginia Satir et al., (1991), who devoted time to the careful consideration of theory and praxis with families and individuals. The essence of facilitation of transition, in her work, was for therapists to adopt an attitude of acceptance when making sense of existing dysfunctional patterns. With an accepting approach, Satir, believed therapists could facilitate the person's awareness of how the pattern has helped the person in terms of survival. According to Satir, this enables the person to show gratitude for the way in which the pattern has served them in the past, and frees the person up to trust themselves to envision new patterns in the now moment; enabling a safe passage through resistances, or to-ing and fro-ing, in the cycle of change (Satir, et al., 1991).

Satir's model has resonance with Prigogine's theory of change, in the identified phase of temporary chaos in the change cycle (Newman, 1990 \& Prigogine et al., 1977). This pattern is echoed in Fielden (2003), whose participants experienced chaos to the level of "emotional disengagement or disembodiment to the world around them" (p.80). The chaos pattern in Satir et al., (1991) signalled the beginning of a repatterning process, where new configurations of self become open to many potential 
options. This chaos moment is seen as crucial, by Satir, because of the many directions the person can take, including returning to the status quo, stagnation, or retreat through fear. The chaos moment, in Satir's theory, is a defining moment in the transformation process. This is especially so if there is an atmosphere of acceptance, non-judgment, and belief in the competence of the person to find their feet and create a new pattern. In this way, the person is able to integrate new meanings and move to a sense of balance and wellbeing. According to Satir, it is also crucial at this time for the facilitator to stay focused, anchoring the person in the present moment. Satir notes that the attitude of the facilitator and their ability to care for self is crucial at this stage because of the potential to show patterns of protection and collusion, in order to lower the level of anxiety for the person, or oneself (Satir et al., 1991). This potential highlights the need for self-care of nurses in transition work.

\section{The importance of self-care in nurse facilitation}

I share Satir's view of self-care, in my heuristic reflection, in recognition of the essential practice of self-reflection, supervision, and energy renewal. Virginia Satir emphasizes the need for self-care by sharing a reflection close to her death from cancer; asking those she worked with and taught "[n]ot to model her lifestyle of not taking care of herself". She said, "I took care of everybody out there, but not of Virginia" (p.328).

Watson (2005a) emphasizes the importance of self-care for nurses in her development of caring theory and practice in 'Clinical Caritas'. Watson highlights the ongoing development of nurses to care for others in a transpersonal frame. Watson's view of transpersonal caring goes beyond ego-self into a sense of spiritual connection. For nurses working in the transpersonal dimension, Watson proposes a deepening ongoing reflective study of self, similar to Johns (2004a), examining one's experiential journey of personal and professional being; to develop ontological competencies for practicing nursing, which encompass mind-body-spirit dimensions at the holographic interconnected universe level.

\section{Transpersonal care}

Caring in a transpersonal frame has been the basis for some controversy especially in the field of psychology where the term transpersonal became associated with 
integration and spirituality by Jung, Assagioli, and Maslow (Rowan, 2007). Rowan claims that integrative psychology is largely ignoring the transpersonal, wondering why this is so. Wilber (2007b) has an answer for this apparent division between integral thinkers and transpersonal schools by suggesting that the transpersonal field has been muddied by attempting to integrate ideas that belong in very different camps. He suggests these camps encompass 'New Age' philosophies; transpersonal therapies that use drugs to induce altered state of consciousness; and postmodernists; who attempt to [r]ead non-dual awareness through the lens of pluralistic relativism, critiques of universalism, and...[a]ttacks on perennial philosophy" (online interview Wilber, 2007b). I think he raises an important point here which may account for the difficulty in nursing mainstream schools to accept energy field and spirituality theories. I think it also highlights the importance of being clear about exactly where one is coming from and the influences that are derived, so that there is clarity of thought on the subject, and an open space to be authentic in ones work.

More explicitly in my nursing context, as with nursing predecessors and contemporaries, Rogers (1971); Krieger (1997); and Watson (2002; 2005a) I specify the need for an intentional consciousness of energy fields to be able to detect the person's condition of being at a spiritual, energy level. According to Watson (2005a) this knowledge, is derived both from the personal experiential understanding and exploration of spirituality and theories outside of nursing. Being intentional is not goal directed as such, instead it is a way of working with the energy field as it is emerging (Watson, 2002). Her philosophical and theoretical base supports my heuristic experience of a growing awareness of energy fields, identified under the umbrella theme of being connected, and encompassing notions of: being connected with self identity, having a sense of interconnectedness with self, others, and environment (oneness), tapping into inner wisdom, seeing patterns of energy with the mind's eye, experiencing serendipity, and being aware of patterns and processes in mind-bodyspirit. I discuss the facilitation of energy in the next section.

\section{Nurse facilitation of energy}

While Rogers (1971) proposed a theory encompassing energy fields, Krieger (1981; 1997; 2002) shifted these notions into the practical arena and set up a research-based, nurse-led, energy-based practice, previously referred to in the thesis as TT. As 
previously stated, Krieger drew on ancient knowledge of the chakra system and a close relationship with her mentor Dora Kunz who was an energy healer and clairvoyant. A number of texts were written by Krieger on the subject of TT, specifying the methods used and refined in nursing contexts (Krieger, 1981; 1997; 2002). These texts became a foundation for energy work facilitated by nurses, which has been recognized internationally and acknowledged by other proponents of energy modalities, such as Gordon (2002), who refers to Krieger's work.

I give a summary of the practice of TT as follows. Essentially, Krieger specifies four phases of TT: centering, assessment, unruffling, and modulation. Centering and assessment relate to the preparation of the practitioner, and unruffling and modulation relate to the actual energy work itself. The principles underpinning these actions are the nursing intent to facilitate healing and balance for the person, with compassion. Centering is a process of focused concentration, moving beyond physical and emotional awareness to a state of stillness and relaxation. This state may be assisted by formal meditative practices, such as mantra or prayer. This facilitates a state of tacit knowing where intuitive insights can be accessed. As stated previously, the intuitive lens focuses on the subtle fields of energy commonly known as the auric field, and energy vortexes, referred to as chakras, located in seven strategic places centrally to the physical form from the area of the coccyx to the crown (Krieger, 1997). Krieger drew on the work of Sir John Woodroffe also known by his pseudonym Arthur Avalon. Woodroffe was a Western writer who detailed the Hindu and Buddhist wisdom traditions about centres of energy in the The Serpent Power (1919; 1964). I was introduced to his writings early in life, by my father.

The practice of TT, although still taught and practiced by nurses, has evolved in nursing; for example, Healing Touch (HT), founded by R.N. Janet Mentgen and other fields; for example, quantum touch (QT) (Gordon, 2002; Mentgen, 1998-2007). Krieger is not rigid about her techniques, indicating an attitude of flexibility and potential for evolution of the work in her writing (Krieger, 1997).

The evolution of HT grew out of the experiential work of Mentgen and developed into a programme for learning in 1989, being accepted by the American Holistic Nurse's Association (A.H.N.A.) and the American Holistic Medical Association (A.H.M.A.). 
Mentgen's methods of healing draw on knowledge and sensitivity to the subtle energies of the chakra system, and similar to TT, involve a process of centering and assessment (Mentgen, 1998-2007; Mentgen \& Hover-Kramer, 2002). In some cases, as with my own process, a pendulum is used to pick up the energy of the chakra wheels, which is interpreted intuitively by the practitioner. The HT practitioner will slowly work with their hand chakra a few inches above the body structure, over the energy system of the person. The person will usually experience a deep state of relaxation. The person is assisted to become grounded before completing the session. People are encouraged to augment the HT work with self-reflective journaling and/or meditations, offered by the practitioner to support self-reflection.

O’Mathuna, Pryjmachuk, Spencer, Stanwick, and Matthiesen (2002) critique energy work such as TT claiming Krieger's research findings do not find support in the scientific world and question her assertion that TT is supported by the principles of quantum physics. Glazer (2001); and O'Mathuna, et al., (2002) also question the ethics and the morality of basing professional practice on the aspect of personal knowing which is intuitive. It is my view there is some merit in this critique if the basis for practice is solely on one aspect of knowing. That is why it is important to take an integral approach to decision making, linking intellectual thinking and reasoning, with emotional experiencing, and spiritual being. This is the essence of the dialectical integration process itself, so that the doing of praxis is informed by the personal reflective self, the canons of empirical science, the ethics and morality of the social world; and the aesthetic of being.

The emphasis on quantitative research in EBP tends to undermine evidence gathered about being and experiencing, thereby casting doubts in the field of health about the validity and efficacy of energy facilitation. Geddes (2002) suggests that because "[r]andomised trials of quantitative scientific inquiry is woefully insufficient in capturing the healing experience from either the recipient's or the practitioner's perspective" (p.25), we need to use research frameworks that resonate with the theoretical frameworks of energy fields. 
Nursing and energy facilitation: Developments and tensions

There is a great deal of research that has been done into both TT and HT (see, Starn 1998; Stravena, 2000; Geddes, 2002; Hover-Kramer, \& Mentgen, 2002; Chang, 2003; Kiesling, 2004; Wind, Wardell \& Weymouth, 2004) but as yet energy facilitation is not widely available in NZ health contexts, nor the practice of it taught in mainstream education facilities for nurses. This fact presents a paradox in a country that supports the holistic tenets of Maori health models which clearly posit spiritual and energy components in their frameworks (MOH, 2002; Durie, 1994; Pere, 1984) ${ }^{28}$ For example, in the Te Whare Tapa Wha model, Durie, (1994); the spiritual component of health (Taha wairua) addresses 'unseen and unspoken energies' and the relationship of Maori with the environment (Te au turoa) as part of the flow of the life-force $(\mathrm{MOH}$, 2002). Pere's (1984) Te Wheke model (the Octopus) extends this spiritual focus of Maori. To explain further, the tentacles of the octopus represent the dimensions of health which are: spirituality (wairuatanga); physical wellbeing (taha tinana); the mind (hinengaro); the extended family (whanaungatanga); the uniqueness of each individual and family (mana ake); life-force (mauri); the breath and life of forebears (ha a koro ma a kui ma); and the open and healthy expression of emotion (whatumanawa); the head of the octopus represents the family (te whanau) and the eyes, total wellbeing for the individual and family (waiora) $(\mathrm{MOH}, 2002)$.

Infused in these models are standards for health and health practices that holds spirituality and life-force as central to wellbeing. It is my view that these standards are also transferable to other cultural groups in Aotearoa NZ and the services of health and education of health workers should match these standards. The Maori people have taken the lead in this shift, and it is my view that other cultural groups should follow, thereby creating health services free from oppressive forces of dominant medical cultures that operate in dualistic ways, and claim sovereignty in the delivery of services and of health funding. I thus envision health services where health workers of all disciplines take their place alongside one another providing services to the diverse cultures and socio-economic circumstances that exist; able to 'scratch where they itch'

\footnotetext{
${ }^{28}$ Although the models of Maori Health are authored by Rose Pere and Mason Durie, their basic tenets were derived from extensive discussions with Maori people in large gatherings (Hui's) thus these models represent the universal thinking of Maori on health at the time they were written.
} 
in all the dimensions of health. This cannot be done if researchers and health providers continue to argue over what counts as a valid empiric and what does not.

The mountain of qualitative evidence from nursing research may be endangered by dominant and colonizing EPB practices which focus primarily on randomized controlled trials (RCTs). I believe that the potential for offering services for energy facilitation is limited in a health delivery climate which privileges RCTs over socially and culturally constructed methods, and does not factor the intangible nature of subtle levels of consciousness energy into the equation of acceptable evidence.

The US National Center for Complementary and Alternative Medicine (NCCAM) (2007) addresses this difficulty and clusters the healing arts under what they term 'putative' energy fields' medicine. These included energy facilitation practices such as Reiki ${ }^{29}$, HT, Qi Gong ${ }^{30}$, and prayer. NCCAM (2007) note there is statistical evidence of a growing use for these approaches in the US population. Although research has been done into the efficacy of energy facilitation, for example, TT in the therapy of wound healing, osteoarthritis, migraine and anxiety in burn patients; overall it was stated by NCCAM that putative energy medicine has a significant body of qualitative anecdotal evidence, but is not able to convincingly show scientific evidence.

Energy facilitation and research: Tensions in method

It is my view that is it counterproductive to continually seek endorsement for energy facilitation work by engaging in attempts to measure subtle energy fields with inappropriate tools. Rather, I believe that it would be more helpful to the populations who are seeking energy facilitation to improve health; for health professionals to craft practices that incorporate integral approaches. It would be necessary to clearly define their practice parameters, clinical pathways, and research processes. Research processes would ideally incorporate plural methodologies and be submitted for peer review.Ken Wilbur (2001) addresses some of the difficulties on agreements in the so

\footnotetext{
${ }^{29}$ Reiki - A treatment in which healing energy is channelled from the practitioner to the patient to enhance energy and reduce stress, pain, and fatigue. This form of energy healing came from Japan Rei means spiritual nature and Ki meaning energy (Baginski \& Sharamon, 1988).

${ }^{30}$ Qi Gong - Comes from China and is a form of energy work.
} 
called scientific world, about what counts as valid. He does this by distinguishing between 'narrow science' and 'broad science' in his online discussion On the Nature of a Post-Metaphysical Spirituality: Response to Habermas and Weis. Wilbur defines narrow science as an approach that holds that validity is based on the perception, conception, and analysis, of information from sensori-motor consciousness. This fits, according to Wilbur, with biological and chemical matter but does not account for the experiences that occur beyond the sensori-motor integration. In the context of my heuristic experiences of being connected, for example, this being moment could not be measured in a narrow way and a 'broad science' empiric would need to be applied. If for example, I am discussing the pattern of seeing energy with the minds eye that I identified alongside being connected, in my reflective findings; Wilbur suggests a test for the empirical reality of that experience would be that of a mutual experience of it's validity by peers who are capable of accessing similar experiences.

This, for me, highlights the importance of practice supervision and peer review in which I am able to discuss and explore the experiences of being connected and seeing patterns of energy with the minds eye in my practice. On many occasions in my discussions in supervision, and peer review, I raised the fear of exposing this intuitive knowing in my thesis, each time coming face to face with my real self as they individually reflected this knowing back to me. As time went on, and as revealed in the six exemplars of case review, this fear was echoed back to me in each of the participant's experiences, and I began to cast aside my fears and open up to deeper layers of real self. My experience of this seemed to provide the catalytic dynamic, helping to free up an open space for real selves to emerge in the individual works.

Wilbur (2007) suggests that broad science is able to move on from dualism between emotions and thought, and investigate phenomena in the sensory, mental and spiritual domains. Wilbur (2001) posits the standard measures for the validity of either narrow or broad science are the common features of "injunction/exemplar, experience/evidence and confirmation/rejection" (p.8). He adds that correlations can be found in the findings of broad science, such as experiences of meditation, with the findings of narrow science, for example, the monitoring of brain wave patterns of the meditator with an electroencephalogram (EEG). These potentials of an integral approach can therefore offer a richer yield of data and expansions of knowing and 
meaning of the 'intentional, behavioural, social and cultural' dimensions of human experience.

Although Wilbur (2007a) has devoted himself to the development of an integral approach in his conceptualization of 'all quadrants all levels' (AQAL), he acknowledges it will take many years of scholarly inquiries to "[t]ruly flesh out an integral theory with any sort of compelling veracity" (p.12). These inquiries, I suggest, must overcome the obstacles put in by narrow science and tunnel vision views by some proponents of EBP and RCTs, and go for breadth and depth.

To this end Rolfe (2005) answers the dissenting voices in nursing which attempt to invalidate knowing coming from reflection on practice, and turns the spotlight of the question of EBP validity onto fundamentalist proponents, noting that as yet there is no compelling evidence to support EPB. Rolfe suggests the use of the words evidence for practice instead of evidence of practice, sets up a confusing dynamic of the real purpose of EBP and RCTs, and points to suppositions and beliefs that evidence gathered is useful in health-care practices. Rolfe (2005) uses the following example to illustrate this point.

To say that there is evidence of the existence of weapons of mass destruction is to make a statement of empirical fact; the weapons have been seen, tested and photographed. To say that those weapons are evidence for war is to make a statement of belief or ideology; the weapons might or might not constitute a reason for war, depending on your views and beliefs (p. 19).

Rolfe's views on this echo the ideas of Japanese education reformer Makiguchi, who in the 1930-40s argued that Western ideology tended to confuse truth with value. In Bethel's (1994) interpretation of Makiguchi's views,

Western pragmatism, ...[m]akes the false assumption that if a thing is true it is beneficial to man. Experience does not support such an 
assumption. On the contrary, experience tells us that some things that have no usefulness to human life are true (p.56).

Makiguchi was a passionate exponent of theory based on experience and formed his value creation theory of education from the ground of his practice as a teacher.

The importance of each health professional developing a coherent ideology on the meaning of EBP was suggested by Mantzoukas (2007) because of the various and contradictory definitions of EBP that exist about what counts as truth. In this way the formation of hegemonic 'grand narratives' which occur around EBP can be held up for critical analysis, such as was exemplified by Rolfe's comments above.

In my reading on energy work, I find that variances in methods and philosophies are too numerous to review in this thesis. Like Krieger (1997); Gordon (2002); Mentgen (1998-2007); and Watson (2005a), I believe each person needs to develop a heuristic perceptual experience of energy, in order to refine the level of sensory sensitivity to subtle energies. The way in which this is done is as unique as fingerprinting. This awareness does not come about through a cognitive process, although it draws extensively on the cognitive knowledge of the physical form and the emotional field. As stated previously, the necessity of self-care for energy renewal, and experienced mentoring, is essential to this development. Most importantly, energy facilitation is a process of encouraging others to access their innate ability to heal themselves and take responsibility for their health and wellbeing. In essence, I perceive my role in this as drawing the person's attention to the energy fields and inviting them to view this knowledge through a frame that seems most relevant to that person; for example, if they are Christian, then it would be considered from that perspective. Frequently, those I work with do not have formal belief systems, nor do they relate to any; thus, energy is framed from the vantage point that is most meaningful and inspiring to that person.

Arguably, nursing holds the forefront for attempting to integrate energy fields and spirituality into mainstream health-care practices through research, theoretical, and philosophical framing. Much of the early work on energy fields disseminates from the 
US. UK authors Biley and Jones (1998) trace the origins of Rogers' (1971) SUHB theory back to ancient Western and Eastern philosophy and to quantum physics, noting that Rogers' grand theory has not been taken up widely outside the US, because of the complexity of its tenets, its abstract nature, and contentiousness of paranormal associations with the concept of the interdependence of energy fields. The attempts by science to quantify and measure energy fields inevitably lead to inconclusive results, creating tensions in the world of nurses who seek to advance extant theories and philosophies (Biley \& Jones, 1998). Fortunately, this has not deterred some nurses, who over the past three decades, have tended to employ qualitative methods to research the phenomena of spirituality and energy fields (see Reed, 1992; Smith, 1994; Begley, 1994; Long, 1997; Golberg, 1997; Martsolf \& Mickley, 1998; Narayanasamy, 1999; Ronaldson,1999; Todaro-Franceschi, 2001; Tanyi, 2002; Delgado, 2005; Wilding, Muir-Cochrane, \& May, 2006).

\section{Nursing and spirituality}

Theories of spirituality, in the context of nursing, were conceptualized by Reed (1992, 2000); and Smith (1994). Four themes were synthesized by Smith (1994) and included: Having a sense of meaning and mission in life; being committed to realizing ones potential; having a sense of interconnectedness; and a sense of the sacredness of life. Smith (1994) found evidence in literature and her research into polio survivors, that suffering adversity and illness could contribute to an awakening of spirituality, increased awareness, developing caring and compassion for others, and changed perspectives. This evidence also resonates with the patterns I saw in my case reviews.

Reed (2000) developed a theory of self-transcendence, informed by Nightingale and Rogers' SUHB. Reed claims that nursing is a basic healing process, and a spiritual discipline. In taking this position, Reed recommends that the nursing profession embraces an integrative philosophy that holds embodiment as a core concept from which to view health experiences. Reed (2000) argues that tagging the term holism onto nursing does not create integration of mind-body-spirit. Rather, it tends to place nursing into the melting pot of generalities, leading others away from the real intent of nursing. Instead, Reed suggests that spirituality is the basis for nursing praxis integrating the ontology and epistemology of nursing health-care settings. Intentionality is linked with spirituality by Reed (2000) as an active process in the 
intimacy of nurse-person relationships, where intentions about health are shared, and actions are 'freely chosen'.

Golberg (1997) in her search for a way of understanding the spiritual relationship in nursing, resonates with Reed's ideas to some extent. Golberg emphasizes the meaning of spirit as an embodied life-force, and not just the sanction of believers of a divine being. Connection was found by Golberg (1997) to be an integrating concept in the understanding of spirituality among nurses, which she believes "facilitates communication" (p. 840). Connection is also the basis of relationship, not only with others, but a sense of higher order some call God. Martsolf and Mickley (1998) found that connectedness shows up as a main theme in common understandings of spirituality.

Tanyi (2002) found connections between ideas about spirituality and energy fields in her search for clarification of the meaning of spirituality. Spirituality was also linked with emotional expression, animation, and the part of people that transcends death, in the literature that Tanyi explored. Tanyi (2002) found many examples of research that cited spiritual belief and strength as a protective function in the face of illness and a positive factor in recovery processes. Thus, emphasizing the importance of spirituality to nurses. Ronaldson (1999) maintains that "Spirituality and nursing are historically and inextricably interwoven" (p.3); often showing itself in the ordinary and mundane activities of nursing, which involve presence and touch. She also suggests that nurses have a significant role to play in assessment and fostering hope in caring for people as a means of strengthening the recovery process. Both Golberg (1997); and Tanyi (2002) found that although the awareness of a sense of spirituality in nurses is considered important, a lack of awareness did not stop nurses being able to provide compassionate care.

These authors have contributed to the literature to define spirituality as it relates to nursing care. I suggest there is still some way to go to translate this knowledge into an ontology that remains open to the many meanings that persons make of their individual understandings of spirituality. 


\section{Summary}

It seems evident that there is considerable resonance in the mainly nursing literature that I have reviewed, which supports the dominant patterns that have shown up in Chapter Eight. Most of this literature supports a unitary, integrative framework for nursing, which synthesizes caring and relational aspects with spirituality and lifeforce. Areas of dissonance, for an integral framework in nursing, incorporating these aspects pervade narrow science and the current emphasis on EBP, which tends to privilege quantitative research findings. This is an antithesis to what might be regarded as implicit and invisible aspects of nursing.

My assumptions on dialogical facilitation are inevitably shaped by my situated-ness and prejudices which I have already made apparent. I locate my assumptions about the facilitative aspects of dialogue underneath an overarching principle of interdependence and connectedness, which in my view, encompasses the Buddhist constructs of dependent origination and the three realms. This enables me to progress in the facilitation work, knowing that I have the energetic antennae to pick up the nuances and energies behind words, to reach another layer of listening. Openness is important here, so that there is the spaciousness of a wide open field, whilst at the same time a sharpening of focus to spotlight the present moment. In the present moment, primary echoes are heard as an exploration of thoughts, feelings, and intuitions, begins. Judgments and pre-judgments remain in the landscape, moving and changing shape, like the filigree of snowflakes on a winter morning. The treasure hunt begins. Gold lies buried in the feelings, thoughts, and energies - in the deep wells of human experience and the tool for getting to them is the quality of acceptance. Respectful, non-directive enquires scratch rough and uneven surfaces, yielding the shining of infinite potentials, too numerous to see. Identities are discovered in polishing and refining, reflecting and mirroring, which persons choose, or do not choose, to integrate into their life moments of transition.

In Chapter Ten I revisit the dialectical self questioning process detailed in Chapter Five and offer a reflection on both the research process and my experience of the research journey. 


\section{CHAPTER TEN Expanding Nursing Horizons in}

\section{Health Care}

This chapter forms the conclusion of this thesis. I begin by revisiting and reflecting upon the research process, answering the central question of this thesis: What patterns emerge in the practice of dialectical nurse facilitation of transition? I summarize patterns for dialectical nurse facilitation of transition and the significance they may have on the nursing profession and research, especially considering the mental health sector. Finally, I close with a personal reflection on the thesis journey.

In this thesis I showed the evolution of a dialectical research method into a way of working with people who are in transition. I found primary, social and realized levels of thinking and feeling in moments of being, doing, experiencing, thinking, integrating, and communicating; in a heuristic praxiological process. These levels and moments are also experienced in the facilitation process itself and mirrored in transitional moments.

Because loss, grief, and transition are common to all, my description of moments of transition will undoubtedly strike a cord for most people who read this thesis. Nurses are often the first point of contact for people facing transitions and this fact has been compelling enough for me to become attracted and engaged with the topic. The insights gained through this exploration reveal a compassionate intentional nursing pattern of helping people to explore tensions, so that they can find a pathway through transition. Compassionate engagement encompasses intentionality, intuition and openness, resonating with simultaneity, unitary, humanistic nursing philosophies and Buddhism.

A transitional pathway moves beyond a sense of impasse, as people search and find transformative insights that lead to expanding awareness and a can result in a heightened sense of wellbeing. These patterns were exemplified in the stories of Sophie, Grace, Rose, Faith, Lilo, and Charles; revealing dialectical nurse facilitation patterns of catalytic mirroring in cycles of actively listening, encouraging, challenging and giving feedback. These patterns incorporate counselling, facilitation, and 
dialogical principles. A mutual pattern of being grounded, having faith, and being real, shows the interconnectedness of people in their social context and environment which is consistent with the Buddhist philosophy of the three realms of existence. Interconnectedness goes beyond relation, into the ethereal layer of energy. In this thesis I opened up a beginning discussion on the facilitation of energy, building on extant nursing research on the subject. This is an area for further expansion in the field of nursing research and education as we enter an age of integral care.

\section{Revisiting dialectical cycles of questioning}

As I consider the diverse potentials for nurses in facilitative roles, I return to questions (refer p. 136) in relation to the research cycles used in this thesis. These being: Is it real? Is it workable? Is there equality? Is it dialectical? Is it ethical? Is it relevant? In addressing the question; is it real? I revisit my agendas at the beginning of my journey into transitional work and reaffirm my passion for being with people at the juncture of their transitions. I find I have a deepening sense of commitment to this energizing nursing work that has previously been implicit in my nursing practice, and lacking clarity.

When I started out exploring transitions my thinking was influenced by psychological and grief theories which I reviewed in Chapters Three and Four. It was hard for me to release my attachment to prevalent nursing prescriptions for care that are dichotomous and seek solutions to problems that people identify. I wrestled with my need to be in control, and to make things better for people.

In my original versions of this thesis assumptions about DNFT were lined up neatly in freeze frames as I grappled with the meaning of a dialectical evolutionary process. Gradually they fell off the pages of my work as I became closer to what seemed like the core essence of this work filling 'the space between the no longer and the not yet' in my transitional process. I now wonder if this sense of space is an illusion as some Buddhist trajectories would imply; or is it a connection with the essence of Real Self found in moment-to-moment Mindfulness which transcends time, space and the substance of embodied consciousness. 
When I was recalling my transitional process of redundancy with reference to William Bridges work in Chapter Three I thought a lot about the sense of space in transitions as a feeling of emptiness; or a corridor which holds the emotion of fear; especially the fear of death. As time goes by and I reflect further, even the notion of death becomes meaningless when an awareness of pure energy is found. This well of energy is a source of real joy as I engage in mutual discoveries about the mysteries of change with people.

These discoveries are not easily shown in the research design of this thesis which is a limitation of this process, especially as I chose case review rather than more in-depth forms of research such as case study or life stories.

As I consider the workability of DNFT, I find tensions existing in Aotearoa, as integral approaches emerge within the narrower confines of a medical focus. The narrow lens of science permeates nursing education and practice, emphasizing tangibles, and disparaging the hidden nature of energy. As I search for equitable ways to synthesize these hidden yet powerful aspects of energy, I find a groundswell of movement arising from communities and cultures which seek alternatives to the status-quo. These stirrings are heard in socio-political halls, and opportunities are conceived and created. Examples include the emergence of expanded roles for nurses along with the foundations for the implementations of integral health frameworks in health-care contexts. As health services and nurses grapple with valid evidence upon which to base their practices, validity is also sought by people from the ground of their experiences of suffering.

I share the views of many of the authors on nursing, cited in this thesis, that to date, nurses are an untapped resource for the facilitation of transitions. I believe facilitation is the hidden gem embedded in nursing and other wisdoms that offers a hopeful exploration of the potentials that individuals and communities have to find a transit through the pain that resistance tension creates in moments of impasse. I hold the vision that nurses can make a difference to the wellbeing of people if facilitative skills are embedded in nursing curricula; as core foundational learning for relational, integral, and humanitarian, nursing practice. It is my opinion that simultaneity, unitary, relational, and humanistic nursing frameworks and Buddhism reviewed in this thesis 
provide an appropriate base for the development and formalization of facilitation skills within the nursing discipline which has national and international implications.

In this thesis I show how I have applied these nursing theories and philosophies to the dialectical facilitation of transition in advanced nursing praxis. I take this knowing forward in a contracted nursing role in primary health care to provide an early intervention mental health service that values the importance of transitions for health promotion and prevention of illness. This role offers scope for innovative health-care and ongoing research to develop that could potentially highlight facilitation in nursing. I believe this signals the beginning of a paradigm shift in health-care provision that could benefit from the specification and explication of a facilitative nursing role posited in this thesis. I expect to progress this work in future research in primary care.

Ethics and morals mingle, as I wonder about the 'credo' of my DNFT praxis. Gradually I gain the courage to locate Real Self in the centre of my practice world. I discover resonances with the realities, previously hidden, of persons seeking an uncensored audience, in their transitions. As I sit with the 'uncut' versions of people's lives, the momentum of energy builds, forming a platform for mutual discoveries about cycles of transitions to occur. The integrity of personal experiences, and being in the world, becomes the central point from which to draw statutory standards of ethics, and personal humanitarian morality, into a creative synthesis.

The relevance of the authentic lived-lives of persons and nurses takes precedence in the practice world. The implications of this reveal the significance of pathways to transformation, inherent in transition work. In addition to the principles of dialectical reasoning I believe the explication of heuristic reflection makes a contribution to both education and practice in nursing. It is in these research processes that the significance of the uniqueness of nursing, existing in the up-close, life-death, dialectics of nurseperson relationships in health-care contexts; is revealed.

To answer the central question of this thesis: What patterns emerge in the practice of dialectical nurse facilitation of transition? I discover an emergent pattern of DNFT in the integration of nursing knowledge and practice; through reflection. A pattern for 
heuristic reflecting upon practice supervision, peer review and case review that I exemplify in this thesis, makes transparent a systematic process of integrating personal experience with theory and translating it into nursing praxis. Self-reflection through supervision is revealed as a way to come to a deeper understanding of oneself in the context of nursing. This understanding of self allows me to open to the other in their process of change in full awareness of what belongs with me and what belongs with them.

Originally, for the purposes of explication, I had intended to tape my sessions of supervision and peer review when I was shaping up my research method and design. There was something about taping that did not resonate with this reflective process and I think it was to do with wanting to get close to the gestalt - the feeling and the thoughts in the moment. In the moment not everything that is said and done is taken in. It is what was taken in - that I wanted to reveal - the impression - the feeling evoked - the essence of the experience. I wanted to get close to that. Finding what to write and what to leave out gets harder if only the intellect is engaged. My uncensored journals were a godsend. Without them I would have been swamped with content and unable to find patterns. Once the patterns were found in periods of immersion and meditation the merging of feelings and thoughts in the creative synthesis of being, doing, experiencing, thinking, integrating and communicating could be revealed in my expanding awareness. This expanding awareness is the central point of integration and the opening up to real self and transformation which became my transitional journey in the research process.

To expand further, I found DNFT is a way of nursing that is grounded in universal principles of life. From this viewpoint I see that human beings experience cycles of transitions in being, doing, and experiencing, birth, aging, sickness, and death. I believe nurses connect with these cycles through the nature of their own humanity and the impasse moments of people's lives in health-care contexts. It is through this association that I think nurses have the capacity through a humanistic quality of compassion to facilitate a deeper awareness of a sense of meaning, purpose, and selfidentity for persons in transition. With expanded awareness people have the potential for transformation, enabling movement towards a greater appreciation of life and their part in it, and an acceptance of death as part of universal cycles of transition. 


\section{Concluding comments}

This heuristic journey has been a pathway of disciplined meditative reflection - to come home to myself. In choosing this pathway I realize there is no turning back. I have felt the resonate footsteps of many others who have come into my world, and a convergence with humanistic, integral and caring philosophies in the interconnectedness of being.

Convergence and merging can seem disquieting to those used to a world of professional symmetry, where the edges of nurse-person relationships are clearly drawn and professional roles stack up like the identities on a pack of cards. The archetype of healer is universally known, appearing into the foreground and fading into the background, as in a dream.. As I merge with this archetype I learn and grow and it becomes a vehicle for movement and a freeing transformation for my-self and others.

I have been privileged to find many resonant and inspiring writers in my literature reviews. These reviews have revealed the compassionate intentions of nurses and philosophers, both nationally and internationally, who share a vision for integral nursing care. In my vision for nursing, I see that the energy of compassion cannot be copyrighted, and neither can it be taught in a perfunctory way. Therein lies a paradox for nurses; the dialectic of basic humanity and professionalism.

Dialectical philosophy is a way of seeing that goes beyond the dichotomies of right and wrong, good and bad, sick and well, life and death; freeing the person up to make discoveries that are transformative and expand awareness. As I go deeper into the meaning of the essence of dialectics, I find that dialectics is about watching the tensions of the lived-life in the moment. It is like reading a heart monitor, as I observe the coming and going, the up and down, of thoughts, feelings, and responses, in the everyday world of change. I find a middle way for reading and working with tensions in facilitation itself. At the centre of facilitation is a dialogical pattern, beyond discussion and the efficacious resolution of problems and symptoms; into the heartbeat of life in the relational world of social contexts. An open exploration of something in facilitative dialogue has its own course. It is what it is - it goes where it goes something is integrated and something is taken away. That something becomes part of 
me - part of those who supervise my work, and part of those I work with. I don't need to judge it - I can only trust the process. In the process orientation of my work, sometimes I grope in the dark and I look for the light. The light is spirit emerging. The light of spirit emerging is the essence of what my work is about. There is no technique; rather, it is a discipline of watching the dialectic of darkness and light. In this work there is a will-ing intention on my part to create a healing space that holds the other in safety to explore and discover, and to have the freedom to choose a pathway. It is watching and waiting - speaking and being silent. In this world, there is unlimited potential, released in the pulsing human experience of interconnectedness.

My search for clarity to describe this process at times has seemed elusive as I write and rewrite reflective journals in the course of this thesis. I conclude with an excerpt of my journeys in and out of chapters and into the lived-life of transition and nursing.

I find it difficult to write and share what I am thinking. I write and rewrite two chapters, three times, and my thoughts are like scenery from the view of a fast moving train. As time passes, thoughts settle into stillness and the being-ness of the moment. I begin to notice a change and a lightness, which manifests as a deep acceptance of life. I become aware that as I work with people, I am as a clear pool, a mirror for people to notice their own reflection. As I am a mirror, I am mirrored, in practice supervision, peer review, and by people who see me. When the dialectic reveals itself in the dance of shadows and light-as on a lake - at the centre there is a still-point - a place of complete acceptance - a place of non-judgement. In that still-point of silence, I hear a sound. This sound is a deep resonant one note that I have not heard before. I feel lightness and peace as I watch my chattering thoughts come and go as waves on the sea. I sense freedom as I release my grasping need to react and respond with emotion to the stronger waves of thoughts. I feel free to laugh as I begin to view my life from a different vantage point and I get on with my day-to-day world. As I take each step, it seems lighter and softer. I take off the heavy boots I have been wearing and I learn to trip lightly in the everyday ordinary world with joy and appreciation for what is. 


\section{APPENDICES}

Appendix A: Ethical approval

Phone $\quad 0-4-4635676$

Fax $\quad 0-4-4635209$

Email Allison.kirkman@vuw.ac.nz

\begin{tabular}{l|l}
\hline TO & Janice Clayton \\
\hline COPY TO & \\
\hline FROM & Dr Allison Kirkman, Convener, Human Ethics Committee \\
\hline
\end{tabular}

\begin{tabular}{l|l}
\hline DATE & September 11,2007 \\
\hline PAGES & 1 \\
\hline
\end{tabular}

SUBJECT Ethics Application: No 81/2005 - Expanding nursing horizons in health care: the application of a dialectical approach to facilitate transition and improve health and well-being.

Thank you for your application for ethical approval, which has now been considered by the Standing Committee of the Human Ethics Committee.

Your application has been approved and this approval continues until 30 August 2007. If your data collection is not completed by this date you should apply to the Human Ethics Committee for an extension to this approval.

Best wishes with the research.

Allison Kirkman

Convener 
Appendix B: Ethical approval of amendments

\author{
VICTORIA UNIVERSITY OF WELLINGTON \\ Te Whare Wananga o te Upoko o te Ika a Maui
}

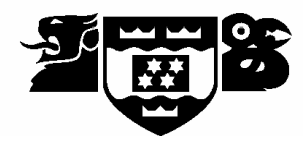

Dear Janice

Thank you for your letter requesting an amendment to your ethics application, No 81/2005 - Expanding nursing horizons in health care: the application of a dialectical approach to facilitate transition and improve health and well-being.

This requested amendment is approved and the documentation will be appended to your original application.

Best regards

\title{
Allison Kirkman
}

Convener (Human Ethics Committee)

Dr Allison Kirkman

Associate Dean (Students) \& Senior Lecturer in Sociology

Faculty of Humanities \& Social Sciences

Victoria University of Wellington

Te Whare Wananga o te Upoko o te Ika a Maui

Box 600, Wellington

$\mathrm{Ph} 463$ 5676, Fax 4635209

http:/www.vuw.ac.nz/fhss

http://webmail.clear.net.nz/webmail.cgi?cmd=item-83\&page=print\&folder=Sent $\% 201 . . \quad$ 17/03/2007 
Appendix C: Information sheet for supervision and peer review

VICTORIA UNIVERSITY OF WELLINGTON

Te Whare Wananga o te Upoko o te Ika a Maui

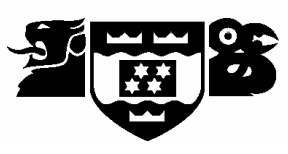

Title of the study: Expanding nursing horizons in health care: The application of a dialectical (integrated) approach to facilitate transition and improve health and wellbeing.

Researcher Janice Clayton RN., BN., PG Cert. Advanced Nursing (Mental Health)., MA, PhD scholarship (candidate). Phone number (03) 477 0688. Email: anjc@ @lear.net.nz

Researcher's academic supervisor Dr Rose McEldowney, RN., PhD., Associate Professor Graduate School of Nursing Midwifery and Health Victoria University of Wellington. Phone number (04) 4636651 Email: rose.mceldowney@vuw.ac.nz

\section{This is a research project describing nurse facilitation of transition using a dialectical approach}

The description of facilitation of transition will be derived from reflection through the supervision and peer review processes using a heuristic research process. This involves direct experience by the researcher in the phenomena of study. In this case, the experience of the researcher with the facilitation of transition using a dialectical approach. It also involves the review of case notes by the researcher for the purpose of developing themes relating to dialectical facilitation of transition. This aspect of the research does not involve the supervisor / reviewer in any way. However, for the supervisors / reviewers information, a copy of the information sheet and consent form for review of case notes is given.

\section{What is a dialectical approach?}

The purpose of this study is to describe a framework for nursing practice that uses an integrated approach. This approach, which in this study is called dialectical, is a way of working with people that acknowledges that life is complex especially when people are dealing with life events, loss and grief. Facilitation involves an exploration of the tensions a person is living with and aspects of life that are important to them. For example, a person may start to think that their core beliefs and values no longer fit with the situation they are now facing. Trying to understand it all can leave them feeling bewildered as they try to grapple with it alone. Everything changes including how a person feels physically, emotionally, socially and spiritually. Some people struggle with this change process especially when those close to them find it difficult to cope with their grief. This may leave a person feeling unable to fully express their feelings of loss and lead to increased stress as the tension builds up. The facilitation process involves an exploration of the tensions being experienced by the person physically, emotionally, socially, and spiritually, and being guided to discover strengths in the person's ability to manage their health in changing situations and crises. 


\section{Supervision}

The supervision for the research process and for practice involves three processes. These are: Academic supervision, practice supervision and peer review. This information sheet addresses practice supervision and peer review explained as follows:

1. Practice supervision involves a written contractual agreement between the researcher and the practice supervisor to address mutual expectations, times of meeting, and payment.

- The practice supervisor has a copy of the researchers practice description and professional codes of practice.

- The practice supervisor's role is to address practice issues of facilitation of transition only.

- The practice supervisor is a person with expertise in the field of grief and loss.

- The practice supervisor is aware that the researcher keeps a journal of these sessions to support a self-reflective process that will form the basis of the findings for research.

- The journal notes are a reflection of the researchers insights about practice through supervision and do not include the opinions or views of the practice supervisor.

2. Peer review involves the same process as practice supervision. The exceptions are:

- The form of the review sessions is a mutual interdependent process involving the exploration of nursing practice in two similar fields where both are registered nurses with similar qualifications and expertise.

- The researcher has two roles, as both facilitator and participant. The structure of these sessions is less formal although time frames are adhered to. For this reason audiotapes are most likely to be used as an adjunct to reflective journaling. The audiotapes of these sessions will also be available to the peer reviewer.

The practice supervisor and peer reviewer are not involved in any aspect of academic supervision or in data analysis. 


\title{
Appendix D: Consent to provide supervision / peer review in the practice context of a $\mathrm{PhD}$ thesis.
}

\author{
VICTORIA UNIVERSITY OF WELLINGTON \\ Te Whare Wananga o te Upoko o te Ika a Maui
}

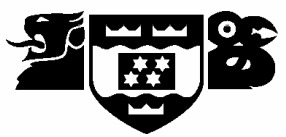

Title of the study: Expanding nursing horizons in health care: The application of a dialectical approach to facilitate transition and improve health and wellbeing.

I have read and I understand the information sheet for this study designed to explain the process of transition facilitation. I have had the opportunity to discuss this study. I am satisfied with the answers I have been given.

I have been given time to consider whether I will provide supervision / peer review of the study.

I agree to provide ongoing supervision / peer review over the course of the research process subject to negotiation if my circumstances change or I choose to withdraw.

I understand that this supervision / peer review will cover only the practice context of the researcher's work and will not involve any other aspect of PhD work.

The researcher will complete a contract for practice supervision / peer review which will address mutually acceptable terms for the supervisory / peer review process.

I am agreeable to be identified by the researcher as practice supervisor / peer reviewer in the acknowledgments of the thesis.

Yes / No

I would prefer a disclaimer included in the thesis which says that the views and theoretical positioning of the researcher are not necessarily a reflection of the practice or views of the supervisor / peer reviewer.

Yes / No

I agree that the researcher can use journal notes written after each session to describe fully the process of facilitation and that this will not include the names or views of the supervisor / peer reviewer.

I agree to have the sessions audio-taped if it seems appropriate to the research process.

Yes / No 
I realize that journals and tapes will be stored in a locked filing cabinet and that the researcher will be the only person with access. I understand that summaries of supervision/peer review may be viewed by the researcher's principle academic supervisor.

I understand that the data will be stored on the researcher's working computer which is used only by the researcher and has an identification entry point.

I understand that tapes and transcriptions of tapes will be destroyed when the research process is completed.

I understand I can discuss issues related to the study with Janice Clayton (phone no. 03477 0688), and Dr Rose McEldowney (phone no. 04463 6651), her designated research supervisor.

I understand that at completion of the study, the research will be assessed by Victoria University of Wellington designated markers.

I appreciate that the study will be lodged in the Victoria University of Wellington Library on completion and that findings may be presented at conferences and be submitted for publication in academic or professional journals.

I will not be asked to meet the cost of any aspect of the research.

If my participation in this research project as practice supervisor/ peer reviewer takes up more than the agreed amount of paid time, I understand fees will be renegotiated to compensate for this.

I wish to receive a full free copy of the thesis on its completion

Yes / No

Signature of supervisor / peer reviewer

Date 
Appendix E: Information sheet for participants

\author{
VICTORIA UNIVERSITY OF WELLINGTON \\ Te Whare Wananga o te Upoko o te Ika a Maui
}

Title of the study: Expanding nursing horizons in health care: The application of a dialectical (integrated) approach to facilitate transition and improve health and wellbeing.

Researcher Janice Clayton RN., BN., PG Cert. Advanced Nursing (Mental Health)., MA, PhD scholarship (candidate). Phone number (03) 4770688 email: anjc@clear.net.nz

Researcher's academic supervisor Dr Rose McEldowney, RN., PhD., Associate Professor Graduate School of Nursing Midwifery and Health Victoria University of Wellington. Phone number (04) 4636651 Email: rose.mceldowney@vuw.ac.nz

\title{
This is a exploratory research project in which the researcher is seeking to define and explain facilitation of transition using a dialectical approach
}

- I would like to review case notes of those who have recently been supported by me for transition issues.

- I would like to do this to confirm themes of transition work that show what facilitation is all about for those might be interested in the way this work can be helpful to people going through life events and changes.

- Those who have worked with me on transitions from March 2005-March 2007 will be invited to sign a consent form to review case notes after having this information explained to them and they have had a chance to read it and decide whether to participate.

- Persons can decide to withdraw consent to allow me to use themes and examples agreed upon at anytime up until November 2007 when the final write up of this thesis will begin.

- The main purpose of this study is to reveal the process of nurse facilitation for those in transition and its effect on the health and wellbeing of participants. Thus this study focuses on the facilitation process of the nurse rather than the person's story of change although examples from participants may be given, with permission, to help people to understand how the facilitation works.

\section{What does case review involve?}

- Notes that I have written from our time together will be summarized and themes identified.

- The summaries and the themes will be checked with you. 
- This will involve one appointment time with me, which will take 30-60 minutes.

- Travel or parking costs for this appointment will be reimbursed.

- To make the themes clear to the readers, it may be valuable to give a brief example of the theme. In this case I will work with you to check what would be all right to use as an example from the summary I have given you.

- No personal details about you will be included in the example and we can choose another name to use so that there is no chance of identification.

In addition:

- Material such as excerpts from your own journals or artwork that depicts your experience of transition and the facilitation process that you would like included as part of the example, will be discussed with you and an agreement will be reached about how these are presented in the thesis. 


\title{
Appendix F: Consent to participate in research
}

\author{
VICTORIA UNIVERSITY OF WELLINGTON \\ Te Whare Wananga o te Upoko o te Ika a Maui
}

Title of the study: Expanding nursing horizons in health care: The application of a dialectical approach to facilitate transition and improve health and wellbeing.

I have read and I understand the information sheet designed to explain the process of case review of transition facilitation. I have had the opportunity to discuss this study. I am satisfied with the answers I have been given.

I have been given time to consider whether I will participate in the study.

I understand that anonymity and confidentiality will be protected by the use of a pseudonym and appropriate changes in personal details.

I understand that the researcher will write a summary of the facilitation process so that I can verify the details.

I agree that the researcher can use themes and examples from the review of case notes. In this instance I will be given a copy of the example to confirm the interpretation and check that confidentiality and anonymity are protected.

I realize that case notes will be stored in a locked filing cabinet and that the researcher will be the only person with access to the notes. I understand that summaries and examples verified by me may be viewed by the researchers principal academic supervisor and that a pseudonym will be used.

I understand that the data will be stored on the researcher's working computer which is used only by the researcher and has an identification entry point.

I realize that I can request withdrawal from the study up until November 2007 and that this will not affect my access to any further facilitation work with the researcher.

I understand I can discuss issues related to the study with Janice Clayton (phone no. 03477 0688), and Dr Rose McEldowney (phone no. 04463 6651), her designated research supervisor.

I understand that at completion of the study, the research will be assessed by Victoria University of Wellington designated markers. 
I appreciate that the study will be lodged in the Victoria University of Wellington Library on completion and that findings may be presented at conferences and be submitted for publication in academic or professional journals.

I will not be asked to meet the cost of any aspect of the research.

I wish to receive a summary of research on its completion Yes / No

In addition I am spontaneously offering material that depicts my experience of transition and the facilitation process to be included as part of the example. I understand this material will be subject to the same conditions as detailed above, or any variation will be documented on this consent form. This will include specifying the types of materials offered.

I wish to be informed if the author is considering writing for publication or presenting at conferences after March 2008 so that I can negotiate and consent to the way in which additional material offered by me is used.

Yes / No

Signature of participant

Date

Variations to use supplementary material: 
Appendix G: Contract and disclaimer

\section{WORKING AGREEMENT FOR FACILITATION WITH JANICE CLAYTON CONCERNING SAFETY NEEDS AND CONTACT WITH OTHER SERVICES}

Do you give permission to liaise with other health professionals if the need arises? In this situation I would only liaise with other practitioners if a deterioration of your health is noted. I would not disclose details of our work together, but I may indicate how you are progressing and whether I notice an impact on your general health, $\underline{o r}$, to inform other practitioners of new emerging threats to health $\underline{\text { or }}$ when there are concerns about any treatments you are currently on.

\section{Yes/No}

Signature

\section{DISCLAIMER}

While all care is taken through this facilitation process, you remain responsible for your health and safety needs. If you have health issues, such as, medical conditions or treatment I recommend you continue your treatments while you are working with me. If you have safety issues historically, such as, doing harm to yourself or others, it is expected that you maintain a relationship with those who normally support you, or that you access emergency services if safety becomes a concern for you while the sessions are underway.

I understand these conditions and agree to them.

Signature

Date

THIS IS A CONFIDENTIAL SERVICE (notes are kept in a locked cabinet and will not be used for research purposes unless written consent is obtained). 


\section{REFERENCES}

Adam, J. S., \& Wright, S.G. (2001). Therapeutic touch. (2 ${ }^{\text {nd }}$ ed.). US: Elsevier Health Sciences.

Annals. G. (2007). Creating positive practice environments. Kai Tiaki Nursing New Zealand, April, 13(3), 2-3.

Antonovsky, A. (1974). Conceptual and methodological problems in the study of resistance resources and stressful life events. In B.S. Dohrenwend, \& B.P. Dohrenwend (1974) (Eds.), Stressful life events: Their nature and effects (pp.245-258). Canada: John Wiley \& Sons, Inc.

Archer, J. (1999). The nature of grief: The evolution and psychology of reactions to loss. US: Routledge.

Arnold, E.C. (2007). Theoretical perspectives and contemporary issues. In E.C., Arnold, \& K. Underman Boggs, (2007) (Eds.), Interpersonal relationships: Professional communication skills for nurses. $\left(5^{\text {th }}\right.$ ed.). (pp.1-25). US: Saunders Elsevier.

Arnold, E.C., \& Underman Boggs, K. (Eds.). (2007). Interpersonal relationships: Professional communication skills for nurses. $\left(5^{\text {th }}\right.$ ed.). US: Saunders Elsevier.

Arvay, M.J. (2001). Shattered beliefs: Reconstructing the self of the trauma Counselor. In R.A. Neimeyer, (2001). (Ed.). Meaning reconstruction and the experience of loss (pp.213-230). Washington, D.C: American Psychological Association.

Assagioli, R. September, (1967). Psychosomatic medicine and bio-synthesis. 
Paper presented at International Psychosomatic Week, Rome.

Attig, T. (2001). Relearning the world: Making and finding meanings. In R.A.

Neimeyer, (2001). (Ed.). Meaning reconstruction and the experience of loss (pp.33-54). Washington, D.C: American Psychological Association.

Barrett, E.A.M. (2002). What is nursing science? Nursing Science Quarterly, 15(1), 51-60.

Barrett, E.A.M. (2003). Emerging pattern in a changing world. Paper presented at the Conference of the Society of Rogerian Scholars. Savannah, Georgia.

Barker, P., \& Whitehill, I. (1997). The craft of care: Towards collaborative caring in psychiatric nursing. In S. Tilley (Ed.), The mental health nurse: Views of practice and education (pp. 15-27). Oxford: Blackwell Science.

Barker, P. (2002). The tidal model. Unpublished manuscript.

Barker, P., \& Buchanan-Barker, P. (2004). (Eds.). Spirituality and mental health: Breakthrough. London: Whurr Publishers.

Barker, P., \& Buchanan-Barker, P. (2005). The tidal model: A guide for mental health professionals. UK: Brunner-Routledge.

Baxter, L.A. (1988). A dialectical perspective on communication strategies in relationship development. In S. Duck (Ed.), Handbook of Personal Relationships (pp. 257-273). UK: John Wiley\& Sons.

Baxter, L.A., \& Montgomery, B.M. (1996). Relating: Dialogues and dialectics. NY: Guilford. 
Begley, S.S. (1994). Tibetan Buddhist Medicine: A transcultural nursing experience. Journal of Holistic Nursing, 12(3), 323-42.

Benner, P. (1984). From novice to expert: Excellence and power in clinical nursing practice. CA: Addison-Wesley.

Benner, P., \& Wrubel, J. (1989). The primacy of caring: Stress and coping in health and illness. CA: Addison-Wesley.

Bethel, D.M. (1994). Makiguchi the value creator. NY: Weatherhill.

Bhagwan Shree Rajneesh. (1974). The book of secrets - (Vol.1): Discourses on "Vigyana Bhairava Tantra”. NY: Harper and Row Publishers.

Biley , F.C. \& Jones, C. (1998). Energy fields nursing: An exploration of new and re-discovered boundaries for practice. Retrieved July, 20, 2007, from http://www.medweb.uwcm.ac.uk/martha/images/energy.doc.htm

Black, J. (2007). Corporate bullying: A virulent organism. Kai Tiaki Nursing New Zealand, April, 13(3), 20-21.

Boeree, C.G. (1997).Towards a Buddhist psychotherapy. Retrieved May, 20, 2007, from http://webspace.ship.edu/cgboer/maslow.htm

Boeree, C.G. (2006). Abraham Maslow. Retrieved May, 20, 2007, from http://webspace.ship.edu/cgboer/maslow.htm

Bohm, D., Factor, D., and Garrett, P. (1991). Dialogue - A proposal. Retrieved June 26, 2007, from http://www.infed.org/archives/etexts/bohm_dialogue.htm 
Bond, M., \& Holland, S. (1998). Skills of clinical supervision for nurses: A practical guide for supervisees clinical supervisors and managers. Buckingham Philadelphia: Open University Press.

Bond, T. (2002). The nature and role of counselling in primary care. In J.

Keithley, T. Bond and G. Marsh. (Eds.), Counselling in primary care. $\left(2^{\text {nd }}\right.$ ed.). (pp.259-266). Oxford: Oxford University Press,

Bowlby, J. (1973). Attachment and loss: Separation anxiety and anger (Vol.11). London: Hogarth Press.

Bowlby, J. (1980). Attachment and loss: Loss, sadness and depression (Vol.111). NY: Basic Books.

Bowles, N., Mackintosh, C., \& Torn, A. (2001). Nurses' communication skills: An evaluation of the impact of solution-focused communication training. Journal of Advanced Nursing, 36(3), 347-354.

Brandon, D. (2004). Chocolate cakes. In P. Barker, \& P. Buchanan-Barker. (Eds.), Spirituality and mental health: Breakthrough (pp. 27-40). London: Whurr Publishers.

Brennan, B.A. (1993). Light emerging. US: Bantam Books.

Bridges, W. (1980). Transitions: Making sense of life's changes. US: AddisonWesley.

Busch, C.J. (2001). On creating a healing story: One chaplain's reflections on bereavement, loss and grief. Innovations in End-of-Life Care, 3(3), Retrieved October 2, 2007, from http://www.edc.org/lastacts 
Burbules. N.C. (1993). Dialogue in teaching: Theory and practice. NY: Teachers College Press.

Burnard, P. (1988). Nurses' perceptions of their interpersonal skills: A descriptive study using Six Category Intervention Analysis. Nurse Education Today, $8,266-272$.

Burnard, P. (1999). Practical counselling and helping. UK: Routledge.

Calhoun, L.G. \& Tedeschi, R.G. (2001). Posttraumatic growth: The positive lessons of loss. In R.A. Neimeyer, (2001). (Ed.), Meaning reconstruction and the experience of loss (pp.157-172). Washington, D.C: American Psychological Association.

Cameron, D., Kapur, R., Campbell, P. (Febuary 2005). Releasing the therapeutic potential of the psychiatric nurse: A human relations perspective of the nurse patient relationship. Journal of Psychiatric and Mental Health Nursing, 12(1), 64-74.

Carroll, L. (1872:1993). Alice's adventures in wonderland and through the looking glass. Unabridged. GB: Wordsworth Editions Limited.

Carper, B. (1978). Fundamental patterns of knowing in nursing. Advances in Nursing Science, 1, 13-23.

Carper, B. (1988). Response to "Perspectives on Knowing: A Model of Nursing Knowledge". Scholarly Inquiry for Nursing Practice: An International Journal, 2(2), 141-144.

Causton, R. (1995). The Buddha in daily life: An introduction to the Buddhism of Nichiren Daishonin. London: Rider. 
Chandler, M.C., \& Mason, W.H. (1995). Solution-focused therapy: An alternative approach to addictions nursing. Perspectives in Psychiatric Care, 31(1), 8-12.

Chang, S.O. (2005). The nature of touch therapy related to Ki: Practitioners' perspectives. Nursing \& Health, 5(2), 103-114.

Chant, S., Jenkinson, T., Randle, J., \& Russell, G. (2002). Communication skills: Some problems in nursing education and practice. Journal of Clinical Nursing, 11, 12-23.

Clayton, J. R., \& Tse, S. (2003). An educational journey towards recovery for individuals with persistent mental illnesses: A New Zealand perspective. Psychiatric Rehabilitation Journal, 27(1), 72-78.

Clayton J. R. (2004). The recovery of hope: A personal journey through paradigms toward emancipatory practice. Unpublished master's thesis, University of Wellington, New Zealand.

Cobb, S. (1974). A model for life events and their consequences. In B.S.

Dohrenwend, \& B.P. Dohrenwend (1974). (Eds.). Stressful life events: Their nature and effects (pp. 151-156). Canada: John Wiley \& Sons, Inc.

Coombs, T. \& Meehan, T. (2003). Mental health outcomes in Australia: Issues for mental health nurses. (Editorial). International Journal of Mental Health Nursing, 12, 163-164.

College of Nurses, Aotearoa (NZ) Inc. (2007). Complementary and Alternative Therapies Policy. Retrieved July 01, 2007, from http://www.nurse.org.nz/misc/misc_comp_therapy.htm 
Conner, M. (2002). Sharing the burden of strife in chronic illness: A praxiological study of nursing practice in a community context. Unpublished doctoral thesis, Victoria University of Wellington, New Zealand.

Conner, M. (2004). Courage and complexity in chronic illness: Reflective practice in nursing. Wellington: Daphne Brasell Associate Press and Whitireia Publishing.

Consedine, M. (2004). Clinical supervision - value and possibilities. Retrieved April 24, 2006, from http://www.tidal-model.co.uk/clinical_supervision.htm

Conti-O'Hare, M. (2007). The nurse as wounded healer: Finding the essence of the therapeutic self. Retrieved May 25, 2007, from http://www.drconti-online.com/theory.htm

Costello, J. (1995). Helping relatives cope with the grieving process. Professional Nurse, 11(2), 89-92.

Cram, F., Smith, L., \& Johnstone, W. (2003). Mapping the themes of Maori talk about health. The New Zealand Medical Journal, 116, 1170.

Crowe, M. \& Luty, S. (2005). Interpersonal psychotherapy: An effective psychotherapeutic intervention for mental health nursing practice. International Journal of Mental Health Nursing, 14, 24-31.

Csikszentmihalyi, Mihaly (1990). Flow: The psychology of optimal experience. NY: Harper and Row.

Csikszentmihalyi, Mihaly (1996). Creativity: Flow and the psychology of discovery and invention. NY: Harper Perennial. 
Davidson, L. (2002). Recovery, the tidal model and person-centred mental health. Retrieved 17 August, 2006, from http://www.tidalmodel.co.uk/New\%20Laurie\%20Davidson.htm

Davis, C.G. (2001). The tormented and transformed: Understanding responses to loss and trauma. In R.A. Neimeyer, (2001). (Ed.). Meaning reconstruction and the experience of loss (pp.137-156). Washington, D.C: American Psychological Association.

Delgado, C. (2005). A discussion of the concept of spirituality. Nursing Science Quarterly, 18(2), 157-162.

Doane, G.H., \& Varcoe, C. (2005). Family nursing as relational inquiry: Developing health-promoting practice. Philadelphia: Lippincott Williams \& Wilkins.

Dockett, K.H. (1993). Resources for stress resistance: Parallels in psychology and Buddhism. The philosophy and practice of the SGI. US: SGI-USA.

Doka, K.J. (2002). Disenfranchised grief: New directions, challenges, and strategies for practice. Champaign, Ill: Research Press.

Donnelly, J. W., Eburn, N., \& Kittleson, M. (2001). Mental health: Dimensions of self esteem and emotional well-being. Boston: Allyn \& Bacon.

Dohrenwend, B.S., \& Dohrenwend B.P. (Eds.). (1974). Stressful life events: Their nature and effects. Canada: John Wiley \& Sons, Inc.

Durie, M. (1998). Whaiora: Maori health development. Auckland NZ: Oxford University Press. 
Durie, M. (1999). Te Pae Mahutonga: A model for Maori health promotion. Health promotion forum of New Zealand Newsletter, 49, 2-5 December.

Eames, D. January 28, (2006). Suicidal sky tower pilot jailed. The New Zealand Herald. Retrieved November 14, 2007, from http://www.nzherald.co.nz

Fielden, J.M. (2003). Grief as a transformative experience: Weaving through different life worlds after a loved one has completed suicide. International Journal of Mental Health Nursing, 12, 74-85.

Fielding, R.G., \& Llewelyn, S.P. (1987). Communication training in nursing may damage your health and enthusiasm: Some warnings. Journal of Advanced Nursing, 12, 281-290.

Frankl, V.E. (1973). Psychotherapy and existentialism. Middlesex England: Penguin Books Ltd.

Frankl, V.E. (1987). Mans search for meaning: An introduction to Logotherapy. (6 ${ }^{\text {th }}$ ed.). London: Hodder \& Stoughton.

Freire, P. (1974). Pedagogy of the oppressed. NY: The Seabury press.

Freire, P. (1985). The politics of education: Culture power and liberation. (D. Macedo, Trans.). London: McMillan Publishers Ltd.

Freire, P. (1998). Teachers as cultural workers. (D. Macedo, D. Koike, \& A. Oliveira, Trans.). Colorado: Westview Press.

Freud, S. (1960). The ego and the id. (J. Riviere. Trans.). J. Strachey. (Ed.). London: W.W. Norton \& Company. 
Freud, S. (1965). New introductory lectures on psycho-analysis. (J Strachey Trans.). London: W.W. Norton \& Company.

Freud, S. (1957). Mourning and Melancholia. Standard Edition of Complete Works. (Vol.14), 239-258. London: Hogarth Press.

Fulton, J., \& Oliver, D. (2001). Clinical supervision: A psychodynamic approach. Research for Nursing Practice. Retrieved May 8, 2006, from http://www.graduateresearch.com/Fulton.htm

Gadamer, H. (1989). Truth and method. (2 ${ }^{\text {nd }}$ ed.). (J. Weimsheimer, \& D. J. G. Marshall. Trans.). London: Sheed \& Ward.

Gadow , S. (1980). Existential advocacy: Philosophical foundations of nursing. In Spicker \& S. Gadow (Eds.), Nursing images and ideals (pp.79-101). NY: Springer.

Geanellos, R. (1998). Hermeneutic philosophy. Part 1: Implications of its use as methodology in interpretive nursing research. Nursing Inquiry, 5, 154-163.

Geddes, N. (2002) Research related to healing touch. In D. Hover-Kramer, \& J. Mentgen, (2002). (Eds.), Healing touch: A guide book for Practitioners. $\left(2^{\text {nd }}\right.$ ed.). (pp.25). US: Thomson Delmar Learning.

Gillespie, S. (2001). Shakespeare's books: A dictionary of Shakespeare sources. London: Athlone Press/Continuum.

Glazer, S. (2001). Therapeutic touch and postmodernism in nursing. Nursing Philosophy, 2(3), 196-212.

Goldberg, B. (1997). Connection: An exploration of spirituality in nursing care. 
Journal of Advanced nursing, 27, 836-842.

Golish, T.D. (2003). 'Ambiguous loss': Managing the dialectics of grief associated with premature birth. Journal of Social and Personal Relationships, 20(3), 309-334.

Gordon, R. (2002). Quantum touch: The power to heal. US: North Atlantic Books.

Gully, E. (1998). A retrospective case study of one wymyn's experience of a life threatening challenging illness. Unpublished master's thesis,Victoria University of Wellington, New Zealand.

Gully, E. (2005). Creating sacred space: A journey to the soul. In C., Johns. \& D. Freshwater, (Eds.). (2005). Transforming nursing through reflective practice (pp.142-161). ( $2^{\text {nd }}$ ed.). UK: Blackwell Publishing Ltd.

Gurudev Shree Chitrabhanu. (1982). Chitrabhanu speaks. In, N. \& E. Gardner, Five great healers speak here. (pp.1-7). US: The Theosophical Publishing House.

Hagman, G. (2001). Beyond decathexis: Toward a new psychoanalytic understanding and treatment of mourning. In R.A. Neimeyer, (2001). (Ed.). Meaning reconstruction and the experience of loss (pp.13-32). Washington, D.C: American Psychological Association.

Harris, W. (1994). Heraclitus: The complete fragments. Translation and commentary and the Greek text. Retrieved September 4, 2007, from http://community.middlebury.edu/ harris/Philosophy/heraclitus.pdf

Hartrick, G. (1997). Relational capacity: The foundation for international nursing 
practice. Journal of Advanced Nursing, 26, 523-528.

Health Information Privacy Code. (1994).Wellington NZ: Govt. NZ.

Harvey, J.H., Carlson, H.R., Huff, T.M. \& Green, M.A. (2001). Embracing their memory: The construction of accounts of loss and hope. In R.A. Neimeyer, (2001). (Ed.). Meaning reconstruction and the experience of loss (pp.231-244). Washington, D.C: American Psychological Association.

Haughton, H. (Ed.). (1998). Introduction. In L. Carroll, Alice's adventures in wonderland and through the looking glass. London: Penguin.

Heaney, P. (2002). Coming to grief: A survival guide to grief and loss. Dunedin: Longacre Press.

Hegel, G. W. F. (1971). Philosophy of mind. Clarendon Press, Oxford.

Heidegger, M. (1996). Being and time. (J. Stambaugh, Trans.). Albany, NY: Suny Press.

Hider, P. (1998). Youth suicide prevention by healthcare professionals: A critical appraisal of the literature. Christchurch, NZ: New Zealand Health Technology Assessment Clearing House.

Higgins, R. (1993). Approaches to case study: Handbook for those entering the therapeutic field. London: Jessica Kingley.

Hirshfield, J. (1997). Nine gates: Entering the mind of poetry. NY: HarperCollins.

Hochswender, W., Martin, G., \& Morino, T. (2001). The Buddha in your mirror: 
Practical Buddhism and the search for self. Santa Monica, CA: Middleway Press.

Holmes, T.H., \& Rahe, R.H. (1967). The social adjustments rating scales. Journal of psychosomatic research, 11:213-218.

Holmes, T. H., \& Masuda, M. (1974). Life change and illness susceptibility In B.S. Dohrenwend, \& B.P. Dohrenwend (1974) (Eds.), Stressful life events: Their nature and effects (pp.45-72). Canada: John Wiley \& Sons, Inc.

Hover-Kramer, D., \& Mentgen, J. (2002). Healing touch: A guide book for Practitioners. ( $2^{\text {nd }}$ ed.). US: Thomson Delmar Learning.

Ikeda, D. (1988). Unlocking the mysteries of birth and death: Buddhism in a contemporary world. London: Warner Books.

Ikeda, D. (2000). Humanism and the art of medicine: A new century of health. Malaysia: Soka Gakkai.

Ikeda, D. (2002a). The humanism of the middle way: Dawn of a global civilization. (Peace Proposal). Tokyo: Soka Gakkai.

Ikeda, D. July, (2002b). Florence Nightingale: A tribute to a century of women. Living Buddhism, (3), 34-41.

Ikeda, D. (2003). Unlocking the mysteries of birth and death. (2 ${ }^{\text {nd }}$ Ed.). CA: Middleway Press.

Ikeda, D. (2006). On attaining Buddhahood in this lifetime. Unpublished study lecture series. 
Ilot, L. (1996). The lost-ness of loss: A reappraisal of loss. British Journal of Occupational therapy, 59(6), 277-276.

Im, E-O., \& Meleis, A.I. (1999). Situation-specific theories: Philosophical roots, properties, and approach. Advances in Nursing Science. December, 11-24.

Jacobs-Kramer, M., \& Chinn, P. (1988). Perspectives on knowing: A model of nursing knowledge. Scholarly Inquiry for Nursing Practice, 2(2), 129-144.

Job. (Revised Standard Version). Old Testament Bible.

Joffrion, 1.P., \& Douglas, D. (1994). Grief resolution: Facilitating selftranscendence in the bereaved. Journal of Psychosocial Nursing, 32(3), 13-19.

Johns, C. (2004a). Being mindful easing suffering: Reflections on palliative care. London: Jessica Kingsley Publishers.

Johns, C. (2004b). Becoming a reflective practitioner. ( $2^{\text {nd }}$ ed.). UK: Blackwell Publishing Ltd.

Johns. C., \& Freshwater, D. (Eds.). (2005). Transforming nursing through reflective practice. ( $2^{\text {nd }}$ ed.). UK: Blackwell Publishing Ltd.

Jung, C.G. (1933). Modern man in search of a soul. New York: Harcourt Brace \& World.

Jung, C.G. (1963). Memories, dreams, reflections. London: Fontana Paperbacks.

Jung, C.G. (1970). The archetypes and the collective consciousness. G. Adler and 
R.F.C. Hull, (Trans.). NJ, US. Princeton University Press. (Collected Works of C.G. Jung, Vol. 9).

Jung, C.G. (1971). Psychological types. London: Routledge \& Kegan Paul. (Collected Works of C.G. Jung, Vol. 6).

Kaplan, H., \& Sadock, B. J. (1998). Synopsis of psychiatry: Behavioural sciences, clinical psychiatry. ( $8^{\text {th }}$ ed.). Sydney: Williams \& Wilkins.

Kaufmann, W. (1965). Hegel: Texts and commentary. London: Doubleday.

Kidd, J. (2005). The tidal model and the Maori context. Conference presentation. Retrieved August 17, 2006, from www.tidal-model.co.uk

Kiesling, S. (March/April 2004). High tech and healing touch. Spirituality and Health, 40-47.

Kirschenbaum, H., \& Henderson, V.L. (Eds.). (1990). The Carl Rogers reader. London: Constable.

Klass, D. (2001). The inner representation of the dead child in the psychic and social narratives of bereaved parents. In R.A. Neimeyer, (2001). (Ed.). Meaning reconstruction and the experience of loss (pp.77-94). Washington, D.C: American Psychological Association.

Koss-Chioino, J.D. December (2006). Spiritual transformation: Ritual healing and Altruism. Zygon, 41(4), 877-892.

Krieger, D. (1981). Foundations for holistic health nursing practices: The renaissance nurse. Philadelphia: J.B. Lippincott Company. 
Krieger, D. (1997). Therapeutic touch inner workbook: Ventures in transpersonal healing. Sante Fe: Bear \& Company, Inc.

Krieger, D. (2002). Therapeutic touch as transpersonal healing. US: Lantern.

Krishnamurti Foundation of America, (2004). Biography. Retrieved 11 July, 2007, from http://www.kfa.org/biography.php

Kübler-Ross, E. (1970). On death and dying. London: Tavistock Publications.

Kübler-Ross, E. (1991). On life after death. US. Touchstone.

Kübler-Ross, E. (1997). To live until we say goodbye. US. Touchstone.

Lakeman, R. (2004). Standardized routine outcome measurement: Pot holes in the road to recovery. International Journal of Mental Health Nursing, 13, 210-215

Lamentations. (Revised Standard Version). Old Testament Bible.

Linehan, M.M. (1993). Cognitive-behavioral treatment of borderline personality disorder. NY: The Guilford Press

Litchfield, M. (2005). The nursing praxis of family health. In C., Picard, \& D., Jones, (2005). (Eds.), Giving voice to what we know: Margaret Newmans's theory of health as expanding consciousness in nursing practice, research and education (p.73-82). US: Jones and Bartlett Publishers, Inc.

Long, A. (1997). Nursing: A spiritual perspective. Nursing Ethics, 4(6), 496-510. 
Longfellow, H.W. (1857). Poem, Santa Filomea. Retrieved November, 20, 2007, from http://www.florence.nightingale.co.uk/image.htm

Luft, J., and Ingham, H. (1955). The Johari window: A graphic model of interpersonal awareness. Proceedings of the western training laboratory in group development. LA: UCLA.

Malinski, V. M., \& Manhart Barrett, E. A. (1994). (Eds). Martha E. Rogers: Her life and her work. US: F.A. Davis Company.

Mantzoukas, S. (2007). The evidence-based practice ideologies. Nursing Philosophy, 8, 244-255

Maslow, A. (1943). A theory of human motivation. Psychological review, 50, 370-396.

Maslow, A. (1973). The farther reaches of human nature. NY: The Viking Press.

Martsolf, D.S., \& Mickley, J.R. (1998). The concept of spirituality in nursing theories: Differing worldviews and extent of focus. Journal of Advanced Nursing, 27, 294-303.

Marx, K., \& Engels, F. (1968). Manifesto of the communist party. In K. Marx \& F. Engels, Selected works. NY: International Publishers.

McEldowney, R.A. (2002). Shape shifting: Stories of teaching for social change in nursing. Unpublished doctoral thesis, Victoria University of Wellington, New Zealand.

Mechanic, D. (1974). Discussion of research programmes on relations between 
stressful life events and episodes of physical illness. In B.S. Dohrenwend, \& B.P. Dohrenwend (1974) (Eds.). Stressful life events: Their nature and effects (pp.87-98). Canada: John Wiley \& Sons, Inc.

Meleis, A, I., \& Trangenstein, P,A. (1994). Facilitating transitions: Redefinition of the nursing mission. Nursing Outlook November/December, 255-259.

Meleis, A.I., Sawyer, L., Im, E.O., Messias, D.K.H., Schumacher, K. (2000). Experiencing transitions: An emerging middle-range theory. Advanced Nursing Science, 23(1) 12-28

Mental Health Commission, November, (1998). Blueprint for mental health services in New Zealand. Wellington NZ: Author.

Mental Health Commission, July, (1999). New Zealand's national mental health strategy: Review of progress. 1994-1999.Wellington NZ: Author

Mental Health Commission, November, (2000). Realising recovery through the education of mental health workers. Recovery-based competencies and resources for New Zealand. Wellington NZ: Author.

Mental Health Commission, March, (2001). Recovery competencies for New Zealand mental health workers. Wellington NZ: Author.

Mental Health Commission, (2004). Our lives in 2014: A recovery vision. Wellington NZ: Author.

Mental Health Commission, April, (2007). Te haererenga mote Whakaorange 1996-2006: The journey of recovery for the New Zealand mental health sector. Wellington NZ: Author. 
Mentgen, J. (1998-2000). Retrieved July 01, 2007, from http://www.heartofhealing.net/about/HT.html

Ministerial Advisory Committee on Complementary and Alternative Health Care in New Zealand (MACCAH). June (2004). Advice to the Minister of Health. Wellington NZ: Ministry of Health.

Ministry of Health, August (1998). Report of the Ministerial taskforce on nursing: Releasing the potential of nursing. Wellington NZ: Author.

Ministry of Health. (2002). Nurse Practitioners in New Zealand. Wellington NZ: Author.

Ministry of Social Development. (2003). Social report. Retrieved July 01, 2007, from http://www.socialreport.msd.govt.nz

Ministry of Health. (December, 2004). The New Zealand Health Strategy. Wellington NZ: Author.

Mookerjee, A. (1982). Kundalini: The arousal of the inner energy. London: Thames \& Hudson Ltd.

Montgomery, C. L. (1993). Healing through communication: The practice of caring. CA: Sage Publications.

Moran, D. (2000). Introduction to phenomenology. London: Routledge.

Morse, J.M., \& Richards, L. (2002). Read me first for a user's guide to qualitative methods. London: Sage.

Morton-Cooper, A., \& Palmer. A. (2000). Mentoring, preceptorship and clinical 
supervision: A guide to professional roles in clinical practice. $\left(2^{\text {nd }}\right.$ ed.). Oxford: Blackwell Science.

Moustakas, C.E. (1990). Heuristic research: Design, methodology, and applications. Newbury Park, CA: Sage Publication.

Moustakas, C.E. (1997). Heuristic research. In P. Reason, \& J. Rowan. (Eds.), Human inquiry: A sourcebook of new paradigm research (pp. 207217). NY: J. Wiley.

Munhall, P.L. (1993). 'Unknowing': Toward another pattern of knowing in nursing. Nursing Outlook, May/June, 125-128

Munhall, P. L. (1994). Revisioning phenomenology: Nursing and health science research. NY: National League of Nursing.

Myers, I.B. and McCaulley, M.H. (1985). Manual: A guide to the development and use of the Myers-Briggs Type Indicator. Palo Alto, CA: Consulting Psychologists Press.

Myss, C. (1997). Anatomy of Spirit: The seven stages of power and healing. UK: Bantam.

Myss, C. (2001). Sacred contracts: Awakening your divine potential. NZ: Bantam.

Naef, R. (2006). Bearing witness: A moral way of engaging in the nurse-person relationship. Nursing Philosophy, 7, 145-156.

Narayanasamy, A. (1999). Asset: A model for actioning spirituality and spiritual 
care education and training in nursing. Nurse Education Today, 19, 274285.

National Center for Complementary and Alternative Medicine. (2007). Energy medicine: An overview. US Department of Health and Human Services: National Institute of Health.

National New Zealand Government Library. (2006). Retrieved July, 07, 2006, from reo@natlib.govt.nz

Newman, M.A. (1986). Health as expanding consciousness. US: The C.V. Mosby Company.

Newman, M.A. (1990). Newman's theory of health as praxis. Nursing Science Quarterly, 3(1), 37-47.

Newman, M.A. (1994). Health as expanding consciousness. ( $2^{\text {nd }}$ ed.). NY: National League for Nursing Press.

Newman, M.A. (2005). Theory is a way of being. In C., Picard, \& D., Jones, (2005). (Eds.), Giving voice to what we know: Margaret Newmans's theory of health as expanding consciousness in nursing practice, research and education (pp. 3-9). US: Jones and Bartlett Publishers, Inc.

New Zealand Association of Counsellors Code of Ethics. Retrieved June 02, 2007, from http://www.nzac.org.nz/ethics

New Zealand Health Information Privacy Code (1994). Retrieved June 02, 2007, from http://www.legislation.govt.nz/

New Zealand Mental Health Act (1992). Retrieved June 02, 2007, 
from http://www.govt.nz

New Zealand Public Health and Disability Act, (2000). Retrieved June 02, 2007, from http://www.govt.nz

Neimeyer, R.A. (2001a). (Ed.). Meaning reconstruction and the experience of loss. Washington, D.C: American Psychological Association.

Neimeyer, R.A. (2001b). The language of loss: Grief therapy as a process of meaning reconstruction. In R.A. Neimeyer, (2001a). (Ed.). Meaning reconstruction and the experience of loss (pp.261-292). Washington, D.C: American Psychological Association.

Nightingale. F. (1969). Notes on nursing: What nursing is and what it is not. (Unabridged) NY: Dover Publications, INC.

North American Nursing Diagnoses Association NANDA-International. (2007). Nursing diagnoses: Definitions and classification, ( $7^{\text {th }}$ ed.). $2007-2008$. Retrieved July 25, 2007, from http://www.nanda.org/index.html

Nursing Council of New Zealand (2004). Code of conduct. Wellington: Authors.

Nursing Council of New Zealand. (2005). Competencies for the registered nurse scope of practice. Wellington NZ: Authors.

Nursing Council of New Zealand. (2002). The nurse practitioner: Responding to health needs in New Zealand. (3 ${ }^{\text {rd }}$ ed.). Wellington: Authors.

O'Donohue, J. (1997). Anam cara: Spiritual wisdom from the Celtic world. GB: 
Bantam.

O’Mathuna, D., Pryjmachuck, S., Spencer, W., Stanwick, M. \& Matthiesen, S. (2002). A critical evaluation of the theory and practice of therapeutic touch. Nursing Philosophy, 3(2), 163-176.

Ozaniec, N. (1994). Chakras for beginners. London: Hodder \& Staughton.

Parker, R. (1990). Nurses' stories: The search for a relational ethic of care. Advance in Nursing Science, 13(1), 31-40.

Parkes, C.M. (1972). Bereavement: Studies of grief in adult life. Harmondsworth: Penguin Books Ltd.

Parkes, C.M. (1980). Bereavement counseling does it work? British Medical Journal, 281-323.

Parkes, C.M. \& Weiss, R. (1983). Recovery from bereavement. NY: Basic Books.

Parkes, C.M. (1996). Bereavement: Studies of grief in adult life. ( $3^{\text {rd }}$ ed.). NY: Pelican.

Parkes, C.M. (2006). Love and loss: The roots of grief and its complications. NY: Routledge.

Parse, R.R. (1981). Man-living-health: A theory of nursing. NY: Wiley.

Parse, R.R. (1992). Human becoming: Parse's theory of nursing. Nursing Science Quarterly, 5(1), 35-42.

Parse, R.R. (1999). Nursing science: The transformation of practice. Journal of 
Advanced Nursing, 30(6), 1383-1387.

Paykel, E. S. (1974). Life stress and psychiatric discord. In B.S. Dohrenwend, \& B.P. Dohrenwend (1974) (Eds.), Stressful life events: Their nature and effects (pp.135-150). Canada: John Wiley \& Sons, Inc.

Peplau, H. (1952). Interpersonal relations in nursing. NY: Putman.

Pere, R. R. (1984). Te Oranga o te Whanau: The health of the family in Hui Whakaoranga: Maori Health Planning Workshop.Wellington: Department of Health.

Perls, F. (1969). Gestalt therapy verbatim. Gestalt Journal. NY: Highland.

Perls, F.S., \& Stevens, J.O. (1975). (Eds.), Gestalt is. Utah: Real People Press.

Perls, F.S. (1975a). Gestalt therapy and human potentialities. In F.S., Perls, \& J.O. Stevens, (1975). (Eds.), Gestalt is (pp. 5-7) Utah: Real People Press.

Perls, F.S. (1975b).Theory and technique of personality integration. In F.S., Perls, \& J.O. Stevens, (1975). (Eds.), Gestalt is (pp.52) Utah: Real People Press.

Picard, C., \& Jones, D. (2005). (Eds.), Giving voice to what we know: Margaret Newman's theory of health as expanding consciousness in nursing practice, research and education. US. Jones and Bartlett Publishers, Inc.

Prigogine, I., Allen, P.M., \& Herman, R. (1977). Long term trends and the evolution of complexity. In E. Laszlo and J. Bierman, (1977). (Eds.), Goals in a global community, Vol. 1. (pp.41-62). Rapport Club de Rome: Pergamon Press. 
Rahe, R.H. (1974). The pathway between subjects' recent life changes and their near future illness reports: Representative results and methodological issues. In B.S. Dohrenwend, \& B.P. Dohrenwend, (1974). (Eds.). Stressful life events: Their nature and effects (pp. 45-72). Canada: John Wiley \& Sons, Inc.

Ramsden, I.M. (2002). Cultural safety and nursing education in Aotearoa and Te Waipounamu. Unpublished doctoral thesis, Victoria University of Wellington, New Zealand.

Rapp, C. A. (1998). The strengths model: Case management with people suffering from severe and persistent mental illness. NY: Oxford Press.

Reed, P.G. (1992). An emerging paradigm for the investigation of spirituality in nursing. Research in Nursing and Health, 15, 349-357.

Reed, P.G. (2000). Nursing reformation: Historical reflections and philosophic foundations. Nursing Science Quarterly, 13(2), 129-136.

Rescher, N. (2002). Process philosophy. Retrieved October 24, 2007, from http://plato.stanford.edu/entries/

Roberts, K., \& Taylor, B. (2002). Nursing research processes: An Australian perspective. ( $2^{\text {nd }}$ ed.). Australia: Nelson Thomson Learning.

Rolls, S. (2007). Self care is an important role for nurses. Kai Tiaki Nursing New Zealand, April, 13(3), 30-31.

Rogers, C. R. (1957). Client-centered therapy: Its current practice implications and theory. London: Constable. 
Rogers, M. (1971). The theoretical basis of nursing. In V. M., Malinski, \& E. A. Manhart Barrett. (1994). (Eds). Martha E. Rogers: Her life and her work (pp.220-224). US: F.A. Davis Company.

Rogers, M. (1980). Nursing a science of unitary man. In V. M., Malinski, \& E. A. Manhart Barrett. (1994). (Eds.), Martha E. Rogers: Her life and her work (pp.225-231). US: F.A. Davis Company.

Rogers, M. (1983). Beyond the horizon. In V. M., Malinski, \& E. A. Manhart Barrett. (1994). (Eds.), Martha E. Rogers: Her life and her work (pp.283). US: F.A. Davis Company.

Rolfe. G. (2005). Evidence, memory and truth: Towards a deconstructive validation of reflective practice. In C. Johns, \& D. Freshwater, (2005). (Eds.), Transforming nursing through reflective practice. $\left(2^{\text {nd }}\right.$ ed.). (pp.1326). UK: Blackwell Publishing Ltd.

Romanoff, B.D. (2001). Research as therapy: The power of narrative to effect change. In R.A. Neimeyer, (2001). (Ed.), Meaning reconstruction and the experience of loss (pp.245-260). Washington, D.C: American Psychological Association.

Ronaldson, S. (1999). Nursing: A caring spirituality. Retrieved June 25, 2007, From http://www.ciap.health.nsw.gov.au/hospolic/stvincents/stvin99/Sue.htm

Rowan, J. (1997). A dialectical paradigm for research. In P. Reason, \& J. Rowan. (Eds.), Human inquiry: A sourcebook of new paradigm research (pp. 93112). NY: J. Wiley.

Rowan, J. (2007). Don't you dare ignore the transpersonal! Paper presented at 
the Annual Conference of the Society for the Exploration of Psychotherapy Integration at Lisborn. Paper retrieved November 02, 2007, from www.eurotas.org/Ignoring\%20the\%20transpersonal.pdf

Rowe, S.C. (1980). Living beyond crisis. NY: Pilgrim Press.

Rühle, O. (1928). Karl Marx: His life and works. Retrieved October 10, 2007, from www.marxist.org

Sarter, B. (1988). Philosophical sources of nursing theory. Nursing Science Quarterly, 52-59.

Sartre, J-P. (1957). Being and nothingness: An essay on phenomenological ontology. London: Methuen

Satir, V., Banmen, J., Gerber, J., \& Gomori, M. (1991). The Satir model: Family therapy and beyond. California: Science and Behavior Books, INC.

Selye, H. (1956). The stress of life. NY: McGraw-Hill Book Company.

Schumacher, K.L., \& Meleis, A.I. (1994). Transitions a central concept in nursing. Image Journal of Nursing Scholarship, 36(2), 119-127.

Smith, D.W. (1994). Toward developing a theory of spirituality. Visions: The Journal of Rogerian Nursing Science, 2(1), 35-43.

Smith, M.K. (2001). Dialogue and conversation: The Encyclopaedia of Informal Education. Retrieved May 04, 2007, from http://www.infed.org/biblio/bdialog.htm 
Smith, M.K. (2007). Carl Rogers, core conditions and education. Retrieved May 4, 2007, from http://www.infed.org?thinkers/et-rogers.htm

Sogyal, Rinpoche. (2002). The Tibetan book of living and dying. Revised. Australia: Random House.

Stake, R.E. (1994). Case studies. In N.K. Denzin, Y. S. Lincoln (Eds). Handbook of qualitative research. (pp.236-247). CA: Sage.

Starhawk, (2004). The earth path: Grounding your spirit in the rhythms of nature. San Francisco: Harper.

Starn, J.R. (1998). Energy healing with women and children. Journal Obstetrics Gynecology Neonatal Nursing Sept- Oct, 27(5), 576-84.

Stravena, J.,A. (2000). Therapeutic touch coming of age. Holistic Nursing Practice. 1-13

Stein, D. (2004). The women's book of healing. Toronto: The Crossing Press.

Stephens, M. October 23, (1994). The theologian of talk: Jurgan Habermas. Los Angeles Times Magazine. Retrieved July 21, 2007, from http://www.nyu.edu/classes/stephens/Habermas\%20page.htm

Stickley, T. (2002). Counselling and mental health nursing: A qualitative study. Journal of Psychiatric and Mental Health Nursing, 3, 301-308

Stroebe, M, S., \& Schut, H. (2001). Meaning making in the dual process mode of coping with bereavement. In R.A. Neimeyer, (2001). (Ed.), Meaning reconstruction and the experience of loss (pp.55-76). Washington, D.C. American Psychological Association. 
Tanyi, R.A. (2002). Towards clarification of the meaning of spirituality. Journal of Advanced Nursing, 39(5), 500-509.

Taylor, B. J. (2000). Reflective practice: A guide for nurses and midwives. Buckingham: Open University Press.

Te Puni Kokiri, (Realising Maori Potential). Retrieved July 07, 2007, from newzealand.govt.nz

The English Buddhist Dictionary Committee, (TEBDC). (2002). The Soka Gakkai Dictionary of Buddhism. Tokyo: Soka Gakkai.

The major writings of Nichiren Daishonin (TWND). (1999). The Gosho Translation Committee. (Eds.).US: Soka Gakkai.

Thorne, B. (1992). Carl Rogers. London: Sage.

Theorell. T. (1974) Life events before and after the onset of a premature myocardial infarction. In B.S. Dohrenwend, \& B.P. Dohrenwend (1974) (Eds.), Stressful life events: Their nature and effects (pp.101-118). Canada: John Wiley \& Sons, Inc.

Todaro-Franceschi, V. (2001). Energy: A bridging concept for nursing practice. Nursing Science Quarterly, 14, 132.

Toller, P.W. February (2005). Negotiation of dialectical contradictions by parents who have experienced the death of a child. Journal of Applied Communication Research, 33(1), 46-66.

Travelbee, J. (1971). Interpersonal aspects of nursing. Philadelphia: F.A.Davis. 
Urdang, L., \& Long, T.H. (Eds.). (1979). Collins English Dictionary. Glasgow: Collins.

Walker, C. (1996). Coalescing the theories of two nurse visionaries: Parse and Watson. Journal of Advanced Nursing, 24, 988-966.

Walters, A. J. (1994). Phenomenology as a way of understanding in nursing. Contemporary Nurse, 3(3), 34-14.

Watson, J. (1979). Nursing: The philosophy and science of caring. Boston: Little Brown and Company.

Watson, J., \& Smith, M.C. (2001). Caring science and the science of unitary human beings: A trans-theoretical discourse for nursing knowledge development. Journal of Advanced Nursing, 37(5), 452-461.

Watson, J. (2002). Intentionality and caring-healing consciousness: A practice of transpersonal nursing [Electronic version]. Holistic Nursing Practice, 16(4), 12-19.

Watson, J. (2005a). Caring science as sacred science. Retrieved June 06, 2005, from http://hschealth.uchsc.edu/son/faculty/caring.htm

Watson, J. (2005b). A meta-reflection on reflective practice and where it leads. In C. Johns, \& D. Freshwater, (2005). (Eds.), Transforming nursing through reflective practice. ( $2^{\text {nd }}$ ed.). (pp.vii-x). UK: Blackwell Publishing Ltd.

Welch, M. (2005). Pivotal moments in the therapeutic relationship. International Journal of Mental Health Nursing, 14, 161-165.

White, J. (1995). Patterns of knowing: Review, critique and update. Advances in 
Nursing Science, 17(4), 73-86.

Wickramasinghe, N.C. (1988). Buddhism: A philosophy for our times: An historical perspective. In D. Ikeda. (1988). Unlocking the mysteries of birth and death: Buddhism in a contemporary world (pp.vii-xiv). London: Warner Books.

Wilber, K. (2001). On the nature of a post-metaphysical spirituality: Response to Habermas and Weis. Online interview Shambhala Publications. Retrieved February 25, 2007, from http://wilber.shambhala.com/

Wilber, K. (2007a). The relation of states of consciousness and stages of consciousness: No model is complete without both. Parts, $1 \& 1 \mathrm{~V} . \mathrm{K}$. Wilber Online: Pragmatic history of consciousness. Shambhala Publications. Retrieved February 25, 2007, from http://wilber.shambhala.com/

Wilber, K. (2007b). The demise of transpersonal psychology. Online interview Shambhala Publications. Retrieved February 25, 2007, from http://wilber.shambhala.com/

Wilding, C., Muir-Cochrane, E., \& May, E. (2006). Treading lightly: Spirituality issues in mental health nursing. International Journal of Mental Health Nursing, 15, 144-152.

Winchester Nadeau, J. (2001) Family reconstruction of meaning. In R.A. Neimeyer, (2001). (Ed.). Meaning reconstruction and the experience of loss (pp.94-112). Washington, D.C. American Psychological Association.

Wind Wardell, D. \& Weymouth, K.F. (2004). Review of studies of healing touch. Journal of Nursing Scholarship, 36(2), 147-154. 
Wing, R.L. (1979). The I Ching workbook. London: The Aquarian press.

Wood, A.W. (1998). Hegel on education. In A. O. Rorty. (Ed.), Philosophers on education: New historical perspectives. London: Routledge.

Woodroffe, J. Alias, Avalon, A. (1919;1964). The Serpent power. Madras, India: Ganesh \& Co. Private Ltd.

Worden, J. W. (1983). Grief counselling and grief therapy. NY: Springer Publishing.

Worden, J. W. (2002). Grief counselling and grief therapy: A handbook for the mental health profession ( $3^{\text {rd }} e d$.).NY: Springer Publishing Inc.

World Health Organisation, (WHO). (2007). Suicide prevention. Retrieved March 03, 2007, from http://www.who.int/mental_health/prevention/suicide/suicideprevent/en/in dex.html

Yalom, I. D. (1985). The theory and practice of group psychotherapy. ( $\left.3^{\text {rd }} \mathrm{ed}.\right)$. US: Basic Books, Inc.

Young, A.E. (1976). The reflexive universe: Evolution of consciousness. San Francisco: Robert Briggs.

Young, R. (1994). Mental space. UK: Process Press.

Zank, M. Spring, (2007). Martin Buber. The Stanford Encyclopaedia of Philosophy. E.N. Zalta. (Ed.). Retrieved October 01, 2007, from www.plato.stanford.edu/archives/ 
Zubizarreta, R. (2002). Facilitating democracy: The evolving practice and theory of dialogue. Retrieved February 25, 2007, from

http://www.tobe.net/papers/RosaDFThesis.html 


\section{Bookmark for Acronyms}
AHNA - American Holistic Nurses Association
AHMA - American Holistic Medical Association
AQAL - All Quadrants All levels
CAM - Complementary and Alternative Medicine
CBT - Cognitive Behavioral Therapy
DNFT - Dialectical Nurse Facilitation of Transition
EBP - Evidenced Based Practice
EEG - Electroencephalogram
GP - General Practitioner
HEC - Health as Expanding Consciousness
HEF - Human Energy Field
HT - Healing Touch

MACCAH - Ministerial Advisory Committee on

Complementary and Alternative Health Care in New

Zealand

MHC - Mental Health Commission

MH - Mental Health

MOH - Ministry of Health

NANDA - I, North American Nursing Diagnosis

Association International

NCCAM - US National Center for

Complementary and Alternative Medicine

NCNZ - Nursing Council of New Zealand

NF - Nurse Facilitation

NFE - Nurse Facilitation of Energy

NP - Nurse Practitioner

NZ - New Zealand

QT - Quantum Touch

RCT - Randomized Controlled Trials

SFBT - Solution Focused Brief Therapy

SUHB - The Science of Unitary Beings

TEBDC - The English Buddhist Dictionary

Committee

TOW - Treaty of Waitangi

TT - Therapeutic Touch

TWND - The Writings of Nichiren Daishonin

UEF - Universal Energy Field

UK - United Kingdom

US - United States

WHO - World Health Organization

PhD Thesis Title: Exploring Transitions: Working in 'the Space Between

the No Longer and the Not Yet' Created by Janice Ruth Clayton 